\title{
MISINFORMATION POLICY IN \\ SUB-SAHARAN AFRICA
}

\author{
From Laws and Regulations \\ to Media Literacy
}

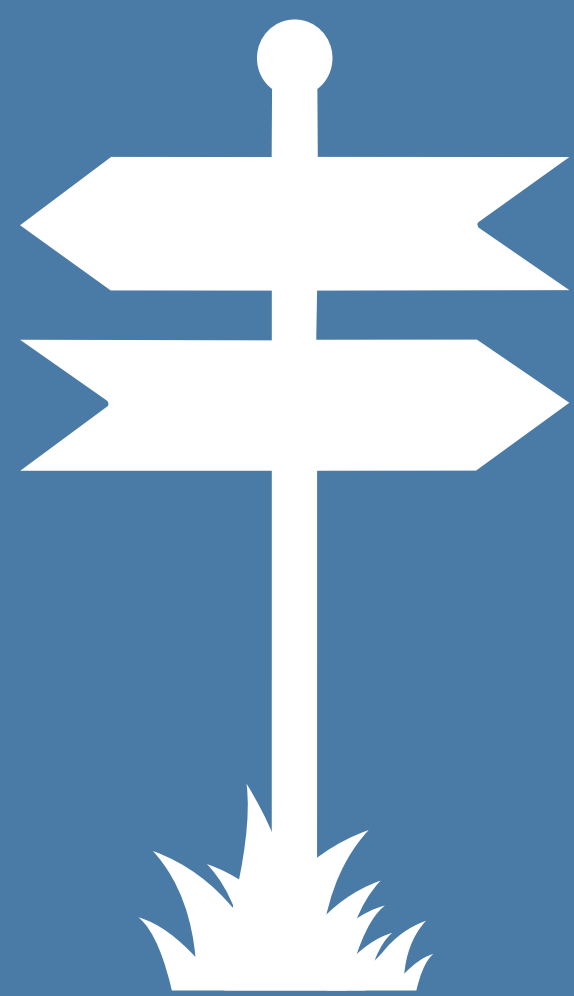




\title{
SERIES DESCRIPTION
}

The CAMRI Policy Brief and Reports provides rigorous and evidence-based policy advice and policy analysis on a variety of media and communication related topics. In an age where the accelerated development of media and communications creates profound opportunities and challenges for society, politics and the economy, this series cuts through the noise and offers up-to-date knowledge and evidence grounded in original research in order to respond to these changes in all their complexity. By using Open Access and easy-to-read formats, this peer-reviewed series aims to make new research from the University of Westminster available to the public, to policymakers, practitioners, journalists, activists and scholars both nationally and internationally.

\section{camri.ac.uk/policy-observatory}

\section{CAMRI Policy Briefs and Reports}

\author{
Series Editors: \\ Professor Steven Barnett \\ Professor Christian Fuchs \\ Dr Anastasia Kavada \\ Dr Maria Michalis
}

THE ONLINE ADVERTISING TAX: A Digital Policy Innovation

Christian Fuchs

ARTIFICIAL INTELLIGENCE AND THE INTERNET OF THINGS

Mercedes Bunz and Laima Janciute

THE GIG ECONOMY AND MENTAL HEALTH

Sally Gross, Laima Janciute, George Musgrave

PORTRAYING DISFIGUREMENT FAIRLY IN THE MEDIA

Diana Garrisi, Laima Janciute, and Jacob Johanssen

\author{
ACHIEVING VIABILITY FOR PUBLIC SERVICE MEDIA IN \\ CHALLENGING SETTINGS \\ Naomi Sakr (editor)
}

FASHION MEDIA AND SUSTAINABILITY

Anastasia Denisova

MISINFORMATION POLICY IN SUB-SAHARAN AFRICA:

From Laws and Regulations to Media Literacy

Peter Cunliffe-Jones, Assane Diagne, Alan Finlay, Sahite Gaye, Wallace Gichunge,

Chido Onumah, Cornia Pretorius and Anya Schiffrin

\section{CAMRI extended policy report (2018)}

THE ONLINE ADVERTISING TAX AS THE FOUNDATION OF A PUBLIC SERVICE INTERNET

Christian Fuchs 
CAMRI CAMRI (the Communication and Media Research Institute) at the University of Westminster is a worldleading centre of media and communication research. It is

UNIVERSITYOF WESTMINSTER ${ }^{\text {用 }}$ renowned for critical and international research that investigates the role of media, culture and

communication(s) in society. CAMRl's research is based on a broader purpose and vision for society: its work examines how the media and society interact and aims to contribute to progressive social change, equality, freedom, justice, and democracy. CAMRI takes a public interest and humanistic approach that seeks to promote participation, facilitate informed debate, and strengthen capabilities for critical thinking, complex problem solving and creativity.

\section{camri.ac.uk}




\section{MISINFORMATION POLICY IN SUB-SAHARAN AFRICA}

\section{From Laws and Regulations to Media Literacy}

Peter Cunliffe-Jones, Assane Diagne, Alan Finlay, Sahite Gaye, Wallace Gichunge, Chido Onumah, Cornia Pretorius and Anya Schiffrin 
Published by University of Westminster Press

115 New Cavendish Street London W1W 6UW

www.uwestminsterpress.co.uk

(C) Peter Cunliffe-Jones

First published 2021

Cover: ketchup-productions.co.uk

Print and digital versions typeset by Siliconchips Services Ltd.

ISBN (PDF): 978-1-914386-05-3

ISBN (EPUB): 978-1-914386-06-0

ISBN (Kindle): 978-1-914386-07-7

DOI: https://doi.org/10.16997/book53

Series: CAMRI Policy Briefs and Reports

ISSN 2752-6240 (Online)

This work is licensed under the Creative Commons Attribution-NonCommercial- NoDerivatives 4.0 International License. To view a copy of this license, visit http://creativecommons or send a letter to Creative Commons, 444 Castro Street, Suite 900, Mountain View, California, 94041, USA. This license allows for copying and distributing the work, providing author attribution is clearly stated, that you are not using the material for commercial purposes and that modified versions are not distributed.

The full text of this book has been peer-reviewed to ensure high academic standards.

For full review policies, see: http://www.uwestminsterpress.co.uk/site/publish/

Suggested citation:

Cunliffe-Jones, P. et al. Misinformation Policy In Sub-Saharan Africa: From Laws and Regulations to Media Literacy. London: University of Westminster Press.

DOI: https://doi.org/10.16997/book53.

License: CC-BY-NC-ND 4.0

To read the free, open access version of this book online, visit https://doi.org/10.16997/book53 or scan this QR code with your mobile device: 


\section{CONTENTS}

PART ONE:THE STATE OF MEDIA LITERACY

IN SUB-SAHARAN AFRICA 2020 AND A THEORY OF MISINFORMATION LITERACY

PETER CUNLIFFE-JONES, SAHITE GAYE, WALLACE GICHUNGE, CHIDO ONUMAH, CORNIA PRETORIUS AND ANYA SCHIFFRIN

PART TWO: BAD LAW - LEGAL AND REGULATORY RESPONSES TO MISINFORMATION IN

PETER CUNLIFFE-JONES, ASSANE DIAGNE, ALAN FINLAY AND ANYA SCHIFFRIN 



\section{PART ONE}

\section{THE STATE OF MEDIA LITERACY IN SUB-SAHARAN \\ AFRICA 2020 AND A THEORY OF \\ MISINFORMATION LITERACY}

\section{Peter Cunliffe-Jones, Sahite Gaye, Wallace Gichunge, Chido Onumah, Cornia Pretorius and Anya Schiffrin}

About this report $\quad 9$

Researchers and declarations of interest I |

I. EXECUTIVE SUMMARY I5

2. THE TYPES, DRIVERS AND EFFECTS OF MISINFORMATION

2.I. Information disorder as a driver of misinformation 19

2.2. Eleven ways misinformation distorts our understanding 19

2.3. Who creates misinformation, where and on what topics 20

2.4. What drives misinformation and why we may believe and share it $\quad 20$

2.5. Understanding the effects of misinformation may change our behaviour

\section{DIFFERENT TYPES OF MEDIA LITERACY:} DIFFERENT EFFECTS

3. I. Many forms of literacy demanded of young people 23

3.2. UNESCO's promotion of Media and Information Literacy 23

3.3. Identifying media literacy sub-types to better understand effects $\quad 24$

3.4. News literacy as knowledge and skills in five domains of news 25

3.5. Misinformation literacy - five domains of specialist knowledge and skills 25

3.6. Misinformation literacy behaviour - a sixth domain of knowledge required 26

\section{How to cite this book chapter:}

Cunliffe-Jones, P. et al. 2021. The State of Media Literacy In Sub-Saharan Africa 2020 and a Theory of Misinformation Literacy, pp. 5-96, in Misinformation Policy In Sub-Saharan Africa: From Laws and Regulations to Media Literacy. London: University of Westminster Press. DOl: https:// doi.org/ I 0.16997/book53.a. License: CC-BY-NC-ND 4.0 


\section{MISINFORMATION LITERACY - THE SIX FIELDS OF KNOWLEDGE AND SKILLS TO IDENTIFY AND DISMISS FALSE INFORMATION}

4. I. Context: knowledge of the contexts - social, cultural, economic, political, informational and events - in which false and accurate information are produced

4.2. Creation: knowledge of the types of people and institutions found to create false and accurate information, their different motivations and the skills to identify those who produce specific information online

4.3. Content: knowledge of the difference between facts and opinions, the different ways information can mislead and the skills and practices to distinguish accurate and inaccurate information

4.4. Circulation: knowledge of the processes by which accurate and inaccurate information circulate and what drives people to share information

4.5. Consumption: knowledge of the reasons we as individuals may believe false or misleading information to be true

4.6. Consequences: knowledge of the different forms of actual and potential harm caused by believing and sharing false and misleading information

\section{MEDIA LITERACY TEACHING AROUND THE WORLD}

5.I. United States - a patchwork of approaches

5.2. Europe - some countries committed, but many weak spots 32

5.3. Latin America - digital skills, no focus on misinformation

5.4. India - limited teaching of media literacy, despite growing demand

5.5. East Asia and Southeast Asia - many governments wary of media literacy

5.6. Media literacy centres, library associations, fact-checking organisations

5.7. Traditional media and social media platforms

\section{MEDIA LITERACY TEACHING IN SEVEN SUB-SAHARAN COUNTRIES}

6. I. Media literacy is barely taught in seven countries, misinformation literacy taught in only one province 
6.1.1. Cote d'lvoire 36

6.1.2. Ghana 37

6.1.3. Kenya 38

6.1.4. Nigeria 39

6.1.5. Senegal 40

6.1.6. South Africa 4I

6.1.7. Uganda 43

7. OBSTACLES TO TEACHING MISINFORMATION LITERACY IN SCHOOL $\quad 45$

7.I. Bureaucratic challenges and a lack of political will 45

7.2. Limited time spent in school, poor teaching performance 46

7.3. Low literacy, numeracy rates complicate the challenge 47

8. EVIDENCE OF MEDIA AND MISINFORMATION LITERACY EFFECTS ON 'REALISM' 49

8. I. African governments and public recognise harm misinformation causes

8.2. In a complex field, meta-review suggests 'positive effects' on 'realism' 50

8.3. Focus on specific knowledge, skills appears to increase efficacy 50

8.4. Evidence of the effects of elements we identify as promoting misinformation literacy

\section{CONCLUSIONS AND RECOMMENDATIONS}

9.1. Conclusions

9. I. I. Broad media literacy is not a 'fake news' antidote.

Misinformation literacy requires specific knowledge and skills

9. I.2. Media literacy barely taught in seven sub-Saharan countries, elements of misinformation literacy in just one province

9. I.3. Many obstacles block misinformation literacy, starting with political will

9. I.4. Preliminary research suggests well-targeted teaching could curb harm 
9.2. Recommendations 56

9.2.1. Governments, public figures and institutions 56

9.2.2. Education and curriculum authorities 57

9.2.3. Media leaders, fact-checkers, media literacy and library associations $\quad 57$

9.2.4. Social media, messaging and search platforms 57

9.2.5. Researchers into education and misinformation 57

BIBLIOGRAPHY $\quad 59$

APPENDIX I - METHODOLOGY AND DEFINITIONS OF KEYTERMS $\quad 67$

I.I. Key premises of the research approach 67

I.2. Definitions of key terms used in the report 68

1.3. The choice of countries studied in the report 71

1.4. The choice of studies of media literacy effects 71

1.5. How we identified the teaching of elements of media
and misinformation literacy in curricula

I.6. The methodology for the studies of fact-checking and misinformation 7 I

APPENDIX 2 - THE REPORT INTO TYPES, DRIVERS

AND EFFECTS OF MISINFORMATION 


\section{ABOUT THIS REPORT}

This report on the 'teaching of different forms of media literacy' in sub-Saharan Africa, and their potential for reducing susceptibility to misinformation, is one of four reports to be published by the University of Westminster Press. The series explores, on the one hand, the types, drivers and effects of misinformation spread in sub-Saharan Africa today, and, on the other hand, three approaches to reducing associated harms: (i) fact-checking, (ii) changes to the legal and regulatory framework for media and information and (iii) media or misinformation literacy.

The four reports all draw in part on a study of more than 1,200 examples of false or misleading information identified as circulating on the continent by one or more of the 14 fact-checking organisations that published fact-checks regularly across Africa between 1 July and 31 December 2019. The report on that study will be published in 2022 .

The series also explores the three main responses put forward in reaction to the rise in concern about misinformation following the unexpected outcome of the United Kingdom's June 2016 referendum on its membership of the EU (Cadwalladr, 2017 and many others), the November 2016 election of US President Donald J. Trump (Read, 2016 and many others) and revelation of governmentbacked disinformation campaigns in South Africa (Skiti \& Shoba, 2017), Kenya (Dahir, 2018) and Nigeria (Cadwalladr, 2018) around the same period.

The first two reports published in the series examine responses that fall within the remit of government. The first report seeks to answer two key research questions:

i. Whether elements of broad media literacy, or of a form of news literacy focused specifically on identifying misinformation, were included in or planned for the curricula taught in state schools in seven sub-Saharan African countries as of June 2020

ii. Whether evidence suggests that teaching young people such elements of broad media literacy, or a form of news literacy focused on the issue of misinformation, reduces their susceptibility to believe and share false information

To answer these questions, the report sets out:

i. Clear definitions drawn from past and recent scholarship of 'broad media literacy' or 'Media and Information Literacy', 'media literacy', 'news literacy', 'misinformation literacy' and 'misinformation literacy behaviours' (see definitions in Appendix 1)

ii. An outline of the six fields of knowledge and skills that the research we have reviewed suggests are essential to the development of what 
we define as misinformation literacy and misinformation literacy behaviours (see definitions in Appendix 1)

iii. Evidence of the extent of teaching of elements of media or news literacy in seven sub-Saharan African countries as of June 2020, drawn from a review of the curricula most widely followed in public schools and interviews with subject experts in those countries

iv. Evidence from past studies around the world of the effectiveness of teaching media literacy or misinformation literacy-type knowledge and skills in reducing individuals' susceptibility to misinformation and leading to misinformation literacy behaviour

The second report looks into the nature and effects of changes made to laws and regulations between 2016 and 2020 in 11 countries $^{1}$ across sub-Saharan Africa. The study found that over the 5 years, the number of laws and regulations in those countries related to 'false information' nearly doubled from 17 to 31 . However, the laws and regulations passed or amended showed little correlation with, or effect on, the drivers, types and effects of misinformation in circulation. Although the changes made appeared to have actual or potential chilling effect on media and political debate in many of the countries studied, the effects of the legislation in reducing the harmful effects of misinformation was minimal, a tiny effect compared to the scale and nature of the problem. At the same time as nearly doubling the number of laws and regulations penalising publication of 'false information', officials and ministers across the continent made repeated calls for the teaching of media literacy - knowledge and skills that would enable young people to identify and reject misinformation.

The third report in the series, to be published in 2022, sets out how the growth in concern about the effects of misinformation worldwide from 2016 onward also added impetus to a growth in fact-checking across the continent. The report shows that, after the first fact-checking organisation, Africa Check, was set up on the continent in $2012^{2}$, more than 14 operations emerged across Africa between 2016 and 2020 and examines their working practices and structures.

The final report in the series seeks to identify the key types, drivers and actual and potential effects of misinformation on the continent, drawing on evidence from the study of more than 1,200 examples of false or misleading information identified by fact-checking organisations as circulating on the continent, and on recent scholarship in the field.

Benin, Burkina Faso, Cote d'Ivoire, Ethiopia, Kenya, Malawi, Niger, Nigeria, Senegal, South Africa and Uganda.

2 For disclosure, the lead author of this report was the founder of Africa Check. 


\section{RESEARCHERS AND DECLARATIONS OF INTEREST}

The co-authors of this report are

- Peter Cunliffe-Jones (Lead author), visiting researcher at the University of Westminster's Communication and Media Research Institute (CAMRI), founder of fact-checking organisation Africa Check and senior advisor to the International Fact-Checking Network

- Sahite Gaye, Researcher and Lecturer at the Centre d'Etudes des Sciences et des Techniques de l'Information (CESTI) at l'Université Cheikh Anta Diop de Dakar (UCAD) Dakar, Senegal

- Wallace Gichunge, Founder and Executive Director of the Centre for Media Information Literacy in Kenya, and Africa Region Representative to the UNESCO Global Alliance for Partnerships on Media and Information Literacy

- Chido Onumah, Coordinator of the African Centre for Media and Information Literacy, at Abuja, Nigeria

- Cornia Pretorius, Researcher and Lecturer at at the School of Communication of North-West University's Potchefstroom site in South Africa

- Anya Schiffrin, Director of the Technology, Media and Communications specialisation at the School of International and Public Affairs, at Columbia University, United States

In Part One:

- Anya Schiffrin was responsible for all of section 5 (i.e. sub-sections 5.1-5.7 'Media literacy teaching around the world')

- Sahite Gaye was responsible for sections 6.1.1 (Cote d'Ivoire) \& 6.1.5 (Senegal)

- Chido Onumah was responsible for sections 6.1.2 (Ghana) \& 6.1.4 (Nigeria) 
- Wallace Gichunge was responsible for sections 6.1.3 (Kenya) \& 6.1.7 (Uganda)

- Cornia Pretorius was responsible for section 6.1.6 (South Africa)

- We were collectively responsible for all of section 7

- Peter Cunliffe-Jones was responsible for the other parts

The report has been reviewed by Dr Peter Goodwin, Principal Research Fellow at the Communications and Media Research Institute at the University of Westminster and by The CAMRI Policy Publications Editorial Board.

The authors are grateful to the following people for making the time to speak to us for this report: Professor Amadou Camara, coordinator of a project promoting curriculum reform in Senegal, the Projet d'Appui au Renouveau du Curriculum, Évelyne Deba, head of information at UNESCO in Cote d'Ivoire, Dr Gertrude Namubiru, Secretary General of the African Curriculum Association, Uganda, Ismail Teladia, senior curriculum planner for Life Orientation at the Western Cape Education Department, John Kimotho, director of educational media at the Kenya Institute of Curriculum Development, Juliet A. Amoah, Executive Director, Penplusbytes, Ghana and Momar Talla Beye, inspector of elementary school teaching in Senegal.

The authors are also grateful to Sofia Bennett and Chloe Oldham, Michelle Mesa, Shruti Kedia and Bei Lin Teo for additional research on the teaching of media literacy in Europe, Latin America, India and Singapore, respectively. And the authors are grateful to the following for their independent expertise in reviewing the report: Ariel Riera, research coordinator at Chequeado, Alphonce Shiundu, Kenya editor of Africa Check, Amy Sippitt, former head of research at Full Fact, Dr Claire Wardle, Director First Draft, Lucas Graves, Associate Professor of Journalism and Mass Communication, University of Wisconsin-Madison, Masato Kajimoto, Associate Professor of Practice of Journalism and Media Studies, University of Hong Kong, Melissa Tully, Associate Professor of Journalism and Mass Communication, University of Iowa, Rabiu Alhassan, Managing Editor of Ghana Fact and Dr Robert Keener, of the Center for an Informed Public at the University of Washington. 
Funding used to support the research was provided by the Facebook Journalism Project, the Google News Initiative and Luminate 3 . They neither sought nor had any influence over the scope or findings of the report. All errors of substance and style remain those of the authors.

3 See https://www.facebook.com/journalismproject, https://newsinitiative.withgoogle.com and https://luminategroup.com. 



\section{EXECUTIVE SUMMARY}

In the past few years alone, false and misleading information has caused or contributed to a wide range of harm to individuals and groups across Africa from vigilante violence and civil unrest in Ethiopia (Nur, 2019) and Nigeria (Adegoke, 2018), through the use of wrong medical treatments for Ebola (Ogala \& Ibeh, 2014), malaria (Faive Le-Cadre, 2019) or Covid-19 (Busari \& Adebayo, 2020), to harms to mental health (Kulundu, 2019), politics (Skiti \& Shoba, 2017), businesses (Ghana Fact, 2019) and much more.

Concern about the actual and potential harmful effects of misinformation has grown both among political leaders (Cissé, 2018; Okakwu, 2018; Olewe, 2018) and the public (Newman et al, 2020; Wasserman \& MadridMorales, 2018) since 2016, leading to calls for solutions ranging from fact-checking (Cunliffe-Jones, 2022a; Graves, 2016; Stencel \& Luther, 2020),

MISINFORMATION
LITERACY ABSENT FROM
AFRICA'S SCHOOLS
I. Media literacy is barely taught
in seven countries studied; ele-
ments of misinformation literacy
present in only one
2. Misinformation literacy is its
own sub-type, distinct from
both media literacy and even
news literacy
3. Misinformation literacy requires
knowledge and skills in six fields
particular to false information
4. Studies suggest these misinfor-
mation knowledge and skills will
help individuals identify and dis-
miss false information
5. Norm-setting by public figures,
institutions and changes from
traditional and social media may
also be vital to bring change in
misinformation behaviour
the introduction of strict laws and regulations against 'false information' (Cunliffe-Jones et al, 2021; Kaye, 2019; Schetzer, 2019), to teaching media literacy (Barron, 2017; Cissé, 2018; Livingstone, 2018).

\section{" Evidence of effects of 'broad media literacy' on susceptibility to misinformation is limited}

A 2012 meta-analytic review of the effects of 51 'media literacy' interventions found that, taken as a whole: 'Media literacy interventions had positive effects on outcomes including media knowledge, criticism, perceived realism, influence, behavioural beliefs, attitudes, self-efficacy and behaviour. The research by Jeong et al (2012) found that the more the teaching time devoted to the subject and the narrower the focus in the courses taught, the more effective they were. Nevertheless, evidence of the effects of teaching this form of broadly defined media literacy on young people's specific ability to identify and reject false information is limited. 
Broadly defined media literacy, known in more recent years as Media and Information Literacy (MIS), was described in 1982 as 'the knowledge, skills and attitudes which will encourage the growth of critical awareness and, consequently, of greater competence among the users of electronic and print media' (UNESCO, 1982). As US educationalist Patricia Aufderheide noted in 1993, this definition was considered broad even then and expected to grow broader. 'Emphases in media literacy training range widely, including informed citizenship, aesthetic appreciation and expression, social advocacy, self-esteem and consumer competence' (Aufderheide, 1993).

These competencies are clearly essential for individuals and society, but their relevance to the ability to identify false information in all its many forms are largely unproven. Media literacy scholar W. James Potter identifies media literacy as taught in the United States as 'a large, complex patchwork of ideas' (Potter, 2010). And as the researchers Robert Keener and Jevin West argue in a forthcoming article, while it would be wrong to say that digital citizenship or media arts are unimportant, 'the many different concepts in media literacy education have not addressed many students' inability to reason effectively with information online' (Keener \& West, 2021).

Instead, we show below, knowledge and skills specific to the types of misinformation in circulation are required to reduce susceptibility to false and misleading claims.

\section{" Six fields of knowledge and skills form misinformation literacy}

Based on a review of (i) empirical evidence of the knowledge and skills used by fact-checking organisations in Africa and worldwide to identify false information and (ii) a series of independent studies of the effects of particular knowledge and skills on this ability (Amazeen \& Bucy, 2019; Brennan et al, 2020; Duffy, 2018; Golebiewski \& Boyd, 2019; Hill, 2020; Shane \& Noel, 2020; Van der Linden et al, 2020; Vicol, 2020), we propose a theory of what we term 'misinformation literacy'.

We set out clear definitions of both what we term broad media literacy, and the narrower sub-field of news literacy, using the theory of news literacy proposed by Vraga et al (2020). We adapt this to apply to the field of misinformation specifically, based on both empirical evidence of the knowledge and skills used by fact-checking organisations and studies of the effects of specifics skills on ability and propensity to identify and reject misinformation. On this basis, we argue that teaching misinformation literacy, or a specific set of knowledge and skills in six named fields, will increase young peoples' ability to identify misinformation and, in combination with other factors, could increase their propensity to dismiss it as such.

We argue the six fields of knowledge and skills necessary to misinformation literacy and misinformation literate behaviour relate to: (i) the context in which 
misinformation and accurate information are produced, (ii) who creates misinformation and who creates accurate information, (iii) the main types or forms of false or misleading content, and how to identify key features distinguishing this from fair and accurate content, (iv) the processes by which false and accurate information circulate, and can thus be identified, (v) the reasons why individuals, ourselves included, consume and believe false information and (vi) the consequences of believing and sharing false information. We recognise that these areas of knowledge and skills will not, in themselves, be enough to change behaviour and for the teaching to have effect, it must be accompanied by a change in the norm-setting shown by public figures, institutions and traditional and social media in relation to falsehoods and misinformation.

" Media literacy barely taught in seven countries studied, only one province includes some elements of misinformation literacy

Despite the many statements of alarm expressed by leaders across Africa about misinformation or 'fake news' since 2016(Cissé, 2018; Okakwu, 2018; Olewe, 2018), our study finds that media literacy, even in the broadest sense, was barely taught in six out of the seven countries studied as of June 2020, and no form of misinformation literacy was taught at all except in one province in South Africa. As we set out in Section 6, only limited elements of the broadly defined media literacy are included in the main state school curricula used in six of the seven countries we studied. Topics taught range from civic education and behaviour in Ghana to selfawareness, empathy and problem-solving in Kenya. As of June 2020, South Africa had the most extensive element of news literacy in its national curricula but with little focus on accuracy. In January 2020, the education department in one province, the Western Cape, introduced teaching of a new syllabus focused on online safety with modules aimed at developing 'click restraint' and how to identify fake websites and false online information. Broader elements of misinformation literacy are not yet reflected in the course. In this report, we set out the obstacles to the introduction and effective teaching of misinformation literacy, starting with a lack of political will, underfunding of schools and poor teacher pay, recruitment and training, bureaucratic challenges and the perception among teachers and planners that curricula are already crowded and misinformation literacy is not a priority.

\section{" A misinformation antidote - if the will is there}

Governments, media and academics across Africa and around the world have since 2016 highlighted the actual and potential harm caused by misinformation worldwide. In June 2020, 130 UN member countries called for measures to combat misinformation (Bontcheva \& Posetti, 2020). If the will is there, our study shows they have the potential to reduce the harm misinformation can cause, by teaching of misinformation literacy in state-run schools. 
Doing so would require providing the necessary teacher training, resources and support to schools. It would need the development of country-appropriate misinformation literacy curricula, developed in partnership with misinformation specialists. It would require teachers' leaders to engage with academics and introduce assessments to test the effects of misinformation literacy at key stages, with benchmarks of misinformation literacy knowledge and skills for different ages.

Politicians, traditional media and tech companies, all the source of much misinformation, all have an enormous responsibility to set norms of good practices of checking information before sharing, correcting false information and transparency about how they work. This can all be done if there is the will to do so.

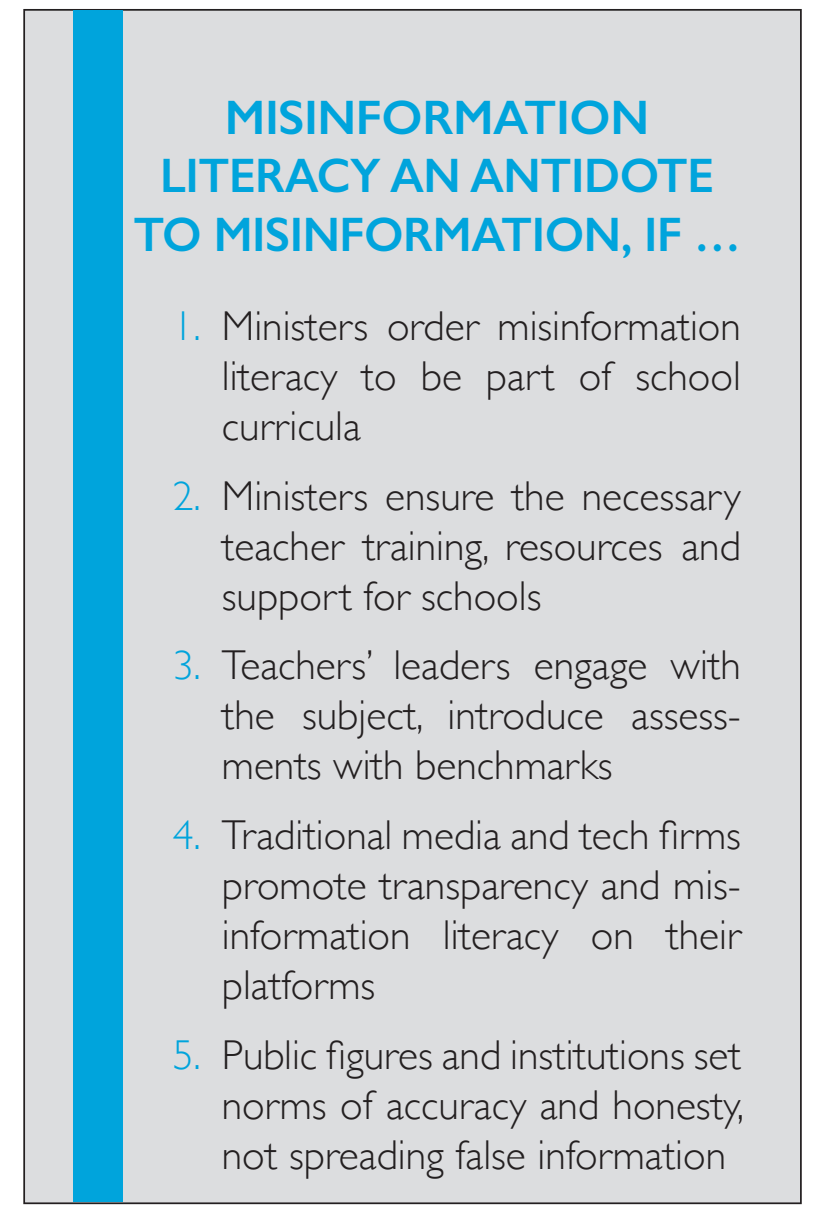

\section{" A method for teaching misinformation literacy and reducing} harmful effects worldwide

While we believe the evidence set out in this report strongly suggests the likely effectiveness of teaching knowledge and skills in the six fields described, specific to the misinformation context of that country, this has not to date been done. It needs to be tested in practice - with benchmarks established and applied not simply in Africa but across continents worldwide. 


\section{THE TYPES, DRIVERS AND EFFECTS OF MISINFORMATION}

To assess the degree to which any form of media literacy addresses the challenge of misinformation, it is necessary first to establish an understanding of the issue itself. To be effective, media literacy would need to provide the ability to address the different types and drivers of misinformation in circulation, in the country or on the continent concerned. The following concepts thus require explanation here.

\section{I. Information disorder as a driver of misinformation}

To understand what drives misinformation, it is necessary first to understand the information disorder. First used in 2017 by Dr Claire Wardle and Hossein Derakhshan as an umbrella term for three different forms of information that cause harm (Wardle \& Derakhshan, 2017), we use the term in this report to describe the broader dysfunction of the information system we observe on the continent (Cunliffe-Jones, 2022b). The expression in this context refers not only to (i) misinformation or disinformation but also to (ii) the distorted focus of information available to the public and (iii) the denial of easy public access to credible information. As noted by a range of studies and articles, distortions in the focus of information available to the public and the lack of access to credible information on key topics both play a major role in distorting understanding (Cunliffe-Jones, 2022a, 2022b; Epstein \& Robertson, 2015; Golebiewski \& Boyd, 2019; Kainja, 2020; Mikkelson, 2016; Ndlela \& Mano, 2020; Shane \& Noel, 2020).

\subsection{Eleven ways misinformation distorts our understanding}

The sorts of misinformation identified by fact-checkers are only rarely entirely false. The ways in which information distorts our understanding are,in fact, often complex, containing elements of both accurate and inaccurate claims. The judgment of what is fair and accurate information is often a complicated one (CunliffeJones, 2022a; Wardle \& Derakhshan, 2017).

The report into misinformation which is part of this series identifies 11 distinct ways in which claims judged by fact-checking organisations to be misinformation can and do distort public understanding: (i) unproven claims stated as known fact; (ii) claims that are outright false; (iii) claims that mislabel or misattribute content such as photographs or videos; (iv) claims that bear an element of truth but overstate or understate a position; (v) claims that bear an element of truth but are misleading in other ways; (vi) claims that are accurate in themselves 
but conflate issues; (vii) satire understood as true; (xiii) deliberately fabricated or manipulated content, where the intention is thus clearly to mislead; (ix) imposter content; (x) hoaxes and scams; and (xi) coordinated inauthentic behaviour - not misleading content as such but patterns of online behaviour intended to distort understanding (Cunliffe-Jones, 2022b; Douek, 2020).

Understanding the complex nature of misinformation is recognised as essential to the ability to properly distinguish misinformation from accurate information, by fact-checking organisations today (Cunliffe-Jones, 2022a) and an essential part of misinformation literacy.

\subsection{Who creates misinformation, where and on what topics}

Although the main focus of much discussion of misinformation since 2016 is false information spread by users of social media, studies show that who creates misinformation, where we find it and what topics it affects are all more varied than is often understood (Cunliffe-Jones, 2020; Newman et al, 2020). The study of misinformation in Africa that is part of this series identifies a wide range of creators of misinformation from traditional media and politicians, to public institutions, business leaders, traditional and religious leaders, special interest groups, offline community networks and ordinary social media users (Cunliffe-Jones, 2022b). The study finds misinformation circulates in a broad spread of different channels from traditional media and social media platforms or messaging apps, to speeches in parliament or at public events, through traditional community networks and on the product labels for medications. It also shows misinformation touches on numerous topics from accidents and disasters to crime and justice, health, politics, the economy and the media (Cunliffe-Jones, 2022b). Understanding who spreads misinformation, where it can be found and the topics it touches on is again considered essential by fact-checking organisations to being able to properly identify misinformation as such (Cunliffe-Jones, 2022a).

\subsection{What drives misinformation and why we may believe and share it}

To properly be able to identify misinformation as such, and distinguish it from accurate information, it is also important to understand what may drive it, and why we may believe and share it ourselves. The research reviewed for this report shows a diverse set of elements driving the creation and spread of false information on the continent. These elements range from psychological factors such as motivated reasoning and strong emotional responses to particular stimuli (Duffy, 2018; Madrid-Morales et al, 2021; Vicol, 2020), to more calculated political motivations driving both politicians' false claims in parliament or in speeches and active disinformation campaigns (Burke \& Harding, 2019; Cunliffe-Jones, 2022b; Oborne, 2005). 
Financial incentives drive the creation of both scams (Cable et al, 2020) and much misinformation that serves as clickbait (Cunliffe-Jones, 2022b). The operating systems of many social media platforms both promote often misleading material to which users show strong emotional responses (Statt, 2020) and provide financial incentives that can drive misinformation. This is one reason critics argue larger tech firms have obligations to financially support public and civil society initiatives to mitigate effects of misinformation. In addition, people and institutions often make mistakes and fail to verify information they originate or share.

\subsection{Understanding the effects of misinformation may change our behaviour}

On the basis of the research reviewed in this report, we argue above that for people to be able to identify misinformation as such, it is necessary to understand the types of misinformation in circulation, who creates and spreads it, the context in which it emerges, where it circulates and why we and others may believe it to be true and share it.

We know, however, from many studies over the years that understanding of a topic does not automatically lead people to adopt behaviour to address the challenge or challenges it poses (McQuail, 2010). As set out in Icek Ajzen's Theory of Planned Behaviour (Ajzen, 1991) for knowledge and skills to affect behaviour, they must be combined with (i) the individuals' attitudes to the perceived behaviour, (ii) social norms relating to the behaviour and (iii) the individuals' perceived ability to control the behaviour. In this case, where the behaviour concerned is the acceptance and sharing of information known to be false, we argue that, although not understanding its harmful effects will not necessarily be sufficient to deter the conduct without strong pro-accuracy social norms, understanding the consequences of misinformation may contribute to the sought-after practices.

Public discussion of the effects of misinformation has often focused on ways in which misinformation may or may not distort the outcomes of political elections or cause harms to public health. The forthcoming study of misinformation that is part of this series identifies a far wider range of fields in which harmful effects can be identified. These comprise (i) physical harms - from vigilante and gender-based violence to harms to individuals' and public health; (ii) harms to mental health - from personal distress to public alarm; (iii) harms to fairness, social cohesion - from entrenching negative stereotypes to enflaming social divisions; (iv) harms to the justice system from distorting particular cases, to judicial policy; (v) harms to the political system - from suppressing voting, and undermining trust, to distorting the focus of debate; (vi) harms to business, economy - from company reputations to economic policy; (vii) harms to the environment - from endangering wildlife to distorting policy 
focus; (viii) harms to international relations - from distorting public understanding to government policy; (ix) harms to individuals' finances, practical harms from financial loss to identity theft, and the spreading of computer viruses; and (x) harm through distorted understanding of the natural world - miscellaneous effects such as discrimination and more. 


\section{DIFFERENT TYPES OF MEDIA LITERACY: DIFFERENT EFFECTS}

Taking account of the types, drivers and effects of misinformation, we can then ask how well they are addressed by the sorts of media literacy taught today.

\section{I. Many forms of literacy demanded of young people}

Around the world, there are many different forms of literacy demanded of young people from written literacy to digital literacy (Hobbs, 2019; Snelling, 2017), ${ }^{4}$ health literacy (NLM, Undated), ${ }^{5}$ news literacy (Kajimoto \& Fleming, 2019; Vraga et al, 2020 $)^{6}$ and more. In some countries, the practice of educating students to reduce susceptibility to false information is a new one. In others, the goal was set out decades ago. 'There are three ways to deal with propaganda - first, to suppress it; second, to try to answer it by counterpropaganda; third, to analyse it', the founder of the Institute for Propaganda Analysis (IPA), Clyde R. Miller, said in a lecture in 1939 in New York (Schiffrin, 2018). Miller was referring not only to his organisation's frequent newsletters but also to its programme to educate schoolchildren in what we would today call a form of media or news literacy skills. The IPA's educational director, Violet Edwards, described the schools' programme as seeking to instil a scientific mindset of fact-finding, logical reasoning and critical thinking (Schiffrin, 2018). The knowledge and skills needed to acquire this mindset remained an open question.

\subsection{UNESCO's promotion of media and information literacy}

In the post-war years, the range of media literacy concepts has grown. Around the world, the main driving force promoting what it calls Media and Information

4 There are different definitions of digital literacy. One that is widely used relates digital literacy to knowledge and skills in four fields: (i) computer skills and access; (ii) skills of creating and sharing content; (iii) evaluating the credibility of information found online; (iv) online social responsibility.

5 Health literacy is defined by the US National Library of Medicine as 'the degree to which individuals have the capacity to obtain, process and understand basic health information and services needed to make appropriate health decisions.'

6 Similarly, there are different definitions of news literacy. Kajimoto and Fleming identify an understanding of the term as 'critical-thinking skills necessary to the evaluation of news reports and the ability to identify fact-based quality information, encourage active participation and engagement among well-informed citizens'. For this report, we use the definition proposed in 2020 by Vraga et al of news literacy as 'knowledge and skills regarding content, systems and practices related to news production'. 
Literacy (MIL) has been the UN Educational, Scientific and Cultural Organisation (UNESCO). In January 1982, UNESCO convened an International Symposium on Media Education at Grunwald, Germany, bringing together educationalists, researchers and communicators from 19 countries. The 'Grunwald Declaration on Media Education' set out a broad definition for the field, declaring media literacy to consist of 'developing the knowledge, skills and attitudes which will encourage the growth of critical awareness and, consequently, of greater competence among the users of electronic and print media' (UNESCO, 1982). As US educationalist Patricia Aufderheide noted in 1993, this definition was considered broad even then and expected to grow broader still. 'The fundamental objective of media literacy is critical autonomy in relationship to all media,' she said, and yet the term media literacy was already then being applied much more extensively. 'Emphases in media literacy training range widely, including informed citizenship, aesthetic appreciation and expression, social advocacy, self-esteem and consumer competence. The range of emphases will expand with the growth of media literacy', she predicted (Aufderheide, 1993). In 2013, UNESCO identified this new, broader concept as MIL, 'bringing together Information Literacy and Media Literacy, along with Information and Communication Technology (ICT) and Digital Literacy'. UNESCO defined the concept as 'a set of competencies that empowers citizens to access, retrieve, understand, evaluate and use, create, as well as share information and media content in all formats, using various tools, in a critical, ethical and effective way, in order to participate and engage in personal, professional and societal activities' (UNESCO, 2013, p. 29).

\subsection{Identifying media literacy sub-types to better understand effects}

For Robert Keener, a researcher at the University of Washington, the concept of 'media literacy' as taught today around the world is so broad as to 'lack all conceptual rigour'. In a forthcoming study of media literacy in US schools, Keener and West identified six main themes present in curricula across the country in 2020: (i) traditional media literacy, including news literacy; (ii) digital citizenship; (iii) digital literacy; (iv) informational literacy; (v) media arts; and (vi) technological media literacy (Keener \& West, 2021). These add to the concepts such as informed citizenship, social advocacy, self-esteem and consumer competence, identified earlier by others such as Aufderheide and taught as civics or media literacy in the United States and in other countries.

This lack of clarity and agreement on the range of themes covered by, and intended outcomes of, media literacy teaching makes it challenging for scholars to assess

7 Email to authors July 2020. 
either the extent of teaching of 'media literacy' or its effects. In 2013, UNESCO published a detailed framework for assessment of MIL competencies around the world (UNESCO, 2013, pp. 41-64). However, in a 2019 report, Huguet et al argued that many of the ways of measuring the effects of media literacy programmes do not capture their effects fully and are difficult to compare. Goals and objectives differ. Some studies rely on self-reporting, whereas others use multiple choice assessments and still others rely on performance-based assessments (Huguet et al, 2019). To properly assess the effects of any one particular media literacy sub-type, across multiple countries, it would be necessary to clearly define both outcomes sought and means of measuring effects.

\subsection{News literacy as knowledge and skills in five domains of news}

In 2020, researchers Emily Vraga, Melissa Tully and colleagues proposed a new definition of the media literacy sub-type news literacy: 'knowledge of the personal and social processes by which news is produced, distributed, and consumed, and skills that allow users some control over these processes' (Vraga et al, 2020). News literacy, according to this, consists of knowledge and skills across five clearly defined domains: (i) context: the social, legal and economic environment in which news is produced; (ii) creation: the process in which journalists and others engage in conceiving, reporting and creating news stories and other journalistic content; (iii) content: the characteristics of a news story or piece of news that distinguishes it from other types of media content; (iv) circulation: the process through which news is distributed and spread to potential audiences; and (v) consumption: the personal factors that contribute to news exposure, attention and evaluation. This is a compelling theory. At the same time, if the goal is the ability to identify inaccurate information, the subject is both too broad to apply perfectly to misinformation, in that it extends to more than the accuracy of news, and too narrow in that it is limited to 'news' which even broadly defined - does not cover all the types or channels in which misinformation circulates (see Section 2.3).

\subsection{Misinformation literacy - five domains of specialist knowledge and skills}

Based on our review of a wider series of studies (Amazeen \& Bucy, 2019; Duffy, 2018; Keener \& West, 2021; Van der Linden et al, 2020; Vicol, 2020; Vraga et al, 2020), and the knowledge and skills identified by fact-checking organisations (Cunliffe-Jones, 2022a), we propose a version, or sub-type of news literacy with its own set of knowledge and skills, adapted to apply specifically to the field of misinformation. 
As Keener and West note in their study of media literacy in the United States, news literacy and media literacy themes unrelated to misinformation can be of great social value in their own right without having any clear effect on susceptibility to misinformation. 'We are not saying that digital citizenship or media arts are not important. However, the many different concepts in media literacy education have not addressed many students' inability to reason effectively with information online' (Keener \& West, 2021). Even teaching the existence of false information without the necessary degree of detail does not ensure students can identify false statements correctly, a UK study found (National Literacy Trust, 2018).

By contrast, studies by Amazeen and Bucy, Van der Linden et al, Vicol and others suggest teaching specific knowledge and skills relevant to misinformation can indeed produce what we would call misinformation literacy effects: the ability or propensity to identify misinformation as such (Amazeen \& Bucy, 2019; Van der Linden et al, 2020; Vicol, 2020). Furthermore, the proposed knowledge and skills are coherent with the knowledge and skills identified, empirically, by fact-checkers as necessary to distinguish false or misleading information from information that is fair and accurate (Cunliffe-Jones, 2022a). We propose to define this new subtype of news literacy as 'Knowledge of the forms that misinformation and accurate information take, the processes by which they are produced or emerge, are distributed and consumed, by whom, where and on what topics, and the skills to distinguish one from the other'.

\subsection{Misinformation literacy behaviour - a sixth domain of knowledge required}

Numerous studies tell us that knowledge alone does not often change behaviour. Icek Ajzen's Theory of Planned Behaviour (Ajzen, 1991) proposes that, for knowledge and skills to influence behaviour, they must be combined with (i) individuals' attitudes to the perceived behaviour, (ii) social norms relating to the behaviour and (iii) individuals' perceived ability to control the behaviour. Put another way, knowledge and skills are necessary to identify, but insufficient to ensure that people dismiss, false information as such. The social norms set by public figures, institutions and traditional and social media related to false information are major factors in shaping behaviour. Evidence drawn from the study of misinformation that forms part of this series suggests knowledge of the harmful consequences of spreading and believing some forms of false information may influence misinformation-related behaviour (Cunliffe-Jones, 2022b). 


\section{MISINFORMATION LITERACY - THE SIX FIELDS OF KNOWLEDGE AND SKILLS TO IDENTIFY AND DISMISS FALSE INFORMATION}

As set out above, in Section 2, misinformation comes in many forms. It ranges from false statistical claims made by ministers in parliaments, to mislabelled photos and videos shared online or on messaging apps, content that falsely purports to come from someone else (imposter content), unproven claims presented as known fact, long-standing myths circulating in community networks and false medical claims made on the labels of unregulated medications. It is a distinct field of information distinguished not so much by form, format or creator as by its quality of inaccuracy; often difficult to detect. And just as misinformation is a distinct field, so the ability to identify and understand misinformation requires a distinct set of knowledge and skills too.

As set out below, the knowledge and skills that help to consistently identify misinformation include understanding of the context in which misinformation emerges, who creates and spreads it, the types of misinformation, where it circulates, and why people believe it to be true and share it. Knowledge of the harmful effects certain types of misinformation may have, may also make people more likely to dismiss false information as such. This is not proven.

\section{I. Context: knowledge of the contexts - social, cultural, economic, political, informational and events - in which false and accurate information are produced}

Knowing in advance the contexts in which to expect to see a surge in false information, 'can reduce susceptibility to misinformation across cultures' studies published in 2020 showed (Van der Linden et al, 2020). This element of forewarning, described by Van der Linden as 'pre-bunking', is built into the training practices of fact-checking organisations across Africa for new staff (Cunliffe-Jones, 2022a).

Studies of misinformation show that particular contexts - social, cultural, economic or political upheaval (Cunliffe-Jones, 2022b; Hill, 2020; Larson, 2018), information blackouts, data deficits (Golebiewski \& Boyd, 2019; Rydzak, 2019; Shane \& Noel, 2020) and worrying natural events such as floods, fires or health crises accurately predict a surge in misinformation and the type of misinformation to be expected. This was demonstrated recently with the wave of false and misleading health information observed worldwide during the 2020 Covid-19 pandemic (Brennan et al, 2020; Thomas, 2020). Teaching this knowledge of the contexts and 
forms in which misinformation is to be expected is thus an important element of misinformation literacy.

\subsection{Creation: knowledge of the types of people and institutions found to create false and accurate information, their different motivations and the skills to identify those who produce specific information online}

To identify misinformation and distinguish it from accurate information consistently it is also important to know the types of people and organisations who create or promote false information, those more likely to produce accurate information, and their different motivations. Studies show the public often see information from certain types of individuals or organisations as more reliable than it is (Newman et al, 2020; Vicol, 2020; Wasserman \& Madrid-Morales, 2018). Learning the types of individuals and institutions who regularly create false information, accurate information, and their different motivations and processes is critical to knowing when to question information on the basis of the source (Amazeen \& Bucy, 2019).

At the same time, much online misinformation is so-called imposter content, concealing the name of its true producer and appearing in the name of another person or organisation. The skills to identify who created information, where, when and potentially why are vital to demasking this type of content. Misinformation literacy needs to include this knowledge of who creates false information, who creates accurate information, and the technical skills to identify who created information when that is not clear.

\subsection{Content: knowledge of the difference between facts and opinions, the different ways information can mislead and the skills and practices to distinguish accurate and inaccurate information}

In a survey in South Africa, $70 \%$ of respondents said they 'struggle to separate fact from fiction online' (Roper et al, 2019), and research from the United States shows members of the public often struggle with even the 'basic task of differentiating between factual and opinion news statements' (Mitchell et al, 2018). Misinformation takes many forms and studies of the training practices of fact-checking organisations show knowledge and skills considered essential to identifying false information cover understanding of a wide range of content types: (i) the differences between a factual claim and an opinion, (ii) the different ways false or misleading information distorts understanding, (iii) different practices to distinguish an accurate from an inaccurate source, (iv) numeracy skills such as basic statistics and numeracy, (v) technical skills to identify and retrieve information online and offline and (vi) technical skills in the verification of information online from the authentication of an image to the location shown (Cunliffe-Jones, 2022a). 
Misinformation literacy needs to include this range of knowledge and skills to be effective.

\subsection{Circulation: knowledge of the processes by which accurate and inaccurate information circulates and what drives people to share information}

To reduce our susceptibility to misinformation, it is necessary to understand when and how different elements of traditional media and social media do and do not verify the information they distribute and why individuals and institutions offline may share false information. In 2019, a study by the US researchers Michelle Amazeen and Erik Bucy provided evidence that 'possessing a working knowledge of how the news media operate aids in the identification and (reducing the) effects of fabricated news' (Amazeen \& Bucy, 2019). Evidence from the study of drivers of misinformation that is part of this series suggests this applies equally to the processes that drive circulation of information on social media and in offline settings. For example, knowing the possible financial or political motivations of those posting false information can reduce its perceived credibility (Cunliffe-Jones, 2022b). And knowing where and when to expect accurate and inaccurate information and why may also contribute to reducing susceptibility to false claims (Van der Linden et al, 2020). To be effective, misinformation literacy needs to include this range of knowledge.

\subsection{Consumption: knowledge of the reasons we as individuals may believe false or misleading information to be true}

A variety of conscious and unconscious biases in the way we think make us all susceptible to believing certain types of false information or to share it even when we do not necessarily believe it to be strictly true. This is as much the case in Africa as it is elsewhere (Madrid-Morales et al, 2021). We are often unaware of these biases. As Professor Bobby Duffy noted in 2018, polling data from around the world finds people often believe misinformation is something that fools others, not themselves (Duffy, 2018). This risks stopping us from asking questions that are needed. US researcher Robert Keener, for his part, argues that the ability to distinguish accurate and inaccurate information is deeply tied to understanding one's own biases, shaped at least in part by one's social identity ${ }^{8}$. Knowing the reasons why we as individuals may believe false or misleading information to be true is essential to misinformation literacy.

8 Email to authors October 2020. 


\subsection{Consequences: knowledge of the different forms of actual and potential harm caused by believing and sharing false and misleading information}

It is long acknowledged that, almost whatever the topic, acquiring knowledge alone does not automatically lead to a change in behaviour. As set out in Icek Ajzen's Theory of Planned Behaviour (Ajzen, 1991), for knowledge and skills to affect behaviour, they must be combined with (i) the individuals' attitudes to the perceived behaviour, (ii) social norms relating to the behaviour and (iii) the individuals' perceived ability to control the behaviour. The forthcoming study of misinformation that is part of this series identifies a wide range of fields in which harmful effects can be identified, knowledge of which, the study suggests, may have the potential to influence information sharing behaviour (Cunliffe-Jones, $2022 \mathrm{~b}$ ). We would therefore argue knowledge of the different forms of actual and potential harm that can be caused by sharing and believing misinformation is a potentially important element of misinformation literacy on this basis. 


\section{MEDIA LITERACY TEACHING AROUND THE WORLD}

Following the surge in concern worldwide since 2016 about the effects of misinformation, educators and commentators on every continent have proposed the use of media literacy as a form of vaccine or antidote to the harms caused by false information (Cissé, 2018; Jakubu, 2017; Seargeant \& Tagg, 2018). In the United States and other countries, schools have introduced courses focused specifically on misinformation (Barron, 2017; Tugend, 2020). In countries including Finland (Charlton, 2019; Henley, 2020) and Norway ${ }^{9}$, programmes aimed at reducing the effects of misinformation have been introduced at a national level. Factchecking organisations and civil society groups have launched a range of media literacy initiatives (Chequeado, Undated ${ }^{10}$ as have social media platforms (Costello, 2019; Facebook, 2020). The nature and likely efficacy of the different initiatives varies greatly.

\section{I. United States - a patchwork of approaches}

In the United States, education policy is devolved to the state level and until recently devoted little funding to media literacy; a mere \$12 million between 2006 and 2016 (Fleming, 2016). In the wake of the rise in concern in 2016, more schools started promoting media literacy as an antidote to misinformation (Barron, 2017; Rosenwald, 2017; Tugend, 2020).

A study by Huguet et al in 2019 found the media literacy programmes offered in US schools tend to fall into three broad categories: (i) those that look at the 'economic motivations that undergird popular media and information streams', (ii) education that relates to democracy and civic life and (iii) efforts to 'evaluate the quality of information' - not exclusively on grounds of accuracy (Huguet et al, 2019). A forthcoming study by researchers Robert Keener and Jevin West identified six categories: (i) traditional media literacy, including news literacy; (ii) digital citizenship; (iii) digital literacy; (iv) informational literacy; (v) media arts and (vi) technological media literacy. While 'every state had at least some expression of media literacy ... states are not emphasizing the type of powerful knowledge that students need to identify fact from fiction in the digital age' their study concluded (Keener \& West, 2021).

9 See the Norwegian news literacy teaching programme Tenk: https://tenk.faktisk.no.

10 This database, created by the Argentinian fact-checking organisation Chequeado, was accessed on I October 2020. It details misinformation literacy initiatives by fact-checking initiatives and others https://educheckmap.factcheckingday.com/dist/index.html\#/projects 


\subsection{Europe - some countries committed, but many weak spots}

Governments across Europe have promoted media literacy education in schools across the continent for decades (Aguadad et al, 2016). Denmark, Greece, Finland and France were judged as among the more advanced EU countries in media literacy in 2017 (Frau-Meigs et al, 2017). In Finland and Norway ${ }^{11}$ media literacy teaching was updated following the rise in concern in 2016 to include a focus on identifying misinformation, with course modules designed in partnership with experts from fact-checking organisations (Charlton, 2019; Henley, 2020). An EU expert group issued in 2018 a call for a new focus in schools on MIL (HLEG EU High Level Expert Group, 2018). The Open Society Institute's Media Literacy Index in 2019 rated Finland as the country most prepared to deal with the impacts of disinformation (OSIS, 2019).

However, the effectiveness reported in Finland is not replicated everywhere. Education policy is left to national governments, approaches vary and resources and course content differs. In the United Kingdom, the official communications regulator OFCOM has been charged since 2003 with promoting media literacy. To the extent that if the goal has been teaching students to identify false information, it has had limited success (National Literacy Trust, 2018; Vicol, 2020). A 2017 study found that policy frameworks, funding and evaluation of media literacy programmes were European programmes' weakest aspects (Frau-Meigs et al, 2017).

\subsection{Latin America - digital skills, no focus on misinformation}

Civil society organisations across Latin America have sought to promote media literacy for decades (Aguadad et al, 2016). However, while schools in countries such as Peru and Mexico do teach elements of digital literacy such as search and digital skills, broader media or misinformation literacy themes do not feature in most school curricula, a 2020 study found (Vicol, 2020). Initiatives by academic and civil society organisations are discussed in the next section.

\subsection{India - limited teaching of media literacy despite growing demand}

There is at present, only limited media literacy teaching in most schools across India, despite increasing demand for its inclusion. The National Council of Educational Research and Training has included some reading on the role of the media in course readings for social and political science subjects (Roy, 2017). However, attention to media literacy is limited and schools that do include broader media literacy themes tend to work with civil society organisations that focus on training

I I See the Norwegian news literacy teaching programme Tenk: https://tenk.faktisk.no 
young people to create radio projects, run mock news coverage or theatre performances. As of June 2020, themes of misinformation literacy did not feature in most school programmes.

\subsection{East Asia and Southeast Asia - many governments wary of media literacy}

In Singapore, education policy is set by the national ministry of education. Media literacy is included in the curriculum with an emphasis on the skills of information access, a critical stance towards information and media content and the notable absence of any mention of creative, expressive production (Weninger, 2017). The revised 2020 English Language Syllabus's declared aim is to develop pupils into 'discerning readers' who are well-informed and well-equipped to 'distinguish fact from falsehood by processing and evaluating information, critically and with discernment according to purpose, audience, context and culture'. As with other countries, the question of how this is taught, in practice, is another matter. In Singapore, strict government control of the media extends to the government identifying and ordering the takedown of what it declares false information, raising questions about the objectivity with media literacy is taught. A 2020 review of the teaching of media literacy in five East and Southeast Asia countries - Indonesia, Japan, Malaysia, the Philippines and Thailand - for UNESCO recognised this issue. It is clear that at this stage what MIL education entails in each country is not aligned, the survey found. 'With restrictive laws and regulations that essentially curtail speech, coupled with limited press freedom, it is not easy for teachers in Malaysia and Thailand to discuss how to critically evaluate information and media content ... in classrooms', the study found. By contrast 'free speech is by and large well protected' in Japan, but in the Philippines, 'the polarizing nature of the current political climate and ongoing attacks on journalists discourage conversations'. Across the region: 'Applying critical thinking skills to decode the meaning of information and media messages could result in questioning or challenging authoritative voices in some cases, including those of teachers, which can be considered disrespectful in all countries', the study concluded (Kajimoto et al, 2020).

\subsection{Media literacy centres, library associations, fact-checking organisations}

Outside the formal education system, media literacy centres, library associations and fact-checking organisations in Africa, the United States, across Europe, Asia and Latin America have taken a growing role in promoting and teaching media literacy. Often they have focused on using fact-checking techniques to identify misinformation. In the United States, like other regions, these efforts tend to be run on a relatively small scale, fragmented and include a wide range of different priorities (Head et al, 2020). Outside the United States, UNESCO continues its work seeking to 
promote broad media literacy through the support provided to regional media literacy centres ${ }^{12}$, staging events and developing media education kits for teachers, students, parents and professionals. In Africa, fact-checking organisations such as Africa Check, Dubawa and PesaCheck operate media literacy programmes in schools and on social media (Cunliffe-Jones, 2022a) ${ }^{13}$. In Europe, a third of media literacy networks are cross-sector collaborations targeting youths and tending to bypass older population groups, and with uncertain outcomes (Council of Europe, 2016). In Latin America, fact-checking organisations such as Argentina's Chequeado and Mexico's Verificado conduct workshops and talks to enhance both awareness and skills like critical thinking and data literacy ${ }^{14}$. In countries such as Taiwan, governments get involved in out of school programmes promoting media literacy too (Huang, 2020).

\subsection{Traditional media and social media platforms}

The role taken by traditional media organisations in media literacy projects tends, with exceptions such as programmes run by major organisations such as the $\mathrm{BBC}^{15}$ to be limited, in part by lack of resources and in part by lack of focus. By contrast, global social media companies, rich in resources and stung by criticism of the harm false and hateful content on the platforms can cause, started recently to both run media literacy messaging on their platforms and provide funding support to media literacy programmes from independent fact-checking organisations and media literacy groups. In 2019, for example, Twitter partnered with UNESCO to produce a handbook for schools to equip younger generations with media literacy skills... enabling them to ask the right questions about content' (Costello, 2019). Meanwhile Facebook developed a media literacy campaign on its platform in partnership with fact-checking organisations to ask people to challenge information they see by asking a series of basic questions about the source and accuracy of the content (Facebook, 2020). Given the scale of the tech companies' operations, these efforts to date appear limited in terms of ambition, adding to wider criticisms made of their efforts to combat the problems that misinformation on their platforms cause (Chee, 2020).

12 Disclosure: co-authors Dr Chido Onumah and Wallace Gichunge run the centres for the promotion of media and information literacy in Nigeria and Kenya, respectively, with support from UNESCO.

13 Disclosure: lead author Peter Cunliffe-Jones is the former director of Africa Check.

14 See this database of misinformation literacy initiatives by fact-checking initiatives and others https://educheckmap.factcheckingday.com/dist/index.html\#/projects.

I5 See for example: http://www.bbc.co.uk/learning/overview/about/digitalliteracy.shtml. 


\section{MEDIA LITERACY TEACHING IN SEVEN SUB-SAHARAN COUNTRIES}

As of June 2020, broad media literacy was barely taught in seven sub-Saharan countries we studied for this report, and just one province in South Africa included any elements of what we identify as misinformation literacy in school teaching. Compared to both the initiatives seen pre-World War II in the United States, and from the 1980s onward in Europe and elsewhere, efforts to promote the teaching of media literacy in Africa are relatively recent. With the launch of the Pan-African Alliance on Media and Information Literacy, in Abuja, Nigeria, in June 2013, advocates of media literacy, supported by UNESCO and others, sought to generate more progress with a flurry of regional meetings and initiatives. However, while leaders such as the president of Senegal demanded a plan in 2018 for schools to counter the spread of false information (Cissé, 2018) and Nigeria's information minister at the same time called on Nigerians to learn about false information (Okakwu, 2018), these calls led to little action. By contrast, the study of laws on false information that is part of this series (Cunliffe-Jones et al, 2021) shows the near doubling of legal measures introduced against misinformation in 11 sub-Saharan countries from 2016 to 2020, showing where political priorities lie.

\section{I. Media literacy is barely taught in seven countries, misinformation literacy taught in only one province}

To assess the teaching of media or misinformation literacy in the seven subSaharan countries surveyed, the research team reviewed the curricula most widely used in state-run primary and secondary schools for the terms 'MIL', 'news literacy' and 'fake news' and related terms, or French-language equivalents, and terms related to key elements of the standard definitions of broad media literacy. Activities suggesting the development of critical thinking skills were also identified. The team focused on curricula taught in state-run schools, rather than those taught in the private sector, because the largest share of the school-age population attend state-run schools and private schools do not follow one main curricula. Across the countries studied, the team found that, while officials responsible for setting curricula in some countries expressed interest, in practice the curricula taught still include barely any elements of broad media literacy and save for in one province of South Africa, no teaching of misinformation literacy at all. 


\begin{tabular}{|c|c|c|c|}
\hline \multicolumn{4}{|c|}{$\begin{array}{c}\text { TABLE I ELEMENTS OF (I) MEDIA AND INFORMATION LITERACY AND } \\
\text { (2) MISINFORMATION LITERACY IDENTIFIED IN STATE SCHOOL CURRICULA } \\
\text { AT JUNE } 2020\end{array}$} \\
\hline Country & $\begin{array}{l}\text { Media and Information } \\
\text { Literacy in June } 2020\end{array}$ & $\begin{array}{c}\text { Misinformation Literacy } \\
\text { in June } 2020\end{array}$ & Plans for June 2020 \\
\hline Cote d'Ivoire & $\begin{array}{l}\text { New curriculum } 2018 / 2019 \\
\text { - ICT/digital skills } \\
\text { - Freedom of expression/media } \\
\text { - News article formats }\end{array}$ & $\begin{array}{l}\text { New curriculum 2018/2019 } \\
\text { - Nothing specific }\end{array}$ & $\begin{array}{l}\text { No changes known to } \\
\text { be planned }\end{array}$ \\
\hline Ghana & $\begin{array}{l}\text { Long-standing curriculum } \\
\text { - Civic education } \\
\text { - Behaviour to others }\end{array}$ & $\begin{array}{l}\text { Long-standing curriculum } \\
\text { - Nothing specific }\end{array}$ & $\begin{array}{l}\text { No changes known to } \\
\text { be planned }\end{array}$ \\
\hline Kenya & $\begin{array}{l}\text { New curriculum } 2019 \\
\text { - Self-awareness } \\
\text { - Empathy } \\
\text { - Critical thinking, problem- } \\
\text { solving } \\
\text { - Communication and } \\
\text { collaboration (new) } \\
\text { - Digital literacy (new) }\end{array}$ & $\begin{array}{l}\text { New curriculum } 2019 \\
\text { - Nothing specific }\end{array}$ & $\begin{array}{l}\text { Kenya Institute of } \\
\text { Curriculum } \\
\text { Development declares } \\
\text { interest in media and } \\
\text { information literacy }\end{array}$ \\
\hline Nigeria & $\begin{array}{l}\text { Long-standing curriculum } \\
\text { - ICT/computer science skills }\end{array}$ & $\begin{array}{l}\text { Long-standing curriculum } \\
\text { - Nothing specific }\end{array}$ & $\begin{array}{l}\text { Curriculum authority } \\
\text { NERDC in talks on } \\
\text { proposals. }\end{array}$ \\
\hline Senegal & $\begin{array}{l}\text { Long-standing curriculum } \\
\text { - News article used as sources } \\
\text { - Visual styles of different media }\end{array}$ & $\begin{array}{l}\text { Long-standing curriculum } \\
\text { - Nothing specific }\end{array}$ & $\begin{array}{l}\text { No changes known to } \\
\text { be planned }\end{array}$ \\
\hline South Africa & $\begin{array}{l}\text { Long-standing curriculum } \\
\text { - Self-esteem and bullying } \\
\text { - Critical thinking, problem } \\
\text { solving } \\
\text { - Responsible citizenship } \\
\text { - Mass media formats } \\
\text { - Use of formats to stereotype } \\
\text { - and mislead } \\
\text { - Accuracy or biases of } \\
\text { - historical sources } \\
\text { - Social effects of technology } \\
\text { Media's role, media freedom }\end{array}$ & $\begin{array}{l}\text { Long-standing curriculum } \\
\text { - Identifying hoaxes } \\
\text { New curriculum elements } \\
\text { Western Cape } 2020 \\
\text { - 'Click restraint' } \\
\text { - Identifying fake websites, } \\
\text { false information } \\
\text { - Harms done by } \\
\text { misinformation } \\
\text { - Political misuse of social } \\
\text { media }\end{array}$ & $\begin{array}{l}\text { Other provinces have } \\
\text { discussed adopting } \\
\text { new elements }\end{array}$ \\
\hline Uganda & $\begin{array}{l}\text { Long-standing curriculum } \\
\text { - Community news } \\
\text { - News terminology } \\
\text { - Online search } \\
\text { - News formats, biases }\end{array}$ & $\begin{array}{l}\text { Long-standing curriculum } \\
\text { - Nothing specific }\end{array}$ & $\begin{array}{l}\text { No changes known to } \\
\text { be planned }\end{array}$ \\
\hline
\end{tabular}

NERDC $=$ Nigerian Educational Research and Development Council.

\section{I.I. COTE D'IVOIRE}

\section{I.I.I. Structure of the school system and curriculum}

In Cote d'Ivoire, the education ministry, the ministère de l'éducation nationale, sets education policy and has oversight of standards whereas local authorities have responsibility for running schools and the provision of services. According to law, children start primary school aged between 5 and 7 years and education remains 
compulsory up to 16 , however the estimated average time spent in school is 5.2 years. See Section 7.2 for details. The most recent figures show that, as of 2014/2015, three quarters of students attended state-funded schools with the share attending private sector schools share higher among secondary-age than among juniorage students.

\section{I.I.2. New curriculum includes digital skills and news formats}

Cote d'Ivoire developed a new national plan for education in 2017, as part of efforts to move the country beyond the divisions of the 2010-2011 civil war. This introduced limited elements of media literacy education into the secondary school curriculum. Between the ages of 12 and 15 students learn basic digital, or ICT, skills under the new programme, including how to access and produce information online and, in theory, the importance of freedom of information and freedom of expression (Ministère de léducation Nationale du Cote d'Ivoire, 2017). In 2019, Cote d'Ivoire was reported to be the only country of francophone West Africa providing any teaching in digital skills (Corroy \& Yanon, 2019). In the final compulsory year, when students are on average 15, the curriculum provides 18 hours of lessons covering news writing and production techniques in traditional media. After the new programme was launched in the 2018/2019 school year, plans were announced to train teachers in digital skills and establish digital labs in schools but neither had been put into practice at the time of writing.

\section{I.I.3. No elements of 'misinformation literacy' taught or planned}

Despite the changes, the new curriculum does not include any focus on the accuracy of information and teaches none of the specific knowledge and skills we identify as required for misinformation literacy. What efforts there have been to train young people in skills related to misinformatio in Cote d'Ivoire have been driven largely by UNESCO.

\section{I.2. GHANA}

\subsubsection{Structure of the school system and curriculum}

The National Ministry of Education sets education policy and has ultimate oversight of standards; however, multiple institutions, such as the National Teaching Council and the National Inspectorate Board, have been set up to help in policymaking and oversight. Responsibility for provision lies at the district level. The National Council for Curriculum and Assessment sets the curriculum. Children start their pre-schooling at the age of 4 years and it is estimated that on average children spend 7.1 years in school. See details in Section 7.2. Around 75\% of students attend state-run schools. 


\section{I.2.2. Curriculum includes civic education and personal behaviour}

The only real aspects of broad media literacy identified in our review of state school curricula at the time of writing were civic education and behaviour. The first major attempt to have a national conversation on media literacy in Ghana took place in August 2017 during a symposium organised by the School of Information and Communication Studies, University of Ghana, in partnership with UNESCO. The symposium became an annual event but has made little progress to date with no plans announced, as of June 2020, for changes to the curriculum.

Media literacy is taught at Ghana's main journalism training centres (the Ghana Institute of Journalism, the African University College of Communications and the University of Ghana), and events promoting media or news literacy have been organised by a range of non-governmental organisations such as the Africa Centre for Media and Financial Literacy, Ghana Fact and the Media Foundation for West Africa.

\section{I.2.3. No elements of misinformation literacy taught or planned}

At the time of writing, only limited elements of broadly defined media literacy and no elements promoting misinformation literacy could be identified in the curricula for junior or secondary schools in Ghana. None were reported as planned.

\section{I.3. KENYA}

\section{I.3.I. Structure of the school system and curriculum}

In Kenya, the Ministry of Education sets education policy and has oversight of standards. Curricula are set by the Kenya Institute of Curriculum Development. Under Kenya's Universal Access to Basic Education law, children can start schooling earlier but most start at 6 years. Accordimg to the law, primary and secondary schooling are compulsory. In practice, however, according to Our World in Data, children spend on average 6.5 years in schooling (see Section 7.2 for details).

\subsubsection{New curriculum includes digital literacy and critical thinking}

Kenya's Ministry of Education launched in 2017 a reform of the national curricula for early learning, primary and secondary schools and teacher training. The new 'Kenya Basic Education Curriculum Framework' was introduced in January 2019 for early learners and rolled out for older age groups progressively. Curriculum support materials were developed for use in both state-run and private sector schools that choose to adopt it.

The previous curriculum, introduced in 1984, included the broad media literacy skills of self-awareness, empathy and problem-solving. The new curriculum introduced seven broad competencies including the fields of 'communication and 
collaboration', teaching how people use messages across different contexts and media, and 'digital literacy', providing basic digital skills to search, evaluate and use information online. In form two, aged 16 on average, students receive 8 hours of lessons on the development of means of communication, as part of their history and government course. The curriculum lists critical-thinking and problemsolving as intended core competencies with the hope that learners will 'use logic and evidence to arrive at conclusions'.

\section{I.3.3. Curriculum body considering misinformation literacy}

Education officials hope that the new curricula will result in some 'media literacy outcomes'. John Kimotho, director of educational media at the Kenya Institute of Curriculum Development, said in an interview for this report. However, at the time of writing, the curricula do not directly address the challenge of misinformation, he agreed.

The Institute recognises the threat posed by misinformation is growing and needs to be addressed. 'It is now time for introduction or mainstreaming of MIL in its raw format in the curriculum ... I do not think we'll want to miss the bus if we have to address the problem of misinformation and disinformation among the citizens,' he said ${ }^{16}$.

\section{I.4. NIGERIA}

\subsubsection{Structure of the school system and curriculum}

In Nigeria, the Federal Ministry of Education sets education policy at the national level. Responsibility for schools at the secondary level is split between federal and state authorities while local governments are, in theory at least, responsible for primary schools. Curricula are set by the Nigerian Educational Research and Development Council (NERDC), a parastatal under the education ministry. Children start primary school at 6 years, in theory, though in practice some start younger. Schooling is compulsory by law for 9 years but in practice it is estimated that children spend on average 6.2 years in school (see Section 7.2 for details). The number of children attending state-funded schools varies greatly across the country. While across the country, a majority attend state-run schools, the share attending private sector schools is higher in the south than in the north.

\section{I.4.2. New curriculum includes Information and Communication Technology skills, no other MIL competencies}

The Nigerian school curriculum, recently approved for junior and senior secondary schools, featured as of June 2020 limited teaching of ICT/computer

16 Interview with John Kimotho 6 May 2020. 
science skills, including use of the Internet and search engines and data processing, but no other elements of broad media literacy. The absence of any elements of news or misinformation literacy from schools continued despite the efforts of a series of initiatives since 2004 aimed at promoting media literacy in schools and the formation of the African Centre for Media and Information Literacy (AFRICMIL).

In 2017, there was a fresh attempt to push MIL into the school curriculum in Nigeria with the establishment of the Media and Information Literacy Coalition of Nigeria (MILCON), supported by UNESCO. MILCON was in 2020 in discussions with the Nigerian Educational Research and Development Council on the development of an MIL curriculum for schools in Nigeria. If or when a curriculum is agreed, it would then need to be approved by the education ministry. This is normally a lengthy process. As of June 2020, the only real elements of media or news literacy teaching that occur did so when the few fact-checking organisations come in to a handful of schools as outside speakers.

\section{I.4.3. No teaching of misinformation literacy taught or planned}

At the time of writing, no elements of misinformation literacy were identified in the curricula taught in junior or secondary schools, and none were reported as planned.

\section{I.5. SENEGAL}

\subsubsection{Structure of the school system and curriculum}

In Senegal, the education ministry, the ministère de léducation nationale, sets education policy and has oversight of standards. Responsibility for running schools lies with local authorities. The curriculum, known as the Programme Décennal de l'Education et de la Formation, is set by the ministry. Children start their primary schooling between 5 and 7 years and education remains compulsory, by law at least, until the age of 16. According to Our World in Data, however, children are estimated to spend in practice an average of just 3 years in school (see Section 7.2 for details). More than $80 \%$ of primary students attend state-funded schools.

\section{I.5.2. Media reports, online content as source for discussions}

In 2018, President Macky Sall demanded that the education ministry develop a media literacy strategy in schools to 'counter "fake news" and other false information' (Cissé, 2018). As of June 2020, however, this and other such calls have had no noticeable effect on the curriculum, what is taught in schools or the time pupils spend in education. 
Under the current curriculum as of June 2020, teaching of any elements of media literacy remained extremely limited. One of the few areas where media entered the schoolroom was the use of either traditional news articles or online resources such as Wikipedia and Google Earth as source materials for discussion. In secondary schools, the French language course examines the visual styles of different forms of media - colour, use of movement and light - but questions of news content and the practices of traditional and online news media were not covered.

\section{I.5.3. No elements of misinformation literacy are taught or planned}

As at mid-2020, no elements at all of misinformation literacy were included in the curricula for state schools in Senegal and none were reported as planned.

\section{I.6. SOUTH AFRICA}

\section{I.6.I. Structure of the school system and curriculum}

In South Africa, the national Department of Basic Education (DBE) sets policy and provides oversight for the school system while nine provincial education departments are mainly responsible for policy implementation. Schools can be broadly categorised into fully or partly state-funded public schools and independent, or private, schools. There continue to be significant resource gaps between schools. Children start their schooling in Grade R, and school is compulsory, by law, from Grade 1 to Grade 9, or the age of 15. Learners can opt to continue until Grade 12. According to Our World in Data, South Africans on average spend 10.1 years in school (see Section 7.2). The core curriculum used in public schools is set by the DBE and called the National Curriculum Statements. It includes Curriculum and Assessment Policy Statements (CAPS) for each of the four schooling phases. According to the Independent Schools Association of Southern Africa only 190,000 children are learners in their member schools. The government curriculum is used in schools reaching about 12 million children. We therefore analysed it for this report.

\section{I.6.2. Wide range of broad media literacy concepts from media formats, to biases of historical sources, self-esteem and identifying bullying}

The national curriculum features a wide range of concepts integral to broad media literacy from knowledge of mass media formats and concepts such as media freedom and bias in historical sources to issues such as self-esteem and identifying bullying. Through the course of a student's time at school, the curriculum (i) creates awareness of mass media formats including news reports, cartoons and photographs, and the ability of these formats to persuade, stereotype and mislead is outlined in the guidelines to teachers, (ii) sets out ways to examine the 
accuracy or biases of historical sources, (iii) covers the social effects of technology, (iv) introduces students to topics such as responsible citizenship, self-esteem and bullying and (v) highlights the importance of critical thinking and the ability to analyse and critically evaluate information and communicate effectively (for all curriculum references see DBE, 2020).

In the foundation phase, when children are generally in the age group of 6 to 9 years, the learners use mass media resources - newspapers, magazines and advertisements - in activities and assessments and engage with the concept of 'news' by expressing their reaction to news texts verbally through speeches, role play as news readers and asking 'higher-order questions' about content and writing book reviews. In the intermediate phase, typically ages 10 to 12 , the concepts of bullying, stereotyping and bias, but not media bias, are covered. In history, the course covers deciding 'whether information can be trusted', with skills outlined as 'Being able to investigate where the information came from: who wrote or created the information and why did they do it? It also involves checking to see if the information is accurate - comparing where the information came from with other information.' While this clearly links to skills and practices required to identify misinformation, it is focused on sources from history and does not specifically address current day concerns. In the senior phase, typically ages 13 to 15 , the curriculum covers aspects of visual literacy and activities include listening for critical analysis and evaluation' and learning to distinguish between 'fact and opinion'. The ability to distinguish what is a claim and what is an opinion is a core skill in identifying false information. In the further education phase, when learners are typically aged 16 to 18 , the curriculum states that: 'Information literacy is a vital skill' but provides no explanation of what information literacy entails. In one subject area the teaching plan includes the role of the media in a democratic society including freedom of expression, how media reflect a democratic society and the critical analysis of media campaigns. The Information Technology (IT) assessment topic focuses on safe Internet use including hoaxes. Misinformation specifically is not covered.

\section{I.6.3. One province launched a module featuring misinformation literacy}

Nothing in the national curriculum, save for the attention paid to online hoaxes in the IT assessment topic, focuses specifically on the challenge of misinformation for society today. To fill this gap for their learners, education officials in Western Cape, one of South Africa's nine provinces, launched in 2020 a new 'online safety' programme for Grades 8 to 12 , typically ages 14 to 18 , with a focus on false information. The programme was developed in a partnership between educators, experts in online safety from Google South Africa, learners, teachers and school heads. In Grade 8, a total of 240 minutes of class time are allocated to being safe online, aimed at establishing a mindset of 'click restraint' - established partly through knowledge of the harm that misinformation can cause. In Grade 9, a further 240 
minutes of classroom time are devoted to promoting 'an awareness that not everything online is accurate and correct. Students are taught the markers to identify websites full of misinformation and 'fake' websites. Activities include comparing websites and online adverts, explaining what makes them trustworthy or not, and 'what may go wrong' when relying on unreliable websites, to again affect learners' attitudes to and perceptions of social norms around information sharing. In Grade 10 , the potential social and political impact of online misinformation is addressed, along with guidelines to help 'distinguish the genuine from the misinformation' and evaluate the credibility of websites. In Grade 11, more time is devoted to the social and political effects of social media, and how social media becomes a tool for political influence.

The goal of the programme, designed to slot into the existing nationally prescribed curriculum, is to benefit not only learners, by making them more aware of the nature and dangers of false information online, but also their parents, teachers and government officials, Ismail Teladia, senior curriculum planner for Life Orientation at the Western Cape Education Department, said in an interview for this report ${ }^{17}$. Whether it does so effectively has not yet been tested. It is worth noting the course focuses strictly on online misinformation though many studies of misinformation show that false information also spreads through traditional media, in official statements and via off-line community networks too (Benkler et al, 2020; Cunliffe-Jones, 2022b; Newman et al, 2020). The course also appears to leave out other important elements of misinformation literacy identified in this report. Nevertheless, it brings a focus to misinformation in the way no previous curricula had done.

\section{I.7. UGANDA}

\section{I.7.I. Structure of the school system and curriculum}

In Uganda, the Ministry of Education sets education policy and has responsibility for the services provided. Responsibility for developing the curricula lies with the National Curriculum Development Centre. Children start their schooling between 3 and 5 years of age. According to Our World in Data, children on average are estimated to spend an average of 6.1 years in schooling (see Section 7.2 for details). The great majority of students attend state-funded public schools.

\section{I.7.2. Limited teaching of news terminology, types and search}

The state school curriculum, updated in 2019, features only limited teaching of broad media literacy concepts at the primary or secondary levels. At the lower primary level, 8-year-olds have one lesson on what makes news in their

17 Interview with Ismail Teladia. I8 May 2020. 
community while, from ages 10 to 12 , learners are introduced to the terminology of traditional and online news media. Secondary school students have a topic called 'finding information', teaching the skills of online search techniques. Another topic called 'the media' teaches them to identify different types of news item, explore the issue of biases and how to write different types of article. The curriculum envisages outcomes in line with certain aspects of broad media literacy, specifically aiming to ensure learners will be creative and innovative in their approach to learning, and life, able to communicate using a range of media, sort and analyse information, cooperate with others and work independently. How these outcomes are achieved is unclear and there is no focus on identifying false information.

\section{I.7.3. No elements of misinformation literacy taught or planned}

As of June 2020, no elements of misinformation literacy were identified in the curriculum we reviewed, and none were reported to be planned. 


\section{OBSTACLES TO TEACHING MISINFORMATION LITERACY IN SCHOOLS}

Although schools in many countries around the world provide substantial elements of broad media literacy, this is not the case in the sub-Saharan countries we studied. Meanwhile the teaching of misinformation literacy - the detailed knowledge and skills required to identify false information as such - is virtually inexistent. From evidence set out below, it appears the reasons for both failings start with a lack of consensus, among politicians, educationalists and others on the need for either media or misinformation literacy and what constitutes a suitable syllabus. Across the seven countries we studied, we noted a range of practical obstacles, ranging from the lack of political will to bureaucratic resistance, the limited number of years spent in school and poor teaching performance. As noted in a report on media literacy in five Asian countries, it is often also 'not easy for teachers ... to discuss how to critically evaluate information and media content' for political and cultural reasons (Kajimoto et al, 2020). Reasons we identified for the failure to promote misinformation literacy, in particular, in the seven countries we studied included the following.

\section{I. Bureaucratic challenges and a lack of political will}

The most profound obstacles to the introduction of either media or misinformation literacy are (i) bureaucratic challenges within the education sector and (ii) a lack of political will to combat the problem of misinformation through teaching misinformation literacy.

In 2018, President Macky Sall of Senegal called publicly for the country's education ministry to 'develop a media literacy strategy in schools to "counter 'fake news"' and other false information' (Cissé, 2018). However, according to Professor Amadou Camara, coordinator of a project promoting curriculum reform in Senegal, the Projet d'Appui au Renouveau du Curriculum, there has been little discussion since in the education ministry, in schools or teacher training centres of how media or misinformation literacy might be introduced as a subject. The most significant factors are the lack of political support and the cross-disciplinary nature of the subject, he suggested. 'The main reason media literacy is not included at present is that it is not the responsibility of any existing discipline... the approach has to be interdisciplinary' he said ${ }^{18}$. Momar Talla Beye, inspector of elementary school teaching in Senegal, added that while media literacy was declared a national priority in 2018: 'On the practical level we have run into difficulties. The need for

I8 Interview with authors May 2020. 
media literacy is not accepted on the ground, teachers are more concerned by assessments, and we lack the specialists to teach the subject' ${ }^{3}$.

In Nigeria, Information Minister Lai Mohammed in 2018 declared that 'each and every Nigerian has a role to play in curtailing the spread of "fake news", urging citizens to learn to distinguish true from false information and avoid spreading misinformation (Okakwu, 2018). However, neither media nor misinformation literacy feature in the national curriculum and, besides the challenge of persuading and training teachers, media literacy advocates cite a lack of funding for media literacy materials in schools and libraries, part of a wider problem of under-funding of the whole state-run education sector: a sign of a lack of political will.

Schools in South Africa, like those in the United States and some European countries, have found time in the curriculum for both media literacy and misinformation literacy. However, Grace Baguma, Director of the National Curriculum Development Centre in Uganda, said for this report that media literacy is not part of the curriculum because of a lack of time for the topic. 'At the primary and secondary level, the focus is on getting the learners literate in numeracy, literacy, science mainly, and these areas take up the bigger part of the programmes of study. The biggest challenge would be to have it as a standalone subject at a time when we still have many subjects on the curriculum', she said. Despite the fact that the government in Uganda joined with others in East Africa in 2018 declaring their alarm at the rise of hate speech and the so-called 'fake news' (Olewe, 2018), Baguma said there were no plans to introduce the subject in the curriculum because it was not a matter of concern. 'There are no plans yet because there has not been any public concern on the need to have it as an area of study at this level', she said ${ }^{20}$.

\subsection{Limited time spent in school, poor teaching performance}

As of June 2020, the seven countries studied had a combined population of almost 440 million, of whom Nigerians accounted for just under half. The population of these seven countries is overwhelmingly young. The median percentage of the population that is of school age or younger is around 40\%; lowest in South Africa, at $27.9 \%$ and highest in Uganda at $48.2 \%$. This large youth population represents, of course, both an opportunity and a challenge for tackling misinformation through school. If such a large, young population can be taught to identify false and dismiss false information, they have the potential to reduce the misinformation effects more quickly than in countries with a smaller school-age population. However, to do so would require, among other factors, both good school attendance and

19 Interview with Momar Talla Beye May 2020.

20 Interview with Grace Baguma June 2020. 
effective teaching, and performance across the seven countries is often poor on both counts.

First, low school participation numbers and early dropouts mean the average number of years that children spend in school is often lower than required by law. According to data specialists Our World in Data, figures from the most recent year available, 2017, show that, not including years spent repeating grades, young adults in Cote d'Ivoire had spent on average 5.2 years in primary and secondary school before leaving school for good. In Ghana, the total was 7.1 years; in Kenya, 6.5 years; in Nigeria, 6.2 years; in Senegal, just 3 years; in South Africa, 10.1 years and in Uganda, 6.1 years. This compares with an average of 7.8 years in Brazil, 12.4 in Finland, 12.8 in Japan and 14.1 in Germany (Roser \& Ortiz-Ospina, 2016) ${ }^{21}$.

Averages such as these of course mask differences and if a subject is included in a curriculum, it will be taught to some learners. However, the time allocated and spent are not the only important performance measures. South Africa ensures its students spend longer in school than any other country in our study. But two reviews of the country's education system in 2018 and 2019 found outcomes harmed by poor teaching performance. This was identified as caused by a lack of teaching expertise, in one study (Mlachila \& Moeletsi, 2019), and widespread teacher absenteeism, in the other (Mashaba \& Maile, 2018). This is despite the fact that funding of South Africa's school system is comparable with that of other countries of the Organization for Economic Co-operation and Development (OCED), a group of some of the world's wealthiest states. Underfunding, poor teacher training and poor resources in schools are reported widely, meanwhile across the region ${ }^{22}$. As indicated earlier regarding media literacy teaching in Asia, it is often also not easy for teachers in many contexts, 'to discuss how to critically evaluate information and media content' for political and cultural reasons (Kajimoto et al, 2020).

\subsection{Low literacy, numeracy rates complicate the challenge}

In order to understand what makes misinformation in circulation false or misleading, it is often necessary to understand the limitations and different possible meanings of words used and/or basic numerical and statistical concepts such as percentages and rates. Basic literacy and numeracy skills are recognised by fact-checking organisations across Africa as essential to the ability to identify false information as such (Cunliffe-Jones, 2022a). In 2013, UNESCO noted that

21 Data retrieved from Our World In Data October 2020. https://ourworldindata.org/global -education.

22 See for example https://wenr.wes.org/20 I 7/03/education-in-nigeria. 
significant challenges remain to the spread of media literacy, 'despite the fact that access to information and knowledge has increased during the last decade due to the higher levels of basic literacy in many countries around the world' (UNESCO 2013). However, literacy and numeracy rates remain low in many countries across the sub-Saharan region which have not seen the changes identified by UNESCO. Low rates of general literacy, defined as the percentage of the population who can read and write with understanding, are one of the results of the poor performance of the education system. As of mid-2020, the literacy rate in Cote d'Ivoire was below 50\%, and numeracy lower still. In South Africa, a 2012 study by the University of Stellenbosch found that while $71 \%$ of children in Grade 6 were functionally literate, only $58.6 \%$ could be considered functionally numerate (Wilkinson, 2014).

If or when media literacy, or misinformation literacy, are introduced into the curricula of schools across the continent, low school attendance, poor teaching performance and low rates of basic literacy and numeracy will still remain. This will make the objective of misinformation literacy harder to achieve. 


\section{EVIDENCE OF MEDIA AND MISINFORMATION LITERACY EFFECTS ON 'REALISM'}

The argument made by Grace Baguma, Director of the National Curriculum Development Centre in Uganda, that the focus in primary and secondary schools is and should be on 'getting the learners literate in numeracy, literacy, science' is a powerful one. This appears particularly the case when actual time spent in school is limited and performance outcomes are often below those required. The only justification for taking time from other subjects in the curriculum, for misinformation literacy, would be if (i) the harms caused or risked by misinformation are seen as major problems for individuals and society; (ii) if teaching the subject can be shown to have positive effects, either on reducing risk of misinformation harm, advancing skills in other fields or both. As we set out below, better research is needed into the effects of both broad media literacy and elements of our proposed misinformation literacy on skills and behaviours. However, our review of available research suggests the introduction of misinformation literacy would be justified on this basis.

\section{I. African governments and public recognise harm misinformation causes}

As this report has set out, the actual and potential harms caused to society by false information are real and serious. They range from vigilante violence (Nur, 2019) to medical harms through to the use of the wrong medical treatments (Busari \& Adebayo, 2020; Faive Le-Cadre, 2019), or the spreading of vaccine resistance (Larson, 2018). They extend to the entrenching of dangerous stereotypes about communities (Tijani, 2019) and the distortion of election processes (Adzongo, 2019). The threats posed by misinformation been recognised both by political leaders from Kenya, Tanzania and Uganda (Olewe, 2018) to Nigeria (Okakwu, 2018) and Senegal (Cissé, 2018), and by the public across the continent (Conroy-Krutz \& Appiah-Nyamekye Sanny, 2020; Wasserman \& MadridMorales, 2018).

Declared concern about the possible effects of misinformation led governments in 11 sub-Saharan countries to nearly double the number of laws and regulations related to false information between 2016 and 2020 (Cunliffe-Jones et al, 2021). Penalties of up to 7 years in jail were introduced for publishing information the authorities declared false. In 10 of 31 laws or regulations reviewed, no evidence of harm caused was required for publication to be penalised (Cunliffe-Jones et al, 2021). This vigorous punitive approach contrasts sharply with the lack of alternative government responses to misinformation, including through education. 


\subsection{In a complex field, meta-review suggests 'positive effects' on 'realism'}

A 2012 meta-analytic review of the effects of 51 broad media literacy interventions carried out in countries from the United States and Australia to Tanzania found overall 'positive effects' resulted from the initiatives. Taken as a whole: 'Media literacy interventions had positive effects on outcomes including media knowledge, criticism, perceived realism, influence, behavioural beliefs, attitudes, self-efficacy and behaviour', the study found (Jeong et al, 2012).

Although this finding is encouraging to advocates of media literacy, it needs to be considered with a degree of caution. In 2019, researcher Alice Huguet and colleagues noted that many of the ways of measuring the effects of media literacy programmes do not capture their effects fully and are difficult to compare (Huguet et al, 2019). A review published the same year by US media literacy scholar James Potter, examining the assessment methods used in 88 media literacy studies, concluded: 'The assessment of validity found that none of the studies presented a test of media literacy that completely captured the elements in their definitions of media literacy, so the content validity of this literature was judged as poor' (Potter \& Thai, 2019). In an email to the authors, Hong Kong media literacy scholar Masato Kajimoto agreed, arguing many studies, some longitudinal, do show positive effects but their systems of evaluation or assessment often appear arbitrary, and with no control group used ${ }^{23}$.

As noted earlier in the report, one of the challenges for scholars seeking to assess the effects of any media literacy programmes is a lack of widespread agreement on definitions both of media literacy and of the intended outcomes and ways to measure them.

\subsection{Focus on specific knowledge, skills appears to increase efficacy}

General awareness of the existence of false information does not of itself ensure that individuals can identify false statements correctly (National Literacy Trust, 2018). Nor does being taught broad media literacy. Perhaps unsurprisingly, the meta-analytic review of 51 studies of media literacy conducted by Se-Hoon Jeong et al found that the narrower the focus of the courses taught, and the more teaching time allocated, the more effective they were. 'Moderator analyses indicated that interventions with more sessions were more effective, but those with more components were less effective' the study found (Jeong et al, 2012).

23 Email to authors October 2020. 


\subsection{Evidence of the effects of elements we identify as promoting misinformation literacy}

Misinformation literacy is still a relatively new and rarely taught topic in schools around the world and there is not yet a large body of research examining the effects of teaching one or more of the six main themes we propose on individuals' ability to identify false information and propensity to dismiss. While the Open Society Institute's 2019 Media Literacy Index rated Finland - the country that has perhaps gone the furthest in promoting teaching of misinformation literacy - as the country most prepared to deal with the impacts of disinformation (OSIS, 2019), the evidence for the claim appears slight and there was no clear proof of cause.

Nevertheless, a growing body of studies published in recent years provide preliminary indication that teaching of specific misinformation themes may increase individuals' ability to identify misinformation. This includes evidence, referred to earlier, from social psychologist Sander Van der Linden and colleagues that providing individuals with forewarning of misinformation they can expect to see, both in terms of context and content, reduces their susceptibility to false claims (Van der Linden et al, 2020). We also know, from an examination of the types of misinformation in circulation, that a common feature of misinformation is that the information may have been created by someone other than its purported creator; hence, skills are required to identify the real originator, and we know that understanding who created a claim affects how credible the claim is seen to be (Vicol, 2020). The work of Amazeen and Bucy shows that teaching 'working knowledge of how the news media operate aids in the identification and effects of fabricated news' (Amazeen \& Bucy, 2019). This indicates that teaching the processes by which accurate and inaccurate information circulate, in traditional media, online and in offline community networks, may have similar effect.

The forthcoming study of misinformation in Africa that is part of this series identifies evidence that, while many individuals know information is false and still share it, understanding the harms false information may cause does affect audience responses (Cunliffe-Jones, 2022b). Furthermore, the forthcoming study of the working practices of fact-checking organisations provides empirical evidence of training practices identified as necessary to develop the skills of identifying accurate and inaccurate information (Cunliffe-Jones, 2022a).

It is important to note, of course, that not all media or misinformation literacy teaching programmes do have clear positive effects either on knowledge and skills, and the ability to identify false information, or behaviour of doing so and dismissing 
false information as such. The indications of effects, or possible effects, offered by the sources cited above can only be considered preliminary evidence at this stage. Most assessments of the effects of teaching either media literacy or specific misinformation literacy have not included before and after testing of the sorts of knowledge and skills that we identified in Sections 3 and 4 as necessary to identify false information and promote misinformation literate behaviour. Many assessments have not included control groups. To assess the effects of such programmes, and of particular elements taught within such programmes, much further research is needed. 


\section{CONCLUSIONS AND RECOMMENDATIONS}

In the past few years alone, false and misleading information spread online, via traditional media and through offline community networks has caused harm to individuals and society across Africa. This has ranged from vigilante violence and incidents of civil unrest (Adegoke, 2018; Nur, 2019), to preventable deaths through the use of the wrong medical treatments (Busari \& Adebayo, 2020; Faive Le-Cadre, 2019). 'In a multi-ethnic and multi-religious country like ours, fake news is a time bomb', Nigerian Information Minister Lai Mohammed said in July 2018. 'But for the prudence and vigilance of Nigerians, they - the religious and ethnic bigots among us - would have set the nation on fire,' he went on. Citizens have a responsibility, the minister said. 'Each and every Nigerian has a role to play in curtailing the spread of fake news' (Okakwu, 2018). The same year, Senegal's President Macky Sall called on the country's education ministry to develop a media literacy strategy to "counter "fake news" and other false information' (Cissé, 2018).

Although much of the harm that misinformation causes may indeed come through influencing the beliefs and actions of the public, it can at times have greater effect by influencing the beliefs and actions of politicians and officials directly. The ban on polio vaccination in several northern Nigerian states from 2002 to 2006 and the HIV treatment policy enacted under President Thabo Mbeki a few years earlier resulted from false information and came at a staggering social cost (Boseley, 2008; Jegede, 2007). Teaching media or misinformation literacy in schools would not have prevented or mitigated bad decision-making in government. Other instruments are at times required. Yet, misinformation literacy still has a critical role.

The two key questions this report has sought to answer are (i) whether elements of media literacy that address the issue of misinformation were included in, or planned for, the curricula taught in state schools in seven sub-Saharan African countries as of June 2020 and (ii) whether teaching young people elements of media or news literacy relevant to the issue of misinformation reduces their susceptibility to believe and share false information, and if so what actions are needed. The report has done this by setting out (i) clear definitions drawn from past and recent scholarship of 'broad media literacy' and 'news literacy', and our own proposed definition of 'misinformation literacy', (ii) the six fields of knowledge and skills that the research we have reviewed suggests are essential to the development of misinformation literacy, (iii) evidence of the teaching of these different topics and (iv) evidence of the effects of the teaching of these fields of knowledge and skill. 


\subsection{Conclusions}

\section{I.I. BROAD MEDIA LITERACY IS NOT A 'FAKE NEWS' ANTIDOTE. MISINFORMATION LITERACY REQUIRES SPECIFIC KNOWLEDGE AND SKILLS}

The first challenge, answering these questions, has been to compare the knowledge and skills that make up broad media literacy with those our research suggests are necessary to be able to identify misinformation. As we set out, MIL, or broad media literacy, encompasses a wide range of themes from knowledge of traditional news production processes and concepts of bias and influence, to understanding of what constitutes informed citizenship and social advocacy, self-esteem and cyber-bullying and consumer competence. These latter themes are rightly seen widely as important. But, as Keener and West note 'the many different concepts in media literacy education have not addressed many students' inability to reason effectively with information online' (Keener \& West, 2021). Indeed, based on the evidence set out in Section 3 and Section 5, we argue that many of the traditional themes of broad media literacy bear little correlation to the antidote needed to misinformation.

Building on the five domains of news literacy identified by Vraga et al (2020), and adapting them to specifics of misinformation, we argue misinformation literacy be defined as: 'Knowledge of the forms that misinformation and accurate information take, the processes by which they are produced or emerge, are distributed and consumed, by whom, where, and on what topics, and the skills to distinguish the one from the other.' And that it requires the teaching of knowledge and skills in the following six domains:

i. Context: knowledge of the contexts - social, cultural, economic, political, informational and events - in which false and accurate information are produced

ii. Creation: knowledge of the types of people and institutions found to create false and accurate information, their different motivations and the skills to identify those who produce specific information online

iii. Content: knowledge of the difference between facts and opinions, the different ways information can mislead and the skills and practices to distinguish accurate and inaccurate information

iv. Circulation: knowledge of the processes by which accurate and inaccurate information circulate and what drives people to share information 
v. Consumption: knowledge of the reasons we as individuals may believe false or misleading information to be true

vi. Consequences: knowledge of the different forms of actual and potential harm caused by believing and sharing false and misleading information

\subsubsection{MEDIA LITERACY BARELY TAUGHT IN SEVEN SUB-SAHARAN COUNTRIES, ELEMENTS OF MISINFORMATION LITERACY IN JUST ONE PROVINCE}

Despite the strong concerns expressed by governments across the region, the curricula taught in state schools in six of the seven countries that we studied - Cote d'Ivoire, Ghana, Kenya, Nigeria, Senegal and Uganda - included only limited elements of broad media literacy in their teaching plans. Although three countries - Cote d'Ivoire, Kenya and Nigeria - had recently updated their curricula, they did not include substantial elements of media literacy. Kenya's new curriculum contains the most of the six, with elements of digital literacy and critical thinking. Those in Cote d'Ivoire, Ghana and Senegal pay almost no attention to the subject.

The curriculum provided to learners in South Africa shows the most attention to broad media literacy themes, including some focus on questions of the accuracy and biases of historical sources. In January 2020, a new module was introduced to the curriculum taught in the country's Western Cape province, adding elements more directly related to identifying misinformation today. (See details for all countries set out in Section 7).

\section{I.3. MANY OBSTACLES BLOCK MISINFORMATION LITERACY, STARTING WITH POLITICAL WILL}

Across the seven countries we studied, we noted a range of obstacles blocking the entry of misinformation literacy teaching to schools. Bureaucratic challenges starting from a lack of political will are the most substantial. Despite statements of concern about the risks posed by misinformation, there has been little discussion in the education ministry, schools or teacher training centres in Senegal of media or misinformation literacy, according to Professor Amadou Camara, coordinator of a project promoting curriculum reform ${ }^{24}$. In Uganda, there are no plans to introduce the subject 'because there has not been any public concern on the need to have it as an area of study', Grace Baguma, responsible for curriculum

24 Interview with authors May 2020. 
planning in Uganda, said ${ }^{25}$. A perception that curricula are already crowded is a hurdle in many countries. And lastly, if the subject is introduced to the curriculum, the low level of school attendance and poor teaching performance in many countries would make it difficult to achieve declared objectives.

\section{I.4. PRELIMINARY RESEARCH SUGGESTS WELL-TARGETED TEACHING COULD CURB HARM}

Misinformation literacy is still a relatively new topic, taught in schools in Norway and Finland but not widely around the world. Unsurprisingly, there is not yet a large body of substantive research examining the effects of teaching the subject, or what propose as one or more of the subject's six main themes.

Nevertheless, studies identified in Sections 5 and 7 of this report, ranging from social psychology to empirical studies of the working practices of fact-checkers, appear to indicate that teaching of themes we identify as misinformation literacy does increase individuals' ability to identify misinformation as such. And the forthcoming study of misinformation in Africa that is part of this series suggests that, while some know information is false and still share it, understanding the harms of false information may affect audience responses (Cunliffe-Jones, 2022b). Further research is, of course, needed, assessing both before and after knowledge and skills, and where possible effects on behaviour.

\subsection{Recommendations}

For governments, public figures and institutions, education and curriculum authorities, media leaders, fact-checkers, library associations and others concerned by misinformation and researchers of education and misinformation, we make the following recommendations.

\subsection{GOVERNMENTS, PUBLIC FIGURES AND INSTITUTIONS}

i. Those who wish to reduce the harm caused by misinformation, must set social norms (Ajzen, 1991) of neither originating nor spreading false information.

ii. Those who wish to reduce the harm caused by misinformation must fund public education, and provide high-quality teacher recruitment and training, making media literacy and misinformation literacy part of the teacher training curriculum.

25 Interview with authors June 2020. 


\subsubsection{EDUCATION AND CURRICULUM AUTHORITIES}

i. Introduce misinformation literacy themes into primary and secondary school curricula featuring these six domains of misinformation knowledge and skills: its context, patterns of creation, content, circulation, consumption and consequences

ii. Liaise with subject experts ranging from educationalists around the world to non-partisan fact-checking initiatives and misinformation researchers to ensure the new curriculum theme remains up to date

iii. Introduce assessment of misinformation literacy at key stages through the student's progress with benchmarks of misinformation literacy knowledge and skills for different ages

\subsubsection{MEDIA LEADERS, FACT-CHECKERS, MEDIA LITERACY AND LIBRARY ASSOCIATIONS}

i. Provide greater transparency about the processes by which you verify the accuracy of information you publish or broadcast and admit any mistakes you make openly and honestly

ii. Work with educational authorities to identify the knowledge and skills, particular to each country, required by students to reach media literacy

\subsubsection{SOCIAL MEDIA, MESSAGING AND SEARCH PLATFORMS}

Develop and strengthen misinformation literacy messaging on your platforms, using the six fields to enable and encourage users to carefully consider the accuracy of information, its source of origin and its potential effects before it is shared

Provide funding support for independent media, fact-checking organisations, media literacy centres and library associations that can provide essential support to the work of educational authorities on misinformation literacy

\subsubsection{RESEARCHERS INTO EDUCATION AND MISINFORMATION}

Review and tests the definitions and arguments of effects proposed in this report 



\section{BIBLIOGRAPHY}

Adegoke, Y. (2018). Like. Share. Kill. Nigerian police say false information on Facebook is killing people. BBC Africa Eye. https://www.bbc.co.uk/news/resources/idt-sh/nigeria_fake_news

Adzongo, S. (2019). Clearance certificate is the only tax document required from candidates for the 2020 municipal and legislative elections. StopBlaBlaCam. https://www.stopblablacam .com/economy-and-politics/1612-3151-clearance-certificate-is-the-only-tax-document -required-from-candidates-for-the-2020-municipal-and-legislative-elections

Aguadad, I, Sandoval-Romero, Y, Rosell, R. (2016). Media literacy from international organizations in Europe and Latin America. Journal of Media Literacy. https://www.researchgate.net /publication/305475789_Media_literacy_from_international_organizations_in_Europe _and_Latin_America

Ajzen, I. (1991). The theory of planned behavior. Organizational Behavior and Human Decision Processes. 50(2), 179-211. DOI: https://doi.org/10.1016/0749-5978(91)90020-T

Amazeen, M, Bucy, E. (2019). Conferring resistance to digital disinformation: The inoculating influence of procedural news knowledge. Journal of Broadcasting \& Electronic Media, 63(3), 415-432. https://open.bu.edu/handle/2144/40224

Article 19. (1966). Universal Declaration of Human Rights. United Nations. https://www.ohchr .org/en/professionalinterest/pages/ccpr.aspx

Aufderheide, P. (1993). A Report of the National Leadership Conference on Media Literacy. https://files.eric.ed.gov/fulltext/ED365294.pdf

Barron, J. (2017). In an era of fake news, teaching students to parse fact from fiction. The New York Times. https://www.nytimes.com/2017/03/20/nyregion/fake-news-brooklyn-middle -school.html

Benkler, Y., et al. (2020). Mail-In Voter Fraud: Anatomy of a Disinformation Campaign. Berkman Klein Center, Harvard University. https://cyber.harvard.edu/publication/2020/Mail-in-Voter -Fraud-Disinformation-2020

Bode, L, Vraga, E. (2020). Americans are fighting coronavirus misinformation on social media. Washington Post. https://www.washingtonpost.com/politics/2020/05/07/americans-are -fighting-coronavirus-misinformation-social-media/

Bontcheva, K, Posetti, J. (Eds) (2020). Balancing Act: Countering Digital Disinformation While Respecting Freedom of Expression. UNESCO. https://www.broadbandcommission.org /Documents/working-groups/FoE_Disinfo_Report.pdf

Boseley, S. (2008). Mbeki AIDS policy 'led to 330,000 deaths'. The Guardian. https://www .theguardian.com/world/2008/nov/27/south-africa-aids-mbeki

Burke, J, Harding, L. (2019). Documents suggest Russian attempt to sway South Africa election. The Guardian. https:/www.theguardian.com/world/2019/may/08/documents-suggest-russian -plan-to-sway-south-africa-election

Busari, S, Adebayo, B. (2020). Nigeria records chloroquine poisoning after Trump endorses it for coronavirus treatment. CNN. https://edition.cnn.com/2020/03/23/africa/chloroquine -trump-nigeria-intl/index.html 
Brennan, JS, Simon, F, Howard, PN, Nielsen, RK. (2020). Types, sources, and claims of COVID-19 misinformation. Reuters Institute for the Study of Misinformation. https://reutersinstitute .politics.ox.ac.uk/types-sources-and-claims-covid-19-misinformation

Cable, J, Grossman, S, Adewoye, Y. (2020). An investigation into domestic Nigerian social media financial scams. Stanford Internet Observatory. https://cyber.fsi.stanford.edu/io/news /binomo-trading-scam

Cadwalladr, C. (2017). The great British Brexit robbery. How our democracy was hijacked. The Guardian. https://www.theguardian.com/technology/2017/may/07/the-great-british-brexit -robbery-hijacked-democracy

Cadwalladr, C. (2018). Cambridge Analytica's ruthless bid to sway the vote in Nigeria. The Guardian. https://www.theguardian.com/uk-news/2018/mar/21/cambridge-analyticas-ruthless-bid -to-sway-the-vote-in-nigeria

Charlton, E. (2019). How Finland is fighting fake news - in the classroom. World Economic Forum. https://www.weforum.org/agenda/2019/05/how-finland-is-fighting-fake-news-in-the -classroom

Chee, FY. (2020). Facebook, Google, Twitter urged by EU to do more against fake news. Reuters. https://uk.reuters.com/article/us-eu-tech-disinformation/facebook-google-twitter-urged -by-eu-to-do-more-against-fake-news-idUKKBN2610GU

Chequeado. (Undated). EduCheck Map. A Database About Critical Thinking and Media, Data and Misinformation Literacy. https://educheckmap.factcheckingday.com/\#/projects

Cissé, C. (2018). Macky Sall en croisade contre les «fake news». Actusen. https://actusen.sn /ceremonie-de-remise-de-prix-aux-laureats-du-concours-general-2018-macky-sall-en -croisade-contre-les-fake-news

Clayton, K, Blair, S, Busam, JA, Forstner, S. (2019). Real solutions for fake news? Measuring the effectiveness of general warnings and fact-check tags in reducing belief in false stories on social media. Political Behavior, 1-23. DOI: https://doi.org/10.1007/s11109-019-09533-0

Conroy-Krutz, J, Appiah-Nyamekye Sanny, J. (2020). Africans are concerned about ills of social media but oppose government restrictions. The Conversation. https://theconversation.com /africans-are-concerned-about-ills-of-social-media-but-oppose-government-restrictions $-137653$

Corroy, L, Apo Yanon, G. (2019). Léducation aux médias et au numérique dans les curricula des pays francophones d'Afrique de l'Ouest. Revue Française des Sciences de l'information et de la Communication. https://journals.openedition.org/rfsic/7664\#tocto2n3

Costello, R. (2019). Twitter builds partnership with UNESCO on media and information literacy. Twitter. https://blog.twitter.com/en_us/topics/company/2019/twitter-launches-new -media-literacy-handbook-for-schools.html

Council of Europe. (2016). Mapping of media literacy practices and actions in EU-28. European Audio-visual Observatory. https://rm.coe.int/1680783500

Cunliffe-Jones, P. (2020). From Church and Mosque to WhatsApp - Africa Check's Holistic Approach to Countering 'Fake News'. Political Quarterly, 91(3), 596-599. https://onlineli brary.wiley.com/doi/10.1111/1467-923X.12899 
Cunliffe-Jones, P. (2022a, projected). The Rise of Fact-Checking in Africa. University of Westminster Press.

Cunliffe-Jones, P. (2022b, projected). Types, Drivers and Effects of Misinformation in Africa. University Of Westminster Press.

Cunliffe-Jones, P, Diagne, A, Finlay, A, Schiffrin, A. (2021). Bad Law - Legal and Regulatory Responses to Misinformation in Eleven African Countries 2016-2020. In Cunliffe-Jones, P. et al. Misinformation Policy In Sub-Saharan Africa: From Laws And Regulations To Media Literacy. University of Westminster Press. DOI: https://doi.org/10.16997/book53.b

Dahir, AL. (2018). We'd stage the whole thing': Cambridge Analytica was filmed boasting of its role in Kenya's poll. Quartz Africa. https://qz.com/africa/1233084/channel-4-news-films -cambridge-analytica-execs-saying-they-staged-kenya-uhuru-kenyatta-elections

Douek, E. (2020). What does 'coordinated inauthentic behavior' actually mean?. Slate. https: //slate.com/technology/2020/07/coordinated-inauthentic-behavior-facebook-twitter.html

Duffy, B. (2018). The Perils of Perception. Why We're Wrong About Nearly Everything. Atlantic Books.

Epstein, R, Robertson, RE. (2015). The search engine manipulation effect (SEME) and its possible impact on the outcomes of elections. Proceedings of the National Academy of Sciences of the United States of America. https://www.pnas.org/content/112/33/E4512

Facebook. (2020). A new campaign to help spot fake news. https://www.facebook.com/formedia /blog/a-new-campaign-to-help-spot-false-news

Faive Le-Cadre, AS. (2019). Non, la tisane à l'artémisia et la noix de cola ne guérissent pas le paludisme. AFPFactuel. https://factuel.afp.com/non-la-tisane-lartemisia-et-la-noix-de-cola -ne-guerissent-pas-le-paludisme

Fazio, L. (2020). Pausing to consider whether a headline is true or false can help reduce the sharing of false news. Harvard Misinformation Review. 10 February 2020. https://misinforeview .hks.harvard.edu/article/pausing-reduce-false-news

Flood, A. (2017). Fake news is 'very real' word of the year for 2017. The Guardian. https://www .theguardian.com/books/2017/nov/02/fake-news-is-very-real-word-of-the-year-for-2017

Frau-Meigs, D, Velez, I, Michel, JF. (2017). Public Policies in Media and Information Literacy in Europe: Cross-Country Comparisons. Routledge. https://www.routledge.com/Public -Policies-in-Media-and-Information-Literacy-in-Europe-Cross-Country/Frau-Meigs -Velez-Michel/p/book/9781138644373

Ghana Fact. (2019). Fact-Check. MTN mobile money service to shut down? Ghana Fact. https: //ghaafact.com/2019/09/mtn-mobile-money-service-to-shut-down/

Golebiewski, M, Boyd, D. (2019). Data voids: Where missing data can easily be exploited. Data and Society. https://datasociety.net/wp-content/uploads/2019/11/Data-Voids-2.0-Final.pdf

Graves, L. (2016). Deciding What's True: The Rise of Political Fact-Checking in American Journalism. Columbia University Press.

Head, A, Fister, B, MacMillan, M. (2020). Information literacy in the age of algorithms. Project Information Literacy. https://infolit.org.uk/project-information-literacy-pil-research -report-information-literacy-in-the-age-of-algorithms 
Henley, J. (2020). How Finland starts its fight against fake news in primary schools. The Guardian. https://www.theguardian.com/world/2020/jan/28/fact-from-fiction-finlands-new-lessons -in-combating-fake-news

Hill, R. (2020). Fighting the causes and consequences of bad information. Full Fact. https: //fullfact.org/media/uploads/fullfactreport2020.pdf

HLEG - EU High Level Expert Group. (2018). Final Report of the High Level Expert Group on Fake News and Online Disinformation. https://ec.europa.eu/digital-single-market/en/news /final-report-high-level-expert-group-fake-news-and-online-disinformation

Hobbs, R. (2019). Defining digital literacy. Media Ed lab. https://mediaedlab.com/2019/02/10 /defining-digital-literacy-2

Huang, A. (2020). Chinese disinformation is ascendant. Taiwan shows how we can defeat it. The Washington Post. https:/www.washingtonpost.com/opinions/2020/08/10/chinese-disinfor mation-is-ascendant-taiwan-shows-how-we-can-defeat-it

Huguet, A, Kavanagh, J, Baker, G, Blumenthal, MS. (2019). Exploring Media Literacy Education as a Tool for Mitigating Truth Decay. RAND Corporation. https://www.rand.org/pubs /research_reports/RR3050.html

Jakubu, M. ${ }^{26}$ (2017). Why media literacy should be included in new curriculum. Business Daily. https://www.businessdailyafrica.com/analysis/Why-media-literacy-should-included-new -curriculum/539548-3828578-n2ecx9z/index.html

Jegede, AS. (2007). What led to the Nigerian boycott of the polio vaccination campaign? PLOS Medicine, 4(3), e73. https://www.ncbi.nlm.nih.gov/pmc/articles/PMC1831725

Jeong, SH, Cho, H, Hwang, Y. (2012). Media literacy interventions: A meta-analytic review. Journal of Communication, 62(3), 454-472. https://pubmed.ncbi.nlm.nih.gov/22736807

Kajimoto, M, Fleming, J. (2019). News Literacy. In Oxford Research Encyclopedias. Oxford University Press. DOI: https://doi.org/10.1093/acrefore/9780190228613.013.848

Kajimoto, M, Ito, M, Lim, ML (Eds). (2020). Media and Information Literacy in Asia - Exploration of Policies and Practices in Japan, Thailand, Indonesia, Malaysia, and the Philippines. UNESCO. https://unesdoc.unesco.org/ark:/48223/pf0000374575

Kainja, J. (2020). How lack of access to information and ICTs has fueled disinformation in Malawi. CIPESA. https://cipesa.org/2020/10/how-lack-of-access-to-information-and-icts -has-fueled-disinformation-in-malawi

Kaye, D. (2019). Speech Police: The Global Struggle to Govern the Internet. Columbia Global Reports. https://globalreports.columbia.edu/books/speech-police

Keener, R, West, J. (Projected 2021). The Current State of Media Literacy: A Qualitative Content Analysis of K-12 Academic Standards Regarding Media Literacy.

Kulundu, M. (2019). Zambian farmer 'greatly distressed' by posts falsely identifying him as victim of South African violence. AFPFactCheck. https://factcheck.afp.com/zambian-farmer -greatly-distressed-posts-falsely-identifying-him-victim-south-african-violence

26 This is a pen name used by one of our co-authors, Wallace Gichunge. 
Larson, HJ. (2018). The biggest pandemic risk? Viral Misinformation. Nature, 562 (7727), 309. DOI: https://doi.org/10.1038/d41586-018-07034-4

Livingstone, S. (2018). Media literacy - Everyone's favourite solution to the problems of regulation. LSE Blogs. https://blogs.lse.ac.uk/parenting4digitalfuture/2018/07/27/media-literacy -problems-of-regulation

LSE (2018). Tackling the Information Crisis: A Policy Framework for Media System Resilience. LSE Commission on Truth, Trust and Technology. http://www.lse.ac.uk/media-and-com munications/assets/documents/research/T3-Report-Tackling-the-Information-Crisis.pdf

Madrid-Morales, D et al. (2021). Motivations for sharing misinformation. A comparative study in six sub-Saharan African countries. International Journal of Communication, 15, 1200-1219. https://ijoc.org/index.php/ijoc/article/view/14801/3378

Mashaba, E, Maile, S. (2018). Factors underlying teacher absenteeism in selected schools located in Tshwane West District, South Africa. International Journal of Educational Development, 4(1), 1-24. https://upjournals.co.za/index.php/IJEDA/article/view/3785

McQuail, D. (1983, Updated 2010). McQuail's Media and Mass Communication Theory. Sage Publications. Chapter 17.

Mikkelson, D. (2016). We Have A Bad News Problem, Not A Fake News Problem. Snopes. https://www.snopes.com/news/2016/11/17/we-have-a-bad-news-problem-not-a-fake -news-problem

Ministère de l'éducation nationale (Senegal). (2017). Stratégie Sénégal Numérique 20-16-2025. https://www.sec.gouv.sn/sites/default/files/Strat\%C3\%A9gie\%20S\%C3\%A9n\%C3\%A9gal \%20Num\%C3\%A9rique\%202016-2025.pdf

Mitchell, A, Gottfried, J, Barthel, M, Sumida, N. (2018). Distinguishing Between Factual and Opinion Statements in the News. Pew Research Center. https://www.journalism.org /2018/06/18/distinguishing-between-factual-and-opinion-statements-in-the-news

Mlachila, M, Moeletsi, T. (2019). Struggling to Make the Grade: A Review of the Causes and Consequences of the Weak Outcomes of South Africa's Education System. IMF Working Papers. https://www.imf.org/en/Publications/WP/Issues/2019/03/01/Struggling-to-Make-the -Grade-A-Review-of-the-Causes-and-Consequences-of-the-Weak-Outcomes-of-46644

National Literacy Trust. (2018). Fake News and Critical Literacy. https://iteracytrust.org.uk /documents/1722/Fake_news_and_critical_literacy_-_final_report.pdf

Newman, N, Fletcher, R, Schulz, A, Andi, S, Nielsen, RK. (2020). Reuters Institute. Digital News Report 2020. RISJ. https://reutersinstitute.politics.ox.ac.uk/sites/default/files/2020-06 /DNR_2020_FINAL.pdf

Newton, K. (2019). It's not the media, stupid. The Political Quarterly. https://onlinelibrary.wiley .com/doi/abs/10.1111/1467-923X.12732

NLM (Undated). Health Literacy - Definition. National Library of Medicine. https://nnlm.gov /initiatives/topics/health-literacy

Nsangi, A, Semakula, D, Oxman, AD et al. (2019). Effects of the informed health choices primary school intervention on the ability of children in Uganda to assess the reliability of 
claims about treatment effects, one-year follow-up: a cluster-randomised trial. Randomized Controlled Trial, 21(1), 27. https://pubmed.ncbi.nlm.nih.gov/31907013

Nur, F. (2019). The rumour that led to medical researchers in Ethiopia being killed by a mob. BBC News. https://www.bbc.co.uk/programmes/p07pvjxx

Oborne, P. (2005). The Rise of Political Lying. Free Press.

Ogala, El, Ibeh, N. (2014). Ebola sparks panic across Nigeria as citizens scramble for salt-water bath 'remedy'. Premium Times. https://www.premiumtimesng.com/news/166257-ebola -sparks-panic-across-nigeria-as-citizens-scramble-for-salt-water-bath-remedy .html\#sthash.Ge0bomNI.dpbs

Okakwu, E. (2018). Nigerian government launches campaign against 'fake news'. Premium Times. https://www.premiumtimesng.com/news/more-news/275846-nigerian-govt-launches -campaign-against-fake-news.html

Olewe, D. (2018). Kenya, Uganda and Tanzania in anti-fake news campaign. BBC News. https: //www.bbc.co.uk/news/world-africa-44137769

OSIS. (2019). The Media Literacy Index 2019. Open Society Institute Sofia. https://osis.bg $/ ? \mathrm{p}=3356 \&$ lang $=\mathrm{en}$

Roser M, Ortiz-Ospina, E. (2016). Global Education. Our World in Data. Information retrieved October 2020. https://ourworldindata.org/global-education

Potter, WJ. (2010). The state of media literacy. Journal of Broadcasting \& Electronic Media, 54(4), 675. https://www.tandfonline.com/doi/abs/10.1080/08838151.2011.521462

Potter, WJ, Thai, C. (2019). Reviewing Media Literacy Intervention Studies for Validity. Review of Communication Research, 7, 38-66. https://www.rcommunicationr.org/index.php/articles /volume-7-2019/finish/23/79

Renne, E. (2006). Perspectives on Polio and Immunization in Northern Nigeria. Social Science \& Medicine, 63(7), 1857-1869. https://pubmed.ncbi.nlm.nih.gov/16765498

Roper, C, Newman, N, Schulz, A. (2019). Reuters Institute Digital News Report 2019. South Africa Supplementary Report. Reuters Institute for the Study of Journalism. https://reuters institute.politics.ox.ac.uk/sites/default/files/2019-06/South_Africa_DNR_FINAL.pdf

Rosenwald, M. (2017). Making media literacy great again. Columbia Journalism Review. https: //www.cjr.org/special_report/media-literacy-trump-fake-news.php

Roy, S. (2017). Significance of media literacy education in India. International Journal of Education \& Applied Sciences Research, 4(3), 01-08. ISSN: 2349-2899 (Online).

Rydzak, J. (2019). Shutting down social media does not reduce violence, but rather fuels it. The Conversation. https://theconversation.com/shutting-down-social-media-does-not-reduce -violence-but-rather-fuels-it-115960

Schetzer, A. (2019). Governments are making fake news a crime, but it could stifle free speech. The Conversation. https://theconversation.com/governments-are-making-fake-news-a-crime -but-it-could-stifle-free-speech-117654

Schiffrin, A. (2018). Fighting disinformation with media literacy - in 1939. Columbia Journalism Review. https://www.cjr.org/innovations/institute-propaganda-analysis.php 
Seargeant, P, Tagg, C. (2018). The role of information literacy in the fight against fake news. Information Literacy Group. https://infolit.org.uk/the-role-of-information-literacy-in-the -fight-against-fake-news

Shane, T, Noel, P. (2020). Data deficits. Why we need to monitor the demand and supply of information in real time. First Draft. https://firstdraftnews.org/long-form-article/data-deficits

Skiti, S, Shoba, S. (2017). 'White monopoly capital' chosen distraction in PR strategy to clear Guptas. The Sunday Times (South Africa).

Snelling, J. (2017). What media literacy means in the age of alternative facts. International Society for Technology in Education, re-published with permission by the Center for Media Literacy. http://www.medialit.org/reading-room/what-media-literacy-means-age-alternative-facts

Spring, M. (2020). Coronavirus: The human cost of virus misinformation. BBC News. https: //www.bbc.co.uk/news/stories-52731624

Statt, N. (2020). Facebook reportedly ignored its own research showing algorithms divided users. https://www.theverge.com/2020/5/26/21270659/facebook-division-news-feed-algorithms

Stencel, M, Luther, J. (2020). Annual census finds nearly 300 fact-checking projects around the world. Duke University Reporters Lab. https://reporterslab.org/annual-census-finds-nearly -300-fact-checking-projects-around-the-world

Thomas, Z. (2020). WHO says fake coronavirus claims causing 'infodemic'. BBC News. https: //www.bbc.co.uk/news/technology-51497800

Tijani, M.. (2019). No evidence supports claim 6,000 Christians were killed in six months in Nigeria. AFPFactCheck. https://factcheck.afp.com/no-evidence-supports-claim-6000-chris tians-were-killed-six-months-nigeria

Tugend, A. (2020). These students are learning about fake news and how to spot it. New York Times. https://www.nytimes.com/2020/02/20/education/learning/news-literacy-2016-election.html

UNESCO. (1982). The Grunwald Declaration on Media Education. International Conference on Media Education. https://milunesco.unaoc.org/mil-resources/grunwald-declaration-on -media-education

UNESCO. (2013). Global Media and Information Literacy Assessment Framework: Country Readiness and Competencies. UNESCO. https://unesdoc.unesco.org/ark:/48223/pf0000224655

Van der Linden, S, Roozenbeek, J, Nygren, T. (2020). Prebunking interventions based on 'inoculation' theory can reduce susceptibility to misinformation across cultures. Harvard Misinformation Review. https://misinforeview.hks.harvard.edu/article/global-vaccination-badnews

Vraga, EK, Tully, M, Maksl, A, Craft, S, Ashley, S. (2020). Theorizing News Literacy Behaviors. Communication Theory, 31(1), 1-21. https://academic.oup.com/ct/article-abstract/doi /10.1093/ct/qtaa005/5867271? redirectedFrom=fulltext

Vicol, DO. (2020). Who is most likely to believe and to share misinformation? Full Fact. https: //fullfact.org/media/uploads/who-believes-shares-misinformation.pdf

Wardle, C, Derakhshan, H. (2017). Information disorder: Toward an interdisciplinary framework for research and policy making. Council of Europe. https://rm.coe.int/information -disorder-toward-an-interdisciplinary-framework-for-researc/168076277c 
Wasserman, H, Madrid-Morales, D. (2018). 'Fake News', disinformation and media trust in Africa: A comparative study of Kenya, Nigeria and South Africa. Africa Journalism Studies, 40, 107-123. https://www.tandfonline.com/doi/abs/10.1080/23743670.2019.1627230?src $=$ recsys\&journalCode $=$ recq 21

Wekesa, B, Vava, B, Mtshali, H. (2018). Getting the Story Straight. In State of the Newsroom (Finlay, ed). University of the Witwatersrand. pp. 21-27. http://www.journalism.co.za/wp -content/uploads/2018/03/WITS-STATE-OF-THE-NEWSROOM_March_2018.pdf

Weninger, C. (2017). Media literacy education in Singapore: Connecting theory, politics and practice. https://www.academia.edu/27323564/Media_literacy_education_in_Singapore _Connecting_theory_policy_and_practice

Wilkinson, K. (2014). Is SA bottom of the class in maths and science? WEF ranking is meaningless. Africa Check. https://africacheck.org/reports/is-sa-bottom-of-the-class-in-maths-and -science-why-ranking-is-meaningless

Zhang, L, Zhang, H, Wang, K. (2020). Media literacy education and curriculum integration: A literature review. International Journal of Contemporary Education, 3(1), 55-64. https: //www.researchgate.net/publication/339955416_Media_Literacy_Education_and_Curriculum _Integration_A_Literature_Review 


\section{APPENDIX I - METHODOLOGY AND DEFINITIONS OF KEY TERMS}

\section{I.I. Key premises of the research approach}

A lack of definitional clarity about what the terms 'media literacy' or 'news literacy' mean makes the task for scholars of identifying school programmes that include elements of 'media literacy' or 'news literacy' relevant to identifying false information a challenging one. In this report, we start from the premise that we need to set out evidence for the different definitions used, starting with the nature of misinformation, since to assess how well any form of media literacy addresses the field, we need to understand what misinformation is. In this regard, in Section 3 of the report, we outline the types of misinformation in circulation, who creates and spreads it, the context in which it emerges, where it circulates, why people believe it to be true and the harmful effects certain types of misinformation may have.

We then review the different elements of media literacy proposed by educators in different countries and contexts. As we have noted, the terms 'media literacy' and 'media and information literacy (MIL)' are understood and applied in a patchwork of approaches across the world, seeking a variety of outcomes. UNESCO, the foremost proponent of MIL education, defines the field as 'a set of competencies that empowers citizens to access, retrieve, understand, evaluate and use, create, as well as share information and media content in all formats, using various tools, in a critical, ethical and effective way, to participate and engage in personal, professional and societal activities' (UNESCO, 2013). On the basis of the studies and theory we cite below, we propose a new term of our own, 'misinformation literacy', as a specific sub-type of news literacy, comprising knowledge and skills that fall into six domains relating to the types and patterns of misinformation found circulating on the continent, who and what drives it and its effects. We set out our supporting evidence for this proposal in Section 5 of the report. We then review the curricula most widely studied in state schools in seven countries - Cote d'Ivoire, Ghana, Kenya, Nigeria, Senegal, South Africa and Uganda - to identify whether any elements of media or news literacy are included, at least in theory, in the teaching programmes offered by these schools, and whether this includes those elements of knowledge and skill we define as misinformation literacy. By this approach, we seek to answer the report's two key research questions of the use and effectiveness of media or news literacy in schools in reducing harm done by misinformation. 


\subsection{Definitions of key terms used in the report}

For this report, we use the following definitions for key aspects of information literacy ${ }^{27}$ :

1.2.1 'Broad media literacy' or 'media and information literacy' are used in this report to describe the widest conceptualisation of the field, agreed in 1982 by the UN agency UNESCO. This defined media literacy as 'developing the knowledge, skills and attitudes which will encourage the growth of critical awareness and, consequently, of greater competence among the users of electronic and print media' (UNESCO, 1982). In addition to media, this term is understood to cover themes such as informed citizenship, aesthetic appreciation and expression, social advocacy, selfesteem, and consumer competence', according to one study (Aufderheide, 1993) and 'digital citizenship, digital literacy, informational literacy, media arts', according to another (Keener \& West, 2021). In 2013, UNESCO defined MIL as 'a set of competencies that empowers citizens to access, retrieve, understand, evaluate and use, create, as well as share information and media content in all formats, using various tools, in a critical, ethical and effective way, to participate and engage in personal, professional and societal activities' (UNESCO, 2013, p. 29).

1.2.2 'Media literacy' is used in this report to refer to the more narrowly focused ability of a citizen to 'decode, evaluate, analyse and produce both print and electronic media' (Aufderheide, 1993). This definition is used among media literacy advocates today as distinct from broader MIL.

1.2.3 'News literacy' has traditionally been identified as a sub-type of media literacy, focused specifically on news information. For this report, we use the definition of news literacy proposed in 2020 by Emily Vraga and colleagues as 'knowledge of the personal and social processes by which news is produced, distributed and consumed, and skills that allow users some control over these processes' (Vraga et al, 2020).

1.2.4 'Misinformation literacy' is a term we propose, building on the above definition of news literacy, to refer to the 'knowledge of the forms that misinformation and accurate information take, the processes by which they are produced or emerge, are distributed and consumed, by whom, where and on what topics and the skills to distinguish the one from the other'.

27 We acknowledge there are many forms of literacy beyond those we describe here, from written literacy to digital literacy to health literacy and more. We do not provide definitions for those that fall outside the scope of the report. 
See Section 4 for a breakdown of the six domains of knowledge and skills this comprises.

1.2.5 'Misinformation literacy behaviour' is the term we propose to describe 'the behaviours and practices that occur when people engage with news and information content and identify and dismiss false information on grounds of falsity'. See Section 4 for the basis of this definition.

1.2.6 'Claim' is a term we use to refer to 'any factual assertion made by a person or organisation, explicitly or on occasion implicitly, whether made by the spoken or written word or through presentation of an image. This definition is drawn from the definition used in the guidelines for signatories of the International Fact-Checking Network, the global umbrella body for fact-checking ${ }^{28}$.

1.2.7 'Fact-checking' is used to refer to 'publishing or broadcasting content that assesses the factual accuracy of factual statements made by public figures and prominent institutions and/or claims widely circulated online in text, visual and other formats. This is also drawn from the International Fact-Checking Network (IFCN) guidelines noted above.

1.2.8 'Information disorder' is a term subject to different definitions. We use it in this report to refer to three broad factors that, together with how people think, combine to undermine public understanding: (i) misinformation, (ii) the distorted focus of information and (iii) the denial of access to accurate information. See Section 2 for a fuller discussion.

1.2.9 'Misinformation' is used to refer to 'misleading or false information that is spread, regardless of intent to mislead'. Section 2 provides a more detailed discussion of what constitutes false information or misinformation.

1.2.10 'Disinformation' is used to refer to 'deliberately false, misleading or biased information, manipulated narrative or facts. This definition is also used by multiple sources. See Section 2 for a more detailed description of this term.

28 For disclosure, the lead researcher on this report is an independent member of the advisory board of the IFCN and oversaw the 2020 review of its 'Code of Principles' for fact-checkers. https://ifcncodeofprinciples.poynter.org/know-more/the-commitments-of-the-code-of -principles 
1.2.11 'Fake news' is used only in quotations. Taken literally, the term applies purely to false or fabricated information produced in a news format to deceive about its origins and accuracy. In practice, the term has been used by headline writers, politicians and the public worldwide since 2016, often to dismiss information as false or biased, regardless. We consider that with such lack of definition 'fake news' is a misleading term best not used save in quotations.

1.2.12 'Access to information' and 'freedom of information' are used to refer to both the rights, and the systems that enable citizens 'to seek, receive and impart information and ideas through any media and regardless of frontiers', set out as a right in Article 19 of the Universal Declaration of Human Rights. As our series of reports shows, lack of access to information remains one of the main drivers of misinformation on the continent.

1.2.13 'Freedom of expression' is used to refer to the right, set out in Article 19 of the Universal Declaration of Human Rights, to express information and ideas through diverse media. This is both a fundamental right for individuals and for a free media to hold governments and institutions to account.

1.2.14 'Distorted focus of information' is our own term, used to refer to the promotion and/or censorship of particular topics such that, while the information disseminated may not be inaccurate in itself, the focus on or absence of the topic distorts audience understanding. Details of the concept are set out in Section 2.

1.2.15 'Denial of access to accurate information' is used to refer not only to the denial of citizens' rights to access to information set out in Article 19 of the Universal Declaration of Human Rights but also the failure of authorities to ensure that public information provided is accurate and credible. Details of the concept are set out in Section 2.

1.2.16 'Harmful effects' (actual or potential). We refer in this report to claims of harmful effects from false information. We differentiate between 'actual' harmful effects, that is, direct, observable harm to an individual or group that can be shown through empirical evidence to have been caused by false or misleading information, and 'potential' harmful effects, that is, harm that a combination of evidence and theory indicates may have or may in future likely be caused by false or misleading information. We set out this details and examples of effects in Section 2. 


\subsection{The choice of countries studied in the report}

The report explores the teaching of elements of media or misinformation literacy in seven countries of sub-Saharan Africa: Cote d'Ivoire, Ghana, Kenya, Nigeria, Senegal, South Africa and Uganda. We selected these countries as each being influential in their respective regions. Due to our own linguistic limitations, we do not cover North Africa in this report.

\subsection{The choice of studies of media literacy effects}

To assess the potential effectiveness of media or misinformation literacy programmes in reducing susceptibility to misinformation, we have:

i. Reviewed existing primary research and meta-analytic reviews of research from Africa and worldwide related to the effectiveness of media and news literacy programmes.

ii. Reviewed existing primary research from Africa and around the world related to knowledge and skills used in the process of identifying false information.

iii. Conducted qualitative interviews with named experts in the field.

iv. Reviewed the findings of two separate studies that are part of this series, one examining the working practices of fact-checking organisations operating across Africa 2019 to 2020 and the other reviewing the types and drivers of false information on the continent.

\subsection{How we identified the teaching of elements of media and misinformation literacy in curricula}

For each country studied, we reviewed the curriculum most widely used in primary and secondary schools for the terms 'MIL', 'news literacy', 'fake news' or 'misinformation, and French-language equivalents, as well as elements of the standard definitions of broad media literacy including references to 'access', 'accuracy', 'bias', 'media', 'mass media' and 'news'. Activities suggesting the development of critical thinking skills were also identified.

\subsection{The methodology for the studies of fact-checking and misinformation}

To establish the applicability of our theory of misinformation literacy, we assessed the skills and knowledge identified in the forthcoming studies of fact-checking (Cunliffe-Jones, 2022a) and of types, drivers and effects of misinformation circulating in Africa (Cunliffe-Jones, 2022b) that are part of this series. Elements of the findings are set out in Section 2. 



\section{APPENDIX 2 - THE REPORT INTO TYPES, DRIVERS AND EFFECTS OF MISINFORMATION}

The report into the types, drivers and effects of misinformation identified as circulating across the continent between July and December 2019 will be put forward for publication in 2022. It is part of the series of four reports into the types, drivers and effects of misinformation and three responses to the phenomenon. We set out here details of the methodology of the report.

\section{The samples of misinformation studied}

The key source for the report is a database of more than 1,200 examples of information circulating in sub-Saharan Africa in the second half of 2019 and identified as false or misleading by one of more of 14 named fact-checking organisations. This information is drawn from fact-checks published between 1 July and 31 December 2019 - a 'business as usual' period on the continent, falling in between 6 months during which the continent saw a series major elections, January to June 2019, and the global health crisis that started in 2020.

The sample was limited to fact-checks published or broadcast in English or French, for reasons of the author's linguistic limitations. Fact-checks of claims found to be accurate are not included as the focus of the report is on misinformation. The sample identified is subject to both the news selection biases of the fact-checking organisations and the still limited number and size of fact-checking organisations operating on the continent. These limitations and other questions concerning the sample studied are discussed in the report.

\section{The accuracy of the assessments of the misinformation sample}

For the study to be sound, the author reviewed the evidence on the basis of which the fact-checking organisations concluded that the information concerned was in some way either false or misleading, and also cross-checked the results of all those fact-checks where the same information was assessed by more than one factchecking organisation. Before the report is published, the validity of these and the other findings on a randomised sample of the entries in the database will be independently reviewed by other, independent researchers.

\section{PROCESS FOR CLASSIFYING TYPES, DRIVERS AND EFFECTS OF MISINFORMATION}

To classify the types and drivers of misinformation examined in the database, the authors of this study assessed all entries using evidence drawn from the fact-checks 
themselves, follow-up enquiries and relevant studies (see more below). This process is not simple, due to both the number of factors that may be involved and the levels of deception inherent in certain forms of misinformation. Nevertheless, the process seems straightforward compared to the more complicated and often uncertain process of assessing the effects misinformation does or may have.

To assess the possible effects of misinformation it is necessary to distinguish between actual, empirically provable effects of specific false or misleading claims, on the one hand, and the less certain, potential effects of claims and sets of claims over time and in different conditions on the other. It is also necessary to consider the effects of information on belief or understanding, and the effects of any changes in belief or understanding on actions and feelings. It is necessary to set out the different degrees of confidence with which such findings can be asserted. Finally, it is necessary to identify the different effects depending on the audience that see and believes the false information. The effect on society of false information when it changes the actions taken by a policy-maker, in a position to set rules for hundreds, thousands or millions of people, may be greater than when believed by an individual member of the public. And yet, widely spread false information may also affect the actions and feelings of millions of individuals too.

\section{THE 25 FEATURES OF THE MISINFORMATION ASSESSED IN THE STUDY}

To determine what can be said about factors that make the different types of false or misleading information in the sample (i) lead to actual, empirically provable harmful effects, with evidence drawn from the fact-checks or further investigation or (ii) potentially contribute to harmful effects, with evidence drawn from the fact-checks, further investigation and existing research, the author assessed all entries in the database according to 25 defined features. The study then reviews the correlation between harm and different combinations of features assessed to put forward a theory of factors that lead to greater or lesser risks of harmful effects, to whom, and how, and sets out the basis for this.

To do this the database sets out both metadata on every false claim (the source of the fact-check, the date published, a link to the source and a summary of the false claim), and classifies every claim entered according to the following 25 features.

The (i) claim checked; (ii) country or countries it concerned; (iii) country or countries in which it was observed; (iv) type of distortion of reality - unproven to false claims; (v) type of information - simple info to stimulation; (vi) topic of claim; (vii) whether claim spread on multiple sources or occasions; (viii) whether 
claim forms part of a specific wider false narrative; (ix) degree of distortion of reality in false claim; (x) format/s in which claim spread; (xi) type of originator or promoter of the claim; (xii) type of channel/s by which claim spread; (xiii) factors that caused or may have caused claim to be created; (xiv) factors that may have facilitated spread of claim; (xv) potential durability of the false claim; (xvi) type of claim's possible effects on belief or understanding; (xvii) whether claim is 'actionable' in near term - if believed; (xviii) type of 'consequential effect' - if believed; (xix) degree of confidence claim caused actual harm; (xx) field and form of actual harm caused; (xxi) whether claim had the potential to cause harm; (xxii) field and form of harm claim had potential to cause; (xxiii) potential scale of harm - 1 to 1 to 1 to many; (xxiv) durability of harm; (xxv) whether responses to the claim may have mitigated harm.

\section{THE EVIDENCE ON WHICH FALSE, MISLEADING CLAIMS ARE CLASSIFIED}

The claims are classified on the basis of evidence drawn from the following three sources.

i. Information contained within the fact-checks. The author draws on evidence from the fact-checks they assessed. This includes data on the claim, evidence of effects and audience responses and the sources they quoted.

ii. Follow-up interviews and empirical evidence. Where the factchecks do not provide enough information, the author carried out follow-up investigations including desk-based research and interviews.

iii. Review of relevant studies. Where useful, the author also assessed relevant studies and reviewed for evidence. As set out in the bibliography, the studies accessed provide evidence of and theories on: (i) the scale and nature of global misinformation; (ii) the scale and spread of misinformation in Africa; (iii) the originators and drivers of misinformation globally; (iv) factors facilitating belief and spread of misinformation; (v) the effect of misinformation on trust and of low trust on society; (vi) the role of misinformation fuelling, feeding off political radicalisation; (vii) the influence misinformation has on the outcome of elections; (viii) the role of misinformation inciting, or sustaining, violence and conflict; (ix) the influence of misinformation in shaping government policy; $(\mathrm{x})$ the influence of vaccine misinformation on vaccination take-up; (xi) the influence of misinformation on public health in general. 


\section{CATEGORIES, CRITERIA AND SOURCES OF EVIDENCE USED}

\section{(i) The claim checked}

The term 'claim' is used to refer to 'any factual assertion made by a person or organisation, explicitly or on occasion implicitly, whether made by the spoken or written word or through presentation of an image. This definition is drawn from the definition used in the guidelines for signatories of the International FactChecking Network, the global umbrella body for fact-checking. The description of each claim in the database is based on evidence in the fact-check.

\section{(ii) Country or countries the claim concerns}

Where a claim relates to events alleged to have taken place in a particular country or countries, the effect of the claim on an audience may depend, in part, on the location of the claim and audience. Using evidence drawn from the published factcheck, the database records the country or countries the claim refers to, including the country of any known source of the claim.

\section{(iii) Country or countries in which claim observed}

The database records the country or countries in which the claim was observed, based, again, on evidence from the published fact-check. The list of countries in which the claim was observed is not exhaustive. Few fact-checks record all countries in which a claim was observed.

\section{(iv) Type of distortion of reality}

There is no evidence that the type of distortion made by the claim shapes its effect on its audiences. However, understanding the way it distorts reality enables audiences to better understand and accept the falsity of information that may contain an element of truth. Using information drawn from the published fact-check, the database classifies entries by the type of distortion shown in one of the following ways - claims that are

1. Unproven - A factual claim for which no definitive proof is publicly available

2. Satire - A factual claim that originated as satire but is understood to be true

3. False - A factual claim that is wholly false

4. Mislabelled or misattributed - A factual claim, often an image or statement, that is labelled or attributed in ways that distort understanding 
5. Misleading - A factual claim that bears some truth but lacks crucial context or detail and so distorts understanding

6. Overstated/understated - A factual claim that overstates or understates the level or scale of a position

7. Conflated - A factual claim that conflates issues or events in a way that distorts understanding

8. Fabricated or manipulated - Content, presented as real, all or part of which is fabricated or manipulated in ways that distort understanding

9. Imposter content - Content falsely presented as having been created by an individual or organisation

10. Coordinated inauthentic behaviour - Fake accounts and manipulation of social media to create a false or misleading understanding, particularly of public attitudes

11. Hoaxes and scams - A false factual claim intended to deceive - often to spread computer viruses, or other harms, to deceive for amusement, illicit reward or other effect

\section{(v) Type of information}

To assess whether the type of information influences its effect, the database categorises the claim according to the five information types identified by McQuail ${ }^{29}$. It does so based on content analysis of the claim in the published fact-check.

1. Simple information

2. Stimulation to action

3. Directing attention differentially

4. Persuasion

5. Defining situation/defining reality

\section{(vi) Topic of claim}

Although much of the debate since 2016 about misinformation has focused on false claims related to politics, health and social divisions, the claims identified by fact-checkers as misinformation covered 20 broad topics. Many claims relate to more than one topic. As noted above, the list of topics identified is not exhaustive. It reflects both the selection biases of the fact-checking organisations whose work

29 McQuail, D. (1983. Updated 20 I0). McQuail's Media and Mass Communication Theory. Sage Publications. Chapter 17. 
is studied - selecting what they consider to be important or interesting to factcheck, not all forms of misinformation - and the limits on their staff and resources. The identification of topics is based on content analysis of the false information.

SUMMARY OF TOPICS: (i) Accidents, disasters and need; (ii) business and economy; (iii) celebrities and the famous; (iv) crime \& justice; (v) education; (vi) environment and climate; (vii) financial \& other opportunities; (viii) gender; (ix) governance; $(x)$ health; (xi) international relations; (xii) job offers; (xiii) media; (xiv) migration and communities; (xv) miscellaneous; (xvi) people drawn into public life; (xvii) politics, politicians and elections; (xviii) sex and sexuality; (xix) state of the country (infrastructure and development); and (xx) unrest and violence.

\section{DETAILS OF THE 20 BROAD TOPICS AND SUB-TOPICS OF CLAIMS IDENTIFIED}

i. ACCIDENTS, DISASTERS OR NEED (False claims related to accidents and disasters, and false claims of need to seek donation). Two sub-topics.

False claim of need to seek donation; claim ref. accident or disaster.

ii. BUSINESS AND ECONOMY - False claims ref. businesses and business sectors, or a variety of economic indicators. Four sub-topics.

Claim ref. a business or business sector; claim ref. cost of living, inflation; claim ref. employment levels, number of job seekers; claim ref. state of economy, trade, investment, debt.

iii. CELEBRITIES AND THE FAMOUS - False claims of celebrity deaths or, claims ref. behaviour or views of well-known people. Four specific topics.

Claim ref. activity, behaviour or view of well-known person; claim well-known person is dead or near death.

iv. CRIME and JUSTICE - False claims ref. particular crimes, crime rates, policing, conviction rates, prison numbers, social factors in crime and more. Thirteen sub-topics.

Claim a food or product has been poisoned; claim a particular type of crime or fraud is a threat; claim ref. a particular criminal case; claim ref. crime rates, risk of crime; claim ref. crime risks to children; claim ref. human rights violations; claim ref. juvenile crime; claim ref. laws, standards, rules of operation; claim ref. policing, conviction rates; claim ref. prison numbers, conditions; claim ref. who 
is responsible for crime; claim related to torture, enslavement of individuals or groups.

v. EDUCATION False claims ref. school attendance, funding and costs, performances and standards. Five sub-topics.

Claim ref. attendance at schools; claim ref. government spending on, costs of education; claim ref. operation of exam system; claim ref. operation of teaching and schools; claims ref. performance levels, standards.

vi. ENVIRONMENT - False claims ref. climate change, state of environment, energy sector, wildlife. Three sub-topics.

Claim ref. climate change; claim ref. energy sector, renewables; claim ref. wildlife, wildlife protection.

vii. FINANCIAL AND OTHER OPPORTUNITIES - False claims of financial or other opportunities such as company giveaways. One sub-topic.

Hoax claim of company giveaways.

viii. GENDER - False claims ref. attributes and status of genders, gender violence, code of dress, marriage laws and other relevant codes of behaviour. Six sub-topics.

Claim ref. attributes and behaviour of the genders; claims ref. code of dress, behaviour for women; claim ref. economic and workplace status of genders; claim ref. gender abuse and violence; claims ref. marriage laws and practices; claims ref. sex trafficking, prostitution.

ix. GOVERNANCE - False claims ref. government success, spending, behaviour, cost of or access to services, cost of governance. Eight sub-topics.

Claim of government competence, success; claim of government incompetence, failure; claim of inappropriate government spending; claim of negative behaviour by government officials; claim ref. corruption; claims ref. cost and level of politicians salaries; claim ref. cost of or access to government services; claim ref. international organisation.

X. HEALTH - False claims on topics from false cures to symptoms, causes and prevalence of health conditions, diet and effect of activity, costs and quality of and access to healthcare. Twenty sub-topics.

Claim a food or product has been poisoned, is deadly; claim of harm to health caused by a type of technology; claim of harmful activity by health practitioners; 
claim a product or ingredient is a health cure or effective treatment; claim on effect of sexual activity on health; claim ref. availability and/or cost of health treatment; claim ref. causes of a health condition; claim ref. general health risks to children; claim ref. health effects of a particular condition; claim ref. effect of diet or activity on health; claim ref. level of public spending on health; claim ref. means of spread of a health condition; claim ref. prevalence of a health condition; claim ref. quality of health services; claim ref. risks of a health treatment or medication; claim ref. susceptibility or immunity to a health condition; claim ref. symptoms and/or effects of a health condition; claim ref. the actions of authorities in health crisis; claims of effect of diet, other on sexual activity; claims related to sexual and reproductive health.

xi. INTERNATIONAL RELATIONS - False claims ref. foreign governments' activity or views, international disputes, public figures' relationship with foreign powers, etc. Three sub-topics.

Claim ref. foreign government's actions or views; claim ref. international dispute; claims ref. public figures relationship with foreign powers.

xii. JOB OFFERS - Fake claims of job opportunities at companies; often financial scams or harvesting user ID. One sub-topic.

Claim a company or organisation is hiring staff.

xiii. MEDIA - False claims about coverage of mainstream media, regulation of media. Imposter content claiming to be mainstream media content. Three sub-topics.

Claim about coverage by mainstream media; claim about government regulation of media; claim information IS coverage by a named media.

xiv. MIGRATION AND COMMUNITIES - False claims ref. size, behaviour, beliefs, economic and legal status of particular communities. Six sub-topics.

Claim ref. behaviour of ethnic, racial or religious group; claim ref. cultural or religious practice or belief; claim ref. economic status of different communities; claim ref. ethnic or religious discrimination; claim ref. illegality by and/or legal status of immigrants; claim ref. size of migrant, ethnic, religious communities.

XV. MISCELLANEOUS - False claims on topics from the natural world to hoaxes for show or audience, satire on misc. topics, random topics. Five sub-topics.

Claim ref. natural world; Hoax for fun, show or to gain audience; random claim - not specific to a topic; ranking a miscellaneous feature in one country against the feature in others; satire miscellaneous topic. 
XVi. PEOPLE DRAWN INTO PUBLIC LIFE - False identification of person as implicated in public life, smear of those drawn into public life. Two topics.

False identification of individual; smear of people drawn into public life.

xvii. POLITICS, POLITICIANS AND ELECTIONS - False claims ref. election processes, results, politicians' views or activity, public opinion or support, political appointments and more. Ten sub-topics.

Claim ref. candidates and parties' participation in elections; claim ref. election fairness, rigging; claim ref. election process; claim ref. facts of election results; claim ref. political and ministerial appointments; claim ref. political party's activities; claim ref. politician or party's policy or view; claim ref. politician or party's support; claim ref. politician's activity or person; claim ref. public mood or political protests.

xviii. SEX AND SEXUALITY - False claims ref. norms of sexual behaviour, status of different sexual relationships, sexual behaviour of teenagers, different genders. Five sub-topics.

Claim ref. norms of sexual behaviour; claim ref. same-sex relationships; claim ref. sex with animals; claim ref. sexual behaviour by genders; claim ref. teenage sexual behaviour.

ix. STATE OF THE COUNTRY (Infrastructure and development) False claims on state of infrastructure (road, rail, electricity, etc.) and development indicators. Two sub-topics.

Claim ref. state of infrastructure; claim ref. status of key human development indicators.

xx. UNREST AND VIOLENCE - False claims ref. security, civil unrest, politically linked violence, ethnic or religious conflict. Four sub-topics.

Claim ref. civil unrest, politically linked violence; Claim ref. ethnic or religious conflict. Claim ref. government spending on military; Claim ref. state security or military issue.

\section{(vii) Whether claim or variant spread on multiple sources, occasions}

It has been known for decades that, due to the so-called 'illusory truth' effect ${ }^{30}$, individuals are more prone to believe information seen or heard from multiple sources, on multiple occasions.

30 Vicol, DO. (2020) 'Who is most likely to believe and to share misinformation?' Full Fact (pp. 7-8) https://fullfact.org/media/uploads/who-believes-shares-misinformation.pdf 
To understand the potential effect of a false claim on audience belief or understanding, it is thus useful to know whether the claim, or a close variant of it, has been spread widely in the recent past ${ }^{31}$. Based on information drawn from the factchecks, each claim is categorised as:

1. Appeared on only one source, one channel - as reported in fact-check

2. Appeared from one source on more than one channel, short period (2 months or lesser)

3. Appeared on several (2-5) sources over short period (2 months or lesser)

4. Appeared on several (2-5) sources over an extended period (more than 2 months)

5. Appeared on numerous (6+) sources over short period (2 months or lesser)

6. Appeared on numerous (6+) sources over extended period

7. Details unclear in fact-check

\section{(viii) Whether claim forms part of a specific wider false narrative}

One theory of misinformation effect suggests that individual examples of misinformation have greatest effect when they contribute to a widely accepted false narrative. The effect is caused, in this instance, by a combination of the 'illusory truth effect' (believing a false claim more readily because it has been seen repeatedly) and of its contribution to or reinforcement of an existing belief system or worldview. For this reason, the database records whether the false claims identified are part of a 'specific wider false narrative', and in the next category, what false narrative that is. Although many false claims may fit into a general false narrative such as the idea that 'all politicians are liars', for this question to be answered in the affirmative, the false narrative must be more specific, for example, that 'vaccines are harmful/deadly', 'crime is rising' (when it is not) or 'authorities are rigging the election' when they are not.

\section{(ix) Explanation of false narrative of which it's part}

In this category, the database provides written details of the specific wider false narrative of which it is a part, and, where possible examples of other citations of the false narrative.

3I The fact that a claim has been spread on multiple occasions does not, of course, guarantee that those who see the most recent version saw all previous ones, but it increases the probability. 


\section{(x) Degree of distortion of reality in false claim}

While all the database entries are false or misleading in some way, the degree to which claims distort reality differs. After previously categorising the 'type' of distortion of reality, the database recognises these differences of degree, categorising all entries as either:

1. Mostly or completely false

2. Includes substantial element of truth but misleading

3. Wrong in some aspect, but picture is broadly accurate

This is recorded on the premise that the degree of distortion of reality, in part, shapes the effect that the information has on audience understanding.

\section{(xi) Explanation of finding on degree of distortion}

In this category, the database provides written explanation of the finding on the degree of distortion.

\section{(xii) Format or formats in which the claim spread}

Many of the false claims identified in the database were made public in more than one format - first broadcast in an interview on TV or radio, and then related online or turned into a meme. Much existing research suggests that the format in which information was originally transmitted appears to have little impact on its effect on belief or understanding ${ }^{32}$. Nevertheless, the database records the format or formats observed for two reasons. Firstly, to test again whether the type of format in which the information is transmitted correlates in any way with greater or lesser effect on understanding. And secondly to understand the range of formats in which misinformation is observed, noting that while much post-2016 debate has focused on misinformation spread in online articles or memes, the range of formats is much greater.

(i) Broadcasts statements (TV or radio); (ii) community rumours or myths; (iii) email statements; (iv) faked documents, web pages or sites; (v) memes shared online; (vi) official statements; (vii) photos or photo captions; (viii) product labels; (ix) public signs or posters; $(x)$ speeches to live audiences; (xi) videos or video captions; (xii) voice notes or phone messages; (xiii) written news articles, written posts online or on messaging apps.

Although details of the format were unclear in the fact-check, that lack of evidence is recorded.

32 Seehttps://www.niemanlab.org/2021/01/yes-deepfakes-can-make-people-believe-in-misinforma tion-but-no-more-than-less-hyped-ways-of-lying/ 


\section{(xiii) Type of originator or promoter of the claim}

To understand what and who drives misinformation, the database categorises the type of originator or promoter of the false claims by their professional or social role, so far as can be shown from the fact-checks. Who originates or spreads misinformation may also be a factor in amplifying or diminishing its effect. The study uses these data and considers possible correlation. Where those who originated or promoted the false claim fall into more than one category, these different categories are all recorded. The categories identified to date are as follows:

\section{Academic or think-tank $k^{33}$; 2. Business or business leader; 3. Celebrity ${ }^{34}$;} 4. Conspiracy theorist ${ }^{35} ; 5$. Domestic media ${ }^{36} ; 6$. Ethnic or religious activist ${ }^{37}$; 7. Foreign media; 8. Foreign politician; 9. Hoaxer or scammer ${ }^{38}$; 10. International $\operatorname{organisation}^{39}$; 11. Junk news site or FB page ${ }^{40}$; 12. Known or suspected

33 This is decided based on who publishes the claim, not where it is published. It applies whether the claim is published in an academic journal, in mainstream media or on social media.

34 'Celebrity' refers to a famous person, notably in the field of entertainment or sport. It does not cover those who are famous for other reasons, such as prominent politicians or scientists, for example.

35 'Conspiracy theorist' refers to people or organisations promoting an established conspiracy theory, such as those related to vaccines or the politically motivated false claim that the Nigerian president had died and been replaced by a 'clone', and the media knows this but does not report it.

36 'Domestic media' refers to national and local broadcast, print and online media - where there is a news-driven editorial structure involved. It distinguishes this from domestic junk news and hyper-partisan media.

37 Refers to individuals or groups who, from information in the fact-check or online, appear to be activists promoting an ethnic or religious agenda (traditional and religious leaders are listed separately).

38 'Hoaxer or scammer' refers to individuals or publications who originate or promote false information intended to deceive either for amusement or financial reward. It does NOT refer to those who create hoaxes for political or social effect - who are referenced as political or social activists.

39 'International organisation' refers to organisations such as the African Union, WHO or UN agencies, which issue statements found in some way to be false.

40 The term 'junk news site or page' applies to online operations purporting to offer news, if analysis of the site suggests the majority of the content comprises false or misleading information. 
political, social activist ${ }^{41}$; 13. Labour union; 14. Myth - unknown origin ${ }^{42}$; 15. $\mathrm{NGO} /$ civil society organisation ${ }^{43} ; \mathbf{1 6}$. Hyper partisan media or online forum ${ }^{44}$; 17. Politician or political party; 18. Religious leader or group; 19. Satirist or satire site $^{45} ; 20$. Self-styled health practitioner or site/page ${ }^{46} ; 21$. Social media influencer/page ${ }^{47} ; 22$. Social media user $^{48} ; 23$. State official ${ }^{49} ; 24$. Selfstyled expert in specialist field ${ }^{50} ; 25$. Traditional ruler or community leader; 26. Unidentified bad actor online - political effect $^{51} ; 27$. Unidentified bad actor online - practical harm ${ }^{52} ; 28$. Unidentified individual or group - offline. ${ }^{53}$

4I 'Known or suspected political, social activist' refers to an individual, or group, who - from information in the fact-check or identifiable online, can be safely identified as a supporter of a political or social cause. This excludes online accounts that appear to support a cause but have no online back history. It does not include politicians or leaders of campaigns.

42 'Myth - unknown origin' refers to a myth that originated from an unknown source but now spreads on community networks, in media, on social media or elsewhere.

43 Refers to domestic NGOs/CSOs.

44 'Hyper-partisan media or online forum' refers to media (broadcast, print or online) or online fora such as Facebook groups or others - that promote exclusively one-sided information as news.

45 The term 'satirist' is applied to content creators or promoters who define themselves as satirists or parody accounts, save where another purpose can be proven.

46 This term applies to individuals, companies and media or news sites that present themselves as offering health services or advice - without recognised medical authority.

47 The term 'Social media influencer or page' is used to refer to an individual or page with at least 30,000 followers online, who is not already well known for their activities offline.

48 The term 'social media user' is used to refer to an online social media account believed to be genuinely that of a real individual - but one not identifiable as belonging to any of the other categories.

49 For example, a police official, army spokesperson or civil servant.

50 An individual who claims, and may have, expertise in a particular specialist field - not health.

5I This term is used for individuals or organisations who (i) have created a fake or imposter online account, (ii) knowingly fabricated false information, (iii) where that information has potential political effect. This can include political hoaxes - where the creator of the hoax is unidentified.

52 This term is used for individuals or organisations who (i) have created a fake or imposter online account, (ii) knowingly fabricated false information, (iii) where that information has potential harmful effects - beyond the political field.

53 Used for an individual or group offline - where they cannot be identified. 


\section{(xiv) Type of channel or channels by which the claim spread}

To understand the audience the misinformation/disinformation may have reached, and thus the effect it may have had, the database records the channel or channels by which it was known to have been transmitted. This is done using information from the fact-checks. This information is not exhaustive. Many fact-checks identify where they saw the false information but do not search beyond that. The channels identified are as follows:

1. Community networks; 2 . Company or organisation website; 3 . Domestic media; 4. Emails; 5. Foreign media; 6. Government documents, reports; 7. Hyper-partisan news website; 8. Junk news site; 9. NGO report; 10. Phone message; 11. Product label; 12. Public poster or signage; 13. Satire site; 14. Social media/messaging platform - Facebook; 15. Social media/ messaging platform - Instagram; 16. Social media/messaging platform - Messenger; 17. Social media/messaging platform - Twitter; 18. Social media/messaging platform - fact-check unclear on which; 19. Social media/messaging platform WhatsApp; 20. Social media/messaging platform - YouTube; 21. Social media/ messaging platform - YouTube; 22. Speech at public event.

\section{(xv) Factors that caused or may have caused the claim to be created}

The database identifies 12 factors that appear to have caused, or may have caused or contributed to, the false claim to be created - beyond the creator's adherence to a particular world view. Drawing on information in the fact-checks and from studies of misinformation, the factors proposed range from mistakes and lack of access to reliable information, to financial or political motivations.

\section{Errors in understanding/explaining complex info and failure to verify simple claims}

- Make error in understanding and explaining complex information

- Fail to verify information they create and share either for lack of verification skills or reflex

\section{Lack of easy access to credible information to check false claims against}

- Create and share false information due to lack of easy access to credible information

- Restricted access to accurate official information

- Lack of trust in official information 


\section{Bad actors create false information to cause harm to particular targets}

- To cause harm by spreading a computer virus

- To cause harm through malice to particular individual

- To cause harm through malice to a particular business or sector

\section{Unknown actors create false information for political or social effect}

- By sowing division between or distrust of particular communities; distrust in institutions; fears related to the economy or people's finances; fears related to crime; fears or panic in other fields or general

5. Individuals, organisations, to raise their audience for financial or other reward

- Hoaxer wanting the gratification of pulling a hoax

- Junk news sites or pages wanting to increase audience for financial reasons

- Satirist wanting either to make a point, or increase audience for financial reasons

- Social media influencer/page wanting to increase audience for financial, other reasons

- Social media user wanting to increase audience for gratification

- Traditional media wanting to increase audience for financial, other reasons

\section{Businesses, legitimate or illegitimate, with an agenda}

- Business talking down its competitors' performance, services

- Businesses talking up its performance, services, sector

- Business, organisations seeking attention - to promote their brand

- Self-styled health practitioners wanting to increase clients

\section{General public - no known affiliation}

- To promote information that they think helpful

- To engage in a public discussion or area of speculation

- To generate support for cause or point of view that matches theirs

- To undermine support for cause or point of view that contradicts theirs 


\section{Media with a political/social agenda}

- To undermine support for a cause or point of view

- To generate support for a cause or point of view

\section{Miscellaneous interests}

- Individual or group seeking to deter or promote a particular behaviour ${ }^{54}$

\section{I0. Non-governmental organisations, campaigners}

- To promote information that they think helpful

- To undermine support for a cause or point of view that matches theirs

- To generate support for a cause or point of view that contradicts theirs

\section{Politicians, officials and social, political or religious activists}

- To increase their own support

- To undermine support for an opponent

- To generate support for a policy or cause

- To suppress voting in an election

- To 'defend their people/religion', or 'stir division' (depends on viewpoint)

- To express or spread their fears of vaccines

- To promote belief in religious phenomena

\section{Scammers and hoaxers seeking money or data}

- Scammers seeking money or personal data

\section{(xvi) Explanation of finding on factors that may have caused false claim}

In this section, the database sets out an explanation of the finding on factors that have or may have caused or contributed to the creation of the misinformation. The motivation of some, such as financial scams or political smears is clear. In other cases, individuals who made false claims have acknowledged and explained an

54 See this as an example: misinformation at a local level to deter behaviour a group objected to. https://factcheck.afp.com/no-johannesburg-has-not-banned-informal-waste-collectors 
error. In such cases, the causes can be attributed with reasonable certainty. Where cause is hard to deduce this uncertainty is acknowledged.

\section{(xvii) Factors that may have facilitated the spread of the claim}

The database also identifies the factors that may have facilitated or played a part in facilitating the spread of the misinformation, over and above two factors which are highly important, and mentioned in the report, but apply to most entries and hence not highlighted here.

1. the availability and functionality of social media and messaging apps that enable and encourage sharing - particularly of emotionally charged content

2. the availability and functionality of other channels such as links between information that is broadcast via TV and radio and offline community networks, that or encourage sharing of information.

The factors the database identifies, using evidence drawn from the fact-checks, and evidence from existing research on the reasons individuals share information $^{55}$, are as follows:

\section{Adherence to a pre-existing view, mindset or knowledge - including \\ - Acceptance of a stereotype of community or group \\ - Adherence to conspiracy theories \\ - Strongly held views on identity-related issues \\ - Belief in supernatural or religious phenomena \\ - Adherence to and desire to spread or defend particular religious, political, social views \\ - Hostility to a foreign power \\ - Hostility to and/or lack of trust in those in authority/the elite \\ - Limited understanding of science \\ - Mindset that finds it acceptable to illustrate a situation with an image of another (real but different) situation \\ - Mindset that speculates about topic of public interest}

55 Vicol, DO. (2020) 'Who is most likely to believe and to share misinformation?' Full Fact. https: //fullfact.org/media/uploads/who-believes-shares-misinformation.pdf 


\section{Emotional response to the information - including}

- It confirms a pre-existing view of the world

- It is seen as an example to follow

- It is seen as funny/amusing

- It is seen as good news, provokes a sense of relief

- It is seen as shocking and daring or shocking and amazing

- It is something authorities/elite 'don't want people to know'

- It makes readers feel confirmed in their view and in the know

- It provokes anger, outrage

- It provokes empathy, pity, desire to help

- It provokes fears in general

- It provokes fears of danger to children

- It provokes interest in the lives of the famous

- It provokes the desire, need to secure a job offer or giveaway

- It provokes the desire to share information you consider helpful

\section{Error and/or the lack of a verification reflex - including}

- Individuals/organisations make error in understanding and explaining complex information

- Individuals/organisations fail to verify information they create and share either for lack of verification skills or reflex

- Individuals/organisations have restricted access to accurate official information

- Individuals/organisations lack trust in official information

\section{(xviii) Explanation of finding on factors that may have facilitated spread}

In this section, the database sets out an explanation of the findings on factors that have or may have facilitated the spread of the misinformation, beyond the functionalities of social and traditional media. This is done through references to existing research into factors that facilitate the spread of information and evidence from the specific fact-check.

\section{(xix) Potential durability of the false claim}

Evidence from both cognitive science and longitudinal studies of belief in false information, suggests that much misinformation is, to cite Stephen Lewandowski's 
word 'sticky' - belief in the false claim persisting even when reliable evidence is presented that the information is fals $e^{56}$. Not all false information has the same effect, however. Not only do other studies show that repeated correction of false information can reduce belief in false information over time, but certain forms of false information are naturally less durable than others. The database categorises claims as

1. Easily disproven ${ }^{57}$

2. Naturally disproven by course of events

3. Potentially durable

4. Uncertain durability

\section{(xx) Explanation of finding on durability of false claim}

In this section, the database sets out an explanation of the findings on the durability of the false information - based on evidence from the fact-check.

\section{(xxi) Type of claim's possible effects on belief or understanding}

False information may have different effects on individuals' beliefs or understanding from no effect, where the information is not believed, to the creation of an entirely new false belief. Starting from a scale set out by Joseph Klapper in 1960, the database categorises false information as having, potentially one or more of the following effects - if believed.

1. Prevention of change in belief or understanding

2. Reinforcement of existing belief or understanding

3. Minor change in form, intensity of belief or understanding

4. Conversion from one belief to another or understanding

5. Creation of false new belief or understanding

\section{(xxii) Explanation of finding on type of effects on belief or understanding}

In this section, the database sets out an explanation of the findings on the type of effects on belief or understanding based on evidence drawn from the fact-check such as (i) whether the situation described is new, (ii) whether responses suggest

56 https://journals.sagepub.com/doi//0.1 177//5291006/245/018.

57 For example - so called 'fake death notices' claiming falsely that a prominent person has been killed. 
the audience has pre-existing views on the topic and (iii) whether responses suggest views have been changed.

\section{(xxiii) Whether the claim is actionable near term - if believed}

The potential for false information to cause harm by changing individuals' beliefs or understanding, depends - in part - on whether or not the changed belief or understanding is one on which the individual has (i) the capacity and (ii) motivation to take some form of action that may be prejudicial to themselves or others.

For example, when misinformation circulates on messaging apps advising people to take a 'health cure', members of the public may have both capacity and feel motivated to follow the advice or suggest others in their circle do so. If the misinformation relates to a policy issue, individual members of the public may have limited capacity to act but policy-makers may be able to do so.

The database assesses each entry for evidence of the combination of audience capacity and motivation to act, based on evidence in the fact-check. Setting aside the question of whether the audience could either spread or peacefully protest the situation falsely defined, it asks whether either individual members of the public or policy-makers could take potentially harmful action, in the near-term, if they believed the false information, or whether there is no such action they would have the capacity and motivation to take. 'Policy-makers' are defined in these terms as anyone in a position to set or define the rules guiding the actions of others such as parliamentarians, members of the judiciary, health administrators and employers.

The database cross-checks these findings against evidence of actual harm to establish whether there is any correlation between whether and by whom misinformation is actionable and harm.

\section{(xxiv) Explanation of finding on actionability}

In this section, the database sets out an explanation of the findings on actionability, based on evidence in the fact-checks and cross-checking with evidence of actual harms caused.

\section{(xxv) Type of 'consequential effect' - if claim believed}

Not all changes of belief or understanding cause an action or feeling that has any consequence. Others do or may bring a change of some value to the individual or society, whether to their benefit or harm. This section of the database identifies whether, according to the best evidence available, the changes in belief or understanding if they occur may have led or might contribute to potential effects for 
individuals or society. Based on evidence from the fact-checks, further investigations and studies, entries are rated as

1. No actual or potential consequential effect identified

2. Actual or potential beneficial effect identified

3. Actual or potential harmful effect identified

\section{(xxvi) Explanation of finding on type of consequential effect}

In this section, the database sets out an explanation of the findings on the type of consequential effect identified. If the effect is identified as of no consequence, or actually or potentially beneficial, the reason for and details of that finding are explained here.

\section{(xxvii) Degree of confidence claim caused actual harm}

The degree of confidence that a claim in the database directly caused harmful effects varies from cases to case. The database categorises that confidence as follows (see below the subsequent field where we explain the evidence)

1. No evidence was identified that the claim caused actual harm

2. Evidence suggests claim may have caused actual harm

3. Strong evidence shows that the claim caused actual harm

\section{(xxviii) Field and form of actual harm caused}

The database then sets out the field in which the actual harm was caused, and the form, or sub-field, of the harm identified. The fields identified are as follows:

1. Physical harms - from vigilante and gender-based violence to harms to individuals' and public health

2. Harms to mental health - from personal distress to public alarm

3. Harms to fairness, social cohesion - from entrenching negative stereotypes to enflaming social divisions

4. Harms to the justice system - from distorting particular cases to judicial policy

5. Harms to the political system - from suppressing voting, to distorting the focus of debate

6. Harm to business, economy - from company reputations to economic policy

7. Harms to the environment - from endangering wildlife to distorting policy focus 
8. Harm to international relations - from distorting public understanding to government policy

9. Harm to individuals' finances, practical harms - from financial loss to identity theft, and the spreading of computer viruses

10. Harm through distorted understanding of the natural world miscellaneous

\section{(xxix) Evidence of actual harm caused}

In this section, the database sets out an explanation of and evidence for the findings on actual harm caused, with links to sources where appropriate.

\section{(xxx) Whether claim had potential to cause harm}

The database then identifies whether evidence suggests that the false claim has the potential to cause harm and how. The fields identified are as follows:

1. Yes, subject to conditions

2. Yes, through cumulative effect

3. No apparent potential to cause substantial harm*

$\left({ }^{*}\right.$ other than reduction in faith in information sources in general - an effect discussed in the report)

\section{(xxxi) Field and form of harm claim had potential to cause}

The database then sets out the field in which the actual harm was caused, and the form, or sub-field, of the harm identified. The fields identified are as follows:

1. Physical harms - from vigilante and gender-based violence to harms to individuals' and public health

2. Harms to mental health - from personal distress to public alarm

3. Harms to fairness, social cohesion - from entrenching negative stereotypes to enflaming social divisions

4. Harms to the justice system - from distorting particular cases to judicial policy

5. Harms to the political system - from suppressing voting, to distorting the focus of debate

6. Harm to business, economy - from company reputations to economic policy

7. Harms to the environment - from endangering wildlife to distorting policy focus 
8. Harm to international relations - from distorting public understanding to government policy

9. Harm to individuals' finances, practical harms - from financial loss to identity theft, and the spreading of computer viruses

10. Harm through distorted understanding of the natural world miscellaneous

\section{(xxxii) Explanation for finding on potential to cause harm}

In this section, the database sets out an explanation of and evidence for the findings on the potential of the claim to cause harm, with links to sources where appropriate.

\section{(xxxiii) Potential scale of harm - from one-to-one to one-to-many}

The scale of the harm that can follow from misinformation depends in part on its audience: whether the harm is one they suffer, themselves, or one they cause to others and, in the latter case, their position to affect others through their role in their community or wider society. The database thus categorises potential harm as carried out:

1. One-to-one self

2. One-to-one other

3. One to many

4. Many to one

5. Many to many

\section{(xxxiv) Evidence for finding on potential scale of harm}

In this section, the database sets out an explanation of and evidence for the findings on the potential scale of the harm that may be caused, with links to sources where appropriate.

\section{(xxxv) Potential durability of harm}

The degree of harm that can follow from misinformation depends in part, also, on the permanence, or durability of that harm. In the simplest terms, harm that leads to individuals dying is permanent. A temporary increase in mental stress may be ameliorated over time.

The database categorises harms as:

1. Permanent

2. Durable 
3. Transitory

4. Uncertain

\section{(xxxvi) Evidence for finding on potential durability of harm}

In this section, the database sets out an explanation of and evidence for the findings on the potential scale of the harm that may be caused, with links to sources where appropriate.

\section{(xxxvii) Whether response to claim may have mitigated harm}

Finally, the database identifies instances in which

(i) the misinformation that was shared was questioned or fact-checked by the public and/or subject of the misinformation

(ii) the originators responded either to this questioning of their claims or the questioning of their claims by the fact-checking organisations

Recent research from the United State ${ }^{58}$ has suggested that the questioning of misinformation shared online, by members of the public who are sceptical about it, has a significant effect in reducing the spread and the perceived credibility of the information. The report both (i) cross-checks this evidence to determine whether there is any observable correlation between the questioning of the misinformation and evidence of harm and (ii) set outs the theoretical evidence mentioned above.

\section{(xxxviii) Evidence for finding on mitigation of harm}

In this section, the database sets out an explanation of and evidence for the findings on mitigation of harm.

58 Bode, L, \& Vraga, E. 'Americans are fighting coronavirus misinformation on social media'. Washington Post. May 7, 2020. https://www.washingtonpost.com/politics/2020/05/07/americans -are-fighting-coronavirus-misinformation-social-media/ 




\section{PART 2 \\ BAD LAW - LEGAL AND REGULATORY RESPONSES TO MISINFORMATION IN SUB-SAHARAN AFRICA \\ 2016-2020}

\section{Peter Cunliffe-Jones, Assane Diagne, Alan Finlay and Anya Schiffrin}

About this report

2. MISINFORMATION: ONE PART OF A WIDER INFORMATION DISORDER

2.I. 'Fake news': a misleading term, used to dismiss information, false or not

2.2. 'Misinformation' or 'disinformation' - the difference is intent

2.3. 'Information disorder' - dysfunction in the information system that undermines public understanding

2.4. The effects of distorted focus of information

2.5. The effects of lack of access to accurate information

2.6. Effective regulation would address all aspects of information disorder 117

3. HOW EXISTING AND NEW LEGISLATION MISSES THE DECLARED TARGET

3.I. Misinformation is more than 'false news' - II ways claims distort reality

3.2. Misinformation affects more than politics, public order and public health -20 common topics of misinformation found

\section{How to cite this book chapter:}

Cunliffe-Jones, P. et al. 2021. Bad Law - Legal and Regulatory Responses to Misinformation in Sub-Saharan Africa 20 16-2020, pp. 99-218, in Misinformation Policy In Sub-Saharan Africa: From Laws and Regulations to Media Literacy. London: University of Westminster Press. DOl: https://doi.org/ I 0.16997/book53.b. License: CC-BY-NC-ND 4.0 
3.3. Misinformation not restricted to traditional and social media false claims spread in public speeches, parliament, on posters and product labels

3.4. Government, religious and traditional leaders among key creators

3.5. Factors that drive the creation and spread of false information

\section{IDENTIFYING WHAT MISINFORMATION CAUSES} ACTUAL OR POTENTIAL HARM

4. I. When and how existing and new laws address misinformation harm 126

4.2. Evidence of actual or potential harm caused by misinformation

4.3. Belief in the effects of misinformation on elections is widespread

4.4. Proving the effects of misinformation on elections is complex

4.5. Effects found in this series - from no difference to shaping policy

4.6. Standards used for identifying harmful effects

5. CHANGES TO THE LEGAL AND REGULATORY FRAMEWORK WORLDWIDE 2016-2020

5. I. Much debate but little change in the United States

5.2. European Commission moves on privacy and stricter code for tech firms

5.3. Germany's NetzDG law - requires rapid content takedowns, other liberal democracies more cautious

5.4. Laws in Singapore, Russia, India and Brazil allow politicians power to censor

5.5. Politicians worldwide fail to update electoral laws, parliament codes

\section{CHANGES TO THE LEGAL AND REGULATORY FRAMEWORK ACROSS AFRICA 2016-2020}

6.1. Pre-2016, focus was on media control, broad and vague definition of harms

6.2. Misinformation has undermined public support for media freedom

6.3. Post-20 I6, governments introduced and toughened legislation against 'false' information in traditional and social media

6.4. Country-by-country changes 
6.4.2. Burkina Faso - new article of penal code criminalises 'false news'

6.4.3. Cote d'lvoire - penal code, cyber law, press law 'gag the press' 143

6.4.4. Ethiopia - raft of laws gives government wide powers over media

6.4.5. Kenya - two new laws penalise different forms of 'false information'

6.4.6. Malawi - false advertising, right of reply and access to information

6.4.7. Niger - new 'cybercrime' law 'used to repress opposition voices'

6.4.8. Nigeria - new broadcasting code, other laws used 'for politics' 148

6.4.9. Senegal - changes to journalism code but no 'fake news' law $\quad 150$

6.4. I0. South Africa - new regulations on Covid, fake news bill proposed

6.4.I I. Uganda - new laws add to controls on media, political opponents

6.5. Thirty-one existing and new laws related to 'false' information

\section{EFFECTS OF LAWS AND REGULATIONS ON MISINFORMATION}

7.I. Set against the scale of the problem - direct effects of legal action minimal

7.2. Regulations are sometimes used against harmful misinformation

7.3. Regulations are used mainly against media, opposition politicians

7.4. Restrictions such as Internet shutdowns have potential harmful effects

7.5. Information standards for media, politicians could mitigate much harm

\section{ACCESS TO INFORMATION AS RESPONSE TO MISINFORMATION}

8.1. Access to information across Africa - in law and in practice

8.2. Steps authorities could take to improve access to accurate information

8.3. Enabling media and civil society to act against misinformation 
9. CONCLUSIONS AND RECOMMENDATIONS

9.I. To curb the harm misinformation causes we need to understand it 165

9.2. Legislation in II countries against 'false' information doubled $2016-2020$

9.3. Laws and regulations miss the declared target, hit media freedom

9.4. Recommendations

9.5. Improve public access to and quality of information of public interest by ...

9.6. Revise regulation of 'false information' by ... $\quad 170$

9.7. Agree codes of conduct that promote honesty in political debate by ... $|7|$

9.8. Partner with others to regulate tech firms to publicly agreed standards - by ...

\section{BIBLIOGRAPHY}

\section{APPENDIX I - RESEARCH METHODOLOGY FOR THIS REPORT I 87}

I.I. Key premises of the research approach

I.2. Definitions of key terms used in the report

1.3. The criteria for selecting the period studied

1.4. The criteria for selecting the countries studied

1.5. The fields of legislation and regulation assessed

1.6. How we identified changes to the legal and regulatory framework

1.7. How we identified restrictions on access to accurate information

1.8. How we analysed the effects of these measures and restrictions

\section{APPENDIX 2 - SUMMARY OF FEATURES OF THE 3I LAWS STUDIED}

\section{APPENDIX 3 - RESEARCH METHODOLOGY FOR REPORT ON MISINFORMATION TYPES AND EFFECTS}

\section{TABLES}

Table I. 'Anti-false news' laws nearly doubled in 20 I 6-2020 in II countries studied 
Table 2. Five Steps: Misinformation harm may be reduced if authorities ... II 3

Table 3. Eleven ways that misinformation or disinformation distort understanding

Table 4. Twenty topics on which potentially harmful misinformation circulates

Table 5. Misinformation on 16 channels, in more than a dozen formats

Table 6. Who spreads misinformation

Table 7. Factors that drive the creation and sharing of misinformation

Table 8. When and how laws identify the harm misinformation may cause

Table 9. 17 laws in II countries on false information pre-2016

Table 10. Thirty-one existing and new laws related to 'false' information in II sub-Saharan countries as of end 2020 



\section{ABOUT THIS REPORT}

This report on the types and effects of changes made to the legal and regulatory framework for media and information in sub-Saharan Africa between 2016 and 2020, is one of four reports to be published by University of Westminster Press in 2021 and 2022. The series explores on the one hand, the types, drivers and effects of misinformation in sub-Saharan Africa today, and, on the other, three approaches to reducing associated harm: (i) fact-checking, (ii) media or misinformation literacy and (iii) changes to the legal and regulatory framework for media and information.

The four reports all draw, in part, on a study of more than 1,200 examples of false or misleading information identified as circulating on the continent by one or more of the 14 fact-checking organisations that published fact-checks regularly across Africa between 1 July and 31 December 2019. The report on types, drivers and effects of misinformation, based on that study will be published in 2022 .

The series also explores the three main responses put forward in sub-Saharan Africa in reaction to concerns about misinformation following the unexpected outcome of the United Kingdom's June 2016 referendum on its membership of the EU (Cadwalladr, 2017), the November 2016 election of US President Donald J. Trump (Read, 2016) and revelation of government-backed disinformation campaigns in South Africa (Skiti \& Shoba, 2017), Kenya (Dahir, 2018) and Nigeria (Cadwalladr, 2018) around that same period.

The first two reports in the series examine responses that fall within the remit of government. This starts with a report into the extent and effects of the teaching of media literacy in seven countries on the continent ${ }^{59}$. The study found only very limited elements of broad media literacy knowledge or skills included in the curricula taught in state schools in six of the seven countries, the exception being South Africa. Elements of media literacy related specifically to misinformation were identified in the curricula in only one province of that country: the Western Cape. The report also proposes recognition of a new model or subtype of media literacy that is focused on teaching knowledge and skills specific to misinformation: misinformation literacy. This identifies the knowledge and skills required to spot and dismiss false information as: (i) the context in which misinformation and accurate information are produced; (ii) who creates misinformation and who creates accurate information; (iii) the main types or forms of false content, and how to identify key features distinguishing this from fair

59 The countries studied were Cote d'Ivoire, Ghana, Kenya, Nigeria, Senegal, South Africa and Uganda. 
and accurate content; (iv) the processes by which false and accurate information circulate, and can thus be identified; (v) that reasons for which individuals, ourselves included, consume and believe false information and (vi) the consequences of believing and sharing false information. I call these knowledge and skills 'misinformation literacy'.

This second report examines the nature and effects of changes made to laws and regulations related to 'false information' between 2016 and 2020 and seeks to answer two key research questions:

i. What changes to legal and regulatory measures related to media and information did authorities in 11 sub-Saharan African countries introduce from 2016 to 2020, in response to declared concerns about misinformation?

ii. What effect, if any, can these measures be shown to have had on (a) the flow of misinformation, harmful or otherwise, and (b) freedom of speech and freedom of the media on the continent?

To answer these questions, the report:

i. Sets out evidence, drawn from official records, news reports, interviews and civil society monitoring, of changes to the regulatory and legal framework for media and information in 11 sub-Saharan countries from 2016 to 2020 .

ii. Sets out evidence, drawn from a separate forthcoming report in this series, other academic papers, civil society reports and news reports, of the types and drivers of misinformation in circulation in subSaharan Africa and what is known of its effects.

iii. Sets the legal and regulatory changes made in Africa in a global context by examining changes to the regulatory and legal framework in countries and regions outside Africa over the same period.

iv. Examines how closely the laws and regulations in place across the continent correlate with what is known of the types, drivers and effects of misinformation, and what is known of their effects.

The third report in the series, to be published in 2022, sets out how the growth in concern about the effects of misinformation worldwide from 2016 onward also added impetus to a growth in fact-checking across the continent. The report shows that, after the first fact-checking organisation was set up on the 
continent in $2012^{60}$, more than 14 operations emerged across Africa between 2016 and 2020 and examines their working practices and structures.

The final report in the series identifies the key types, drivers and actual and potential effects of misinformation on the continent, drawing on evidence from the study of more than 1,200 examples of false or misleading information identified by fact-checking organisations as circulating on the continent, and on recent scholarship in the field.

60 For disclosure, the lead author of this report was the founder of the first fact-checking organisation. 



\section{RESEARCHERS AND DECLARATIONS OF INTEREST}

The co-authors of this report are:

- Peter Cunliffe-Jones (lead author), visiting researcher at the University of Westminster's Communications \& Media Research Institute, founder of fact-checking organisation Africa Check and senior advisor to the International Fact-Checking Network

- Assane Diagne, Director of Reporters Without Borders for West Africa, lecturer at the Ecole Supérieure de Journalisme, des Métiers de l'Internet et de la Communication (EJICOM), Dakar, Senegal, and former Africa Check Chief Editor for francophone Africa

- Alan Finlay, an Internet and media rights researcher, and lecturer with the University of the Witwatersrand, in Johannesburg, South Africa

- Anya Schiffrin, Director of the Technology, Media and Communications specialisation at the School of International and Public Affairs, at Columbia University, United States

In Part Two:

- Anya Schiffrin was responsible for all of section 5 (i.e. sub-sections 5.1-5.5 'Changes to the legal \& regulatory framework around the world 2016-2020')

- Assane Diagne was responsible for sections 6.4.1, 6.4.2, 6.4.3, 6.4.7 \& 6.4.9 on Benin, Burkina Faso, Cote d'Ivoire, Niger \& Senegal respectively)

- Alan Finlay was responsible for sections 6.4.4, 6.4.5, 6.4.6, 6.4.8, 6.4 .10 \& 6.4.11 on Ethiopia, Kenya, Malawi, Nigeria, South Africa and Uganda, respectively)

- Peter Cunliffe-Jones was responsible for the other parts

The research has been supervised by Dr Peter Goodwin, Principal Research Fellow at the Communication and Media Research Institute at the University of Westminster.

The authors are grateful to the following for making the time to speak with us for this report: Abebe Chekol, Independent researcher and consultant, ICT 
policy expert (Ethiopia); Adedeji Adekunle, Premium Times Centre for Investigative Journalism/Dubawa (Nigeria); Daniel Mwesigwa, Project officer at the Collaboration on International ICT Policy for East and Southern Africa (CIPESA) (Uganda/Kenya); Estelle Massé, a policy analyst with digital rights campaigners Access Now; Fola Odufuwa, ICT consultant for businesses and institutions such as the United Nations, World Bank and Nigerian Communications Commission (Nigeria); Gabriella Razzano, Lawyer and Research Fellow with Research ICT Africa (South Africa); Ibrahim Bbossa, Head of public and international relations at the Uganda Communications Commission (Uganda); Kate Skinner, Executive director of the South African National Editors' Forum (South Africa); Kinfe Yilma, Assistant professor of law at Addis Ababa University Law School (Ethiopia); Peter Mwesige, Executive director of The African Centre for Media Excellence (Uganda); Sangwani Mwafulirwa, Director of Media and Public Relations at the Malawi Electoral Commission (Malawi); Sigi W. Mwanzia, Digital Policy Consultant and as at late 2020 steering the Digital Rights programme at ARTICLE 19 Eastern Africa (Kenya); William Bird, CEO of Media Monitoring Africa; and Y.Z. Ya'u, Executive director at the Centre for Information Technology and Development (CITAD) (Nigeria).

Funding used to support the research was provided by the Facebook Journalism Project, the Google News Initiative and Luminate. (See https://www.facebook .com/journalismproject, https://newsinitiative.withgoogle.com and https://lumi nategroup.com). They neither sought nor had any influence over the scope or findings of the report. 


\section{EXECUTIVE SUMMARY}

In the 5 years since 2016, 10 of the 11 sub-Saharan countries we surveyed for this report introduced or amended laws or regulations penalising publication or broadcast of information authorities declare 'false', whereas the other country used existing laws for the same purpose. This almost doubled the number of laws or regulations in place from 17 to 31 .

In this report, we compare the terms of this legislation with what we know of misinformation in Africa and show that many existing and new laws and regulations have a chilling effect on media freedom and public debate. They also miss the declared target of reducing the harm caused by false information, failing to address the harm misinformation causes in an effective or proportionate manner or on an effective scale.

" One third of laws penalise publication regardless of whether harm may be caused

In the case of 10 of the 31 existing and new laws or regulations we examined, no evidence is required that the publication or broadcast of the allegedly false information caused actual or potential harm for publication to be penalised. The alleged falsity of the information is enough. Penalising the dissemination of information that cannot be shown to cause, or risk par-

TABLE I ‘ANTI-FALSE NEWS' LAWS NEARLY DOUBLED IN 20 I 6-2020

\section{IN II COUNTRIES STUDIED}

The laws undermine media freedom but miss declared target of reducing harm, by

1. Failing to require evidence the allegedly false information caused or risked potential harm - for publication to be an offence

2. Using broad, vague terms for what is "false" and applying laws in partisan way against journalists and political critics

3. Employing punitive approaches illegitimate in international law

4. Failing to promote access to reliable information

5. Failing to enable media and civil society to counter harmful misinformation with corrective information

6. Failing to counter the problem of harmful misinformation coming from politicians, officials

Countries: Benin, Burkina Faso, Cote d'Ivoire, Ethiopia, Kenya, Malawi, Niger, Nigeria, Senegal, South Africa \& Uganda. ticular serious types of harm not only violates international laws such as Article 19 of the Universal Declaration of Human Rights (Article 19, 1966). It also does nothing to reduce the harm that misinformation can cause. 
Our research shows that while 14 out of 31 of the laws and regulations studied relate to types of information said to cause or risk harm in fields in which restrictions on free expression are permitted under Article 19 - the rights or reputation of individuals or institutions, public order or public health - six laws relate to harms caused, or alleged, in fields under which restrictions are not permitted by international law (see Table 10 for details).

In total, almost half the new or existing laws thus restrict freedom expression in fields not agreed by international law. Moreover, where they do apply to fields where restrictions are permitted, proving harmful effects is often either difficult or impossible and the laws and regulations we reviewed offer no guidance for how the harm or risk of harm they address should be established.

" Laws and regulations do not address the key types, drivers or originators of harmful false information, have minimal effect in curbing harm

Coming after information is published, reactive legal punishment will not directly reduce or prevent harm already caused. Where laws or regulations are used to deter or prevent individuals or institutions from continuing to spread directly harmful misinformation - be that financial hoaxes perpetrated against Ugandan radio listeners, or dangerous public health misinformation related to Covid-19 in South Africa, both described in Section 7.2, - it is plausible they may reduce harm caused. In practice, however, we found the laws and regulations we reviewed fail to address the many different types, topics and channels of misinformation, what drives it and who originates it. And measured against the vast scale of harmful misinformation in circulation on the continent, the scale on which reactive legal action is taken is minimal. With a dozen examples of enforcement action taken in 3 months in the 11 countries we studied, most of those applied to cases not shown to cause harm, the whole body of laws and regulations have very limited direct effect on the levels of harm misinformation can cause ${ }^{61}$.

\section{" Broad, vague terms make laws open to partisan abuse}

While doing little to directly reduce the harm caused by misinformation, the broad and vague terms used for what constitutes 'false' information and how harm is caused allow courts to use laws in partisan ways. And as we set out in Section 7.3, this is what appears to happen. The majority of those punished for 'false' information in the first half of 2020 under laws we reviewed were critics of the government. No evidence showed officials were prosecuted.

61 The Disinformation Tracker project identified 12 law enforcement actions taken against 'false' information in the I I countries we studied in 3 months, March to May 2020. See https://www .disinformationtracker.org 


\section{" Ensuring access to trustworthy information is one of the best ways to reduce the harm from misinformation - but is not implemented in practice}

By contrast with the punitive approach, our study suggests that providing the public with easy access to reliable official information on important topics reduces the flow of misinformation. And, while the number of governments that have passed freedom of information legislation has increased since 2016, implementation and focus on the accuracy of official information remain poor.

"A replicable method for identifying appropriate laws against 'false information'

This method for identifying legal responses to misinformation, appropriate under international law on freedom of expression, thus involves examining the terms of such laws against what is known of misinformation types, drivers and effects. We reviewed the effects of punitive policies and those of positive approaches that provide accountability in political debate, the media and online by promoting access to accurate information and corrective speech. While our study focused on laws related to 'false information' in Africa, this approach is replicable worldwide.

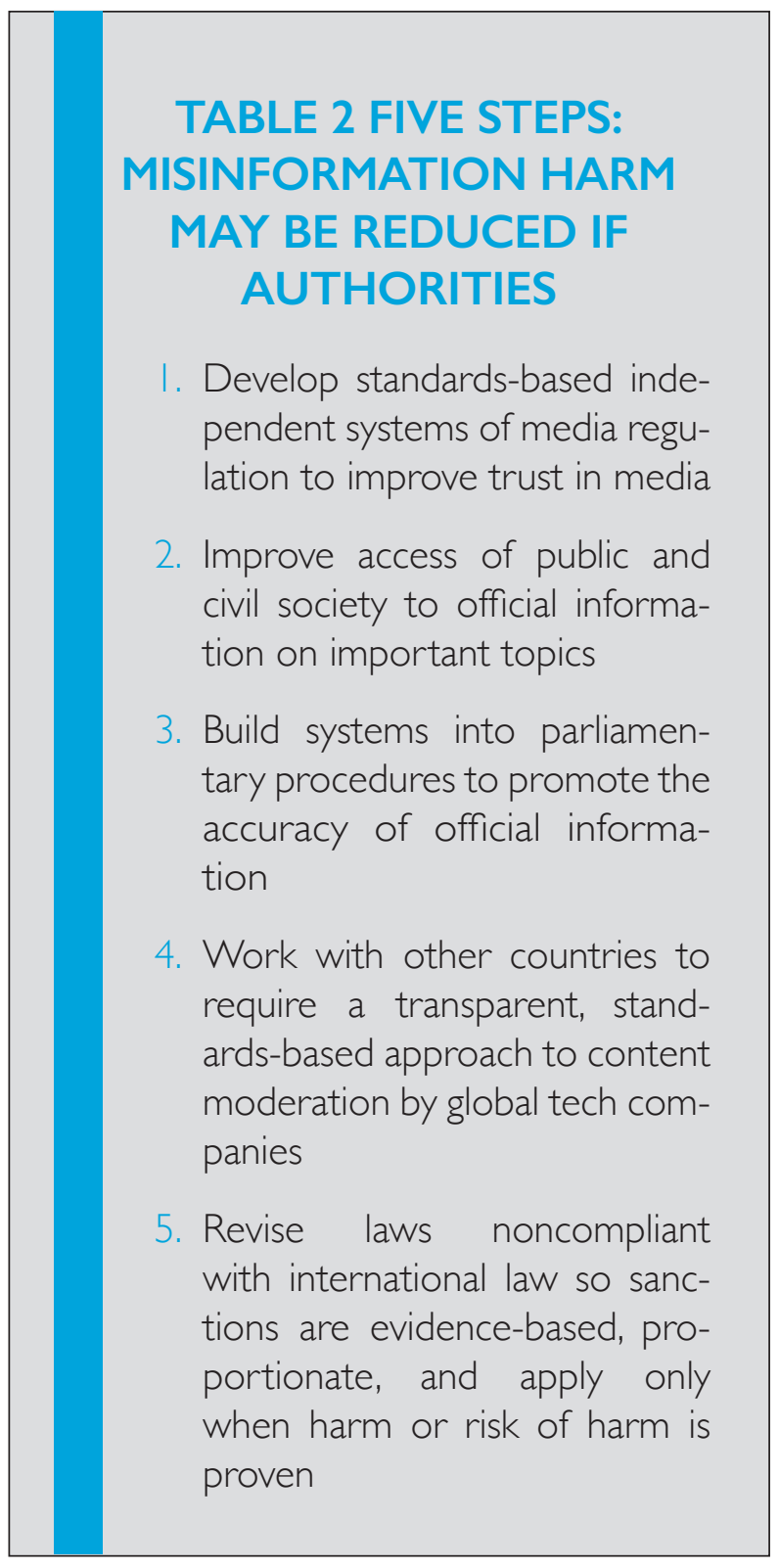




\section{MISINFORMATION: ONE PART OF A WIDER INFORMATION DISORDER}

To understand the effects that any laws or regulations may or may not have in reducing the harm misinformation causes, it is necessary to understand the types and drivers of false information. To do so, it is essential to understand the extent to which much if not all misinformation is both part of and often driven by a broader dysfunction in the information system. For that, we need first to fully understand the terms that we use.

\section{I. 'Fake news': a misleading term, used to dismiss information, false or not}

The term 'fake news', which if taken literally would apply only to fabricated information produced in a news format to deceive about its origins or accuracy, has been used widely since 2016 by politicians, headline writers and the public to dismiss all sorts of information as false or biased, without needing to detail ways in which the information is wrong, and regardless of its accuracy (Farksas \& Schou, 2018; Habgood-Coote, 2018; HLEG - EU High Level Expert Group, 2018; Le Roux, 2020a $)^{62}$. Although the term is used so widely that it cannot be ignored, we believe that it is not a useful definitional term and it is only used in this report in quotations.

\section{2. 'Misinformation' or 'disinformation' - the difference is intent}

By contrast, the term 'misinformation', is used throughout the report, referring as it does to false or misleading information created or spread without necessarily being intended to mislead. The term 'disinformation' is used to refer to false or misleading information known to have been created and spread to mislead. The key difference is known intent. Differentiating between these different forms of false information matters for regulation of information where authorities take intent into account. We set out examples of these different forms of false information in Section 3.1.

\section{3. 'Information disorder' - dysfunction in the information system that undermines public understanding}

Misinformation and disinformation are identified as key components of what Dr Claire Wardle and Hossein Derakhshan defined in 2017 as 'information disorder'.

62 The Final Report of the High-Level Expert Group on Fake News and Online Disinformation in 2018 urged that the term 'fake news' be dropped, arguing. 'The term "fake news" is not only inadequate, but also misleading, because it has been appropriated by some politicians and their supporters, who use the term to dismiss coverage that they find disagreeable'. 
This, they argued, comprises misinformation, disinformation and 'mal-information', defined as 'genuine information shared to cause harm, such as through the public sharing of private information' (Wardle \& Derakhshan, 2017). While all three forms of information do circulate in Africa, as elsewhere, mal-information has not been identified as a widespread issue in studies we have reviewed.

Based on study of the types and drivers of misinformation for this series, we argue that the key elements of dysfunction in the information system are: (i) mis/disinformation, (ii) the distorted focus of information and (iii) the lack of easy public access to accurate information. Together, all three are crucial factors in undermining public understanding. The latter two are crucial in the creation and spread of false information.

\subsection{The effects of distorted focus of information}

Information need not to be specifically inaccurate to mislead its audience. The promotion and/or censorship of information on particular topics may distort audience understanding, even where the information distributed is not inaccurate in itself. The distortion in the focus of information available to the public happens through political censorship by authorities, editorial choices made by mainstream media and the operational design of social media platforms and messaging systems, among other mechanisms.

Up to the late 1980s, mass media in a majority of sub-Saharan countries was predominantly government-controlled and had limited penetration beyond urban centres in the majority of African countries. This remains the case in several countries today (Ndlela \& Mano, 2020). Even without government controls, mass media around the world often focus on issues in ways that, even if the information itself may be accurate, risk distorting their audience's understanding of particular issues in society.

To consider one example, a 2019 study of media coverage of crime in South Africa found that whereas fewer than $20 \%$ of femicides carried out during the study period were reported in South African media, more than $70 \%$ of so-called 'farm murders' received media coverage; a disparity reflected in public perceptions of risks of crime to white farm owners and to women as a whole (Brodie, 2019). While direct causal links have not been proven between the balance of this media coverage and these public perceptions of crime risks, studies such as Tiegreen and Newman, in 2009, and Lagos Lira and Toledo, in 2014, show 'exposure to certain types of news coverage of crime is related to elevated fears of crime and perceptions of personal risk' (Brodie, 2019).

Other studies have also found the focus of information that the public receive can affect both public understanding and behaviour. Five field studies undertaken in 
the United States and India and published in 2015 suggested that distorting the information voters found online through the manipulation of online search rankings could, in certain conditions 'shift the voting preferences of undecided voters by $20 \%$ or more' (Epstein \& Robertson, 2015). Distortions of the focus of information available to the public, through the promotion or censorship of particular information, this suggests has the potential to distort public understanding. Furthermore, as other studies show, elevated fears of phenomena such as crime or health risks, due to such distortion, may raise susceptibility to misinformation (Vicol, 2020).

\subsection{The effects of lack of access to accurate information}

An important means of countering false information is ensuring access to reliable information. However, the studies of fact-checking and misinformation that are part of this series show a lack of easy public access to reliable information on matters of public interest on the continent, and show this plays a major role in undermining public understanding and causing the spread of misinformation.

First, studies of 'data voids', identified by the US researchers Golebiewski and Boyd as topics 'for which the available relevant data are limited, non-existent or deeply problematic', and 'data deficits', as defined by Shane and Noel, are neither limited in Africa to the online world nor to obscure topics. Rather they drive the creation and spread of much misinformation (Cunliffe-Jones, 2022b; Golebiewski \& Boyd, 2019; Kainja, 2020; Shane \& Noel, 2020). This can be illustrated by the example of false claims made by health officials and their critics in South Africa in 2012 about the percentage of children receiving all the necessary childhood vaccinations (Dyosop, 2012) and claims made by officials and activists in Nigeria about the level of gender-based violence in the country (Adebajo, 2019a). In both cases, lack of access to reliable data was a crucial factor in driving the false claims made.

The lack of access to reliable data also hinders efforts to counter misinformation. For fact-checkers in Africa: 'The number one challenge is access to data. Number two is access to officials,' Annie Payep-Nlepe, founder of the Cameroonian factchecking organisation Stop Intox, told the study of fact-checking that is part of this series (Cunliffe-Jones, 2022a), confirming a point made by other fact-checking organisations interviewed.

These inter-related problems - misinformation and disinformation, the distorted focus of information and the lack of access to accurate information - are not, of course, responsible alone for the misperceptions that all individuals hold on important issues. As the social researcher Bobby Duffy has noted, individuals across the world show poor understanding of many topics - from the level of crime in 
their country to the number of people of retirement age - not simply because of information they take in but also 'how they think'; their natural biases and heuristics (Duffy, 2018). Nevertheless, the studies of misinformation and factchecking that are part of this series show that these three aspects of information disorder do all either reduce or distort public understanding on important topics, and the distorted focus of information and lack of access to accurate information contribute to driving misinformation.

\subsection{Effective regulation would address all aspects of information disorder}

To be effective, we therefore argue, any strategy to reduce the spread of and harm caused by this wider information disorder would need to include appropriate responses to potentially harmful false information in circulation. At the same time, it would also need to include both systems of ensuring appropriate balance in the media, such as enabling standards-based media self-regulation, and measures to ensure greater public access to accurate information on important topics. It is on the basis of all three points that we assess the legal and regulatory measure in place. 


\section{HOW EXISTING AND NEW LEGISLATION MISSES THE DECLARED TARGET}

In the years since 2016, researchers have proposed numerous taxonomies of the different forms of misinformation and disinformation in circulation; defining ways in which information may be false, partly false or misleading, the different ways inauthentic online behaviours may mislead the public and the means to determine intent (Douek, 2020; Posetti \& Matthews, 2018; Wardle \& Derakhshan, 2017). For this report, we draw on these taxonomies and add our own and examine the terms of the laws and regulations brought in across the countries studied for this report, in the light of the types and patterns of misinformation found in our study to be circulating in sub-Saharan Africa (Cunliffe-Jones, 2022b). Doing so, enables us to assess how closely the regulatory measures address the different forms and drivers of misinformation in circulation and the effects they have.

\section{I. Misinformation is more than 'false news' - II ways claims distort reality}

Laws and regulations studied in this report identify information as either true and legitimate, or false and subject to penalties. Studies of misinformation, by contrast, show the ways in which misinformation distorts understanding can be complex. This matters in terms of the legislation's effects. Many 'false' statements contain elements of both accurate and inaccurate information our study shows. The judgment of what is a fair or unfair claim is often complicated, as fact-checking organisations observe (Cunliffe-Jones, 2022a; Graves, 2016). Moreover, what distorts understanding is often not an isolated false claim, but a whole set formed into a wider false narrative, giving claims not isolated but cumulative effect. And online misinformation includes phenomena such as manipulating platform systems to artificially promote a topic (distorted focus of attention) or create a false impression of public opinion - 'coordinated inauthentic behaviour' (Douek, 2020; Le Roux, 2020b). The report on misinformation, found 11 ways misinformation distorts reality - the majority of which are not reflected in the laws and regulations we studied.

This failure to reflect the complexity of misinformation is significant, since, if laws are only applied to information that can reasonably be found to be entirely false, they risk failing to address many types of misinformation that are potentially harmful to individuals and society. But if laws apply in the same way to all misinformation, they risk unfairly penalising claims that are a matter of reasonable debate. 
TABLE 3 ELEVEN WAYS THAT MISINFORMATION OR DISINFORMATION DISTORT UNDERSTANDING

Seven types of false or misleading information - intent to mislead may or may not be known

- Unproven (A factual claim for which no definitive proof is publicly available)

- Satire (A factual claim that originated as satire but is understood to be true)

- False (A factual claim that is wholly false)

- Mislabelled or misattributed (A factual claim, often an image or statement, that is labelled or attributed in ways that distort understanding)

- Misleading (A factual claim that bears some truth but lacks crucial context or detail and so distorts understanding)

- Overstated or understated (A factual claim that overstates or understates the level or scale of a position)

- Conflated (A factual claim that conflates issues in a way that distorts understanding)

Four types of false information - intent to mislead clear from the deliberate nature

- Fabricated or manipulated (Content, presented as real, all or part of which is fabricated or manipulated in ways that distort understanding)

- Imposter content (Content falsely presented as having been created by an individual or organisation)

- Coordinated inauthentic behaviour (Fake accounts and manipulation of social media to create a false or misleading understanding, particularly of public attitudes)

- Hoax or scam (A false factual claim intended to deceive - often to spread computer viruses, or other harms, to deceive for amusement, illicit reward or other effect)

\subsection{Misinformation affects more than politics, public order and public health - 20 common topics of misinformation found}

Laws and regulations will also only be fully effective in reducing harm if they address the full range of topics where misinformation causes harmful effects. Much of the concern expressed by politicians and the media about misinformation around the world since 2016 has focused on the actual or potential effects of misinformation on just three fields: electoral politics, public order and public health (Okakwu, 2018; Read, 2016; Thomas, 2020).

As we show, concerns about these three fields are reflected in the existing and new laws in place today across the continent. Article 173 of the Penal Code of Cote d'Ivoire sanctions publication of 'false information' that could harm the reputation of institutions. Section 43(7) of the 2008 Mass Media and Freedom of Information Proclamation in Ethiopia prohibits publication of 'false accusations' against multiple categories of public official. Section 60 of the Penal Code in Malawi criminalises publication of false statements that may 'cause fear and alarm to the public or do disturb the public peace'. And in South Africa, the 2002 Disaster Management Act was used in 2020 to make it a crime to publish any statement with the intent to deceive' about Covid-19, or measures taken by the government in response to Covid-19 (see Section 6.4.11 for details). 
Although these three fields - politics, public order and public health - are all important, the study of misinformation that is part of this series found potentially harmful false information relating a far wider range of fields, set out below (Table 4).

\begin{tabular}{|c|c|}
\hline \multicolumn{2}{|c|}{$\begin{array}{l}\text { TABLE } 4 \text { TWENTY TOPICS ON WHICH POTENTIALLY HARMFUL } \\
\text { MISINFORMATION CIRCULATES }\end{array}$} \\
\hline I. Accidents, disasters and need & I I. International relations \\
\hline $\begin{array}{l}\text { False claims related to accidents, disasters and hoax } \\
\text { claims of need to appeal for donations }\end{array}$ & $\begin{array}{l}\text { False claims ref. a foreign government's activity or views, } \\
\text { international disputes, public figures' relationship with } \\
\text { foreign powers, etc. }\end{array}$ \\
\hline 2. Business and economy & I 2. Job offer \\
\hline $\begin{array}{l}\text { False claims ref. businesses, business sectors or a variety } \\
\text { of economic indicators }\end{array}$ & $\begin{array}{l}\text { Fake claims of job opportunities at companies; often } \\
\text { financial scams or harvesting of user IDs }\end{array}$ \\
\hline 3. Celebrities and the famous & 13. Media \\
\hline $\begin{array}{l}\text { False claims of celebrity deaths or, claims ref. behaviour } \\
\text { or views of well-known people }\end{array}$ & $\begin{array}{l}\text { False claims about coverage of mainstream media, } \\
\text { regulation of media. Also, imposter content claiming to } \\
\text { be mainstream media content }\end{array}$ \\
\hline 4. Crime and justice & I4. Migration and communities \\
\hline $\begin{array}{l}\text { False claims ref. particular crimes, crime rates, policing, } \\
\text { conviction rates, prison numbers, social factors in crime } \\
\text { and more }\end{array}$ & $\begin{array}{l}\text { False claims ref. size, behaviour, beliefs, economic and } \\
\text { legal status of particular communities }\end{array}$ \\
\hline 5. Education & I5. Miscellaneous topics, including natural world \\
\hline $\begin{array}{l}\text { False claims ref. school attendance, funding and costs, } \\
\text { performances and standards }\end{array}$ & $\begin{array}{l}\text { False claims on topics from the natural world, hoaxes for } \\
\text { show or audience, satire on misc. topics, random topics }\end{array}$ \\
\hline 6. Environment and the climate & 16. People drawn into public life \\
\hline $\begin{array}{l}\text { False claims ref. climate change, state of environment, } \\
\text { energy sector and wildlife }\end{array}$ & $\begin{array}{l}\text { False identification of person as implicated in public life } \\
\text { and/or smear of those drawn into public life }\end{array}$ \\
\hline 7. Financial and other opportunities & I7. Politics, politicians and elections \\
\hline $\begin{array}{l}\text { False claims of financial or other opportunities such as } \\
\text { company giveaways }\end{array}$ & $\begin{array}{l}\text { False claims ref. election processes, results, politicians' } \\
\text { views or activity, public opinion or support, political } \\
\text { appointments and more }\end{array}$ \\
\hline 8. Gender & 18. Sex and sexuality \\
\hline $\begin{array}{l}\text { False claims ref. attributes and status of genders, gender } \\
\text { violence, code of dress, marriage laws and other relevant } \\
\text { codes of behaviour }\end{array}$ & $\begin{array}{l}\text { False claims ref. norms of sexual behaviour, status of dif- } \\
\text { ferent sexual relationships, sexual behaviour of teenag- } \\
\text { ers, different genders }\end{array}$ \\
\hline 9. Governance & $\begin{array}{l}\text { 19. State of the country (infrastructure and } \\
\text { development) }\end{array}$ \\
\hline $\begin{array}{l}\text { False claims ref. government success, spending, behav- } \\
\text { iour, cost of or access to services and cost of governance }\end{array}$ & $\begin{array}{l}\text { False claims on state of infrastructure (road, rail, elec- } \\
\text { tricity, etc.) and development indicators }\end{array}$ \\
\hline 10. Health & 20. Unrest and violence \\
\hline $\begin{array}{l}\text { False claims on topics from false cures to symptoms, } \\
\text { causes and prevalence of health conditions, diet, effect of } \\
\text { activity, costs and quality of and access to healthcare }\end{array}$ & $\begin{array}{l}\text { False claims ref. security, civil unrest, politically linked } \\
\text { violence, ethnic or religious conflict }\end{array}$ \\
\hline
\end{tabular}

Note: Data drawn from the study of information identified as false by one or more of 14 fact-checking organisations in Africa between January 2019 and June 2020 (Cunliffe-Jones, 2022b). The list is not exhaustive. 
Setting aside, for now, the question of how laws might be used to address misinformation, it is clear that existing regulations do not effectively address the potentially harmful misinformation affecting this wide range of topics.

\subsection{Misinformation not restricted to traditional and social media - false claims spread in public speeches, parliament, on posters and product labels}

Our study found that new and existing laws related to false information are, for the most part, not concerned by its format, proposing sanctions whether it is transmitted in a written article, the spoken word, a photograph or meme. The focus of the laws is overwhelmingly on the means by which material spreads; aimed at information spread on traditional or social media channels, not at misinformation spread in other settings such as in parliament, at political rallies, in church or mosque, or even in product labels on fake medicine bottles.

In Benin, the Code du numérique (2018), for example, prescribes sanctions for 'anyone who creates or shares false information against a person, via social media or digital means'. In Ethiopia, the Mass Media and Freedom of Information Proclamation (2008) prohibits false claims made in mass media. In Cote d'Ivoire, the Loi 2017-867 (2017) prohibits the publication of any 'false news' through the press. In Nigeria in 2015 and Niger in 2019, authorities introduced 'cybercrime' laws, dealing with 'false information' or 'false news' spread on social media and online. In Uganda, the Computer Misuse Act (2011) criminalises the use of 'electronic communication', false or not, that authorities decide may disturb or attempt to disturb the peace. Meanwhile the Uganda Communications Act (2013) allows authorities to prohibit TV or radio broadcasts they find to present 'distortion of facts'. Against this, we found few examples of legislation relating to false information spread in other channels.

However, while traditional and social media are indeed major channels of false information, studies show that harmful misinformation spreads via a broad range of channels, online and offline, from false statements made at political meetings to false claims on medical product labels or posters in the streets (Cunliffe-Jones, 2022b; Hitchen, 2018; Kondowe, 2019). Such claims have clear potential to cause harm, from distorting public policy to causing serious medical harm.

In total, the study of misinformation that is part of this series identified false information being shared in a dozen different formats and on 16 different types of channel. Regulations focused primarily on addressing misinformation circulating in traditional media thus risk missing much misinformation that is their declared target. 
TABLE 5 MISINFORMATION ON I6 CHANNELS, IN MORE THAN A DOZEN FORMATS

\section{Misinformation - on multiple channels}

Drawn from the study of misinformation identified across Africa from January 2019 to June 2020 (Cunliffe-Jones, 2022b). The list is not exhaustive.

- Community networks

- Company or org website

- Domestic media

- Email

- Foreign media

- Government documents, reports

- Hyper-partisan news website

- Junk news site

- NGO report

- Phone message

- Product label

- Public poster or signage

- Satire site

- Social media/messaging platform

- Speech at public event

\section{In more than a dozen formats}

Drawn from the study of misinformation identified across Africa January 2019-June 2020. (Cunliffe-Jones, 2022b) The list is not exhaustive.

1. Broadcast statements

2. Community rumours or myths

3. Email chain statements

4. Faked documents, web pages, sites

5. Memes shared online

6. Official statements

7. Photos or photo captions

8. Product labels

9. Public signs or posters

10. Speeches to live audiences

11. Videos or video captions

12. Voice notes or phone messages

13. Written news articles, written posts online or on messaging apps

\subsection{Government, religious and traditional leaders among key creators}

As we set out in Section 7.3, the primary targets of the laws in place relating to false information, put in place since 2016, have been either journalists in traditional media or opposition politicians making criticisms of the governments. This is shown both by the framing of the regulations themselves and by how they have been applied in practice. Among the 11 countries studied, Benin, Cote d'Ivoire, Ethiopia, Kenya, Nigeria and Uganda all have existing or new legislation penalising the publication or broadcast of 'false' information by the media. Data from the civil society project Disinformation Tracker, meanwhile, show that in all but one case, those targeted by law enforcement actions in the 11 countries studied were either journalists or opposition politicians (Section 7.3 for details) ${ }^{63}$.

By contrast, studies of misinformation show sources of misinformation range from government politicians to religious and traditional leaders, journalists and opposition politicians but also business leaders, self-declared health practitioners and others. The Reuters Institute Digital News Report 2020 found that the source of misinformation that most concerns average citizens worldwide is domestic politicians, both government and opposition (Newman et al, 2020). And numerous reports on misinformation have identified examples of the role of both government and opposition politicians, among others in spreading false information (Brennan et al, 2020; Le Roux, 2020a).

The study that is part of this series found that, in every country studied, misinformation is created and spread by a wide range of actors from media and opposition 


\section{TABLE 6 WHO SPREADS MISINFORMATION}

Well known public figures and institutions - media and politicians, celebrities, businesses, religious and traditional leaders - via official and mainstream channels

This includes: academics and think-tanks; businesses and business leaders; celebrities; domestic politicians; foreign politicians; mainstream domestic media; mainstream foreign media; international organisations; labour leaders; news websites and blogs; NGOs/civil society organisations; religious leaders and groups; satirists; social media users; supposed experts in specialist fields; state officials, and; traditional rulers/community leaders.

Lesser known but identifiable activists/promoters - most often via social media and offline community networks

This includes: self-styled health practitioners or sites; conspiracy theorists; ethnic or religious activists; known or suspected political activists; hyper partisan news websites; and junk news sites or social media pages.

Unknown individuals or groups - most often via social media and off-line community networks

This includes: 'bad actors' seeking to cause practical harm (e.g. spread computer viruses); bad actors seeking to cause political effects; community networks spreading myths; hoaxers and scammers; unknown social media users; and unknown individuals or groups acting off-line.

Note: Findings from the study of misinformation identified across Africa January 2019 to June 2020 (CunliffeJones, 2022b). The list is not exhaustive.

politicians to governments, public institutions, business leaders, traditional and religious leaders, special interest groups, offline community networks and ordinary social media users. The study groups these sources into three broad categories of well-known, easily identified elite individuals and groups, those lesser known but identifiable and unknown individuals and groups (Cunliffe-Jones, 2022b). This range is not reflected in the laws we studied.

The failure of the laws and regulations we reviewed for this study to address the active role taken by government officials and politicians, traditional and religious leaders, businesses and other powerful individuals and institutions in originating much of the harmful misinformation identified limits the potential effectiveness of the regulations in reducing the harm certain types of misinformation can cause.

\subsection{Factors that drive the creation and spread of false information}

To be effective in deterring behaviour carried out on a large scale by a diverse group of actors, laws also need to address what motivates or drives the behaviour. In the case of misinformation, studies show a diverse set of elements involved in driving the creation and spread of false information. These range from psychological factors such as motivated reasoning and strong emotional responses to stimuli (Duffy, 2020; Vicol, 2020) to more calculated political motivations (Burke \& Harding, 2019; Cunliffe-Jones, 2022b; Oborne, 2005). Financial incentives drive the creation of both scams (Cable et al, 2020) and much misinformation that serves as clickbait (CunliffeJones, 2022b). The operating systems of many social media platforms promote material to which users show strong emotional responses (Statt, 2020; Wardle, 2019). In addition, people and institutions both make mistakes and fail to verify information they originate or share. The study of misinformation in Africa that is part of this series for its part identified a similar range of factors driving misinformation. 
TABLE 7 FACTORS THAT DRIVE THE CREATION AND SHARING OF MISINFORMATION

The study that is part of this series identified a wide range of overlapping factors driving the creation and sharing of false information (Cunliffe-Jones, 2022b).

Nine factors were identified as driving the creation of misinformation observed

[List is not exhaustive]

(i) Errors in explaining or understanding complex information

(ii) Failure to check information that could easily be shown to be false

(iii) Lack of access to or trust in official information to check claims against

(iv) Desire to promote information thought to be accurate and useful

(v) Desire to promote a political, social or religious agenda or view

(vi) Desire for a direct financial reward - via a scam or hoax

(vii) Desire for attention for reasons of influence or financial motivation

(viii) Desire of individuals and institutions to promote an agenda for advancement

(ix) Tendencies to speculate, exaggerate or see the best or worst in a scenario

\section{Six factors identified as driving the sharing of misinformation}

[List is not exhaustive]

(i) Errors in explaining or understanding complex information

(ii) Failure to check information that could easily be shown to be false

(iii) Restricted access to or trust in other information to check claims against

(iv) Desire to promote information thought to be accurate and useful

(v) Adherence to a pre-existing view or mindset

(vi) Emotional responses to the information from anger to affirmation and fear

In addition to this mix, the study identified a set of broader factors in the working practices of three key societal sectors as major drivers of false information.

First, the competitive nature of politics drives many politicians to make false statements in order to advance. And the failure of parliamentary authorities to sanction those doing so in parliament or campaign speeches provides politicians with little perceived reason to stick to the truth. While publicly condemning those who spread false information, many politicians are known in practice to go further, and sponsor illicit operations creating and spreading false claims online about their opponents. In Kenya, for example, the executive office of the presidency was reported in 2015 to have employed two groups known as the 36 bloggers, and the 527 militia, to attack its opponents online with false information (Freedom House, 2019; Kenya Today, 2015). And ahead of Nigeria's 2019 elections, politicians were reported to have employed so-called 'propaganda secretaries' to spread false information about their opponents (Hassan \& Hitchen, 2019). To have effect in curbing the spread of false information, laws or regulations, such as parliamentary codes of practice and electoral laws would need to address these issues, penalising the politicians who take part.Our study found they do not do so.

Second, structural weaknesses in the governance of both traditional and online media are also a major driver of misinformation. In 2020, the South African National Editors' Forum (Sanef) declared itself worried about the widespread 
use by under-trained, overworked journalists of information drawn from social media or messaging platforms; a practice seen as driving the spread of misinformation and undermining media credibility ${ }^{64}$. Media ownership structures in many countries allow owners to require journalists to take particular political lines, regardless of the facts. And the failure of proprietors in many countries to pay their staff adequate salaries, and pay them regularly, often leaves journalists seeking payments in ways that distort their coverage - a practice known as 'brown envelope journalism' (Sanef, 2019). The media regulation systems in the countries studied have not to date addressed these issues effectively.

Third social media and messaging platforms enable the spread of misinformation through design mechanisms that promote emotionally charged inaccurate posts, and by providing financial incentives to clickbait (Crook, 2017; Read, 2016; Silverman, 2016). Patchy and inconsistent approaches to moderating content and a lack of transparency from dominant players in response to misinformation, have hampered those efforts that have been made since 2016 to tackle these problems (Ananny, 2018; Chee, 2020; Full Fact, 2019). Proper transparent regulation of the way social media and messaging platforms respond to misinformation globally, in ways consistent with both national and international laws on freedom of expression is thus also a part of any solution to the harms misinformation causes. This approach is currently missing from the regulatory approaches in most countries studied.

64 Interview Kate Skinner, Executive Director of Sanef, September 2020. 


\section{IDENTIFYING WHAT MISINFORMATION CAUSES ACTUAL OR POTENTIAL HARM}

We set out above five ways that existing and new laws and regulations miss the declared target of curbing the spread of and harm done by false information: failing to reflect (i) the diverse ways misinformation distorts understanding, (ii) the topics it affects, (iii) the channels through which it is transmitted, (iv) who creates it and (v) what drives it. Another crucial factor remains to be addressed: it is the question of misinformation's effects.

If false information were to have no actual or potential harmful effects, there would be no justification under international laws on freedom of expression for suppressing or reducing its circulation. Under Article 19 of the Universal Declaration of Human Rights, individuals worldwide have the right to 'seek, receive and impart information and ideas' subject only to restrictions that are both 'provided in law and necessary ... [to ensure either] ... respect of the rights or reputation of others... [or] the protection of national security or of public order or of public health or morals' (Article 19, 1966). In practice, this means laws should be used only to ensure individuals are protected from hate speech, unwanted sexual speech or abuse or defamation and society is protected from speech, or information, which risks imminent harm to national security, public order or public health (Kaye, 2019a). Simple falsity alone is not enough.

\section{I. When and how existing and new laws address misinformation harm}

To understand the effects of the existing and new laws in place against 'false' information in the countries we studied, we examined when and how the terms of the legislation address the potential of the information to cause actual or potential harm, and whether they set out a clear standard for how that actual harm or potential harm might be assessed.

Our study found almost one third of the laws examined offer no requirement that harm be shown to penalise publication. In a further 6 of the 31 laws, the alleged harms concerned are not recognised as reasons to permit restrictions on speech under Article 19. And in none of the laws or regulations studied did we find clear standards for how the actual or potential harm caused must be proven, for penalties to be imposed. A summary of our findings are shown below in Table 8. Details of the laws are set out in Section 6.4 of the report.

What the findings show is that more than half the 31 existing and new laws and regulations we reviewed either require no evidence of harm caused or focus on the potential for harm in fields not recognised by Article 19, and none of the regulations provide details of how such harmful effects might be proven. 

MISINFORMATION MAY CAUSE

- Ten of the 31 existing or new laws and regulations that we reviewed penalise the publication of 'false' information on the basis of falsity alone, with no evidence required that specific harm was or could have been caused by the information. These laws apply in Benin, Burkina Faso, Cote d'Ivoire, Ethiopia, Nigeria and Uganda.

- Six of the laws that we reviewed require proof that harms have or could have been caused, but in ways not accepted as reasons to restrict free speech under Article 19. These laws apply in Cote d'Ivoire, Kenya, Malawi, Niger, Nigeria and Senegal.

- Fourteen of the laws we reviewed require proof of actual or potential harm in ways that may be permitted under Article 19 (infringements of the rights or reputations of citizens, public order or public health). However, the terms used in many laws are broad and vague and the means by which proof for harm or risk of harm should be proven are not provided.

- One law requires media to allow a right of reply to those affected by false information but does not otherwise penalise its publication.

Note: More details are set out in Table 10.

\subsection{Evidence of actual or potential harm caused by misinformation}

The failure of the laws and regulations studied to require proof of actual or potential harm, in fields permitted under Article 19, and set out reasonable standards for what would constitute proof is not for lack of evidence of actual or potential harm caused. Evidence of the potential of misinformation to cause harmful effects is identified in a wide range of studies and reports from across Africa and around the world.

Evidence of public disorder sparked by false information has been documented in a series of studies and reports from around Africa (Adegoke, 2018; Cunliffe-Jones, 2022b; Hassan \& Hitchen, 2020; Nur, 2019), India (Goel et al, 2018; McLaughlin, 2018), Myanmar (Ellis-Peterson, 2018; Kaye, 2019a) and Brazil (Cardoso \& Marques, 2017).

Evidence of harms to public health caused by misinformation is documented in studies of the effects of so-called 'bad science' (Boseley, 2008; Larson, 2018), antivaccination information (Larson, 2018; Mills et al, 2005), anti-retroviral treatment for HIV in Tanzania (Thielman et al, 2014), unfounded rumours about healthcare workers in Liberia during the 2014 Ebola crisis (Roth Allen et al, 2015) and false claims about medical treatments in Nigeria (Amobi, 2020; Ogala \& Ibeh, 2014) and in a systemic review of the effect of health misinformation across the world (Wang et al, 2019).

Evidence of effects of misinformation is also documented in a wide range of other fields from harms to reputations and mental health (Cunliffe-Jones, 2022b), to political polarisation (Fisher \& Taub, 2019; Tucker et al, 2018) and to financial hardship and identify theft (Cunliffe-Jones, 2022b). Some of these fields would fall under areas in which it is legitimate to restrict freedom of information, and others would not. 
Proof of the effects of misinformation is not always as certain as many imagine, however. In one of the standard textbooks on media theory, first published in 1983, most recently updated in 2010, the academic Dennis McQuail identified a 'paradox' in discussion of the effects of mass media in general. 'There is a widespread belief nearing on certainty, that the mass media are a powerful instrument of influence on opinion and of effects on behaviour. At the same time, there is great difficulty in predicting effects, engineering them by design or in proving that they have happened after the event' (McQuail, 2010).

From the start of the last century to the 1930s, a broad consensus developed that the mass media of print, radio and film were a new and powerful tool, re-shaping society, able to 'mould behaviour more or less according to the will of their controllers', McQuail noted. Such ideas, although untested by serious research, were widely accepted until the 1930s and 1940s when academics began to question these assumptions. While the advertising industry promoted claims of strong effects, and officials in Allied governments expressed alarm about the possible effects of enemy propaganda in World War II, research found the effects were complicated to study and measure and the media's role in shaping society had been overstated. In the new view: 'It was not that the media had been found to be without effects or influence; rather there was no direct or one-to-one link' (McQuail, 2010). In the 1970s, the pendulum swung again, a new generation of scholars arguing that this failure to identify direct effects was the result of the way earlier academics ran their studies. And from the 1980s onwards, the consensus has moved once more to an understanding of so-called 'negotiated' media influence that sees media as setting an agenda, and providing information and constructing meanings, with different audiences having the capacity to choose what to accept and what to reject (McQuail, 2010). Furthermore, other factors, such as social structure, were identified as far more influential than media.

\subsection{Belief in the effects of misinformation on elections is widespread}

In the first days, months and years following the shocks to UK and US politics in 2016, many commentators followed the early-20th century school of thinking, ascribing the unexpected votes to the influence of false information received from the media. The only difference this time was that the information they attributed this to was not published in traditional media but shared on social media platforms. Some saw the influence of social media as agenda-setting (Vargo et al, 2017). Others saw it as influencing voter decisions directly. 'Donald Trump won because of Facebook' the US media commentator Max Read declared, the day after the 2016 US election. While many factors had played a part in the US president's victory, Read suggested Facebook was the biggest. 'The most obvious way in which Facebook enabled a Trump victory has been its inability (or refusal) to address the problem of hoax or fake news' (Read, 2016). Many agreed. 'Conventional 
wisdom now holds that without Facebook's help spreading misinformation, Trump probably would not be in office, US media critic Margaret Sullivan wrote in 2020 (Sullivan, 2020).

Some academics backed this position. Richard Gunther and colleagues at Ohio State University, conducted a study of US voters who had switched party allegiance between 2012 and 2016, going from voting for former president Barack Obama to backing Trump. After establishing their subject's voting history, they identified those who believed three widely promoted false news stories that cast the Democrat 2016 candidate Hillary Clinton in a poor light, discounted for the role of other factors that may have counted against Clinton such as negative attitudes toward female candidates, and concluded that 'fake news most likely did have a substantial impact on the voting decisions of a strategically important set of voters... sufficient to deprive Hillary Clinton of a victory' (Gunther et al, 2018).

The claim that misinformation may affect election outcomes is not limited to the United States. Martin Moore, Director of the Centre for the Study of Media, Communication and Power at Kings College London, identifies misinformation as a problem for electoral politics globally. The techniques that 'successfully distorted the 2016 US election ... memetic warfare tools, amassing vast voter datasets, developing sophisticated behavioural targeting methods ... poisoning the democratic well with false information' are now being deployed globally he argued in 2018. 'Techniques and tools pioneered in America can as easily be tried in Britain, Germany, India, Malaysia or Brazil' (Moore, 2018). And for British journalist Carole Cadwalladr, false information shared online with undecided voters in the 2016 Brexit referendum determined the outcome (Cadwalladr, 2017).

Researchers, media commentators and politicians across Africa also identify false information as affecting political events across the continent. In 2017, a study of the outcome of senatorial elections in Nigeria's Taraba State in 2015 concluded 'deliberate distortions in the information about opponents... distortion of the facts about personal performance, and misinformation, spread on Facebook, had 'influenced [the] electorate to vote [for] a particular candidate' (Apuke \& Apollos, 2017). In June 2017, reports in Kenyan media suggested misinformation, which was widespread in the country's election campaign, had 'undermined' a leading candidate for governor of a county in western Kenya (Dahir, 2017). The following year, news of the role that British consultancy Cambridge Analytica had played spreading false information online in an effort to sway the elections in Kenya in 2013 and 2017 (Channel 4, 2018) and Nigeria in 2015 (Cadwalladr, 2018) emerged.

In late 2017, a false claim spread online that Nigerian President Muhammadu Buhari, who was known to have been suffering from ill-health, had died and been replaced by a body double from Sudan named 'Jubril', potentially weakening his 
candidacy in forthcoming elections (Akinwotu, 2019). Although no evidence has been found that the claim had any effect in the 2019 elections, which he went on to win, media reports suggested a similar claim helped spark an unsuccessful military coup d'état in Gabon in January 2019. The claims that a stilted video of President Ali Bongo's traditional New Year's Eve speech was not real, and had been faked because the president had died, spurred elements in the military to attempt to seize power, media reports suggested (Breland, 2019; Cahlan, 2020).

In 2020, a study in Zimbabwe by Admire Mare and Trust Matsilele found politicians on all sides believed misinformation and disinformation had 'played a huge role' in the country's July 2018 elections. Tendai Chirau of the ruling ZANU-PF party, told the researchers 'fake news had the effect of creating panic' among party supporters. Misinformation and disinformation, ranging from false claims about the state of the country to attempts to intimidate voters with false claims of violence at voting centres, were widespread and 'blamed by respondents for their parties' poor showing at the polls', the researchers found (Mare \& Matsilele, 2020). And in Nigeria, a study conducted into the use of WhatsApp in the 2019 elections found politicians and political activists were concerned about effects they believed false information was having. 'The increasing prominence attached to WhatsApp by candidates' supporters and strategists is an indication that they believe it has an impact, even if this is hard to quantify', noted the researchers. WhatsApp had been widely taken up as an operational tool by political activists, both to coordinate campaign events and mobilise their voters and to suppress the vote for their opponents through a combination of political smears and voter intimidation, suggesting, for example, that violence was taking place close to polling stations in rival party strongholds, they said (Hitchen et al, 2019).

\subsection{Proving the effects of misinformation on elections is complex}

Although the belief that false information spread online and in traditional media can affect the outcome of elections is widespread among politicians and the media, in Africa as elsewhere, and spurred calls for action against those responsible (Olewe, 2018; Okakwu, 2018), such effects are hard to prove in practice and the lessons for the regulation of political speech unclear.

The alarm expressed by many about the potential effects of false information on elections is partly a reflection of concern about, on the one hand, the immense reach of information spread online and, on the other, tech companies' capacities to micro-target, or allow others to micro-target, individuals with politically affective messages. Many of those who claim online misinformation affects election outcomes point to the vast reach of the online platforms (Parkinson, 2016; Read, 2016). Others note that false information often spreads further and brings more 
reader engagement online than accurate information, due in part to the use by tech companies of design features that favour posts that generate strong emotional responses (Silverman, 2016).

As the researchers Ndlela and Mano note, the poor penetration of the Internet in many African countries imposes some limits on the reach of online information circulating on the continent. 'Social media's efficacy is ... undermined by its poor penetration, creating a divide in knowledge between those connected and those outside the net' (Ndlela \& Mano, 2020, p. 17). However, even where direct access to the Internet is limited, information that started online often reaches a wide community through offline sharing, the researcher Jamie Hitchen and colleagues found in their study in Nigeria. 'Many of our respondents said that they had heard stories circulating on WhatsApp referred to in sermons by pastors or relayed by traditional and community leaders who have online access. Radio news and phonein-shows, calls from relatives and word of mouth discussions in the street are other ways in which WhatsApp messages can be widely shared. Understanding that Internet penetration does not equate to Internet influence is critically important' (Hitchen et al, 2019).

Although the reach of false information moving between both online and offline worlds can thus be substantial, this does not always equate directly to influence. A study by US political scientist Brendan Nyhan and colleagues suggests the effect of false information on voters' choice of candidates in the 2016 US presidential election was 'limited' (Nyhan et al, 2018). The study reviewed data on web traffic histories from a national sample of Americans and found the audience for false information from 'untrustworthy sites' was largely restricted to a subset of the population with a strong pre-disposition to particular political views, and played the role of reinforcing, not changing, their existing attitudes. While the data were statistically imprecise, and the researchers, could thus not exclude the possibility of effects at the margins, they could 'rule out very large effects', they said (Nyhan et al, 2018).

The Nyhan et al study also disputed the findings of the Gunther et al study that suggested 'fake news most likely did have a substantial impact on the voting decisions of a strategically important set of voters' in the US 2016 election. Among other points, Nyhan et al argued the evidence did not establish causality and ignored the fact that 'the effects of brief exposure to persuasive messages have been found to be small in partisan election campaigns' (Nyhan et al, 2018). A meta-analysis (Kalla \& Broockman, 2017) of 49 field experiments undertaken in the United States, 'found that the average effect of personal and impersonal forms of campaign contact is zero, as Nyhan et al noted. And others have been similarly sceptical about the influence claimed for misinformation campaigns led in Kenya 
and Nigeria by Cambridge Analytica (Cheeseman et al, 2018). The claims made for the alleged effect of false information in the attempted coup in Gabon and the senatorial election in Nigeria, meanwhile, are based on perceptions, not evidence, of influence. The conclusion of Apuke and Apollos's 2017 study, cited earlier, was, as they acknowledge, based not on clear proof but on 'a strong perception' among respondents that false information spread on social media had influenced the electorate to vote for a particular candidate (Apuke \& Apollos, 2017).

Although this suggests the effects of false information on the choice of who people vote for are often over-stated, particularly the effects of limited or near-term exposure to false information with political overtones, this does not exclude the possibility of false information having a decisive influence on the outcome of closely fought elections in a number of ways. First, we know that both true and false information has greater effect on attitudes if repeated over time so misinformation spread over the longer term may have more effect (Fazio et al, 2021). Second, even if, as evidence suggests, 'the effects of brief exposure to persuasive messages' in election campaigns are small (Nyhan et al, 2018), persuading even a very small number of undecided voters who to vote for may have a significant effect on the election outcome, in a very closely fought race. Third, studies of false information spread during other elections suggest false information may have more effect by persuading voters whether to vote rather than who to vote for. For example, in Nigeria, fact-checkers identified false claims that violence was taking place around polling stations, reportedly deterring intending voters from the attending the vote (Cunliffe-Jones, 2022b; Hassan \& Hitchen, 2020). And in Europe, a study conducted after the 2019 UK election found the perception that politicians of all types were 'peddling untruths' was a cause of voter apathy, potentially lowering voter turnout (Britain Thinks \& Full Fact, 2020). Fourth, the study of misinformation in Africa that is part of this series suggests that where false information is related to individual candidates for elections where party loyalty is less of a factor than in national polls, it may have stronger effects on voter decisions than in national elections (Cunliffe-Jones, 2022b).

\subsection{Effects found in this series - from no difference to shaping policy}

While the belief nearing on certainty is widespread that misinformation is a powerful instrument, affecting both attitudes and behaviours, our study of misinformation circulating in Africa found in practice that more than one in four examples of misinformation studied ${ }^{65}$ had caused or risked no actual or potential harmful effects

65 A preliminary assessment for the study of 429 examples of information identified by factcheckers across Africa found no evidence in 124 cases (29\%) that substantial actual harm had 
to anyone (Cunliffe-Jones, 2022b). At the same time, based on a review of a combination of the empirical evidence from these cases and theories of effects, the study identified 10 fields in which actual or potential harmful effects did or could have occurred - a range of fields far beyond those reflected in the terms set out in most laws or regulations we studied. The fields of actual and potential harm identified included: (i) physical harms - from vigilante and gender-based violence to harms to individuals' and public health; (ii) harms to mental health - from personal distress to public alarm; (iii) harms to fairness, social cohesion - from entrenching negative stereotypes to enflaming social divisions; (iv) harms to the justice system - from distorting particular cases to judicial policy; (v) harms to the political system - from suppressing voting, to distorting the focus of debate; (vi) harms to business, economy - from company reputations to economic policy; (vii) harms to the environment from endangering wildlife to distorting policy focus; (viii) harm to international relations - from distorting public understanding to government policy; (ix) harm to individuals' finances, practical harms - from financial loss to identity theft, and the spreading of computer viruses; and ( $\mathrm{x}$ ) harms through distorted understanding of the natural world - miscellaneous.

\subsection{Standards used for identifying harmful effects}

Despite such evidence of harm, most of the laws and regulations we have reviewed for this study provide no clear guidelines for how the harm alleged in particular cases might be assessed. The study of misinformation that is part of this series divides harm into 'actual' and 'potential' harmful effects. Actual harmful effects are defined as direct, observable harm to an individual or group, shown by empirical evidence to have been caused directly by false or misleading information, and potential harmful effects are defined as harm that a combination of empirical evidence and theory indicates may have or may in future be caused by false or misleading information.

These definitions draw on the theory of four forms of effects set out in 2001 by Elizabeth M. Perse: (i) direct effects, (ii) conditional effects, (iii) cumulative effects and (iv) cognitive-transactional effects (Perse, 2001) ${ }^{66}$. They also draw on the theory of four ways in which effects bring or prevent change, set out by Joseph

been caused or potential harm risked as a result of the information's dissemination. Details are set out in the Appendices.

66 Elizabeth M. Perse defines 'Direct effects' as immediate, observable, short-term with an emphasis on change; 'Conditional effects' as reinforcement as well as change, affecting cognitive, affective (attitude/feeling) and behaviour, long or short term; 'Cumulative effects' as based on cumulative exposure, enduring effects - cognitive or affective; and 'Cognitivetransactional effects' as immediate and short-term, one-shot exposure. 
Klapper in 1960: (i) conversion (change of opinion or belief), (ii) minor change (change in form or intensity of belief, cognition), (iii) reinforcement (confirmation of existing attitudes or beliefs) and (iv) prevention of change (when change would otherwise take place) (Klapper, 1960). Finally, the model also seeks to understand how the change occurs, drawing on five ways noted by McQuail by which influence is exerted: (i) information, (ii) stimulation to action, (iii) directing attention differentially, (iv) persuasion or (v) defining situations and framing 'reality' (McQuail, 2010).

When assessing whether actual or potential harmful effects can be identified, the study also assesses both the level and severity of the harm identified, reviewing whether these effects, where they exist, would apply to (i) individuals, (ii) specific groups or (iii) society as a whole, and the severity and the duration for which the effects may apply. These distinctions are important to consider in reviewing laws and regulations that limit free speech. And as we have noted above, not only do a majority of the laws or regulations we have studied fail to address the wide range of types of misinformation, topics, channels, originators and factors that drive misinformation to be observed across the continent. Ten of the 31 existing or new laws and regulations that we reviewed for this study provide authorities with the power to penalise information on grounds of alleged falsity alone. And none of the laws or regulations provide clear guidelines for how to prove harm or risk of harmful effects. 


\section{CHANGES TO THE LEGAL AND REGULATORY FRAMEWORK WORLDWIDE 2016-2020}

A large body of national and international laws protect the rights of citizens worldwide to freedom of expression and access to information. Article 19 of the Universal Declaration of Human Rights affirms the right of citizens around the world to 'seek, receive and impart' information and ideas, subject only to limited restrictions necessary to protect to the rights and reputations of others, public order and public health (Article 19, 1966). These rights are reflected in the European Convention of Human Rights and the national laws of dozens of countries and defended by representatives of international bodies (UN, OSCE OAS \& AU rapporteurs, 2017). The First Amendment to the US Constitution, which provides broad protection of free speech, accepting fewer restrictions than most other constitutions, is largely reflected in the way major US-headquartered online platforms such as Facebook, WhatsApp, Twitter and YouTube, have approached the issue since they were created (Kaye, 2019a).

\section{I. Much debate but little change in the United States}

The United States, home to more of the world's major technology companies than any other country, has seen much debate since 2016 about misinformation and the right to limits of free speech. While the US Constitution's First Amendment is understood by many to be near absolute in the protection it provides to free expression, a series of rulings have over the years allowed for limited restrictions on forms of speech shown to cause 'clear and present danger' to individuals or society. Arguments since 2016 about the appropriate responses to misinformation have been primarily political in nature, revolving around whether 'moderation' of false information by social media companies is partisan in nature, amounts to censorship and is legitimate under the First Amendment (Bazelon, 2020; DiResta, 2020; Feldman, 2016). Such change, as has come, has been made not by government but has come in changes to the content regulation policies of the tech firms themselves, such as the decisions that led some major companies to 'de-platform' former US President Donald Trump in 2021 (Lakier, 2021; Romano, 2021).

\subsection{European Commission moves on privacy and stricter code for tech firms}

Even before the surge in concern about online misinformation in 2016, the European Commission introduced a measure aimed at protecting EU citizens from loss of control of their online data, used by political campaigns to target voters with false information. In April 2016 the Commission introduced the General Data Protection Regulation (GDPR), coming into effect 2 years later, to enhance online data 
protection and privacy for citizens (European Commission, 2016). This regulation has proven a spur to authorities in countries around the world to introduce or improve online data protections, aimed among other things at reducing the ability of tech company clients to micro-target misinformation at ordinary users. 'Since the adoption of the GDPR we have seen the beginning of a race, to the top hopefully, for the adoption or upgrade of data protection laws around the world,' said Estelle Massé, a policy analyst with digital rights campaigners Access Now ${ }^{67}$.

While the United States and many Asian countries are resisting similar measures, US states such as California and countries such as New Zealand and South Africa introduced or updated laws or regulations with similar safeguards for citizens. In September 2018, the European Commission moved further, introducing a voluntary code of practice for media and technology firms including commitments to greater transparency about political advertising, the closure of fake accounts and the ending of financial incentives for those spreading false information (European Commission, 2018). Major platforms including Facebook, Google and Mozilla signed up. Two years later, the Commission criticised the platforms' adherence to the code, identifying shortcomings as: 'inconsistent and incomplete application of the code ... lack of uniform definitions ... and limitations intrinsic to the selfregulatory nature of the code' (Chee, 2020). In December 2020, the Commission announced a revision of the code, the Digital Services Act and Digital Markets Act, promising yearly checks on how the platforms tackle illegal content, and new powers to levy huge fines (Kelion, 2020). The problem of the lack of legally set definitions of what constitutes 'illegal' false information remained.

\subsection{Germany's NetzDG law - requires rapid content takedowns, other liberal democracies more cautious}

Several European countries including the UK, France and Germany introduced or announced additional measures of their own. Germany's so-called NetzDG, or Network Enforcement Act, which came into effect in January 2018, went furthest. It requires social media networks with more than 2 million registered users to remove posts featuring 'manifestly unlawful' content within 24 hours of their being identified to the company or face major fines of up to 50 million euros (BBC News, 2018). Although the German government sees this measure as successful in reducing the effects of hate speech in particular, critics of the legislation have noted the law has served as a model for more authoritarian governments to restrict legitimate criticism (Mchangama \& Fiss, 2019). Liberal democracies France and Australia introduced measures aimed at forcing major tech firms to pay news providers for content, not acting against false information but strengthening

67 Interview with Estelle Massé of Access Now. 
the provision of evidence-based news (Meade, 2020; Stiglitz \& Schiffrin, 2020). And in December 2020, the UK announced plans to set up a new competition markets regulator for major tech firms (Hern, 2020). The government's plans for responding to online harms in the UK were still to come to parliament in late 2020 (BBC News, 2020; Le Conte, 2016).

\subsection{Laws in Singapore, Russia, India and Brazil allow politicians power to censor}

In contrast to the more hesitant approach of liberal democracies, authoritarian powers such as Singapore and Russia introduced legislation that human rights defenders said were less aimed at reducing any harm to individuals or society caused by false information, and more about giving government greater powers to muzzle their critics (BBC News, 2019; Corpus Ong, 2021; Heijmans, 2019). In Singapore, the final arbiter of what must be removed under its Protection from Online Falsehoods and Manipulation Act, known as the 'fake news bill', is a minister and judgements made have reflected this (Yuen-C, 2020). In Russia, laws were introduced banning publication of loosely defined 'unreliable information' ${ }^{68}$ or statements that show 'blatant disrespect' for the state (Schetzer, 2019).

In India, the police as well as government and individuals were given powers to request that social media platforms take down information that the government deems false, without clear standards set for what constitutes false information and why it should be removed. (Bahree, 2019). In 2021, this brought Twitter into conflict with the government (Aryan, 2021). In Brazil, laws about hate speech in offline media apply online too; tech platforms are liable for third-party content if they do not remove it following a judicial order to do so. Individuals may also request takedowns and if tech companies do not act then judges can rule on the takedown notice, again with little clear definition of how courts should determine what must be taken down and why (de Souza Abreu, 2018). Neither country has a legal definition of misinformation.

\subsection{Politicians worldwide fail to update electoral laws, parliament codes}

Despite the concern declared by governments worldwide about misinformation spread in traditional media and online, little action was taken in this period to update electoral laws to respond to misinformation spread by political campaigns

68 'Unreliable information' is defined as 'socially significant information disseminated under the guise of reliable messages which creates a threat to life and/or the health of citizens or property, the threat of mass disturbance of public order and public safety or the threat of creating or impairing the proper operation of vital elements of transport or social infrastructure, credit institutions, energy facilities, industry or communications'. 
or to ensure that politicians and officials are required to correct false claims they make in their official capacities, in parliament or the national assembly.

In the United Kingdom, parliamentary rules require that any MP or minister found guilty by parliament of 'misleading the House' inadvertently must apologise and correct the record. Ministers found guilty of knowingly misleading parliament have traditionally been required to offer their resignation, and over the years, many have done so (Marsh, 2020). The code also requires ministers to adhere to the rulings of the independent UK Statistics Authority which both enforces the standards of official UK statistics (Barrett, 2014) and offers public rebukes to government ministers and officials found misquoting official data (Illman, 2020).

The practice of seeking to uphold at least basic levels of accuracy in official statements in parliament is rare around the world, however. Kenya has such a requirement in its parliamentary code, but this has rarely been enforced. And in many countries, from Italy to Zimbabwe, parliamentarians are specifically exempt from any form of penalty for any statement they make in the national assembly. Calls in the United Kingdom to update the country's electoral laws in 2020 to allow electoral authorities to act against online misinformation spread during election campaigns were rebuffed. 


\section{CHANGES TO THE LEGAL AND REGULATORY FRAMEWORK ACROSS AFRICA 20I 6-2020}

\begin{tabular}{|l|l|}
\hline \multicolumn{2}{|c|}{ TABLE 9 I7 LAWS IN I I COUNTRIES ON FALSE INFORMATION PRE-20I6 } \\
\hline \multicolumn{1}{|c|}{ Country } & \multicolumn{1}{c|}{ I7 Laws in I I countries on 'false information' pre-2016 } \\
\hline Benin & No specific legislation \\
\hline Burkina Faso & No specific legislation \\
\hline Cote d'Ivoire & $\begin{array}{l}\text { - Penal Code Article 173 } \\
\text { - Loi 2013-451 - relative à la lutte contre la cybercriminalité (2013) }\end{array}$ \\
\hline Ethiopia & $\begin{array}{l}\text { - Criminal Code Article 486 } \\
\text { - Mass Media and Freedom of Information Proclamation Article 43 (7) (2008) } \\
\text { - Anti-Terrorism Proclamation (2009) }\end{array}$ \\
\hline Kenya & - Penal Code Section 66 \\
\hline Malawi & $\begin{array}{l}\text { - Penal Code Section 60 } \\
\text { - Public Security Regulations. Regulation 4 }\end{array}$ \\
\hline Niger & No specific legislation \\
\hline Nigeria & $\begin{array}{l}\text { - Criminal Code Section 59 } \\
\text { - Electoral Act, 2010 } \\
\text { - Cybercrimes (Prohibition, Prevention, etc.) Act (2015). }\end{array}$ \\
\hline Senegal & - Penal Code Article 255 \\
\hline South Africa & - The Electoral Act of 1998. Section 89 \\
\hline Uganda & $\begin{array}{l}\text { - Penal Code Section 171 } \\
\text { - Witchcraft Act (1957) } \\
\text { - Computer Misuse Act Section 25 (2011) } \\
\text { - Uganda Communications Act, Schedule 4 (2013) }\end{array}$ \\
\hline
\end{tabular}

\section{I. Pre-2016, focus was on media control, broad and vague definition of harms}

Following a period of media liberalisation across Africa in the 1990s, the first decade-and-a-half of this century saw governments in the 11 countries surveyed use a variety of colonial-era and newer laws, regulations and policy to control the operations of TV, broadcast, print and online media, to a greater or lesser degree. Restrictions on speech were typically framed as protecting society against harm to the rights or reputations of individuals and organisations or information that might undermine public order.

Other than legislation penalising defamation, specific laws against the spreading of false information per se were relatively scarce. While Penal Codes, laws and regulations on occasion included falsehood among the grounds on which information could be prohibited, the provisions in the legislation were often framed in a broad and vague way and not specific to particular types of falsehood.

Authorities in the countries studied often justify broad and vague restrictions on what media may publish or broadcast as enabling them to limit the media's 
potential to stir ethnic divisions and violence. Media legislation in Uganda, for example, uses deliberately broad wording to enable authorities to limit the risk of conflict in a country composed of 70 different ethnic groups, Ibrahim Bbossa, director of media for the Uganda Communications Commission (UCC), the country's main media regulator, said in an interview ${ }^{69}$. In Kenya, legislation was introduced in 2013 which authorities said aimed to reduce the risk of hate speech, spread by the media, stirring conflict. The Media Council Act set a code of conduct for journalists and media audiences prohibiting racist and derogatory remarks based on ethnicity. These actions did not relate specifically to misinformation per se.

Human rights defenders and lawyers in Nigeria and Uganda argue the use of broad and vague language in legislation enables authorities to apply laws selectively to penalise government critics without the need to show harm was caused. Authorities in Nigeria have since 2016 detained dozens of journalists and bloggers for information they published that was critical of the authorities, often on ground the information was 'false'. However, officials such as President Muhammadu Buhari's social media aide Lauretta Onochie suffered no sanction after acknowledging spreading false information favourable to the president (Adebajo, 2019b). In Uganda, regulators in 2019 ordered 13 TV and radio networks to suspend news executives and producers they accused of 'misreporting the news' of the arrest of an opposition politician. The suspensions were politically motivated, critics argued (RSF, 2019).

We noted in Section 3.3 and show below in more detail that legislation introduced to penalise allegedly 'false' information has focused on content spread by traditional media despite the fact that much of false information identified in the countries we surveyed originated from government figures and institutions, and traditional and religious leaders, to correct misinformation. Where codes of conduct for political leaders exist, such as in Kenya or South Africa, they have rarely been enforced in practice.

At the same time, and in contrast to countries such as South Africa, Nigeria and Kenya, where the legal framework enabled fact-checking initiatives to play a role exposing misinformation, the absence of such a framework in countries such as Ethiopia or Uganda has limited the ability of civil society and media organisations to intervene (Cunliffe-Jones, 2022a; Kaye, 2019b). In countries such as Benin, DR Congo and Ethiopia, through to Gabon, Uganda and Zimbabwe, authorities also shut down the Internet at times of political tension, reducing access to reliable and unreliable information alike (Access Now, 2020; Article 19, 2019).

69 Interview in October 2020 with Ibrahim Bbossa, the head of public and international relations at the Uganda Communications Commission. 


\subsection{Misinformation has undermined public support for media freedom}

From the early 1990s onward, the number of radio, television and print media not directly controlled by the state rose across Africa. From the mid-2000s on, access to independent news websites, blogs and information spread by the public on social media and messaging apps has leapt (Ndlela \& Mano, 2020). While these changes have been broadly welcomed by the public, support for media freedom across Africa had declined in recent years. This is due, in part, to the public's perception of media as a source of misinformation (Conroy-Krutz, 2019; Wasserman \& Madrid-Morales, 2018).

A survey of more than 45,000 people in 34 African countries between 2016 and 2018 by the group Afrobarometer asked respondents to choose between supporting the media's 'right to publish any views and ideas without government control' and supporting the government's 'right to prevent the media from publishing things that it considers harmful to society'. Compared to a previous survey conducted between 2011 and 2013, support for media's right to publish fell from 56\% to $46 \%$ while backing for government control of the media rose from $39 \%$ to $49 \%$. The researchers found that the cause of the change appears to have been public concern about the harm caused by false information, bias and hate speech, much of it spread online. 'Unfortunately, when Africans think of "the media", more and more often they think of the hatemongers and fake news peddlers. In this light, giving governments greater powers to limit what is broadcast, printed, tweeted or shared might seem sound' the researchers said (Conroy-Krutz, 2019).

At the same time, the public's attachment to the social media and messaging apps they use has also grown and Afrobarometer surveys conducted in the second half of 2019 found a return to a slight majority in support for media freedom, perhaps influenced by public anger at frequent Internet shutdowns, the imposition of taxes on the use of social media in some countries and reports of persecution of journalist, the researchers said (Conroy-Krutz \& Appiah-Nyamekye Sanny, 2020). This research also found that $66 \%$ of respondents identified politicians and political parties as spreading misinformation; substantially more than the $50 \%$ who identified news media and journalists as doing so. This again echoed other research into originators of misinformation (Cunliffe-Jones, 2022b; Newman et al, 2020).

\subsection{Post-20/6, governments introduced and toughened legislation against 'false' information in traditional and social media}

Between 2016 and 2020, the authorities in 10 of the 11 countries surveyed for this report either introduced or amended laws or regulations relating to 'false information' in traditional and social media. This raised from 17 to 31 the number of laws authorities said were aimed at reducing the harm caused by false information. 
In Benin, a new law covering 'false information' spread in online media was introduced in 2018 and the following year, Burkina Faso, amended an article of the country's Penal Code criminalising the publication or broadcast of 'false news'. In Cote d'Ivoire, the Press Code was amended in 2017, prohibiting publication of 'false news' by traditional media. In Ethiopia, a new Act, introduced in 2020, made the publication of what authorities declare to be disinformation a crime. Kenya, in 2018, criminalised the publication of data known to be false or misleading. Niger in 2019 made it an offence to publish 'false news' that disturb 'public order' or 'human dignity'. Nigeria, South Africa and Uganda introduced new laws or regulations in 2019 and 2020 and, as of late 2020, Nigeria and South Africa were both still debating proposed legislation on false information online. The measures represented a substantial limitation of free expression.

\subsection{Country-by-country changes}

While the move to regulate has been seen almost across the board, the countries we surveyed started out from different positions and applied their existing and new legislation in different ways. We set out country-by-country changes below.

\subsection{BENIN - NEW DIGITAL LAW PENALISES INFORMATION FOR 'FALSITY' ALONE}

In Benin, a country of 11.5 million people in West Africa ${ }^{70}$, the principal media law, the 2015 Code de l'information et de la communication, applies civil, not criminal law, to regulate the press and does not sanction statements for falsity alone. This was not changed but in April 2018, a new digital law, the Code du numérique, was introduced to govern use of social media and digital communications, including news articles posted online. Under Article 550(3) of the new code, anyone who: 'creates or shares false information against a person, via social media or digital means, will be punished with either 1 to 6 months in prison and a fine of between 500,000 and 1 million CFA Francs, or one of these punishments'. We identified no standard shown for how the courts should determine what is 'false information against a person' and no proof harm caused to make publication an offence. Falsity alone is enough.

In the first 2 years after the code came into force, at least 17 journalists and bloggers were prosecuted under the new code, according to human rights group Amnesty International (2020a); some though not all under Article 550(3). Media rights organisation Reporters Without Borders criticised the new code in 2020 as a 'new

70 Estimate of population as of 20 I 8: World Bank. 
weapon to neutralise the press' and suggested it conflicts with the existing 2015 media law (RSF, 2020a).

\subsubsection{BURKINA FASO - NEW ARTICLE OF PENAL CODE CRIMINALISES 'FALSE NEWS'}

The National Assembly of Burkina Faso, a land-locked country of the west African Sahel with a population of around 20 million people ${ }^{71}$, in June 2019 adopted an amendment to Article 312-13 of the country's Penal Code providing heavy punishments of 5 to 10 years in prison and fines of up to 10 million CFA francs for intentionally publishing 'false news likely to make others believe an attack had taken place or was expected against a person or property' The means by which a court would judge the information intentionally false is unclear. From our review, no proof of harm is needed for publication to be an offence. Media rights body Reporters Without Borders criticised the change and called for it to be declared unconstitutional. 'In addition to allowing the state to exercise strict control over information, this amendment introduces extremely serious restrictions on the freedom of the media in a country that was until recently considered a model in terms of freedom of information,' the group said (RSF, 2020b).

\subsubsection{COTE D'IVOIRE - PENAL CODE, CYBER LAW, PRESS LAW 'GAG THE PRESS'}

President Alassane Ouattara of Cote d'Ivoire, a country of 25 million people in West Africa ${ }^{72}$, called in June 2018 for a new law to punish those spreading false information. 'On top of the existing legal framework, it is necessary for us to go further to craft a law on 'fake news' to protect our fellow citizens and our country,' Ouattara said (Eburnie.com, 2018). The following year, the proposals were dropped on grounds that key elements of the proposed law were already part of existing legislation.

Article 173 of the Penal Code, introduced in 1998, criminalised the publication of false information found to lead to civil disobedience or undermine either 'public morale' or the reputation of institutions. The standard for determining what information is false, or how to define and prove the alleged harms, was not set out. Nevertheless, those found guilty of violating the Article can face up to 3 years in prison and a fine of up to 5 million CFA Francs. Meanwhile Article 65 of a law on cybercrime introduced in 2013 criminalised distribution online of 'false information' related to attacks on people or property and other emergency situations. The

7I Estimate of population as of 2018: World Bank.

72 Estimate of population as of 20 I 8: World Bank. 
standard for determining what is false was again unclear. No proof of harm was required for publication to be penalised. In May 2020, the leader of an opposition party was jailed on grounds of spreading false news and other offences under these two Acts (RFI, 2020).

In 2017, a new press law, Loi 2017-867 - régime juridique de la presse, was introduced. The new law decriminalised infringements of the previous law but, under Article 97, introduced heavy fines of up to 5 million CFA Francs for the publication by the press, broadcast or online media of any 'false news'. The new law again provides no standard for what constitutes false news, and requires no proof the information caused any harm, to make its publication an offence. In May 2020, two newspaper editors were fined 2.5 million CFA Francs each under this law for publishing a statement released by lawyers for an opposition politician detained since the previous December. 'The law does not understand the work of the press. It is being used to gag the press', Coulibaly Vamara, one of the two editors, told reporters (AFP, 2020)

\subsubsection{ETHIOPIA - RAFT OF LAWS GIVES GOVERNMENTWIDE POWERS OVER MEDIA}

For much of the past 20 years, the government in Ethiopia, a country of 109 million people in East Africa $^{73}$, has relied on a combination of media laws, an antiterrorism law and extra-legal means to monitor and control the media. During this period, and until today, journalists have had to face numerous challenges including the imprisonment of them and their colleagues, the censorship of the media under state of emergency legislation and Internet shutdowns (Barr, 2011; Human Rights Watch, 2020; Jeffrey, 2019).

Political and legal analysts suggest these legal measures have been used to reduce the spread of neither hate speech nor disinformation but to restrict legitimate journalistic work (Human Rights Watch, 2019). This has continued since 2018, heralded by some as a reform era ${ }^{74}$. Extra-legal measures such as Internet shutdowns and legally questionable moves such as filtering and blocking websites and shutting down television and radio stations have been used to restrict the spread of information and opinions that the government feared could lead to unrest ${ }^{75,76}$. One of the challenges for authorities is that much of the information objected to

73 Estimate of population as of 20 18: World Bank.

74 Interview with Kinfe Yilma, September 2020.

75 Interview with Kinfe Yilma, September 2020.

76 Interview with Abede Chekol, September 2020. 
is created by members of the Ethiopian diaspora in countries such as Germany, the United Kingdom and the United States which have been approached for help, but to limited effect ${ }^{77}$. The Cyber Army Development Institute, created within the Information Network Security Agency to train 'soldiers' for the country's 'cyber force', was formally disbanded when the new prime minister was elected by his party in 2018, and its powers and functions transferred to INSA ${ }^{78}$.

In 2008, Ethiopia's national assembly, the House of People's Representative, approved a new media law, the Mass Media and Freedom of Information Proclamation. Originally drawn up in 2002 to replace the country's first press law of 1992, it was used for a decade up to the change in government in 2018 to ban and jail journalists, sometimes for genuinely problematic practices ${ }^{79}$. The legislation seeks to limit what it calls 'moral damage caused by mass media', although what this means is not clearly defined. Article 43(7) of the Act protects 'constitutionally mandated legislators, executives and judiciaries' against 'false accusations' and vests power in the government to prosecute in these cases even if a charge is not brought forward by the person affected by the accusations (Mushtaq, 2008). The standard by which claims are determined to be false is left open to interpretation. No proof of harm is required.

In addition to this act, Article 486 of the long-standing Criminal Code, specifically criminalises spreading 'false rumours, suspicions or false accusations' against the government or authorities. The standard for determining what information is false is not set out and no proof of harm required. In 2009, the government also introduced the Anti-Terrorism Proclamation, focused in theory on preventing those planning or inciting terrorist acts but used in several instances in practice to charge members of the political opposition, bloggers and journalists over social media posts critical of the government (Gordan et al, 2015; Solomon, 2016).

In 2016, the government introduced further legislation, the Computer Crime Proclamation, which has provisions that apply to altering or falsifying computer data, distributing misleading computer data, concealing facts they have a duty to reveal, or taking advantage of a person's erroneous beliefs, in ways that may injure the rights or interests of another'. Offences committed under the law are punishable by fines or prison terms of up to 5 years.

77 Interview with Abede Chekol, September 2020.

78 Interview with Kinfe Yilma, September 2020.

79 Interview with Kinfe Yilma, September 2020. 
In 2019, a new Electoral Law included a limited range of measures prohibiting the spreading of false claims about the electoral process, such as that 'the secrecy of the ballot has not been maintained'80. In 2020, the government introduced the Hate Speech and Disinformation Prevention and Suppression Proclamation, which repealed the widely criticised article 486 of the criminal code and provided a more consistent basis for legal action. Until the adoption of the proclamation, Ethiopia's legislative approach to false information was piecemeal, not properly defined in one overarching piece of legislation, allowing the state to act largely as it determined, according to Addis Ababa law professor Kinfe Yilma ${ }^{81}$. The new legislation was introduced in response to concerns information on social media could spark a renewal of the ethnic tensions and unrest that emerged after the government came into power, and which flared in 2020 , analysts said ${ }^{82}$. In 2020 , it was used to penalise the publication of allegedly false information relating to Covid-19.

\subsubsection{KENYA - TWO NEW LAWS PENALISE DIFFERENT FORMS OF 'FALSE INFORMATION'}

In Kenya, in addition to the National Cohesion and Integration Act of 2008, which provides sanctions for discrimination and hate speech, and the 2013 Media Council Act which penalises derogatory remarks in the media based on ethnicity or race, Section 66 of the Penal Code, in existence decades, made it already a criminal offence to publish false information that authorities in the East African nation say is likely to cause fear and alarm to the public, or disturb the public peace.

While Section 66(2) of the Act allows a defence that the accused sought to verify the information before publication and reasonably believed it to be true, the law does not set out the basis on which information may be found to be false or likely to cause fear or disturb the peace. Those found guilty under the law are liable for a prison term of up to 2 years or an unspecified fine or both.

Since 2016, two further laws have been introduced, penalising what the authorities declare false information. First, Kenya's Elections Offenses Act of 2016 penalises publication during an election campaign of any 'false statement of withdrawal of any other candidate at such election' or anyone who 'forges, defaces or destroys any campaign or promotional material of an opposing candidate or political party'.

80 Interview with Kinfe Yilma, September 2020.

8I Interview with Kinfe Yilma, September 2020.

82 Interview with Abede Chekol, an independent researcher and consultant. September 2020. See also: Human Rights Watch, 2019. 
Section 17 of the Act prohibits the altering of documents. Then, in 2018, the government introduced the Computer Misuse and Cybercrimes Act. Section 22 of the Act criminalises publishing intentionally misleading or false information intended to be seen as true, whereas Section 23 criminalises the 'publication of false information' in print, broadcast or online, either intended to cause 'panic, chaos or violence' or which could 'discredit the reputation of a person'. As in other countries, how courts should decide what is false information and determine the effects of the information is not made clear.

\subsubsection{MALAWI - FALSE ADVERTISING, RIGHT OF REPLY AND ACCESS TO INFORMATION}

In Malawi, a country of 18 million people in Southeast Africa, Section 60 of the Penal Code, established in 1930, makes it a crime for a person to publish 'any false statement, rumour or report which is likely to cause fear and alarm to the public or to disturb the public peace'. As with Kenya's penal code, it would be a permitted defence if the person could prove they sought to verify the information before publication and had a reasonable basis for believing it to be true. However, how the courts should decide what is false, likely to cause fear and alarm or disturb the peace, and what is a reasonable basis for believing something untrue are unclear. At the same time, regulation 4 of the Public Security Regulations prohibits publication of anything that may 'prejudice public security; undermine public confidence in the Government; promote a feeling of ill-will or hostility between any sections or classes or races ... or promote industrial unrest. The grounds on which this should be decided are unclear.

In 2016, the government introduced a new Communications Act, requiring broadcasters to air 'counter-versions' from 'entities affected by an assertion of fact' if that individual or organisation can show the claim is false. What is unusual is that the Act does not seek to restrict speech but to require balancing counter-speech. Also new in 2016, the Electronic Transaction and Cyber Security Act, known as the $\boldsymbol{e}$-Transactions Act, included prohibitions against 'misleading advertising, which could be used against false claims for medical treatments and other harmful misinformation. In October 2020, the Access to Information Act came into effect. Among its other aspects, it prohibits the provision of 'false information with malice with an aim to injure another person. How this is determined remained unclear. As recently as 2015, the body overseeing the media, the Conseil Supérieur de la Communication, approved a system of media self-regulation requiring media to verify information they publish, based on agreed standards, and to ensure audiences receive a diversity of views and opinion but imposing few other restrictions (CSC - Conseil Supérieur de la Communication, 2015). 


\subsubsection{NIGER - NEW 'CYBERCRIME' LAW 'USED TO REPRESS OPPOSITIONVOICES'}

Unlike many of its neighbours, Niger, a country of 22 million people in the Sahel region $^{83}$, operated until recently a modestly liberal regime of media regulation. This changed in June 2019 with a new 'cybercrime law'. Article 31 of the new law prohibits publication of 'false news' that might 'disturb the public order or infringe on human dignity', punishable by a jail term of 6 months to 3 years and a fine of up to 5 million CFA francs (Bonny, 2019). How courts should determine what is false and what type of false news would disturb public order or human dignity is not set out. Proof of harm is not required to make publication an offence. Under the legislation, bloggers and journalists have been pursued on a variety of charges for articles posted to social media, previously exempt under the law (RSF, 2020c). Journalist Samira Sabou, the president of the Nigerien bloggers association, spent 48 days in detention in mid-2020 after being accused by the president's son of defamation over a comment left by a social media user on an article she had published on Facebook (Aboubacar, 2020). Human rights group Amnesty International criticised the law as 'a tool used to repress opposition voices' (Amnesty International, 2020b).

\subsubsection{NIGERIA - NEW BROADCASTING CODE, OTHER LAWS USED 'FOR POLITICS'}

Nigeria, Africa's most populous country with a population estimated at 196 million in $2018^{84}$, has a long tradition of media institutions offering a challenge to authorities dating back to before its independence from Britain in 1960. The legislative framework under which media operates remains complex, however, and the detention and harassment of journalists a common professional hazard.

Section 59 of the 1990 Criminal Code makes it a criminal offence in Nigeria to publish or reproduce any statement 'likely to cause fear and alarm to the public or to disturb the public peace, knowing or having reason to believe that such statement, rumour or report is false. The code does not make clear how a court should determine what is false, what might be likely to cause fear or disturb the public peace or require proof of harm.

The Electoral Act of $\mathbf{2 0 1 0}$ prohibits the false declaration of election results or the publication of false statements about a candidates' character or false claims a candidate has withdrawn. Voter impersonation is also illegal. Analysts see the act as

83 Estimate of population as of 2018: World Bank.

84 Estimate of population as of 20 I 8: World Bank. 
ineffective as its provisions are in general not put into practice ${ }^{85}$. The effect of false information during elections has nevertheless raised the concern of the country's electoral commission, which held a retreat for national and state officials on the topic, to no known outcome to date.

In 2015, the National Assembly passed the Cybercrimes (Prohibition, Prevention, etc.) Act that added further restrictions on traditional and online media. Section 24(b) of the Act made it a criminal offence to publish information online knowing it to be false and intended to cause annoyance, inconvenience, danger, obstruction, insult, injury, criminal intimidation, enmity, hatred, ill will or needless anxiety to another. How such broad effects should be determined was unclear and in 2020, the ECOWAS Court declared this section of the Act violated Nigerians' rights to freedom of expression regardless and ordered the government to either appeal or amend the section (Odoh, 2020). At the time of writing, the government had yet to do so.

In 2016, the country's Broadcasting Code of Conduct was updated to require broadcasters reporting on disasters and emergencies to 'ensure the veracity and credibility of originating material and content' and make sure that 'fictional events or non-factual materials shall not be presented as real.' As elsewhere, the standards for determining what is false are not set out, and no proof of harm is required to make broadcasting the information punishable. Since it was introduced, authorities have used the Code to fine and shutdown radio stations for broadcasting what authorities declare false information ${ }^{86}$. In 2020, authorities extended the scope of the Code from terrestrial to digital TV and radio stations. 'Where a service provider or a platform provider breaches any or all of the provisions of the Code on web/online broadcasting, sanctions as provided in the Code, including a takedown order, a block or a shutdown order shall apply, the Code states. Civil society and academia criticised the provisions of the Code as an attack on freedom of expression (Adegboyega, 2020).

In 2019, the government sought to introduce, a further bill, the Protection from Internet Falsehoods and Manipulation and Other Related Matters Bill. Quickly dubbed the 'Social Media Bill' by the media the bill was blocked in the National Assembly after strong objections from both civil society and media freedom groups (Cunningham, 2019; Turnbull, 2019). As of the time of writing, the bill remained stalled, however fears were growing the government would seek to revive the bill following a wave of protests in late 2020, partly organised online (Kazeem, 2020).

85 Interview Y.Z. Ya'u. Executive director at the Centre for Information Technology and Development. September 2020.

86 Interview Y.Z.Ya'u. September 2020. 
Analysts portrayed the Bill as evidence the authorities were seeking to control social media for political purposes, rather than a concern with the effects of disinformation ${ }^{87}$.

\subsubsection{SENEGAL - CHANGES TO JOURNALISM CODE BUT NO 'FAKE NEWS' LAW}

In Senegal, a country of 15 million people in west Africa ${ }^{88}$ authorities have since 2016 frequently expressed concern about the rise of false information. This, in part, follows a surge in the number of online news sites to around 300, in the past two decades. Many of these sites are identified by fact-checking organisations as publishing false information as clickbait, to drive up their audiences and earnings. Journalists in traditional media have expressed concern about the potential effects this false information may have on traditional media and on society.

Article 255 of the Penal Code in Senegal already made it a criminal offence, subject to up to 3 years in jail and fines of up to 1.5 million CFA Francs, to publish 'false information' that causes or may cause 'civil disobedience, damage to public morale or to the reputation of public institutions. How the courts should determine what is false or its effects are not set out. In March 2020, three prominent community leaders were questioned by police for allegedly violating Article 255 by making statements denying the existence of Covid-19 in Senegal. They were released without charge after questioning (DakarActu, 2020). Such actions were rare, however, and no new law penalising false information was adopted between 2016 and 2020 .

At the same time, a new press code, the Code de la Presse, was approved by the National Assembly in 2017 (Journal Officiel, 2017) after 8 years of negotiations with media organisations. The Code created a set of professional qualifications for journalists and required that, to be approved as news organisations, print, broadcast or online operations must show they have an editorial structure of at least three people, at least two of whom must have a minimum 7 and 10 years' experience, respectively as working journalists. The Code sets out a combination of external and self-regulation. Mamadou Thior, chair of the media self-regulatory body, the Conseil pour l'observation des règles d'éthique et de déontologie dans les médias (CORED), argues that unregulated news sites had been a major source of misinformation undermining the reputation of the media as a whole and the introduction of the code would have a useful effect. 'These sites carry a lot of misinformation. People who are not professional journalists hardly worry about misinformation', he said in an interview. If the new system works as is hoped 'news

87 Interviews Y.Z. Ya'u and Adekunle. September 2020.

88 Estimate of population as of 20 I 8: World Bank. 
will be better verified before publication', he added ${ }^{89}$. Implementation of the Code started in 2019. The launch of the Committee overseeing media staffing was due in February 2020 but was delayed by the emergence of the Covid pandemic.

\subsection{I0. SOUTH AFRICA - NEW REGULATIONS ON COVID, FAKE NEWS BILL PROPOSED}

South Africa, a country with a strong history of independent media, had, at the time of writing, only limited legislation sanctioning publication or broadcast of false information other than on grounds of defamation.

The Electoral Act of 1998 includes provisions under section 89 sanctioning officials or politicians who make intentionally false statements that could adversely affect an election. Under the law, no official required by the Act to make a statement may do so knowing that it is false and no person at all may publish any false information with the intention of disrupting, preventing or influencing the outcome or conduct of an election. Meanwhile, the Electoral Code of Conduct, which is part of the Act, prohibits political parties from disseminating false information about 'a party, its candidates, representatives or members; or ... a candidate or that candidate's representatives'. Although the Act has rarely been used this way, it was taken up by the opposition Democratic Alliance, to protest statements made by the ruling ANC in South Africa in 2014 (SA Constitutional Court Ruling, 2015).

In 2017, the government introduced a new piece of legislation it declared aimed at responding to concerns about rising levels of misinformation. The Cybercrimes and Cybersecurity Bill would criminalise messages that are inherently false in nature' and 'aimed at causing mental, psychological, physical or economic harm to a specific person or group of persons. How this would be proven is unclear and proof of harm caused is not required. The bill faced opposition and had yet to be passed by parliament at the time of writing.

In 2020, authorities issued new regulations under the Disaster Management Act, 2002 that criminalised the publication of any statement made 'with the intention to deceive' any other person about Covid-19 or any action taken by the government to address Covid-19 and took actions to enforce the law later that year.

As in Senegal, however, independent media standards bodies have taken a major role in responding to evidence of misinformation spread by the traditional media. Recent inquiries such as the Zondo Commission of Inquiry into State Corruption exposed the extent of corruption, or so-called 'brown-envelope' journalism, within parts of the media (Sanef, 2019). The Press Council, set up in 2007 as a selfregulatory body for the media, intervened in several instances, adjudicating on 
cases and requiring the media to publish corrections on false reports. During the most recent election in 2019, the Independent Electoral Commission (IEC) also worked with a media standards organisation, Media Monitoring Africa, to identify examples of misinformation and require false information to be taken down or corrected ${ }^{90}$.

\subsection{I.UGANDA - NEW LAWS ADD TO CONTROLS ON MEDIA, POLITICAL OPPONENTS}

Authorities in Uganda, an east African country of 43 million $^{91}$, known for its strong legal controls on the media and political opposition, have since 2016 brought in two new laws related to 'false information'.

In 2002 the Supreme Court revoked provisions in the 1950 Penal Code that criminalised the publication of 'false statements, rumours or reports which were likely to cause fear and alarm to the public or to disturb the public peace, and in 2010 the Constitutional Court struck down a related provision on sedition. However, a wide range of other legislation remains available to the authorities to use, sufficiently broadly worded to enable authorities to penalise information published or broadcast largely at will.

On occasion, these powers are used in line with the public interest. Authorities in 2020 used Section 171 of the Penal Code which covers 'any act' that might contribute to the spread of life-threatening diseases, to prosecute the publication of what they said was false information related to the Covid-19 pandemic. And some years earlier, regulators used the $\mathbf{1 9 5 7}$ Witchcraft Act, to prosecute groups responsible for financial hoaxes on radio stations (See Section 7.2 for details).

However, more commonly legislation has been used against critics of the government, media and politics. Introduced in 2013, Schedule 4 of the Uganda Communications Act requires that news broadcasts be 'free from distortion of facts' and provides broad powers to the UCC to caution, fine, revoke licenses and confiscate equipment from broadcasting companies. The Commission typically uses this power against entities rather than individuals ${ }^{92}$. The Act does not make clear how the UCC should decide what constitutes a factual distortion. Proof of harm is not required. In 2019, the UCC issued a raft of media regulations under these powers including, in Section 10, broadly worded prohibitions on 'distortion, exaggeration [and] misrepresentation'.

90 See the misinformation tracking project: https://real4 I I.org.

9I Estimate of population as of 20 I 8: World Bank.

92 Interview Ibrahim Bbossa. September 2020. 
The UCC also uses provisions of the Data Protection and Privacy Act, of 2019, when investigating and prosecuting what it calls 'false claims. This Act again leaves unclear what may be defined as false or how harm may be shown. In mid-2020, the Ugandan parliament updated electoral laws, prohibiting among other things, 'offensive communication', again without clear definitions of what this means.

\subsection{Thirty-one existing and new laws related to 'false' information}

\begin{tabular}{|c|c|c|}
\hline \multicolumn{3}{|c|}{$\begin{array}{l}\text { TABLE IO THIRTY-ONE EXISTING AND NEW LAWS RELATED TO ‘FALSE’ } \\
\text { INFORMATION IN II SUB-SAHARAN COUNTRIES AS OF END } 2020\end{array}$} \\
\hline \multicolumn{3}{|l|}{ Country } \\
\hline Benin & 6.5 .1 & $\begin{array}{l}\text { Code du numérique (2018). Article } 550(3) \text { of the code provides that: 'anyone who } \\
\text { creates or shares false information against a person, via social media or digital means', } \\
\text { will face either } 1 \text { to } 6 \text { months in prison or a fine of between } 500,000 \text { and } 1 \text { million CFA } \\
\text { francs or both. No proof of harm is required to make publication an offence. Falsity } \\
\text { alone is enough. }\end{array}$ \\
\hline Burkina Faso & 6.5 .2 & $\begin{array}{l}\text { Code penal (as amended 2019). Article } 312-13 \text {, amended in } 2019 \text {, makes it a criminal } \\
\text { offence to intentionally publish false information related to an attack on property or } \\
\text { person. No proof of harm is required to make publication an offence. Falsity is enough. }\end{array}$ \\
\hline \multirow[t]{3}{*}{ Cote d'Ivoire } & 6.5 .3 & $\begin{array}{l}\text { Code Penal, Article } 173 \text { (introduced in 1998), criminalises the publication of false } \\
\text { information that the court finds did or could lead to civil disobedience or undermine } \\
\text { 'public morale' or the reputation of institutions. Causing civil disobedience or under- } \\
\text { mining 'public morale' would not be considered reason under Article } 19 \text { to restrict } \\
\text { free speech. }\end{array}$ \\
\hline & 6.5 .4 & $\begin{array}{l}\text { Loi 2013-451 - relative à la lutte contre la cybercriminalité (2013). Article } 65 \text { of this } \\
2013 \text { law criminalises distribution of false information related to attacks on people or } \\
\text { property and other emergency situations. No proof of harm is required to make publi- } \\
\text { cation an offence. Falsity alone is enough. }\end{array}$ \\
\hline & 6.5 .5 & $\begin{array}{l}\text { Loi } 2017-867 \text { - régime juridique de la presse (2017). Article } 97 \text { prohibits the publica- } \\
\text { tion of any 'false news' by the press, broadcasters or online media. No proof of harm is } \\
\text { required to make publication an offence. Falsity alone is enough. }\end{array}$ \\
\hline \multirow[t]{5}{*}{ Ethiopia } & 6.5 .6 & $\begin{array}{l}\text { Mass Media and Freedom of Information Proclamation (2008). Article } 43 \text { (7) of the } \\
\text { Act protects 'constitutionally mandated legislators, executives and judiciaries' against } \\
\text { 'false accusations'. Although Article } 19 \text { allows restrictions on speech causing unfair } \\
\text { damage to reputations, this law requires no proof the accusations caused such harm. } \\
\text { Falsity alone is enough. }\end{array}$ \\
\hline & 6.5 .7 & $\begin{array}{l}\text { Anti-Terrorism Proclamation (2009). This act has been used against political opposi- } \\
\text { tion and journalists for spreading what authorities declared false information with } \\
\text { security implications. Although Article } 19 \text { allows restrictions on false information } \\
\text { that undermines public order, it does not do so where it relates to unspecified security } \\
\text { matters. Moreover, no proof of harm is required to make publication an offence. Fal- } \\
\text { sity alone is enough. }\end{array}$ \\
\hline & 6.5 .8 & $\begin{array}{l}\text { Computer Crime Proclamation (2016). This applies to altering or falsifying computer } \\
\text { data, distributing misleading computer data or taking advantage of a person's errone- } \\
\text { ous beliefs in ways that may 'injure the rights or interests of another'. Although it is } \\
\text { unclear how this harm would be proven, Article } 19 \text { does permit restrictions on speech } \\
\text { that could injure individuals' rights. }\end{array}$ \\
\hline & 6.5 .9 & $\begin{array}{l}\text { Electoral Law (2019). This prohibits the spreading of false claims about the elec- } \\
\text { toral process, such as claims that 'the secrecy of the ballot has not been maintained'. } \\
\text { Although Article } 19 \text { does not specifically refer to election-related misinformation, it } \\
\text { would be accepted by many as a legitimate concern. }\end{array}$ \\
\hline & 6.5 .10 & $\begin{array}{l}\text { Hate Speech and Disinformation Prevention and Suppression Proclamation (2020). } \\
\text { Article } 2 \text { provides a broad definition of disinformation and Article } 5 \text { criminalises } \\
\text { its publication. No proof of harm is required to make publication an offence. Falsity } \\
\text { alone is enough. With the adoption of the new law, article } 486 \text { of the criminal code, } \\
\text { was repealed. }\end{array}$ \\
\hline
\end{tabular}




\begin{tabular}{|c|c|c|}
\hline Kenya & 6.5 .12 & $\begin{array}{l}\text { Penal Code (1930). The code's Section 66, which has been in existence for at least } \\
\text { more than a decade, criminalises what the court finds are false statements 'likely to } \\
\text { cause fear and alarm to the public or to disturb the public peace'. This would be cov- } \\
\text { ered by Article 19. How these should be determined is not clear. } \\
\text { Elections Offenses Act (2016). The Act prohibits alteration of election-related docu- } \\
\text { ments or the making or publishing of false statements about the withdrawal of any } \\
\text { other candidate. Although Article } 19 \text { does not specifically refer to election-related } \\
\text { misinformation, it would be accepted by many as a legitimate concern. } \\
\text { Computer Misuse \& Cybercrimes Act (2018). Section } 22 \text { criminalises the publication } \\
\text { of data known to be false or misleading. Section } 23 \text { makes it a crime to knowingly } \\
\text { publish false information which is 'calculated [to] or results in panic, chaos or vio- } \\
\text { lence... or which is likely to discredit the reputation of a person'. Although Article } 19 \\
\text { does permit restrictions on information that undermine public order (cause chaos or } \\
\text { violence) or undermine an individual's reputation, Section } 22 \text { is potentially too broad. }\end{array}$ \\
\hline Malawi & 6.5 .16 & $\begin{array}{l}\text { Penal Code. Section } 60 \text { of the code criminalises the publication of 'any false state- } \\
\text { ment, rumour or report which is likely to cause fear and alarm to the public or to } \\
\text { disturb the public peace.' If public peace is understood to be synonymous with public } \\
\text { order, this restriction would be permitted under Article } 19 \text {. } \\
\text { Public Security Regulations. Regulation } 4 \text { prohibits publication of anything that may } \\
\text { 'prejudice public security; undermine public confidence in the Government; promote } \\
\text { a feeling of ill-will or hostility between any sections or classes or races... or promote } \\
\text { industrial unrest.' Article } 19 \text { does not permit restrictions on speech just because it } \\
\text { undermines confidence in the government or promotes industrial unrest. } \\
\text { Communications Act (2016). This law obliges broadcasters to air 'counter-versions' } \\
\text { from 'entities affected by an assertion of fact' if that the claim is shown to be false. No } \\
\text { proof of harm is required. } \\
\text { e-Transactions Act (2016). The Act includes prohibitions against 'misleading } \\
\text { advertising', such as action against false claims made for medicinal products. Where } \\
\text { it relates to areas such as public health, restrictions on speech could be permitted by } \\
\text { Article } 19 . \\
\text { Access to Information Act (2020). Among other aspects, it prohibits officials provid- } \\
\text { ing 'false information with malice with an aim to injure another person'. Depending } \\
\text { how 'injuries' are understood, and proven, this may be permitted under Article 19. }\end{array}$ \\
\hline Niger & 6.5 .19 & $\begin{array}{l}\text { Cybercrime law (2019). Article } 31 \text { of this law makes it a crime to publish 'false news' } \\
\text { which is found to be likely to disturb public order or infringe on human dignity. } \\
\text { Article } 19 \text { would not permit restrictions on speech for affecting a field as broadly } \\
\text { framed as 'human dignity'. }\end{array}$ \\
\hline Nigeria & 6.5 .20 & $\begin{array}{l}\text { Criminal Code (1990). Section } 59 \text { makes it a crime to publish or reproduce 'any } \\
\text { statement, rumour or report which is likely to cause fear and alarm to the public or } \\
\text { to disturb the public peace, knowing or having reason to believe that such statement, } \\
\text { rumour or report is false.' This could be permitted under Article 19, if the public } \\
\text { peace is understood as synonymous with public order. } \\
\text { Electoral Act (2010) prohibits any false declaration of election results, or the publica- } \\
\text { tion of false statements about any candidates' character or claiming wrongly that a } \\
\text { candidate has withdrawn from any election. Although Article } 19 \text { does not specifically } \\
\text { refer to election-related misinformation, it would be accepted by many as a legitimate } \\
\text { concern under Article 19. } \\
\text { Cybercrimes (Prohibition, Prevention, etc.) Act (2015). Section } 24(\mathrm{~b}) \text { of the Act crimi- } \\
\text { nalised publishing online a message online known 'to be false, for the purpose of causing } \\
\text { annoyance, inconvenience, danger, obstruction, insult, injury, criminal intimidation, } \\
\text { enmity, hatred, ill will or needless anxiety to another.' Causing 'annoyance, 'inconven- } \\
\text { ience' 'insult' or 'needless anxiety' are not covered by Article 19. In 2020, the ECOWAS } \\
\text { Court declared this section violated Nigerians' right to freedom of expression and } \\
\text { ordered Nigeria to appeal or amend the section. At the time of writing it had not done so. } \\
\text { Broadcasting Code of Conduct (2016) requires broadcasters covering disasters and } \\
\text { emergencies to 'ensure the veracity and credibility of originating material and content' } \\
\text { and that 'fictional events or non-factual materials shall not be presented as real. No } \\
\text { proof of harm is required to make publication an offence. Falsity alone is enough. } \\
\text { How falsity should be proven is not made clear. }\end{array}$ \\
\hline
\end{tabular}




\begin{tabular}{|c|c|c|}
\hline Senegal & 6.5 .24 & $\begin{array}{l}\text { Code Penal. Article } 255 \text { criminalises publication of 'false news' that causes or may } \\
\text { cause civil disobedience, damage to public morale or the reputation of public institu- } \\
\text { tions. Article } 19 \text { does not permit restrictions on speech on grounds of causing harm } \\
\text { to as broadly framed a field as 'public morale. }\end{array}$ \\
\hline South Africa & 6.5 .25 & $\begin{array}{l}\text { Electoral Act of 1998. Section } 89 \text { sanctions officials or politicians who make inten- } \\
\text { tionally false statements that could adversely affect an election. Although Article } 19 \\
\text { does not specifically refer to election-related misinformation, it would be accepted by } \\
\text { many as a legitimate concern under Article } 19 \text {. } \\
\text { Regulation in } 2020 \text { related to Disaster Management Act (2002). Prior to 2016, no } \\
\text { specific media legislation related to false information. However, in 2020, during the } \\
\text { Covid-19 pandemic, regulations were issued in relation to the Disaster Management } \\
\text { Act, } 2002 \text {. Section 11(5) of the regulations made it a crime to publish any statement } \\
\text { 'with the intention to deceive any other person' about Covid-19, the infection status of } \\
\text { any person, or any measure taken by the government to address Covid-19. This could } \\
\text { be covered by Article 19. How the harms would be determined is not clear. }\end{array}$ \\
\hline Uganda & $\begin{array}{l}6.5 .30 \\
6.5 .31\end{array}$ & $\begin{array}{l}\text { Penal Code. Section } 171 \text { sets penalties of up to } 7 \text { years in prison for 'any act' that may } \\
\text { contribute to the spread of life-threatening diseases. This could be permitted under } \\
\text { Article } 19 \text {, as a public health matter, although responses would need to be proportion- } \\
\text { ate. How harms would be determined is not clear. } \\
\text { Witchcraft Act (1957) has been used to prosecute the broadcasting of fraud by people } \\
\text { claiming magical powers. Penalties for fraud of this type would be permitted restric- } \\
\text { tions on speech under by Article } 19 \text {. How else the Act might be used is unclear. } \\
\text { Schedule } 4 \text { of the Uganda Communications Act (2013) sets out the functions of the } \\
\text { UCC including prohibiting news broadcasts that show 'distortion of facts. How 'dis- } \\
\text { tortion of facts' should be proven is not made clear. No proof of harm is required to } \\
\text { make publication an offence. Falsity is enough. } \\
\text { Data Protection and Privacy Act, (2019) is used to prosecute false claims. No proof } \\
\text { of harm is required to make publication an offence. Falsity alone is enough. } \\
\text { Electoral laws updated in } 2020 \text { prohibit, among other things, 'offensive communica- } \\
\text { tion. This could be used in relation to false information. Although Article } 19 \text { does } \\
\text { not specifically refer to election-related information, if it applies to hate speech and/ } \\
\text { or false information that could disrupt an election, it would be accepted by many as a } \\
\text { legitimate concern under Article } 19 \text {. }\end{array}$ \\
\hline
\end{tabular}

Note: Information is drawn from our research and work of the Disinformation Tracker project. The list is not exhaustive. Highlighted entries are new or amended between 2016 and 2020. 


\section{EFFECTS OF LAWS AND REGULATIONS ON MISINFORMATION}

We set out in Section 2 the extent to which misinformation is both one part of and driven by the broader dysfunction of the information disorder. And in Section 3 and Section 4, we explain, first, five key ways that much of the existing or new legislation we have studied misses the declared target of deterring or reducing the circulation of false information, and then the failure of the laws and regulation we reviewed to address the question of how to best to reduce the harm that certain types of misinformation can cause. Having in Sections 5 and 6 detailed laws and regulations around the world and across Africa, we review in this section the legislation's actual effects.

\section{I. Set against the scale of the problem - direct effects of legal action minimal}

Measured against the numerous statements made to parliament or at public events by leaders across the continent every day, let alone the many millions of words broadcast and published, or posts uploaded online, the direct effects of the existing and new laws and regulations in place since 2016 on the flow of misinformation appear minimal.

Over the 6 months to 31 December 2019, 14 independent fact-checking organisations whose work is reviewed for the study of misinformation that is part of this series, investigated and reported on 1,219 examples of misinformation circulating in politics, traditional media, on social media and other channels in more than two dozen countries across the continent (Cunliffe-Jones, 2022b). Of these, 917 examples were found to be circulating in one or more of the 11 countries that are part of this study. At the time, no fact-checking organisations were operating regularly in 6 of the 11 countries we studied for this report ${ }^{93}$. Had there been regular operations in all countries and had the organisations working in the other countries studied been more fully staffed ${ }^{94}$, the number of examples identified would likely have been substantially higher. With small staffs and limited means: 'I feel we are seeing the tip of the iceberg' commented Sophie Nicholson, deputy chief editor of AFP FactCheck ${ }^{95}$.

93 As of the end of 2019, there were no fact-checking organisations identified as working regularly in Benin, Burkina Faso, Cote d'Ivoire, Ethiopia, Malawi or Niger.

94 Seven of the 14 organisations studied had five or fewer staff as of June 2020.

95 Interview with authors July 2020. 
Nevertheless, the number of claims identified by even these understaffed organisations run into the many hundreds and, by contrast, the Disinformation Tracker project set up in 2020 by a coalition of freedom of expression organisations including Article 19 and CIPESA ${ }^{96}$, identified a total of just 12 law enforcement actions (prosecutions, arrests or legal threats) ${ }^{97}$, launched between March and May 2020 against those accused of publishing or broadcasting 'false information' under the existing and new laws in 11 countries we have studied. Of these, only three cases in Kenya, South Africa and Uganda - related to an 'objectively legitimate aim', they found ${ }^{98}$. Even if the Disinformation Tracker project identified, for sake of argument, less than a quarter of the legal actions taken, their direct effects on the flow of misinformation is clearly minimal in scale compared to either the far larger flow of misinformation or the efforts of the fact-checkers ${ }^{99}$.

\subsection{Regulations are sometimes used against harmful misinformation}

It is important to note that laws and regulations have on occasion been used against potentially harmful misinformation. In 2018, the Ugandan Communications Commission, accused by many politically motivated judgements, suspended the broadcasting licences of 23 radio stations for 3 months for 'advertising witchcraft content' and 'aiding electronic fraud'. The stations had hosted programmes by

\section{See https://www.disinformationtracker.org. \\ 97 The actions identified were:}

Nine legal actions without an objective legal aim, according to the project: In Benin: 'Arrest of Casimir Kpedjo, April 2020'. Burkina Faso: 'No data on the enforcement of these laws in response to disinformation'. Cote d'lvoire: 'Newspaper directors fined, May 2020', 'Arrest of opposition leader, May 2020'. Ethiopia: 'Arrest of journalist Yayesew Shimelis, April 2020'. Kenya 'Arrest of [blogger] Robert Alai, March 2020'; Malawi: 'No data on the enforcement of these laws in response to disinformation'. Niger: 'Arrest of [journalist) Mamane Kaka Touda, March 2020'. Nigeria: 'Arrest of poet Rotimi Jolayemi, May 2020'. Senegal: 'Three individuals questioned for spreading false information, March 2020'. Uganda 'Arrest of Adam Odec, April 2020'.

Legal actions with an objective legal aim, according to the project: Kenya 'Arrest of Elijah Muthui Kitonyo, March 2020'. South Africa: 'Arrest of Stephen Birch, April 2020'. Uganda: 'Arrest of Pastor Augustine Yiga, March 2020.'

98 Note that the 12 law enforcement actions that Disinformation Tracker identified related specifically to alleged false information. Journalists and others are commonly arrested and detained on other grounds and those actions are not reflected in this list.

99 In an email in December 2020, researchers for the Disinformation Tracker project confirmed their finding but acknowledged they could not guarantee they had identified all possible examples of legal action taken in the II countries under the legislation in the period. 
self-proclaimed 'herbalists' - people claiming magical powers through the use of herbs - who promised audiences instant wealth or solutions to life's difficulties if the listeners paid money into the self-proclaimed herbalist's mobile money account. To 'prove' their trick would work, the scammers, who had paid the broadcasters for the privilege of going on air, would, for example, arrange for a caller to phone in who claimed to have paid the money and who would then suddenly 'find' a large amount of money under their bed. The UCC suspended the broadcasters' licences for 3 months and required them to reimburse the money lost by their listeners (Nassuna, 2018). Meanwhile in 2020 in South Africa, authorities took a man to court under Section 11(5) of the Disaster Management Act for posting videos online making false claims about the safety of the government's Covid-19 response. If believed, these claims might, have had harmful effects on public health (Hyman, 2020; Williams, 2020) ${ }^{100}$. These actions were also clearly taken against harmful or potentially harmful information.

\subsection{Regulations are used mainly against media, opposition politicians}

Nevertheless, as identified by Disinformation Tracker and others, the majority of actions taken by authorities under laws and regulations against 'false information' in the first half of 2020 focused on claims made by either opposition politicians or independent or pro-opposition journalists or bloggers. In Cote d'Ivoire, two newspaper editors were fined 2.5 million CFA Francs each in May 2020 for publishing statements by lawyers acting for an opposition politician previously jailed for publishing allegedly false information (AFP, 2020). In Nigeria, a journalist who sang a poem criticising the country's information minister was detained and charged with making false claims causing 'annoyance' to the minister (Sahara Reporters, 2020). In Uganda, regulators in 2019 ordered 13 TV and radio networks to suspend 39 news executives and producers they accused of 'unbalanced broadcasting, sensational, false and misrepresentative coverage' ${ }^{101}$ of the arrest of an opposition politician (RSF, 2019).

Of the legal enforcements identified by Disinformation Tracker as taken between March and May 2020, action was also taken against journalists or bloggers in Ethiopia, Kenya, Niger, Senegal and Uganda for publishing claims critical of the government. The analysts identified no action taken against pro-government journalists, government politicians or officials, business leaders or others known to have spread potentially harmful false information. Senior officials in Nigeria such as President Muhammadu Buhari's social media aide Lauretta Onochie, for example, suffered no sanction despite spreading pro-government false information online

100 At the time of writing, the trial was still awaiting completion.

I0I Considered a breach of Section 3 I of the Uganda Communications Act. 
about government programmes (Adebajo, 2019b; Vanguard, 2020). One analyst at a civil society organisation, who would only speak on grounds of anonymity, said that in Uganda: 'Self-censorship has increased in the recent past due to the state's continued arbitrary application of the law and violence against reporters and social media journalists. This points to a chilling effect on media freedom that is wider than the direct effect of action against particular examples of misinformation.

\subsection{Restrictions such as Internet shutdowns have potential harmful effects}

To restrict the flow of what they consider potentially unhelpful information ahead of elections and at times of feared unrest, governments across Africa have turned frequently in recent years to shutting down the Internet. Doing so, they have been part of a trend adopted by authoritarian governments around the world from Bangladesh, India and Sri Lanka, to Ecuador, Russia and Venezuela (Access Now, 2020; Article 19, 2019).

In Sri Lanka, as in other countries, given the potential of information online to provoke violence, and a lack of effective action by the tech firms, some commentators applauded these moves. 'What the Sri Lankan government did was authoritarian, but it is also probably what needed to be done to prevent social media from really throwing fuel onto this fire afterward, said Ankit Panda, senior editor at The Diplomat (Stewart, 2019).

However, research into the effects of Internet shutdowns on protests in India in 2016 by digital rights researcher Jan Rydzak suggests that blocking online access not only harms digital economies (CIPESA, 2017), deprives citizens of impartial news reports about events, and disconnects them from family members and friends. It may actually exacerbate unrest and violence, which the authorities say they wish to avoid (Rydzak, 2019a). After studying dozens of protests in Indian states where authorities shut the Internet down and others where they kept it on, Rydzak concluded that 'Under a blackout, each successive day of protest had more violence than would typically happen as a protest unfolded with continued Internet access... In no scenario were blackouts consistently linked to reduced levels of protest over the course of several days. Instead of curtailing protest, they seemed to encourage a tactical shift to strategies that are less orderly, more chaotic and more violent' (Rydzak, 2019b).

\subsection{Information standards for media, politicians could mitigate much harm}

Multiple studies worldwide have shown that much misinformation originates in three particular arena: (i) traditional media, (ii) online and social media and (iii) political settings and networks (Benkler et al, 2020; Brennan et al, 2020). This 
is confirmed in the study of misinformation that is part of this series (CunliffeJones, 2022b). False claims spread in traditional media - on television, radio and print media - for many reasons. They do so due, in part, to the effects on professional standards of the ownership and funding structures common across the sector (Ndlela \& Mano, 2020; Sanef, 2019). Online, the proliferation of both serious news sites and blogs and junk news operations has been both an opportunity for voices to be heard, and for good information and disinformation to spread. Meanwhile the role of global social media companies in incentivising and facilitating the sharing of content which emerges as misinformation has been widely documented. False online information often spreads further, and brings more reader engagement, than accurate information (Silverman, 2016). And in politics, where the competitive nature of political systems promotes the spread of misinformation, little is done either to penalise those who spread falsehoods or to promote honest debate. While countries such as the United Kingdom, South Africa and Kenya do have laws and codes of conduct aimed, in theory, at ensuring honesty from political leaders, these codes tend to be weakly enforced at best, in Africa or around the world. Moreover, while governments across the continent also have an obligation, under both international and national laws, to ensure the public has easy access to official information on public interest topics, this responsibility has, in practice, long been more ignored than respected (AFOIC, 2017; Corruption Watch, 2018; Cunliffe-Jones, 2022a).

Measures to solve entrenched structural problems in traditional media and politics are often mooted, as researchers note (Wasserman \& Benequista, 2017). They are rarely enacted. Situated at different ends of the continent, Senegal, South Africa and Malawi nevertheless provide examples of how different models of media regulation and engagement of civil society may prove more effective than most existing and recent legislation in reducing the harm misinformation can cause.

In Senegal, a new press code was introduced in 2017 after 8 years of negotiations with media organisations, creating a requirement for all news operations, including the sort of online news sites identified by fact-checkers as major sources of misinformation, to operate with a senior team with several years' experience operating to a strict professional code of journalism. Whether the introduction of the code will have a positive effect long term is yet to be seen. Mamadou Thior, chair of the media self-regulatory body CORED, argues that if implemented as intended 'news will be better verified before publication' than was previously the case ${ }^{102}$. Self-regulatory press codes are spreading on the continent (Sampaio-Dias et al, 2019) and in South Africa, the current Press Council, set up in 2007, intervenes in instances of misinformation that appear in the media, adjudicating on cases and

102 Interview Mamadou Thior, September 2020. 
often requiring the media to publish corrections. Ahead of the 2019 elections in South Africa, a media standards watchdog, Media Monitoring Africa, went further, setting up an online platform, Real411, to allow the public to alert them to examples of possible false election-related claims from journalists or politicians. The claims are then assessed and, if necessary, taken to the IEC which can, subject to appeal, order them to be taken down or corrected, a counter-narrative published or an apology made ${ }^{103}$. Meanwhile, in 2016, authorities in Malawi introduced a new law, the Communications Act, obliging broadcasters to air 'counter-versions' from 'entities affected by an assertion of fact' if that entity claims the fact is false. The long-term effects of such information standards are yet to be seen but, we argue, combined with measures enabling the growth of fact-checking initiatives, regulation of tech companies on the basis of transparent standards based in international law, and codes of conduct promoting honesty among politicians, could achieve more than is achieved by current laws and regulations. 


\section{ACCESS TO INFORMATION AS RESPONSE TO MISINFORMATION}

As we set out in Section 2, the failure of authorities around the world to ensure easy public access to accurate information on important topics plays a major role in undermining the public's understanding of important public affairs. The lack of public access to reliable information both helps misinformation to flourish and makes efforts to counter false information less effective (Cunliffe-Jones, 2022a, 2022b; Golebiewski \& Boyd, 2019; Kainja, 2020; Shane \& Noel, 2020). For this reason, while acknowledging the important role of other factors in undermining understanding (Duffy, 2018; Vicol, 2020), any strategy to reduce the spread of harmful misinformation needs to address the problems of the wider information disorder, and not simply respond to misinformation alone.

\section{I. Access to information across Africa - in law and in practice}

A review of access to information laws in Africa by the Open Democracy Advice Centre, published in 2018, found that the number of countries with access to information laws in place had risen from 7 out of 12 it studied in 2015 to 10 out of 12 two years later. The remaining two countries, Madagascar and Namibia, had new bills under consideration the study found (Corruption Watch, 2018) ${ }^{104}$. In Senegal, Amadou Kanouté, spokesman for the Ministry of Culture and Communication acknowledged in 2020 Senegal did not have a law guaranteeing access to information, although it is required by the constitution. But Mamadou Thior, chair of the media self-regulatory body, CORED, said his organisation was now working with the ministry on such legislation ${ }^{105}$.

While the increase in the number of access to information laws in place on the continent is clear (AFEX 2017), application of the laws in practice remains often inconsistent and weak, the ODAC study showed. In South Africa, an independent Office of the Information Regulator ${ }^{106}$ was set up in 2016 to both protect the privacy of personal data and oversee public access to information but few other countries had similar measures in place. Among other effects, the lack of access to accurate information online or offline to check claims against was identified in a

104 In 20 I5, Kenya, Madagascar, Malawi, Namibia and Tanzania had no such laws in place, but did have access to information bills under consideration, the study said In 2017, Cote d'Ivoire, Kenya, Malawi, Mozambique, Niger, Nigeria, South Africa, Tanzania, Uganda and Zimbabwe had access to information laws in place, the study found.

I05 Interviews Amadou Kanouté and Mamadou Thior September 2020.

106 https://www.justice.gov.za/inforeg. 
survey of African fact-checking organisations as the biggest single challenge they face in their work (Cunliffe-Jones, 2022a). Implementation of the laws in practice would help both reduce the flow of false claims, many of which are caused by lack of access to reliable information, and support efforts to reduce misinformation spread and effects.

\subsection{Steps authorities could take to improve access to accurate information}

The first hurdle to ensuring public access to reliable information is ensuring that reliable information is collected in the first place. In 2012, the fact-checking organisation Africa Check was asked to check a claim that South African officials had overstated the percentage of children who had received all the mandated childhood vaccines by the age of 12 years ${ }^{107}$. As the researcher found, the governmentrun vaccination programme had announced a high official figure but accepted that there were 'data quality issues' with its information. The data it used was often 'poor and unreliable', with districts using 'old data collection tools that are not updated' and 'no consistency in the data tools used in the same district', while often 'data is not verified and monitored by supervisors', the officials admitted (Dyosop, 2012). Without reliable data available, it was not possible for officials to present a reliable picture: a major cause of misinformation.

Proper funding, training and support for those responsible for gathering and analysing official data are essential to improving the flow of reliable information and reducing the spread of false information. Even in relatively well-resourced countries such as South Africa, funding for statistics and data programmes is often in short supply, the budget for a statistical survey of income and poverty cut due to the effects of the Covid-19 pandemic on government finances (Wilkinson, 2020). The independence of statistics organisations from political, commercial and other authorities is also critical. In countries such as the United Kingdom, that is assured by the independent statistics regulator, which oversees the standards of statistics and periodically publicly rebukes government and opposition politicians for misleading statistical claims, but such independent self-regulation of statistics is not widely known (Jerven, 2013).

\subsection{Enabling media and civil society to act against misinformation}

Strong, independent media can help push back against false narratives found in biased media and public debate. Alongside traditional media, specialist

107 Disclosure, one of the co-authors of this report was Africa Check Director at the time of the report. 
fact-checking organisations have a role to play. In Africa, the number of factchecking organisations operating has grown since the first was founded in 2012 to more than a dozen by late 2020 (Cunliffe-Jones, 2022a). This nevertheless left the majority of sub-Saharan countries without any such initiatives focussed specifically on identifying and disproving potentially harmful false claims without curbing freedom of expression. Many who would set up such organisations are hampered by a hostile environment created for independent media operations by the authorities.

However, as noted above, where they are allowed to operate, non-partisan factchecking and independent media organisations provide a constructive response to far more examples of false information, via their work, than regulations introduced by governments not penalising but correcting false claims. The environment that has enabled this to happen has, in part, been facilitated by a move towards more liberal media regulation regimes in a majority of countries (Sampaio-Dias et al, 2019). The creation and sustaining of this enabling environment is essential to any real drive to reduce the circulation of and harm caused by false information. The drivers and effects of this work are explored in more detail in another report in this series, examining the growth and role of fact-checking organisations on the continent over the past decade (Cunliffe-Jones, 2022a). 


\section{CONCLUSIONS AND RECOMMENDATIONS}

We sought in this report to answer two fundamental questions set out at the beginning. First, what changes took place to laws and regulations governing media and information 2016 to 2020 in the 11 sub-Saharan countries studied, and second, what effects this had on the circulation of misinformation, harmful or otherwise and on freedom of speech and the media.

Our research found that, in the 5 years since 2016, 10 of the 11 sub-Saharan countries we surveyed for this report introduced or amended laws or regulations penalising publication or broadcast of information authorities declare 'false', seizing on legitimate concerns about the harms that misinformation and disinformation can cause, to almost double the number of laws or regulations in place from 17 to 31 .

We also found that while many existing and new laws and regulations have a chilling effect on media freedom and public debate, they also miss the declared target of reducing the harm caused by false information, failing to address the harm misinformation causes in an effective or proportionate manner or on an effective scale. One third of laws studied penalise publication of information declared 'false' regardless of whether or not it caused or risked harm. Almost half the new or existing laws thus restrict freedom expression in fields not agreed by international law. And a review of legal enforcement actions undertaken against 'false' information in 11 countries, found only three instances in 3 months where objectively legitimate punitive action was taken. By contrast, fact-checking organisations operating in half of the sample countries published more than 900 reports, identifying, correcting and - through partnerships with tech firms - reducing the circulation of false information.

While our study has focused on laws related to 'false information' in Africa, we argue the approach we have taken - examining the terms and effects of regulatory frameworks for countering false information against what is known empirically and in theory of misinformation types, drivers and effects - is one that is replicable worldwide. It can help distinguish between regulatory approaches aimed at partisan social or political objectives, that do little to reduce harm, and effective approaches, reducing harm without curbing legitimate speech.

\section{I. To curb the harm misinformation causes we need to understand it}

It is evident from numerous studies, including the study of misinformation that is part of this series, that different types of misinformation cause or contribute to a range of harmful effects or potential effects on individuals and societies. It is important, if for this reason alone, for society to address the challenge misinformation 
poses. At the same time, given the harms caused by restrictions on freedom of speech, it is important to do so without undermining freedom of speech legitimate in international law. To achieve this, it is necessary for laws and regulations to take account of the complex nature of misinformation: its different types, who creates and spreads it, what drives this process, the actual and potential harms it does and does not cause, and the most effective way of countering it.

The study of misinformation that is part of this series shows that a substantial share, perhaps more than one in four of examples of information that independent fact-checkers across Africa identify as false information, appear to cause no harm or plausible risk of harm (Cunliffe-Jones, 2022b). There would thus be no justification in international law for those who publish it to face any sanction. And yet, almost a third of the existing and new laws in place today in the 11 countries studied enable authorities to penalise the publication of information on grounds of falsity alone.

For authorities to achieve their declared goal of reducing the circulation of harmful misinformation, without violating international laws on freedom of expression, it is thus necessary, we argue, to adopt an entirely new approach, based on a proper, evidence-based understanding of the types, drivers and effects of misinformation, the distorted focus of information and the lack of access to accurate information, an approach aimed at enabling the media and information environment to counter these effects.

\subsection{Legislation in II countries against 'false' information doubled 2016-2020}

As we set out above, 8 of the 11 countries studied for this report already had legislation or regulations in place providing often harsh penalties for publication or broadcast of what authorities claimed to be 'false' information, long before concern about misinformation surged worldwide in 2016. Some, such as the 1957 Ugandan Witchcraft Act or elements of the penal or criminal codes in Kenya or Malawi, dated to the colonial era. Ethiopia and Uganda had the highest number of laws and regulations related to 'false' information. In the case of South Africa, regulation was restricted to Section 89 of the Electoral Act of 1998, prohibiting, at least in theory, politicians and officials from making certain forms of false claims about their opponents in elections. Only three countries studied, Benin, Burkina Faso and Niger, had no legislation against false information in place, excluding laws related to defamation.

In the 5 years after 2016, the number of laws and regulations on the statute books almost doubled. As of the end of 2020, all 11 countries studied have legislation or 
regulations in place penalising publication or broadcast of false information. Ten of the 11 countries - Benin, Burkina Faso, Cote d'Ivoire, Ethiopia, Kenya, Malawi, Niger, Nigeria, South Africa and Uganda - introduced or amended legislation or regulations between 2016 and 2020, many with harsh penalties. The total number of regulations or laws in the 11 countries against 'false' information rose 17 from to $31^{108}$.

\subsection{Laws and regulations miss the declared target, hit media freedom}

What matters more than the number of acts or regulations is their effects, if any, on the flow of misinformation, harmful or otherwise, and on freedom of speech and of the media. As we set out above, legislation and regulations can and have been used in a few cases to penalise, the publication of types of misinformation causing clear specific harm. This has occurred in instances of fraud in Uganda and potential harms to public health in South Africa. However, as we set out above and summarise below, the majority of the laws and regulations reviewed miss the declared target of deterring or reducing the circulation of potentially harmful false information.

\subsection{LAWS AND REGULATIONS FAIL TO ADDRESS TYPES AND DRIVERS OF MISINFORMATION}

First, we identified five ways in which the terms of the legislation and regulations fail to address many of the types and drivers of potentially harmful misinformation:

(i) The laws and regulations we reviewed address information as being either true or false when most misinformation in fact contains elements of both true and false information. If restricted to addressing wholly false information, the legislation thus risks failing to provide a response to harmful information that is, for example, accurate in a narrow sense but misleading. If interpreted broadly, the legislation risks applying sometimes heavy sanctions to publication of information that may be at least partly if not wholly true.

(ii) Almost one third of the laws we reviewed penalise publication of information said to be false on grounds of falsity alone. Other laws

108 Given the timescales, it was not possible for us to review all regulation or legislation already in place in each country studied as of 2016, and we recognise of course that there may be examples we have missed. This includes, for example, legislation and regulation related to claims of false information in important but more specific or niche areas such as regulations around the claims of pharmaceuticals firms in advertisements or product labels. We believe we have, however, captured most areas where legislation or regulation was changed. 
penalise publication of allegedly false information on topics not covered by international law on freedom of expression.

(iii) Most laws or regulations we reviewed focus on misinformation created and/or spread via traditional and social media and thus fail to address the circulation of misinformation in many other channels, from parliament to product labels, thus failing to address much potentially harmful misinformation.

(iv) By focusing on misinformation created by traditional media, or other actors on social media, these laws fail to address the important role of government, religious and traditional leaders in creating false information offline and outside the media. This again leads legislation to miss its declared target of reducing harms caused by misinformation.

(v) Most laws or regulations we reviewed fail to address the diverse set of factors - from political to financial motivations, misunderstandings and the lack of access to accurate information - that drive the creation or spread of misinformation and thus fail to reduce the causes of misinformation.

\subsubsection{NO PROOF OR STANDARD OF PROOF OF HARM REQUIRED, HIT PARTISANTARGETS}

Second, we show in the report that the majority of laws and regulations we reviewed either require no proof that any type of actual or potential harm was caused or risked by the false information, in order to make its publication or broadcast an offence, or, where they do so, set out no proper standard of how such harm should be proven and weighed. Ten out of 31 examples of legislation or regulations we examined require no proof of any harm caused in order to penalise publication of what authorities deem false. Four laws or regulations focused on alleged harms not recognised by Article 19 as legitimate reasons to restrict freedom of expression and most of the remainder set no standards for proving harm. At the same time, the study of misinformation that is part of this series shows, first, that a substantial share of information identified as false or misleading by fact-checkers causes no identifiable harm, and second, that actual or potential harm can occur but is difficult to prove. Our review suggests the targets chosen for action under these laws are often driven by partisan political considerations.

\subsubsection{ACTIONS TAKEN DO NOT MATCH THE MASSIVE SCALE OF MISINFORMATION}

Third, we show that, while the actual and feared effects of the laws they create do curb media and political freedoms, actions taken under the legislation or are on a 
tiny scale when compared to the huge volume of harmful, or potentially harmful, false information found circulating online, on TV, radio or in print media, in parliaments, at public events, and in statements put out by traditional, religious, business and civil society leaders across a continent. In the 11 countries we surveyed, the project Disinformation Tracker identified for the months March to May 2020 a total of 12 legal actions taken over what authorities alleged was 'false information', only three of which were potentially legitimate actions. The tiny scale of actions taken contrasts with the scale of misinformation and the limited (if larger) extent of work undertaken by media and fact-checking organisations, and the potential of others including tech firms to act, countering misinformation on the continent (CunliffeJones, 2022a).

\subsubsection{INTERNET SHUTDOWNS MAY EXACERBATE TENSIONS AND UNREST}

Fourth, we noted research findings that Internet shutdowns, used frequently by governments across Africa to curb protests in the run up to elections or at times of social tension (Access Now, 2020), may exacerbate both the misinformation and the unrest they are intended to quell. The research suggests that blocking online access not only causes economic harms and disconnects citizens but may also exacerbate unrest and violence (Rydzak, 2019b). This is coherent with the work of Golebiewski and Boyd, Shane and Noel and the study in this series on drivers of misinformation, all of which suggest that the lack of access to sources of reliable information helps drive rumour and misinformation, to actual or potential harmful effect (Cunliffe-Jones, 2022b; Golebiewski \& Boyd, 2019; Shane \& Noel, 2020).

\subsubsection{EFFECTIVE INDEPENDENT REGULATION, ENABLING OF CIVIL SOCIETY AND MEDIA, AND ACCESS TO RELIABLE INFORMATION}

Fifth, we propose that the most effective means of reducing harm caused by misinformation would be to enable, on the one hand, independent, transparent, standards-based regulation of media, tech companies and political debate to drive up the accuracy of information in the public arena, and, on the other hand, to improve public access to accurate information. Every honest appraisal of traditional media, online and social media and politics across Africa, and the world, recognises that misinformation originates in all three sectors. We provide examples of steps taken by regulators and civil society in Senegal, South Africa and Malawi to tackle the problems misinformation can cause. We set out below recommendations for regulation of all three sectors based on three principles: (i) a function of regulation should be to enable and support independent media and civil society to fairly scrutinise and report on events and claims made in public debate; (ii) regulation of media, political behaviour and social media should be independent of partisan political and commercial interests, in line with the principles agreed in 
international law, and based on evidence; (iii) the best way to render false information harmless is to improve access to accurate information.

\subsection{Recommendations}

We write from the point of view that free expression is a fundamental right, access to trustworthy information is as vital, and the problems caused by and leading to misinformation should not be used as cover for stifling free expression. We recognise the role of the state and the importance of regulation because governments have the ability to standardise, scale and implement in a way that civil society organisations do not. We argue that, to reduce the actual and potential harm caused by misinformation, without infringing unnecessarily on freedom of expression, governments and regulators should:

\subsection{Improve public access to and quality of information of public interest by}

(i) Ensuring proper funding and independent management of statistics agencies to improve the quality of information gathered on topics of public interest

(ii) Setting up an independent, non-partisan statistics regulator to both certify the quality of public statistics and publicly report on any abuse of public statistics by public figures

(iii) Setting up and empowering an independent regulator of information, with powers to both ensure and report publicly on the state of (i) protection of the privacy of personal data and (ii) public access to information on topics of public interest ${ }^{109}$

\subsection{Revise regulation of 'false information' by}

(i) Repealing or amending legislation that penalises the publication or broadcast by traditional (TV, radio, print and online) news media of information on grounds of its accuracy or falsity to ensure that any penalties are both (i) proportionate and (ii) only applied where publication or broadcast of that information can be proven according to publicly set out criteria to have caused substantial harm or plausibly risked imminent

109 Of the countries in our study, SA is the only country to have implemented a GDPR-style law, the Protection of Personal Information Act (POPIA). In Kenya, a Data Commissioner is yet to be appointed but the digital governance community is strong and expected to be bolstered by a legal framework. 
harm to individuals or society in the fields set out in Article 19 of the rights or reputations of others, public health or public order

(ii) Requiring publicly owned or -controlled news broadcasters and other public news media to provide fair space in their coverage for minority and opposition voices and uphold the highest standards of accuracy in their own reporting

(iii) Putting in place laws, like those in France, to help protect journalists, particularly women, covering controversial topics from online harassment, as recommended by the OSCE and the IPI and the Rabat Plan of Action on hate speech, while following international principles on freedom of expression

(iv) Requiring independently owned or controlled news media (TV, broadcast, print or online) to publicly disclose their ownership structure and provide details of political and commercial interest advertising and financing, to ensure due transparency

(v) Putting in place a system of media regulation, independent of government, commercial or sectarian interests, regulating the media according to professional standards agreed with the sector, with the powers to enforce those standards

(vi) Recognising that substantial actual and potential harms can be caused to individuals and society by false or misleading claims made through false claims from the business world, and ensure that existing agencies such as drug agencies and advertising authorities are funded and empowered to ensure that claims made by companies in their labels, advertising and statements are accurate and cause no risk of harm

\subsection{Agree codes of conduct that promote honesty in political debate by}

(i) Putting in place elements in a parliamentary code of conduct empowering non-partisan parliamentary authorities to require any member of parliament or minister found to have intentionally or unintentionally mislead the assembly on a point of fact to correct their statement

(ii) Ensuring the electoral law prohibits politicians and political parties from making factually inaccurate claims about their rivals, and provide 
the independent electoral authority with the powers to ensure that any such inaccurate statements are corrected and withdrawn

(iii) Provide the independent electoral authority with the power to monitor claims made widely in public debate during election campaigns and ensure that, where they can be shown to be both factually inaccurate and materially distorting of public understanding, those claims be corrected and withdrawn

\subsection{Partner with others to regulate tech firms to publicly agreed standards - by}

Recognising that the major technology companies are global operations, governments should engage with governments across the continent and around the world to bring pressure to bear on the existing and new dominant companies to:

(i) Provide substantially greater public transparency related to both the principles and practice of enforcement of content moderation policies for information that is found to be false or misleading, based on principles agreed in Article 19

(ii) Provide substantially greater public transparency on the algorithms used to rank and disseminate information so that the public, government and regulators know the criteria being used. French laws on algorithmic transparency could be a model. ${ }^{110}$ Meet a consistent industry-agreed, publicly declared set of standards encouraging users to consider and understand information before they post or share it

(iii) Learn from the effects of models tried by Australia, France and elsewhere in 2020/2021 either using taxation of technology companies to help fund public service media or using competition law to require firms to pay directly for the news they circulate, in ways that help support the supply of quality public service news

For this to have effect, we recognise it needs debate in policy-making institutions at national, sub-regional, regional and international fora - from national commissions on misinformation to debates in regional and global bodies. We are happy to engage in any such debate.

I 10 For more information see https://www.isdglobal.org/isd-publications/algorithm-inspection-and -regulatory-access 


\section{BIBLIOGRAPHY}

Aboubacar, S. (2019). Plainte de Sani Issoufou Mahamadou Contre Samir Sabou - les précisions de Me. Yacouba Boulama. Niger Inter. https://nigerinter.com/2020/06/plainte-de-sani -issoufou-mahamadou-contre-samira-sabou-les-precisions-de-me-yacouba-boulama

Access Now. (2020). Targeted, cut off, and left in the dark: how internet shutdowns became an even greater threat to human rights in 2019. https://www.accessnow.org/keepiton-2019-review

Adebajo, K. (2019a). No, it's not true Nigeria has recorded only 18 convictions in rape cases. ICIR. https://www.icirnigeria.org/fact-check-no-it-isnt-true-nigeria-has-recorded-only-18 -convictions-in-rape-cases

Adebajo, K. (2019b). Fact-Check: The many social media lies of Lauretta Onochie, President Buhari's aide. ICIR. https://www.icirnigeria.org/fact-check-many-social-media-crimes -president-buhari-social-media-aide

Adegboyega, A. (2020). Criticisms as Nigeria's new broadcasting code targets internet TV, radio stations. Premium Times. https://www.premiumtimesng.com/news/top-news/410641-criti cisms-as-nigerias-new-broadcasting-code-targets-internet-tv-radio-stations.html

Adegoke, Y. (2018). Like. Share. Kill. Nigerian police say false information on Facebook is killing people. BBC Africa Eye. https://www.bbc.co.uk/news/resources/idt-sh/nigeria_fake_news

AFEX. (2017). List of African countries that have passed access to information laws. African Freedom of Expression Exchange. https://www.africafex.org/access-to-information/22-african -countries-that-have-passed-access-to-information-laws

AFOIC. (2017). The State of the Right to Information in Africa Report 2017. Africa Freedom of Information Centre. https://africafoicentre.org/download/the-state-of-the-right-to-infor mation-in-africa-report-2017

AFP. (2020). Cote d'Ivoire: deux journaux condamnés pour fausses informations. https://fr .africanews.com/2020/03/31/cote-d-ivoire-deux-journaux-condamnes-pour-fausses-infor mations

Africa Times. (2019). Facebook expands fact-checking to 15 African nations. https://africatimes .com/2019/10/10/facebook-expands-fact-checking-to-15-african-nations

Akinwotu, E. (2019). Whose Truth? Disinformation and misinformation online in Nigeria. West Africa Insight, 7(1). https://media.africaportal.org/documents/Keeping-Track-in-2019 -January-Edition_web.pdf

Amnesty International. (2020a). Bénin. Au moins 17 personnes poursuivies en moins de deux ans. https://www.amnesty.org/fr/latest/news/2020/01/benin-au-moins-personnes-poursuivies -en-moins-de-deux-ans

Amnesty International. (2020b). Niger. La loi sur la cybercriminalité est un instrument de répression des voix dissidentes. https://www.amnesty.org/fr/latest/news/2020/05/niger-la -loi-sur-la-cybercriminalite-est-un-instrument-de-repression

Amobi, T. (2020). Monitoring health misinformation in Nigeria - A collection of potentially harmful claims from October to December 2019. Africa Check. https://africacheck.org 
/wp-content/uploads/2020/05/Africa-Check-Health-Misinformation-in-Nigeria_Quarterly -report-1_January-2020.pdf

Ananny, M. (2018). The partnership press: Lessons for platform-publisher collaborations as Facebook and news outlets team to fight misinformation. https://www.cjr.org/tow_center _reports/partnership-press-facebook-news-outlets-team-fight-misinformation.php

Apuke, OD, Apollos, NI. (2017). Public perception of the role of Facebook usage in political campaigns in Nigeria. International Journal of Community Development \& Management Studies, 1, 85-102. https://www.informingscience.org/Articles/v1p085-102Apuke4069.pdf

Article 19 of the Universal Declaration of Human Rights. (1966). https://www.ohchr.org/en /professionalinterest/pages/ccpr.aspx

Article 19. (2019). Africa: Increasing internet shutdowns and media banks limiting access to information. https://www.article19.org/resources/africa-increasing-internet-shutdowns-and -media-bans-limiting-access-to-information

Aryan, A. (2021). Gov't pulls up Twitter: 'Differential treatment on Capitol Hill, Red Fort'. The Indian Express. https://indianexpress.com/article/india/capitol-hill-red-fort-violence-govt -pulls-up-twitter-7183557

Aufderheide, P. (1993). A report of the national leadership conference on media literacy. https: //files.eric.ed.gov/fulltext/ED365294.pdf

Bahree, M. (2019). India's new rules to govern social media raise fears of more censorship. Forbes. https://www.forbes.com/sites/meghabahree/2019/01/22/indias-new-rules-to-govern -social-media-raise-fears-of-more-censorship

Bajo, C. (2019). Fake news and censorship in Africa. Cultural Research and Innovation. http: //lab.cccb.org/en/fake-news-and-censorship-in-africa

Barr, C. (2011). Ethiopia uses anti-terror laws to silence critical journalists. The Guardian. September 2011. https://www.theguardian.com/media/greenslade/2011/sep/29/press-freedom-ethiopia

Barrett, D. (2014). Watchdog strips official status from police crime figures. Daily Telegraph. https: //www.telegraph.co.uk/news/uknews/crime/10574424/Watchdog-strips-official-status -from-police-crime-figures.html

Bazelon, E. (2020). The First Amendment in the age of disinformation. New York Times. https: //www.nytimes.com/2020/10/13/magazine/free-speech.html

BBC News. (2018). Germany starts enforcing hate speech law. https://www.bbc.co.uk/news /technology-42510868

BBC News. (2019). Facebook bows to Singapore's 'fake news' law with post 'correction'. https: //www.bbc.co.uk/news/world-asia-50613341

BBC News. (2020). Online Harms bill. Warning over 'unacceptable delay'. https://www.bbc .co.uk/news/technology-53222665

Benkler, Y, Tilton, C, Etling, B, Roberts, H, Clark, J, Faris, R, Kaiser, J, Schmitt, C. (2020). Mail-In Voter Fraud: Anatomy of a Disinformation Campaign. Berkman Klein Center, Harvard University. https://cyber.harvard.edu/publication/2020/Mail-in-Voter-Fraud-Disinformation-2020 
Bonny, A. (2019). La cybercriminalité officiellement pénalisée au Niger. CIO-Mag. https://cio -mag.com/la-cybercriminalite-officiellement-penalisee-au-niger

Boseley, S. (2008). Mbeki AIDS policy 'led to 330,000 deaths'. The Guardian. https://www.the guardian.com/world/2008/nov/27/south-africa-aids-mbeki

Bradshaw, S, Neudert, LM, Howard, PN. (2018). Government responses to malicious use of social media. Stratcom NATO. https://www.stratcomcoe.org/government-responses-mali cious-use-social-media

Breland, A. (2019). The bizarre and terrifying case of the 'deep fake' video that helped bring an African nation to the brink. Mother Jones. https://www.motherjones.com/politics/2019/03 /deepfake-gabon-ali-bongo

Brennan, JS, Simon, F, Howard, PN, Nielsen, RK. (2020). Types, Sources, and Claims of COVID-19 Misinformation. Reuters Institute for the Study of Misinformation. https://reu tersinstitute.politics.ox.ac.uk/types-sources-and-claims-covid-19-misinformation

Britain Thinks \& Full Fact. (2020). Research into British views on truth and untruth in the 2019 general election. https://britainthinks.com/pdfs/Full-Fact_election_research_report_final _version.pdf

Brodie, N. (2019). Using Mixed-Method Approaches to Provide New Insights into Media Coverage of Femicide. University of the Witwatersrand. http://wiredspace.wits.ac.za/handle $/ 10539 / 29294$

Burke, J, Harding, L. (2019). Documents suggest Russian attempt to sway South Africa election. The Guardian. https://www.theguardian.com/world/2019/may/08/documents-suggest -russian-plan-to-sway-south-africa-election

Busari, S, Adebayo, B. (2020). Nigeria records chloroquine poisoning after Trump endorses it for coronavirus treatment. CNN. https:/edition.cnn.com/2020/03/23/africa/chloroquine -trump-nigeria-intl/index.html

Cable, Jack, Grossman, S, Adewoye, Y. (2020). An Investigation Into Domestic Nigerian Social Media Financial Scams. Stanford Internet Observatory. https://cyber.fsi.stanford.edu/io /news/binomo-trading-scam

Cadwalladr, C. (2017). The Great British Brexit robbery. How our democracy was hijacked. The Guardian. https://www.theguardian.com/technology/2017/may/07/the-great-british-brexit -robbery-hijacked-democracy

Cadwalladr, C. (2018). Cambridge Analytica's ruthless bid to sway the vote in Nigeria. The Guardian. https://www.theguardian.com/uk-news/2018/mar/21/cambridge-analyticas -ruthless-bid-to-sway-the-vote-in-nigeria

Cahlan, S. (2020). How misinformation helped spark an attempted coup in Gabon. Washington Post. https://www.washingtonpost.com/politics/2020/02/13/how-sick-president-suspect-video -helped-sparked-an-attempted-coup-gabon/

Cardoso, PH, Marques, A. (2017). Multidão tenta linchar casal após boato de sequestro em WhatsApp. Globo. 5 April. http://g1.globo.com/rj/regiao-dos-lagos/noticia/2017/04/multidao -cerca-carro-e-tenta-linchar-casal-suspeito-de-sequestrar-crianca.html 
Chee, FY. (2020). Facebook, Google, Twitter urged by EU to do more against fake news. Reuters. https://uk.reuters.com/article/us-eu-tech-disinformation/facebook-google-twitter-urged -by-eu-to-do-more-against-fake-news-idUKKBN2610GU

Cheeseman, Nic, Lynch, G, Willis, J. (2018). Claims about Cambridge Analytica's role in Africa should be taken with a pinch of salt. The Conversation. https://theconversation.com/claims -about-cambridge-analyticas-role-in-africa-should-be-taken-with-a-pinch-of-salt-93864

CIPESA. (2017). Economic Impact of Internet Disruptions in Sub-Saharan Africa. (Collaboration on International ICT Policy for East and Southern Africa - CIPESA). https://cipesa .org/2017/09/economic-impact-of-internet-disruptions-in-sub-saharan-africa

Cissé, C. (2018). Macky Sall en croisade contre les «fake news». Actusen. https://actusen.sn/cere monie-de-remise-de-prix-aux-laureats-du-concours-general-2018-macky-sall-en-croisade -contre-les-fake-news/

Conroy-Krutz, J. (2019). African governments are cracking down on the news media. And their citizens might be okay with that. Afrobarometer. https://www.afrobarometer.org/blogs /african-governments-are-cracking-down-news-media-their-citizens-might-be-okay

Conroy-Krutz, J, Appiah-Nyamekye Sanny, J. (2020). Africans are concerned about ills of social media but oppose government restrictions. The Conversation.https://theconversation .com/africans-are-concerned-about-ills-of-social-media-but-oppose-government-restric tions- 137653

Corpus Ong, J. (2021). Southeast Asia's Disinformation Crisis: Where the State is the Biggest Bad Actor and Regulation is a Bad Word. Social Science Research Council. https://items.ssrc.org /disinformation-democracy-and-conflict-prevention/southeast-asias-disinformation-crisis -where-the-state-is-the-biggest-bad-actor-and-regulation-is-a-bad-word

Corruption Watch. (2018). Access to Information in Africa - Highs and Lows. https://www.cor ruptionwatch.org.za/african-access-information-law-good-implementation-not

Crook, J. (2017). Facebook will never take responsibility for fake news. https://techcrunch.com /2017/03/19/facebook-will-never-take-responsibility-for-fake-news

CSC - Conseil Supérieur de la Communication (2015). Délibération du 2 mars 2015.' http: //www.csc-niger.ne/images/docs/Deliberations/del_2_2mar15.PDF

Cunliffe-Jones, P, Zommer, L, Moy, W, Makgato, N. (2019). How Fact-Checking Can Win the Fight Against Misinformation. Project Syndicate. October 17, 2019. https://www.project -syndicate.org/commentary/fact-checking-in-post-truth-world-by-peter-cunliffe-jones-et -al-2019-10?barrier=accesspaylog

Cunliffe-Jones, P. (2022a, projected). The rise of fact-checking in Africa. University of Westminster Press.

Cunliffe-Jones, P. (2022b, projected). Types, drivers and effects of misinformation in Africa. University of Westminster Press.

Cunliffe-Jones, P, Gaye, S, Gichunge, W, Onumah, C, Pretorius, C, Schiffrin, A. (2021). The State of Media Literacy in Sub-Saharan African 2020 and a Theory of Misinformation Literacy. In Misinformation Policy In Sub-Saharan Africa: From Laws and Regulations to Media Literacy. University of Westminster Press. DOI: https://doi.org/10.16997/book53.a 
Cunningham, A. (2019). The Nigerian government's war on social media. The Article.com. https://www.thearticle.com/the-nigerian-governments-war-on-social-media

Dahir, AL. (2017). Fake news is already disrupting Kenya's high-stakes election campaign. Quartz Africa. https://qz.com/africa/1011989/fake-news-and-misinformation-are-upstaging -kenyas-forthcoming-high-stakes-election

Dahir, AL. (2018). 'We'd stage the whole thing': Cambridge Analytica was filmed boasting of its role in Kenya's poll. Quartz Africa. https://qz.com/africa/1233084/channel-4-news-films -cambridge-analytica-execs-saying-they-staged-kenya-uhuru-kenyatta-elections

DakarActu. (2020). Brigade de recherches. Pékh accuse la presse, Selbé Ndom et Gane Mésséré convoqué. https://www.dakaractu.com/BRIGADE-DE-RECHERCHES-Pekh-accuse-la-presse -Selbe-Ndom-et-Gane-Messere-convoques_a185417.html

Darnton, R. (2017). The True History of Fake News. New York Review of Books. https://www .nybooks.com/daily/2017/02/13/the-true-history-of-fake-news

de Souza Abreu, J. (2018). Disrupting the disruptive: Making sense of app blocking in Brazil. Internet Policy Review, 7(3), 1-16. https://policyreview.info/articles/analysis/disrupting -disruptive-making-sense-app-blocking-brazil

DiResta, R. (2020). Social Media Fact-Checking Is Not Censorship. Slate. https://slate.com/tech nology/2020/06/twitter-fact-checking-trump-misinformation-censorship.html

Douek, E. (2020). What Does 'Coordinated Inauthentic Behavior’ Actually Mean?. Slate. https: //slate.com/technology/2020/07/coordinated-inauthentic-behavior-facebook-twitter.html

Duffy, B. (2018). The Perils of Perception: Why We're Wrong About Nearly Everything. Atlantic Books.

Dyosop, N. (2012). Flawed data undermines SA claims on vaccination coverage. Africa Check. https://africacheck.org/reports/flawed-data-undermines-sa-claims-on-vaccination -coverage

Eburnie.com. (2018). Fake news: une loi pour rien en Côte d'Ivoire? http://eburnietoday.com /fake-news-une-loi-pour-rien-en-cote-divoire

Ellis-Peterson, H. (2018). Facebook admits failings over incitement to violence in Myanmar. https://www.theguardian.com/technology/2018/nov/06/facebook-admits-it-has-not-done -enough-to-quell-hate-in-myanmar

Epstein, R, Robertson, RE. (2015). The Search Engine Manipulation Effect (SEME) and its Possible Impact on the Outcomes of Elections. Proceedings of the National Academy of Sciences of the United States of America, 112(33), E4512-E4521. https://www.pnas.org/content/112/33 /E4512

European Commission. (2016). General Data Protection Regulation. https://gdpr-info.eu

European Commission. (2018). Code of Practice on Disinformation. https://ec.europa.eu/digital -single-market/en/news/code-practice-disinformation

Farksas, J, Schou, J. (2018). Fake News as a Floating Signifier: Hegemony, Antagonism and the Politics of Falsehood. Javnost - The Public, 3(3):298-314. https://www.tandfonline.com/doi /full/10.1080/13183222.2018.1463047 
Fazio, L, Pillai, R, Patel, D. (2021). The effects of repetition on belief in naturalistic settings. https://psyarxiv.com/r85mw

Feldman, N. (2016). Fake News May Not Be Protected Speech. https://www.bloomberg.com /opinion/articles/2016-11-23/fake-news-may-not-be-protected-speech

Fisher, M, Taub, A. (2019). We wanted to know how online radicalization was changing the world. We started with Brazil. The New York Times https://www.nytimes.com/2019/08/11 /reader-center/brazil-youtube-radicalization.html

Freedom House. (2019). Kenya country report 2019. https://freedomhouse.org/country/kenya /freedom-net/2019

Full Fact. (2019). Report on the Facebook Third Party Fact-checking Programme. https://full fact.org/media/uploads/tpfc-q1q2-2019.pdf

Goel, V, Raj, S, Ravichandran, P. (2018). How WhatsApp Leads Mobs to Murder in India. New York Times. https://www.nytimes.com/interactive/2018/07/18/technology/whatsapp-india -killings.html

Golebiewski, M, Boyd, D. (2019). Data voids: Where missing data can easily be exploited. Data and Society. https://datasociety.net/wp-content/uploads/2019/11/Data-Voids-2.0-Final.pdf

Gordan, L, Sullivan, S, Mittal, S, Stone, K. (2015). Ethiopia's Anti-Terrorism Law: A Tool to Stifle Dissent. Oakland Institute. https://www.oaklandinstitute.org/sites/oaklandinstitute.org /files/OI_Ethiopia_Legal_Brief_final_web.pdf

Graves, L. (2016). Deciding What's True: The Rise of Political Fact-Checking in American Journalism. Columbia University Press.

Gunther, R, Beck, PA, Nisbet, EC. (2018). Fake News May Have Contributed to Trump's 2016 Victory. Ohio State University. https://www.documentcloud.org/documents/4429952-Fake -News-May-Have-Contributed-to-Trump-s-2016.html

Habgood-Coote, J. (2018). The term fake news is doing great harm. The Conversation. https: //theconversation.com/the-term-fake-news-is-doing-great-harm-100406

Haciyakupoglu, G, Yang Hui, J, Suguna, VS, Leong, D, Bin Abdul Rahman, MF. (2018). Countering Fake News. A Survey of Recent Global Initiatives. RSIS Policy Report. https://www.rsis .edu.sg/wp-content/uploads/2018/03/PR180307_Countering-Fake-News.pdf

Halakhe, A. (2017). East Africa: Now is the time to stand up for media freedom. https://www .amnesty.org/en/latest/news/2017/05/east-africa-now-is-the-time-to-stand-up-for-media -freedom-1

Hassan, I, Hitchen, J. (2019). Nigeria’s 'propaganda secretaries'. Mail \& Guardian. https://mg.co .za/article/2019-04-18-00-nigerias-propaganda-secretaries

Hassan, I, Hitchen, J. (2020). Driving division. Disinformation and the New Media Landscape in Nigeria. Centre for Democracy and Development. https://www.cddwestafrica.org/wp -content/uploads/2020/04/Driving-Division-Disinformation-and-the-New-Media-Land scape-in-Nigeria.pdf

Heijmans, P. (2019). Singapore's 'fake news' law takes effect as critics sound alarm. AFP News Agency. https://www.thestar.com.my/tech/tech-news/2019/10/02/singapores-controversial -fake-news-law-comes-into-effect 
Hern, A. (2020). New UK tech regulator to limit power of Google and Facebook. The Guardian. https://www.theguardian.com/technology/2020/nov/27/new-uk-tech-regulator-to-limit -power-of-google-and-facebook

Hitchen, J. (2018). The WhatsApp rumours that infused Sierra Leone's tight election. African Arguments. https://africanarguments.org/2018/04/10/the-whatsapp-rumours-infused-sierra -leone-tight-election-social-media

Hitchen, J, Hassan I, Fisher, J, Cheeseman, N. (2019). WhatsApp and Nigeria's 2019 Elections: Mobilising the People, Protecting the Vote. University of Birmingham, Centre for Democracy \& Development. https://www.cddwestafrica.org/wp-content/uploads/2019/07/WHAT SAPP-NIGERIA-ELECTION-2019.pdf

HLEG - EU High Level Expert Group. (2018). Final Report of the High Level Expert Group on Fake News and Online Disinformation. https://ec.europa.eu/digital-single-market/en/news /final-report-high-level-expert-group-fake-news-and-online-disinformation

Human Rights Watch. (2019). Ethiopia: Bill threatens free expression. https://www.hrw.org /news/2019/12/20/ethiopia-bill-threatens-free-expression

Human Rights Watch. (2020). Ethiopia: Communications Shutdown Takes Heavy Toll. https: //www.hrw.org/news/2020/03/09/ethiopia-communications-shutdown-takes-heavy-toll

Hyman, A. (2020). Steven Birch appears in court over fake news video on Covid-19 tests. https: //www.timeslive.co.za/news/south-africa/2020-04-07-steven-birch-appears-in-court-over -fake-news-video-on-covid-19-tests/

Illman, J. (2020). Hancock challenged over Covid testing numbers by stats watchdog. Health Service Journal. https://www.hsj.co.uk/free-for-non-subscribers/hancock-challenged-over -covid-testing-numbers-by-stats-watchdog/7027620.article

Jeffrey, J. (2019). The challenges of navigating Ethiopia's new media landscape. Al Jazeera. https: //www.aljazeera.com/news/2019/10/29/the-challenges-of-navigating-ethiopias-new -media-landscape

Jerven, M. (2013). Poor Numbers: How We Are Misled by African Development Statistics and What To Do About It. Cornell University Press.

Journal Officiel - Senegal. (2017). Code de la Presse. http://www.numerique.gouv.sn/sites /default/files/CODE\%20PRESSE.pdf

Kainja, J. (2020). How lack of access to information and ICTs has fuelled disinformation in Malawi. CIPESA. https://cipesa.org/2020/10/how-lack-of-access-to-information-and-icts -has-fueled-disinformation-in-malawi

Kalla, J, Broockman, D. (2017). The minimal persuasive effects of campaign contact in general elections: Evidence from 49 field experiments. American Political Science Review, 112(1), 148-166. DOI: https://doi.org/10.1017/S0003055417000363

Kaye, D. (2019a). Speech police: The global struggle to govern the internet. Columbia Global Reports. https://globalreports.columbia.edu/books/speech-police

Kaye, D. (2019b). Ethiopia, the scourge of 'hate speech' and American social media. https: //medium.com/@dkisaway/ethiopia-the-scourge-of-hate-speech-american-social-media -952 c9228e21c 
Kazeem, Y. (2020). Nigerians are bracing for another government attempt to regulate social media after national protests. Quartz Africa. https://qz.com/africa/1926334/endsars-nigerian -government-looks-to-regulate-social-media

Kelion, L. (2020). EU reveals plan to regulate Big Tech. BBC News. https://www.bbc.co.uk/news /technology-55318225

Kenya Today (2015). Uhuru regime hires 38 bloggers as online war with opposition rages. https://www.kenya-today.com/news/government-hires-36-bloggers-as-online-war-with -opposition-rages

Klapper, J. (1960). The Effects of Mass Communication. Free Press.

Kondowe, R. (2019). Despite a low internet penetration, Malawi is worried about fake news in its election run-up. Quartz Africa. https:/qz.com/africa/1616511/malawi-election-has-a -fake-news-problem-on-whatsapp-facebook

Lagos Lira, CP, Toledo, P. (2014). The Media and Gender-Based Murders of Women: Notes on the Cases in Europe and Latin America. Heinrich Böll Stiftung. https://eu.boell.org/en/2014/07/24 /media-and-gender-based-murders-women-notes-cases-europe-and-latin-america

Lakier, G. (2021). The Great Free-Speech Reversal. The Atlantic. https://www.theatlantic.com /ideas/archive/2021/01/first-amendment-regulation/617827

Larson, HJ. (2018). The Biggest Pandemic Risk? Viral Misinformation. Nature, 562(7727), 309-309. DOI: https://doi.org/10.1038/d41586-018-07034-4

Le Conte, M. (2016). The Government Says It's Looking Into Fake News. Buzzfeed News UK. https://www.buzzfeed.com/marieleconte/the-government-says-its-looking-into-fake -news?utm_term=.rdqWNQdno9\#.oeqg1wxAqY

Le Roux, J. (2020a). Nigerian army dismisses Lekki Toll Gate massacre as 'fake news'. DFR Lab https://medium.com/dfrlab/nigerian-army-dismisses-lekki-toll-gate-massacre-as-fake -news-6e4665eed6d7

Le Roux, J. (2020b). South African Twitter accounts gamed trending algorithms to promote prank political hashtags'. DFR Lab. https://medium.com/dfrlab/south-african-twitter -accounts-gamed-trending-algorithms-to-promote-prank-political-hashtags-7ad1c6cb0622

Mare, A, Matsilele, T. (2020). Hybrid Media System and the July 2018 Elections in 'Post-Mugabe' Zimbabwe. (pp 147-176). In Ndlela, M, Mano, W (Eds) Social Media and Elections in Africa, Volume 1 Theoretical Perspectives and Election Campaigns. Palgrave Macmillan. Chapter 8. https://www.palgrave.com/gp/book/9783030305529

Marsh, S. (2020). Ministerial code: five who did resign over breach accusations. The Guardian. https://www.theguardian.com/politics/2020/nov/20/ministerial-code-five-who-did-resign -breach-accusations

Meade, A. (2020). Backers of Australia's mandatory news code welcome French ruling on Google. The Guardian. https://www.theguardian.com/media/2020/oct/10/backers-of-aus tralias-mandatory-news-code-welcome-french-ruling-on-google

Mchangama, J, Fiss, J. (2019). Germany's Online Crackdowns Inspire the World's Dictators. Foreign Policy. https://foreignpolicy.com/2019/11/06/germany-online-crackdowns-inspired-the -worlds-dictators-russia-venezuela-india/ 
McLaughlin, T. (2018). How WhatsApp Fuels Fake News and Violence in India. Wired. https: //www.wired.com/story/how-whatsapp-fuels-fake-news-and-violence-in-india/

McQuail, D. (1983. Updated 2010). McQuail's Media and Mass Communication Theory. Sage Publications. Chapter 17.

Mills, Edward, Jadad, AR, Ross, C, Wilson, K. (2005). Systematic review of qualitative studies exploring parental beliefs and attitudes toward childhood vaccination identifies common barriers to vaccination. Journal of Clinical Epidemiology, 58(11), 1081-1088. https://pubmed .ncbi.nlm.nih.gov/16223649/

Moore, M. (2018). Democracy Hacked: How Technology is Destabilising Global Politics. One World Publications.

Mushtaq, N. (2008). New Media Law, New Threat to Press Freedom. Inter Press Service. http://www.ipsnews.net/2008/07/rights-ethiopia-new-media-law-new-threat-to-press -freedom

Nassuna, J. (2018). UCC switches off 23 radio stations over airing witchcraft content. PML Daily. https://www.pmldaily.com/news/2018/03/ucc-switches-off-23-radio-stations-over-airing -witchcraft-content.html

Ndlela, M, Mano, W (Eds). (2020). Social Media and Elections in Africa, Volume 1 Theoretical Perspectives and Election Campaigns; Social Media and Elections in Africa, Volume 2: Challenges and Opportunities. Palgrave Macmillan. https://www.palgrave.com/gp/book /9783030305529; https://www.palgrave.com/gp/book/9783030326814

Newman, N, Fletcher, R, Schulz, A, Andi, S, Nielsen, RK. (2020). Reuters Institute. Digital News Report 2020. RISJ. https://reutersinstitute.politics.ox.ac.uk/sites/default/files/2020-06 /DNR_2020_FINAL.pdf

Nur, F. (2019). The rumour that led to medical researchers in Ethiopia being killed by a mob. BBC News. https://www.bbc.co.uk/programmes/p07pvjxx

Nyhan, B, Guess, AM, Reifler, J. (2018). Exposure to untrustworthy websites in the 2016 US election. https://www.dartmouth.edu/ nyhan/fake-news-2016.pdf

Oborne, P. (2005). The Rise of Political Lying. Free Press.

Odoh, I. (2020). ECOWAS orders Nigeria to amend its law on cybercrime. Business Day. https: //businessday.ng/security/article/ecowas-court-orders-nigeria-to-amend-its-law-on-cybercrime

Ogala, E, Ibeh, N. (2014). Ebola sparks panic across Nigeria as citizens scramble for saltwater bath 'remedy'. Premium Times. https://www.premiumtimesng.com/news/166257 -ebola-sparks-panic-across-nigeria-as-citizens-scramble-for-salt-water-bath-remedy .html\#sthash.Ge0bomNI.dpbs

Okakwu, E. (2018). Nigerian government launches campaign against 'fake news'. Premium Times. https://www.premiumtimesng.com/news/more-news/275846-nigerian-govt-launches -campaign-against-fake-news.html

Olewe, D. (2018). Kenya, Uganda and Tanzania in 'anti-fake news campaign'. BBC News. https: //www.bbc.co.uk/news/world-africa-44137769

Paquette, D. (2019). Nigeria's 'fake news' bill could jail people for lying on social media. Critics call it censorship. Washington Post. https://www.washingtonpost.com/world/africa/nigerias 
-fake-news-bill-could-jail-people-for-lying-on-social-media-critics-call-it-censorship /2019/11/25/ccf33c54-0f81-11ea-a533-90a7becf7713_story.html

Parkinson, HJ. (2016). Click and elect: How fake news helped Donald Trump win a real election. The Guardian. https://www.theguardian.com/commentisfree/2016/nov/14/fake-news -donald-trump-election-alt-right-social-media-tech-companies

Perse, EM. (2001). Media Effects and Society. Routledge.

Posetti, J, Matthews, A. (2018). A Short Guide to the History of 'Fake News' and Disinformation. ICFJ. https://www.icfj.org/news/short-guide-history-fake-news-and-disinformation-new -icf-learning-module

Read, M. (2016). Donald Trump won because of Facebook. Intelligencer - New York Magazine. https://nymag.com/intelligencer/2016/11/donald-trump-won-because-of-facebook.html

RFI. (2020). Côte d'Ivoire: arrestation de l'opposant Étienne Daïpo N'Ponon de la plateforme EDS. https://www.rfi.fr/fr/afrique/20200520-c\%C3\%B4te-divoire-arrestation-lopposant -\%C3\%A9tienne-da\%C3\%AFpo-nponon-la-plateforme-eds

Romano, A. (2021). Kicking people off social media isn't about free speech. Vox.

Roth Allen, D, Lacson, R, Gborie, A, Patel M, Beach, M. (2015). Understanding Why Ebola Deaths Occur at Home in Urban Montserrado County, Liberia. Centre for Disease Control and Prevention. http://www.ebola-anthropology.net/wp-content/uploads/2015/07/FINAL -Report-to-Liberia-MoH-Understanding-Why-Ebola-Deaths-Occur-at-Home-Liberia.pdf

Roudik, P. (2019). Initiatives to Counter Fake News in Selected Countries. Library of Congress. https://www.loc.gov/law/help/fake-news/counter-fake-news.pdf

RSF. (2019). Uganda 'suspends' 39 journalists for covering politician's arrest. https://rsf.org/en /news/uganda-suspends-39-journalists-covering-politicians-arrest

RSF. (2020a). Le code du numérique, nouvelle arme pour neutraliser la presse.' https://rsf.org /fr/benin

RSF. (2020b). Burkina Faso: l'amendement du Code pénal doit être déclaré inconstitutionnel' https://rsf.org/fr/actualites/burkina-faso-lamendement-du-code-penal-doit-etre-declare -inconstitutionnel-2

RSF. (2020c). Arrestations de journalistes au Niger: 'un recul inquiétant de la liberté de la presse dans le pays'. https://rsf.org/fr/actualites/arrestations-de-journalistes-au-niger-un-recul -inquietant-de-la-liberte-de-la-presse-dans-le-pays

Rydzak, J. (2019a). Of blackouts and bandhs: The strategy and structure of disconnected protest in India.SSRN. https://papers.ssrn.com/sol3/papers.cfm?abstract_id=3330413

Rydzak, J. (2019b). Shutting down social media does not reduce violence, but rather fuels it. The Conversation. https://theconversation.com/shutting-down-social-media-does-not-reduce -violence-but-rather-fuels-it-115960

SA Constitutional Court Ruling. (2015). SA Constitutional Court Ruling. Democratic Alliance v. African National Congress and Another. (2015) http://www.saflii.org/za/cases /ZACC/2015/1.html. Constitutional Court of South Africa. 
Sahara Reporters. (2020). Rotimi Jolayemi, Journalist Who Sang Critical Poem Against Nigeria’s Information Minister, Lai Mohammed, Released On Bail' http://saharareporters.com /2020/06/19/rotimi-jolayemi-journalist-who-sang-critical-poem-against-nigerias-informa tion-minister

Sampaio-Dias, S, Mabweazara, HM, Townend, J, Osman, I. (2019). Practices, policies and regulation in African journalism: Mapping a research agenda. African Journalism Studies, 40(3), 1-9. https://www.tandfonline.com/doi/full/10.1080/23743670.2019.1750197

Sandefur, J. (2018). Tanzania Outlaws Fact-Checking, Seeks World Bank Aid to Create New Facts. Center for Global Development. https://www.cgdev.org/blog/tanzania-outlaws-fact -checking-seeks-world-bank-aid-create-new-facts

Sanef. (2019). Further allegations against journalists at Zondo Commission deeply concerning - Sanef. https://sanef.org.za/further-allegations-against-journalists-at-zondo-commission -deeply-concerning

Schetzer, A. (2019). Governments are making fake news a crime, but it could stifle free speech. The Conversation. https://theconversation.com/governments-are-making-fake-news-a-crime -but-it-could-stifle-free-speech-117654

Shane, T, Noel, P. (2020). Data deficits. Why we need to monitor the demand and supply of information in real time. First Draft. https://firstdraftnews.org/long-form-article/data-deficits

Silverman, C. (2016). This Analysis Shows How Viral Fake Election News Stories Outperformed Real News on Facebook. https://www.buzzfeednews.com/article/craigsilverman/viral-fake -election-news-outperformed-real-news-on-facebook\#.hw4YdXDKYd

Skiti, S, Shoba, S. (2017). 'White monopoly capital' chosen distraction in PR strategy to clear Guptas. The Sunday Times (South Africa).

Solomon, S. (2016). Ethiopia's Anti-terrorism Law: Security or Silencing Dissent?' https://www .voanews.com/africa/ethiopias-anti-terrorism-law-security-or-silencing-dissent

Statt, N. (2020). Facebook reportedly ignored its own research showing algorithms divided users. https://www.theverge.com/2020/5/26/21270659/facebook-division-news-feed-algorithms

Stewart, E. (2019). Can Facebook be trusted to combat misinformation? Sri Lanka's shutdown suggests no. https://www.vox.com/2019/4/23/18511640/facebook-sri-lanka-bombing-social -media-attack

Stiglitz, J, Schiffrin, A. (2020). Australia's new tech regulator is a road worth exploring. Financial Times. https://www.ft.com/content/234d44b5-b876-489c-8639-056f48205ac7?share Type= nongift

Sullivan, M. (2020). Facebook has a huge truth problem. A high-priced 'oversight board' won't fix it. Washington Post. https://www.washingtonpost.com/lifestyle/media/facebook-has-a -huge-truth-problem-a-high-priced-oversight-board-wont-fix-it/2020/05/14/c5b53cba -95d9-11ea-9f5e-56d8239bf9ad_story.html

Thielman, NM, Ostermann, J, Whetten K, Whetten R, Itemba, D, Maro, V, Pence, B, Reddy, E. (2014). Reduced Adherence to Antiretroviral Therapy among HIV-infected Tanzanians Seeking Cure from the Loliondo Healer. DOI: https://doi.org/10.1097/01.qai.0000437619.23031.83 
Thomas, Z. (2020). WHO says fake coronavirus claims causing 'infodemic'. BBC News. https: //www.bbc.co.uk/news/technology-51497800

Tiegreen, S, Newman, E. (2009). Violence: Comparing Reporting and Reality. Dart Center for Journalism and Trauma. https://dartcenter.org/content/violence-comparing-reporting-and -reality

Tucker, JA, Guess, A, Barbera, P, Vaccari, C, Siegel, A, Sanovich, S, Stukal, D, Nyhan, B. (2018). Systematic review of global evidence. Social Media, Political Polarization, and Political Disinformation: A Review of the Scientific Literature. SSRN, 19 March. https://papers.ssrn.com /sol3/papers.cfm?abstract_id=3144139

Turnbull, M. (2019). Africa faces a balancing act on social media regulation. The Africa Report. December 4, 2019. https:/www.theafricareport.com/20741/africa-faces-a-balancing-act-on -social-media-regulation/

UNESCO. (1982). The Grunwald Declaration on Media Education. https://milunesco.unaoc .org/mil-resources/grunwald-declaration-on-media-education/

UN, OSCE, OAS, AU rapporteurs joint statement. (2017). Joint declaration on freedom of expression and 'fake news', disinformation and propaganda. https://www.osce.org/fom/302796

Vanguard. (2020). Lauretta Onochie unfit as INEC Commissioner. Vanguard. https://www.van guardngr.com/2020/10/lauretta-onochie-unfit-as-inec-commissioner

Vargo, C, Guo, L, Amazeen, MA. (2017). The agenda-setting power of fake news: A big data analysis of the online media landscape from 2014 to 2016. New Media \& Society, 20(5), 2028-2049. https://journals.sagepub.com/doi/10.1177/1461444817712086

Vicol, DO. (2020). Who is most likely to believe and to share misinformation? Full Fact. https: //fullfact.org/media/uploads/who-believes-shares-misinformation.pdf

Wang, Y, McKee, M, Torbica, A, Stuckler, D. (2019). Systematic literature review on the spread of health-related misinformation on social media. Social Science \& Medicine 240, 112552. DOI: https://doi.org/10.1016/j.socscimed.2019.112552

Wardle, C, Derakhshan, H. (2017). Information Disorder: Toward an interdisciplinary framework for research and policy making. Council of Europe. https://rm.coe.int/information -disorder-toward-an-interdisciplinary-framework-for-researc/168076277c

Wardle, C. (2019). Misinformation has created a new world disorder. Scientific American. https: //www.scientificamerican.com/article/misinformation-has-created-a-new-world-disorder

Wasserman, H, Benequista, N. (2017). Pathways to Media Reform in Sub-Saharan Africa Reflections from a Regional Consultation. Centre for International Media Assistance. https://www .cima.ned.org/publication/pathways-to-media-reform-in-sub-saharan-africa

Wasserman, H. \& Madrid-Morales, D. (2018). 'Fake News', Disinformation and Media Trust in Africa: A Comparative Study of Kenya, Nigeria and South Africa. ICAfrica Biennial Conference 2018 Accra. http://danimadrid.net/research/2018_icafrica_fakenews.pdf.

Wilkinson, K. (2020). South Africa's poverty and income statistics fall victim to Covid-19. Africa Check. https://africacheck.org/2020/07/20/comment-south-africas-poverty-and -income-statistics-fall-victim-to-covid-19 
Williams, M. (2020). Man who posted fake contaminated Covid-19 test kits video in court, media barred from covering. News24. https://www.news24.com/news24/SouthAfrica/News/man -who-posted-fake-contaminated-covid-19-test-kits-video-in-court-media-barred-from -covering-20200407

Yuen-C, T. (2020). Right to let ministers act swiftly on fake news, says Iswaran. Straits Times. https://www.straitstimes.com/singapore/right-to-let-ministers-act-swiftly-on-fake-news -says-iswaran 



\section{APPENDIX I - RESEARCH METHODOLOGY FOR THIS REPORT}

\section{I.I. Key premises of the research approach}

The response from many governments to the rise of misinformation has been to introduce new or stricter regulation of traditional and social media (Bradshaw et al, 2018; European Commission, 2018a; Haciyakupoglu et al, 2018; Kaye, 2019a; Roudik, 2019; Sandefur, 2018). At the same time, governments from Bangladesh and India to Algeria, Cameroon and Ethiopia have pursued extra-legal measures such as shutting down the Internet in the name of stopping the spread of 'fake news' and hate speech (Access Now, 2020; Ndlela \& Mano, 2020). Critics of these measures argue that, in many if not all cases, the actual and perhaps intended effect has been to restriction freedom of expression and censor opposition voices (Bajo, 2019; Cunningham, 2019; Halakhe, 2017; Paquette, 2019; Schetzer, 2019). This critique does not tell us, however, whether the approach has, nevertheless, reduced the harm false information causes.

We start from the premise that, to be an effective response to the harmful effects misinformation has or may have on individuals and society, laws and regulations would need to address the types of misinformation actually in circulation, who creates them and what drives them, and takes into account the actual and potential harmful effects this misinformation can or cannot be shown to have.

On this basis, we set out, first, evidence from the other study that is part of this series that misinformation in Africa is part of a wider, inter-linked 'information disorder' encompassing not simply (i) false and misleading information but also, (ii) the distorted focus of information online and offline and (iii) the failure of authorities to ensure easy public access to reliable official information (CunliffeJones, 2022b). Second, we set out evidence drawn from the same source on the types, drivers and effects of misinformation in the region. It is after establishing this basis, that we then assess the effects of existing and new laws and regulations in the 11 countries surveyed for this report.

\section{I.2. Definitions of key terms used in the report}

For this report, we use the following definitions for key terms:

1.2.1. 'Access to information' and 'freedom of information' are used to refer to both the rights, and the systems that enable citizens 'to seek, receive and impart information and ideas through any media and regardless of 
frontiers', set out as a right in Article 19 of the Universal Declaration of Human Rights (Article 19, 1966). Our reports show a lack of access to information is one of the main drivers of misinformation in Africa.

1.2.2. 'Freedom of expression' is used to refer to the right, set out in Article 19 of the Universal Declaration of Human Rights, to express information and ideas through diverse media. This is both a fundamental right for individuals and for a free media to hold governments and institutions to account.

1.2.3. 'Distorted focus of information' is our own term, used to refer to 'the promotion and/or censorship of particular topics such that, while the information disseminated may not be inaccurate in itself, the focus on or absence of the topic distorts audience understanding. Details of the concept are set out in Section 2.

1.2.4. 'Lack of access to accurate information' is used to refer 'the lack of legal rights and/or the practical ability of the public to access to accurate information on topics of public interest, and/or the failure of the authorities to ensure that public information that is available is accurate. Details of the concept are set out Section 2.

1.2.5. 'Information disorder' is defined in this report as 'the combination of three factors: mis/disinformation, the distorted focus of information and the lack of access to accurate information, that, together with the way people think, combine to undermine public understanding. See Section 2 for a fuller discussion.

1.2.6. 'Claim' is a term we use to refer to 'any factual assertion made by a person or organisation, explicitly or on occasion implicitly, whether made by the spoken or written word or through presentation of an image. This definition is drawn from the definition used in the guidelines for signatories of the International Fact-Checking Network, the global umbrella body for fact-checking ${ }^{111}$.

1.2.7. 'Misinformation' is used to refer to 'information that is false or misleading, whether or not it was intended to mislead'. Section 3 provides a

I I For disclosure, the lead researcher on this report is an independent member of the advisory board of the IFCN and oversaw the 2020 review of its Code of Principles for fact-checkers. 
more detailed discussion of what constitutes false information or misinformation.

1.2.8. 'Disinformation' is used to refer to 'information that is false or misleading and was created or spread with the intention of misleading. This definition is also used by multiple sources. See Section 2 for a more detailed description of this term.

1.2.9. 'Fake news' is used only in quotations. Taken literally, the term applies purely to false or fabricated information produced in a news format to deceive about its origins and/or accuracy. In practice, the term has been used by headline writers, politicians, and the public worldwide since 2016, often to dismiss information as false or biased, regardless. We consider that with such lack of definition 'fake news' is a misleading term best not used save in quotations.

1.2.10. 'Harmful effects' (actual or potential). We refer in this report to claims of harmful effects from false information. We differentiate between 'actual' harmful effects, that is, direct, observable harm to an individual or group that can be shown through empirical evidence to have been caused by false or misleading information, and 'potential' harmful effects, that is, harm that a combination of evidence and theory indicates may have or may in future likely be caused by false or misleading information. We set out this details and examples of effects in Section 4.

1.2.11. 'Fact-checking' is used to refer to 'publishing or broadcasting content that assesses the factual accuracy of factual statements made by public figures and prominent institutions and/or claims widely circulated online in text, visual and other formats. This is also drawn from the IFCN guidelines noted above.

\section{I.3. The criteria for selecting the period studied}

We selected the period 1 January 2016 to 30 June 2020 to study for two main reasons. First, we seek to explore evidence of change in legislation and regulation brought in or planned due to declared concerns about misinformation. As set out above, the levels of concern expressed about the real or imagined effects of misinformation on individuals and society rose sharply in Africa, and around the world, from 2016. For this reason, we made 2016 the starting point for our study and continued the survey up to mid-2020 in order to examine the effects of the emergence of the Covid-19 pandemic on media and information legislation. 


\section{I.4. The criteria for selecting the countries studied}

This study examines changes made to legislation and regulation of media and information in 11 countries, roughly one quarter of the total in sub-Saharan Africa - Benin, Burkina Faso, Cote d'Ivoire, Ethiopia, Kenya, Malawi, Niger, Nigeria, Senegal, South Africa and Uganda. We selected these countries as presenting a combination of Anglophone and Francophone nations, with different media traditions, a blend of populous and smaller nations, and different political traditions. For reasons of our linguistic limitations, we did not cover North Africa.

\section{I.5. The fields of legislation and regulation assessed}

We started our study from the point of view that regulation of the media, public speech and information can, in principle, if exercised independently of party political, commercial and sectarian interests, provide a legal framework that helps to protect trust, the privacy of personal data, access to and transparency and accuracy of public information, transparency of media ownership, accurate reporting and the expression of minority and oppositional opinion and can reduce the harm caused by false and other harmful content.

With this in mind, we examined legislation and regulation in the selected countries for:

1.5.1. Any aspects relating to the accuracy, falsity and effects of information published or broadcast by traditional print and broadcast media, and news websites

1.5.2. Any aspects relating to the accuracy, falsity and effects of information published on social media platforms, online search, and messaging services

1.5.3. Any changes to the general rules of operation for traditional print and broadcast media, news websites, social media platforms, online search, and messaging services if premised on concern about false information and its effects

1.5.4. Any legislation or codes of conduct as may exist requiring politicians and officials to ensure the accuracy of claims they make in public debate

1.5.5. Any legislation or codes of conduct as may exist relating to public access to, and the accuracy of, information from public bodies 


\subsection{How we identified changes to the legal and regulatory framework}

We conducted interviews with regulators and media freedom advocates, and carried out a search of academic literature and research published by relevant civil society organisations and official bodies across the 11 identified countries relating to:

1.6.1. The accuracy, falsity and effects of information published or broadcast by traditional print and broadcast media and news websites

1.6.2. The accuracy, falsity and effects of information published on social media platforms, online search and messaging services

1.6.3. Requirements on politicians and officials to ensure the accuracy of claims they make

1.6.4. Public access to, and the accuracy of, information from public bodies

1.6.5. Reviewed current legislation and regulation against the 2016 baseline

1.6.6. Extra-legal measures such as Internet shutdowns between 2016 and 2020, where those were claimed to have been taken due to concerns about false information

\section{I.7. How we identified restrictions on access to accurate information}

To identify restrictions on access to accurate information, we:

1.7.1. Carried out interviews with media regulators, information ministry officials, and statisticians to establish whether such officials see easier access to accurate information as a potential useful response to tackling misinformation.

1.7.2. Carried out a review of the evidence from monitors of freedom of information and access to information relating to:

1.7.2.1. Internet shutdowns, take-down notices or other forms of online censorship where tackling false information was cited as a cause

1.7.2.2. Bans on media publications where tackling false information was cited as a cause

1.7.2.3. Evidence of the implementation or not of existing FOI legislation or the introduction of new FOI legislation where tackling false information was cited as a cause 


\section{I.8. How we analysed the effects of these measures and restrictions}

The methods used to analyse the effect these measures can be shown or are said to have had on (i) the flow of misinformation and (ii) freedom of speech and of the media, included:

For evidence on the measures' effects on the flow of misinformation:

1.8.1. A review of reports from media and civil society organisations for evidence of specific examples of misinformation stopped through such legislation and regulatory responses, and analysis of broader effects on the flow of misinformation

1.8.2. Evidence from the research conducted for another report in this series (Cunliffe-Jones, 2022b) of examples of when lack of access to accurate information caused or contributed to the spread of false information

1.8.3. Qualitative interviews with regulators, as available, to seek evidence of specific examples or types of misinformation stopped through such legislation and regulatory responses, and of any possible broader effects on the flow of misinformation

1.8.4. Qualitative interviews with leading journalists, press freedom and Internet rights advocates, and spokespeople for social media platforms, as available, to establish if they agree such measures reduced the flow of misinformation

For evidence on the measures' potential effect on freedom of speech and the media:

1.8.5. A review of news reports and reports from civil society organisations and monitors of freedom of speech for evidence as to whether any such measures reduced or promoted freedom of speech and the media

1.8.6. Qualitative interviews with leading journalists, press freedom and Internet rights advocates, and spokespeople for social media platforms, as available, for evidence as to whether any such measures reduced or promoted freedom of speech and the media 


\section{APPENDIX 2 - SUMMARY OF FEATURES OF THE 3I LAWS STUDIED}

1. One law reviewed requires media to allow a right of reply to, but does not otherwise penalise publication of, allegedly 'false' information

- Malawi: Communications Act (2016)

2. Fourteen laws or regulations penalise allegedly 'false' information alleged to cause harm in fields that may be permitted under Article 19

- Ethiopia: Electoral Law (2019) + Computer Crime Proclamation (2016). Kenya: Penal Code (1930). Section $66+$ Elections Offenses Act (2016). Malawi: Penal Code. Section $60+$ e-Transactions Act (2016) + Access to Information Act (2020). Nigeria: Criminal Code. (1990) + Electoral Act. (2010). South Africa: Electoral Act of 1998. Section 89 + Regulation in 2020 related to Disaster Management Act (2002). Uganda: Penal Code. Section 171 + Witchcraft Act (1957) + Electoral laws updated in 2020

3. Six laws penalise allegedly 'false' information alleged to cause harm in ways not permitted under Article 19

- Cote d'Ivoire: Code Penal, Article 173, (1998). Kenya: Computer Misuse \& Cybercrimes Act - Section 22 (2018). Malawi: Public Security Regulations. Regulation 4. Niger: Cybercrime law. (2019). Nigeria: Cybercrimes (Prohibition, Prevention, etc.) Act (2015). Section 24(b). Senegal: Article 255 of Code Penal

4. Ten laws penalise allegedly 'false' information regardless of alleged harm, on grounds of its falsity alone

- Benin: Code du numérique (2018). Article 550(3). Burkina Faso: Penal Code, as amended 2019. Article 312-13. Cote d'Ivoire: Loi 2013-451 - relative à la lutte contre la cybercriminalité (2013) + Loi 2017-867 régime juridique de la presse (2017). Ethiopia: Mass Media and Freedom of Information Proclamation (2008) + Anti-Terrorism Proclamation (2009) + Hate Speech and Disinformation Prevention and Suppression Proclamation (2020). Articles 2 \& 5. Nigeria: Broadcasting Code of Conduct (2016). Uganda: Schedule 4 of the Uganda Communications Act (2013) + Data Protection and Privacy Act, (2019) 



\section{APPENDIX 3 - RESEARCH METHODOLOGY FOR REPORT ON MISINFORMATION TYPES AND EFFECTS}

The report into the types, drivers and effects of misinformation identified as circulating across the continent between July and December 2019 will be put forward for publication in 2022. It is part of the series of four reports into the types, drivers and effects of misinformation and three responses to the phenomenon. We set out here details of the methodology of the report.

\section{I. THE SAMPLES OF MISINFORMATION STUDIED}

The key source for the report is a database of more than 1,200 examples of information circulating in sub-Saharan Africa in the second half of 2019 and identified as false or misleading by one of more of 14 fact-checking organisations. This information is drawn from fact-checks published between July 1 and December 31, 2019 - a 'business as usual' period on the continent, falling in between 6 months during which the continent saw a series major elections, January to June 2019, and the global health crisis that started in 2020 .

The sample was limited to fact-checks published or broadcast in English or French, for reasons of the author's linguistic limitations. Fact-checks of claims found to be accurate are not included as the focus of the report is on misinformation. The sample identified is subject to both the news selection biases of the fact-checking organisations and the still limited number and size of fact-checking organisations operating on the continent. These limitations and other questions concerning the sample studied are discussed in the report.

\subsection{THE ACCURACY OF THE MAKE UP OF THE MISINFORMATION SAMPLE}

For the study to be sound, the author reviewed the evidence on the basis of which the fact-checking organisations concluded that the information concerned was in some way either false or misleading, and also cross-checked the results of all those fact-checks where the same information was assessed by more than one factchecking organisation. Before the report is published, the validity of these and the other findings on a randomised sample of the entries in the database will be independently reviewed by other, independent researchers.

\subsection{PROCESS FOR CLASSIFYING TYPES, DRIVERS AND EFFECTS OF MISINFORMATION}

To classify the types and drivers of misinformation examined in the database, the author assessed all entries using evidence drawn from the fact-checks 
themselves, follow-up enquiries and relevant studies (see more below). This process is not simple, due to both the number of factors that may be involved and the levels deception inherent in forms of misinformation. Nevertheless, the process seems straightforward compared to the more complicated and often uncertain process of assessing the effects misinformation does or may have.

To assess the possible effects of misinformation it is necessary to distinguish between actual, empirically provable effects of specific false or misleading claims, on the one hand, and the less certain, potential effects of claims and sets of claims over time and in different conditions. It is also necessary to consider the effects of information on belief or understanding, and the effects of any changes in belief or understanding on actions and feelings. It is necessary to set out the different degrees of confidence with which such findings can be asserted. Finally, it is necessary to identify the different effects depending on the audience that see and believes the false information. The effect on society of false information when it changes the actions taken by a policy-maker, in a position to set rules for hundreds, thousands or millions of people, may be greater than when believed by an individual member of the public. And yet, widely spread false information may also affect the actions and feelings of millions of individuals too.

\subsection{THE 25 FEATURES OF THE MISINFORMATION ASSESSED IN THE STUDY}

To determine what can be said about factors that make the different types of false or misleading information in the sample (i) lead to actual, empirically provable harmful effects, with evidence drawn from the fact-checks or further investigation or (ii) potentially contribute to harmful effects, with evidence drawn from the fact-checks, further investigation and existing research, the author assessed all entries in the database according to 25 defined features. The study then reviews the correlation between harm and different combinations of features assessed to put forward a theory of factors that lead to greater or lesser risks of harmful effects, to whom, and how, and sets out the basis for this.

To do this the database sets out both metadata on every false claim (the source of the fact-check, the date published, a link to the source, and a summary of the false claim), and classifies every claim entered according to the following 25 features.

The (i) claim checked; (ii) country or countries it concerned; (iii) country or countries in which it was observed; (iv) type of distortion of reality - unproven to false claims; (v) type of information - simple info to stimulation; (vi) topic of claim; (vii) whether claim spread on multiple sources or occasions; (viii) whether claim 
forms part of a specific wider false narrative; (ix) degree of distortion of reality in false claim; (x) format/s in which claim spread; (xi) type of originator or promoter of the claim; (xii) type of channel/s by which claim spread; (xiii) factors that caused or may have caused claim to be created; (xiv) factors that may have facilitated spread of claim; (xv) potential durability of the false claim; (xvi) type of claim's possible effects on belief or understanding; (xvii) whether claim is 'actionable' in near term - if believed; (xviii) type of 'consequential effect' - if believed; (xix) degree of confidence claim caused actual harm; (xx) field and form of actual harm caused; (xxi) whether claim had the potential to cause harm; (xxii) field and form of harm claim had potential to cause; (xxiii) potential scale of harm - 1 to 1 to 1 to many; (xxiv) durability of harm; (xxv) whether response to claim may have mitigated harm.

\subsection{THE EVIDENCE ON WHICH FALSE, MISLEADING CLAIMS ARE CLASSIFIED}

The claims are classified on the basis of evidence drawn from the following three sources.

(i) Information contained within the fact-checks. The author draws on evidence from the fact-checks they assessed. This includes data on the claim, evidence of effects and audience responses and the sources they quoted

(ii) Follow-up interviews and empirical evidence. Where the factchecks do not provide enough information, the author carried out follow-up investigations including desk-based research and interviews.

(iii) Review of relevant studies. Where useful, the author also assessed relevant studies were reviewed for evidence. As set out in the bibliography, the studies accessed provide evidence of and theories on: (i) the scale and nature of global misinformation, (ii) the scale and spread of misinformation in Africa, (iii) the originators and drivers of misinformation globally, (iv) factors facilitating belief and spread of misinformation, (v) the effect of misinformation on trust and of low trust on society, (vi) the role of misinformation fuelling, feeding off political radicalisation, (vii) the influence misinformation has on the outcome of elections, (viii) the role of misinformation inciting, or sustaining, violence and conflict, (ix) the influence of misinformation in shaping government policy, $(\mathrm{x})$ the influence of vaccine misinformation on vaccination take-up, (xi) the influence of misinformation on public health in general. 


\subsection{CATEGORIES, CRITERIA AND SOURCES OF EVIDENCE USED}

\section{(i) The claim checked}

The term 'claim' is used to refer to 'any factual assertion made by a person or organisation, explicitly or on occasion implicitly, whether made by the spoken or written word or through presentation of an image. This definition is drawn from the definition used in the guidelines for signatories of the International FactChecking Network, the global umbrella body for fact-checking. The description of each claim in the database is based on evidence in the fact-check.

\section{(ii) Country or countries the claim concerns}

Where a claim relates to events alleged to have taken place in a particular country or countries, the effect of the claim on an audience may depend, in part, on the location of the claim and audience. Using evidence drawn from the published factcheck, the database records the country or countries the claim refers to, including the country of any known source of the claim.

\section{(iii) Country or countries in which claim observed}

The database records the country or countries in which the claim was observed, based, again, on evidence from the published fact-check. The list of countries in which the claim was observed is not exhaustive. Few fact-checks record all countries in which a claim was observed.

\section{(iv) Type of distortion of reality}

There is no evidence that the type of distortion made by the claim shapes its effect on its audiences. However, understanding the way it distorts reality enables audiences to better understand and accept the falsity of information that may contain an element of truth. Using information drawn from the published fact-check, the database classifies entries by the type of distortion shown in one of the following ways - claims that are:

1. Unproven - A factual claim for which no definitive proof is publicly available

2. Satire - A factual claim that originated as satire but is understood to be true

3. False - A factual claim that is wholly false 
4. Mislabelled or misattributed - A factual claim, often an image or statement, that is labelled or attributed in ways that distort understanding

5. Misleading - A factual claim that bears some truth but lacks crucial context or detail and so distorts understanding

6. Overstated/understated - A factual claim that overstates or understates the level or scale of a position

7. Conflated - A factual claim that conflates issues or events in a way that distorts understanding

8. Fabricated or manipulated - Content, presented as real, all or part of which is fabricated or manipulated in ways that distort understanding

9. Imposter content - Content falsely presented as having been created by an individual or organisation

10. Coordinated inauthentic behaviour - Fake accounts and manipulation of social media to create a false or misleading understanding, particularly of public attitudes

11. Hoaxes and scams - A false factual claim intended to deceive - often to spread computer viruses, or other harms, to deceive for amusement, illicit reward or other effect

\section{(v) Type of information}

To assess whether the type of information influences its effect, the database categorises the claim according to the five information types identified by the academic McQuail ${ }^{112}$. It does so based on content analysis of the claim in the published factcheck.

1. Simple information

2. Stimulation to action

3. Directing attention differentially

4. Persuasion

5. Defining situation/defining reality

II2 McQuail, D. (1983, Updated 2010). McQuail's Media and Mass Communication Theory. Sage Publications. Chapter 17. 


\section{(vi) Topic of claim}

While much of the debate since 2016 about misinformation has focused on false claims related to politics, health and social divisions, the claims identified by fact-checkers as misinformation covered 20 broad topics. Many claims relate to more than one topic. As noted above, the list of topics identified is not exhaustive. It reflects both the selection biases of the fact-checking organisations whose work is studied - selecting what they consider to be important or interesting to fact-check, not all forms of misinformation - and the limits on their staff and resources. The identification of topics is based on content analysis of the false information.

SUMMARY OF TOPICS: (i) Accidents, disasters and need; (ii) business and economy; (iii) celebrities and the famous; (iv) crime and justice; (v) education; (vi) environment and climate; (vii) financial and other opportunities; (viii) gender; (ix) governance; $(x)$ health; (xi) international relations; (xii) job offers; (xiii) media; (xiv) migration and communities; (xv) miscellaneous; (xvi) people drawn into public life; (xvii) politics, politicians and elections; (xviii) sex and sexuality; (xix) state of the country (infrastructure and development); and $(x x)$ unrest and violence.

\section{DETAILS OF THE 20 BROAD TOPICS AND SUB-TOPICS OF CLAIMS IDENTIFIED}

(i) ACCIDENTS, DISASTERS OR NEED (False claims related to accidents and disasters, and false claims of need to seek donation). Two sub-topics.

False claim of need to seek donation; Claim re accident or disaster.

(ii) BUSINESS AND ECONOMY - False claims ref. businesses and business sectors, or a variety of economic indicators. Four subtopics.

Claim ref. a business or business sector; Claim ref. cost of living, inflation; Claim ref. employment levels, number of job seekers; Claim ref. state of economy, trade, investment, debt.

(iii) CELEBRITIES AND THE FAMOUS - False claims of celebrity deaths or, claims ref. behaviour or views of well-known people. Four specific topics.

Claim ref. activity, behaviour or view of well-known person; Claim well-known person is dead or near death. 
(iv) CRIMEA ND JUSTICE - False claims ref. particular crimes, crime rates, policing, conviction rates, prison numbers, social factors in crime and more. Thirteen sub-topics.

Claim a food or product has been poisoned; Claim a particular type of crime or fraud is a threat; Claim ref. a particular criminal case; Claim ref. crime rates, risk of crime; Claim ref. crime risks to children; Claim ref. human rights violations; Claim ref. juvenile crime; Claim ref. laws, standards, rules of operation; Claim ref. policing, conviction rates; Claim ref. prison numbers, conditions; Claim ref. who is responsible for crime; Claim related to torture, enslavement of individuals or groups.

(v) EDUCATION False claims ref. school attendance, funding and costs, performances and standards. Five sub-topics.

Claim ref. attendance at schools; Claim ref. government spending on, costs of education; Claim ref. operation of exam system; Claim ref. operation of teaching and schools; Claims ref. performance levels, standards.

(vi) ENVIRONMENT - False claims ref. climate change, state of environment, energy sector, wildlife. Three sub-topics.

Claim ref. climate change; Claim ref. energy sector, renewables; Claim ref. wildlife, wildlife protection.

(vii) FINANCIAL AND OTHER OPPORTUNITIES - False claims of financial or other opportunities such as company giveaways. One sub-topic.

Hoax claim of company giveaways.

(viiii) GENDER - False claims ref. attributes and status of genders, gender violence, code of dress, marriage laws and other relevant codes of behaviour. Six sub-topics.

Claim ref. attributes and behaviour of the genders; Claims ref. code of dress, behaviour for women; Claim ref. economic and workplace status of genders; Claim ref. gender abuse and violence; Claims ref. marriage laws and practices; Claims ref. sex trafficking, prostitution.

(ix) GOVERNANCE - False claims ref. government success, spending, behaviour, cost of or access to services, cost of governance. Eight sub-topics.

Claim of government competence, success; Claim of government incompetence, failure; Claim of inappropriate government spending; Claim of negative behaviour by government officials; Claim ref. corruption; Claims ref. cost and 
level of politicians salaries; Claim ref. cost of or access to government services; Claim ref. international organisation.

(x) HEALTH - False claims on topics from false cures to symptoms, causes and prevalence of health conditions, diet, effect of activity, costs and quality of and access to healthcare. Twenty sub-topics.

Claim a food or product has been poisoned, is deadly; Claim of harm to health caused by a type of technology; Claim of harmful activity by health practitioners; Claim a product or ingredient is a health cure or effective treatment; Claim on effect of sexual activity on health; Claim ref. availability and/or cost of health treatment; Claim ref. causes of a health condition; Claim ref. general health risks to children; Claim ref. health effects of a particular condition; Claim ref. effect of diet or activity on health; Claim ref. level of public spending on health; Claim ref. means of spread of a health condition; Claim ref. prevalence of a health condition; Claim ref. quality of health services; Claim ref. risks of a health treatment or medication; Claim ref. susceptibility or immunity to a health condition; Claim ref. symptoms and/or effects of a health condition; Claim ref. the actions of authorities in health crisis; Claims of effect of diet, other on sexual activity; Claims related to sexual and reproductive health.

(xi) INTERNATIONAL RELATIONS - False claims ref. foreign governments' activity or views, international disputes, public figures' relationship with foreign powers, etc. Three sub-topics.

Claim ref. foreign government's actions or views; Claim ref. international dispute; Claims ref. public figures relationship with foreign powers.

(xii) JOB OFFERS - Fake claims of job opportunities at companies; often financial scams or harvesting user ID. One sub-topic.

Claim a company or organisation is hiring staff.

(xiii) MEDIA - False claims about coverage of mainstream media, regulation of media. Imposter content claiming to be mainstream media content. Three sub-topics.

Claim ABOUT coverage by mainstream media; Claim about government regulation of media; Claim information is coverage by a named media.

(xiv) MIGRATION AND COMMUNITIES - False claims ref. size, behaviour, beliefs, economic and legal status of particular communities. Six sub-topics.

Claim ref. behaviour of ethnic, racial or religious group; Claim ref. cultural or religious practice or belief; Claim ref. economic status of different communities; 
Claim ref. ethnic or religious discrimination; Claim ref. illegality by and/or legal status of immigrants; Claim ref. size of migrant, ethnic, religious communities.

(xv) MISCELLANEOUS - False claims on topics from the natural world to hoaxes for show or audience, satire on misc. topics, random topics. Five sub-topics.

Claim ref. natural world; Hoax for fun, show or to gain audience; Random claim - not specific to a topic; Ranking a miscellaneous feature in one country against the feature in others; Satire miscellaneous topic.

(xvi) PEOPLE DRAWN INTO PUBLIC LIFE - False identification of person as implicated in public life, smear of those drawn into public life. Two topics.

False identification of individual; Smear of people drawn into public life.

(xvii) POLITICS, POLITICIANS AND ELECTIONS - False claims ref. election processes, results, politicians' views or activity, public opinion or support, political appointments and more. Ten sub-topics.

Claim ref. candidates and parties' participation in elections; Claim ref. election fairness, rigging; Claim ref. election process; Claim ref. facts of election results; Claim ref. political and ministerial appointments; Claim ref. political party's activities; Claim ref. politician or party's policy or view; Claim ref. politician or party's support; Claim ref. politician's activity or person; Claim ref. public mood or political protests.

(xviii) SEX AND SEXUALITY - False claims ref. norms of sexual behaviour, status of different sexual relationships, sexual behaviour of teenagers, different genders. Five sub-topics.

Claim ref. norms of sexual behaviour; Claim ref. same-sex relationships; Claim ref. sex with animals; Claim ref. sexual behaviour by genders; Claim ref. teenage sexual behaviour.

(xvix) STATE OF THE COUNTRY (Infrastructure and development) - False claims on state of infrastructure (road, rail, electricity etc) and development indicators. Two sub-topics.

Claim ref. state of infrastructure; Claim ref. status of key human development indicators.

(xx) UNREST AND VIOLENCE - False claims ref. security, civil unrest, politically linked violence, ethnic or religious conflict. Four sub-topics. 
Claim ref. civil unrest, politically linked violence; Claim ref. ethnic or religious conflict; Claim ref. government spending on military; Claim ref. state security or military issue.

\section{(vii) Whether claim or variant spread on multiple sources, occasions}

It has been known for decades that, due to the so-called 'illusory truth' effect ${ }^{113}$, individuals are more prone to believe information seen or heard from multiple sources, on multiple occasions.

To understand the potential effect of a false claim on audience belief or understanding, it is thus useful to know whether the claim, or a close variant of it, has been spread widely in the recent past ${ }^{114}$. Based on information drawn from the fact-checks, each claim is categorised as:

1. Appeared on only one source, one channel - as reported in fact-check

2. Appeared from one source on more than one channel, short period (2 months or lesser)

3. Appeared on several (2-5) sources over short period (2 months or lesser)

4. Appeared on several (2-5) sources over an extended period (>2 months)

5. Appeared on numerous (6+) sources over short period (2 months or lesser)

6. Appeared on numerous (6+) sources over extended period

7. Details unclear in fact-check

\section{(viii) Whether claim forms part of a specific wider false narrative}

One theory of misinformation effect suggests that individual examples of misinformation have greatest effect when they contribute to a widely accepted false narrative. The effect is caused, in this instance, by a combination of the 'illusory truth effect' (believing a false claim more readily because it has been seen repeatedly) and of its contribution to or reinforcement of an existing belief system or worldview. For this reason, the database records whether the false claims

I 3 Vicol, DO. (2020) 'Who is most likely to believe and to share misinformation?' Full Fact. pp. 7-8 https://fullfact.org/media/uploads/who-believes-shares-misinformation.pdf

I 14 The fact that a claim has been spread on multiple occasions does not, of course, guarantee that those who see the most recent version saw all previous ones, but it increases the probability. 
identified are part of a 'specific wider false narrative', and in the next category, what false narrative that is. While many false claims may fit into a general false narrative such as the idea that 'all politicians are liars', for this question to be answered in the affirmative, the false narrative must be more specific, for example that 'vaccines are harmful/deadly', 'crime is rising' (when it is not) or 'authorities are rigging the election' when they are not.

\section{(ix) Explanation of false narrative of which it's part}

In this category, the database provides written details of the specific wider false narrative of which it is a part, and, where possible examples of other citations of the false narrative.

\section{(x) Degree of distortion of reality in false claim}

While all the database entries are false or misleading in some way, the degree to which claims distort reality differs. After previously categorising the 'type' of distortion of reality, the database recognises these differences of degree, categorising all entries as either:

1. Mostly or completely false

2. Includes substantial element of truth but misleading

3. Wrong in some aspect, but picture is broadly accurate

This is recorded on the premise that the degree of distortion of reality, in part, shapes the effect that the information has on audience understanding.

\section{(xi) Explanation of finding on degree of distortion}

In this category, the database provides written explanation of the finding on the degree of distortion.

\section{(xii) Format or formats in which the claim spread}

Many of the false claims identified in the database were made public in more than one format - first broadcast in an interview on TV or radio, and then related online or turned into a meme. Much existing research suggests that the format in which information was originally transmitted appears to have little impact on its effect on belief or understanding ${ }^{115}$. Nevertheless, the database records the format or formats observed for two reasons. Firstly, to test again whether the type of format in which the information is transmitted correlates in any way with greater or

I 5 See https://www.niemanlab.org/2021/0 I/yes-deepfakes-can-make-people-believe-in-misinforma tion-but-no-more-than-less-hyped-ways-of-lying/ 
lesser effect on understanding. And secondly to understand the range of formats in which misinformation is observed, noting that while much post-2016 debate has focused on misinformation spread in online articles or memes, the range of formats is much greater. At the time of writing, the formats identified were as follows, noting that where details of the format were unclear in the fact-check, that lack of evidence is recorded.

(i) Broadcasts statements (TV or radio); (ii) Community rumours or myths; (iii) Email statements; (iv) Faked documents, web pages or sites; (v) Memes shared online; (vi) Official statements; (vii) Photos or photo captions; (viii) Product labels; (ix) Public signs or posters; (x) Speeches to live audiences; (xi) Videos or video captions; (xii) Voice notes or phone messages; (xiii) Written news articles, written posts online or on messaging apps.

\section{(xiii) Type of originator or promoter of the claim}

To understand what and who drives misinformation, the database categorises the type of originator or promoter of the false claims by their professional or social role, so far as can be shown from the fact-checks. Who originates or spreads misinformation may also be a factor in amplifying or diminishing its effect. The study uses these data and considers possible correlation. Where those who originated or promoted the false claim fall into more than one category, these different categories are all recorded. The categories identified to date are as follows:

\section{Academic or think-tank ${ }^{116} ; 2$. Business or business leader; 3. Celebrity ${ }^{117}$; 4. Conspiracy theorist ${ }^{118} ; 5$. Domestic media ${ }^{119} ; 6$. Ethnic or religious activist ${ }^{120}$;}

I 16 This is decided based on who publishes the claim, not where it is published. It applies whether the claim is published in an academic journal, in mainstream media or on social media.

I 17 'Celebrity' refers to a famous person, notably in the field of entertainment or sport. It does not cover those who are famous for other reasons, such as prominent politicians or scientists, for example.

I 8 'Conspiracy theorist' refers to people or organisations promoting an established conspiracy theory, such as those related to vaccines or the politically motivated false claim that the Nigerian president had died and been replaced by a 'clone', and the media knows this but does not report it.

I 19 'Domestic media' refers to national and local broadcast, print and online media - where there is a news-driven editorial structure involved. It distinguishes this from domestic junk news and hyper-partisan media.

120 Refers to individuals or groups who, from information in the fact-check or online, appear to be activists promoting an ethnic or religious agenda (traditional and religious leaders are listed separately). 
7. Foreign media; 8. Foreign politician; 9. Hoaxer or scammer ${ }^{121}$; 10. International organisation ${ }^{122} ; 11$. Junk news site or FB page ${ }^{123} ; 12$. Known or suspected political, social activist ${ }^{124}$; 13. Labour union; 14. Myth - unknown origin ${ }^{125}$; 15. NGO/civil society organisation ${ }^{126} ; 16$. Hyperpartisan media or online forum $^{127} ; 1$ 17. Politician or political party; 18. Religious leader or group; 19. Satirist or satire site $^{128} ; 20$. Self-styled health practitioner or site/page ${ }^{129} ; 21$. Social media influencer/page ${ }^{130} ; 22$. Social media user ${ }^{131} ; 23$. State official ${ }^{132} ; 24$. Selfstyled expert in specialist field ${ }^{133} ; 25$. Traditional ruler or community leader;

121 'Hoaxer or scammer' refers to individuals or publications who originate or promote false information intended to deceive either for amusement or financial reward. It does NOT refer to those who create hoaxes for political or social effect - who are referenced as political or social activists.

122 'International organisation' refers to organisations such as the African Union, WHO or UN agencies which issue statements found in some way to be false.

123 The term 'junk news site or page' applies to online operations purporting to offer news, if analysis of the site suggests the majority of the content comprises false or misleading information.

124 'Known or suspected political, social activist' refers to an individual, or group, who - from information in the fact-check or identifiable online, can be safely identified as a supporter of a political or social cause. This excludes online accounts that appear to support a cause but have no online back history. It does not include politicians or leaders of campaigns.

125 'Myth - unknown origin' refers to a myth that originated from an unknown source but now spreads on community networks, in media, on social media or elsewhere.

126 Refers to domestic NGOs/CSOs.

127 'Hyper-partisan media or online forum' refers to media (broadcast, print or online) or online fora such as Facebook groups or others - that promote exclusively one-sided information as news.

128 The term 'satirist' is applied to content creators or promoters who define themselves as satirists or parody accounts, save where another purpose can be proven.

129 This term applies to individuals, companies and media or news sites that present themselves as offering health services or advice - without recognised medical authority.

I 30 The term 'Social media influencer or page' is used to refer to an individual or page with at least 30,000 followers online, who is not already well known for their activities offline.

131 The term 'social media user' is used to refer to an online social media account believed to be genuinely that of a real individual - but one not identifiable as belonging to any of the other categories.

I 32 For example, a police official, army spokesperson or civil servant.

133 An individual who claims, and may have, expertise in a particular specialist field - not health. 
26. Unidentified bad actor online - political effect ${ }^{134} ; 27$. Unidentified bad actor online - practical harm ${ }^{135} ; 28$. Unidentified individual or group offline. ${ }^{136}$

\section{(xiv) Type of channel or channels by which the claim spread}

To understand the audience the misinformation/disinformation may have reached, and thus the effect it may have had, the database records the channel or channels by which it was known to have been transmitted. This is done using information from the fact-checks. This information is not exhaustive. Many factchecks identify where they saw the false information but do not search beyond that. The channels identified are as follows:

1. Community networks; 2 . Company or organisation website; 3 . Domestic media; 4. Emails; 5. Foreign media; 6. Government documents, reports; 7. Hyper-partisan news website; 8. Junk news site; 9. NGO report; 10. Phone message; 11. Product label; 12. Public poster or signage; 13. Satire site; 14. Social media/messaging platform - Facebook; 15. Social media/messaging platform - Instagram; 16. Social media/messaging platform - Messenger; 17. Social media/messaging platform - Twitter; 18. Social media/messaging platform factcheck unclear on which; 19 . Social media/messaging platform - WhatsApp; 20. Social media/messaging platform - YouTube; 21 . Social media/messaging platform - YouTube; 22. Speech at public event.

\section{(xv) Factors that caused or may have caused the claim to be created}

The database identifies 12 factors that appear to have caused, or may have caused or contributed to, the false claim to be created - beyond the creator's adherence to a particular world view. Drawing on information in the fact-checks and from studies of misinformation, the factors proposed range from mistakes and lack of access to reliable information, to financial or political motivations.

134 This term is used for individuals or organisations who (i) have created a fake or imposter online account (ii) knowingly fabricated false information (iii) where that information has potential political effect. This can include political hoaxes - where the creator of the hoax is unidentified.

I 35 This term is used for individuals or organisations who (i) have created a fake or imposter online account (ii) knowingly fabricated false information (iii) where that information has potential harmful effects - beyond the political field.

136 Used for an individual or group offline - where they cannot be identified. 


\section{Errors in understanding/explaining complex info and failure to verify simple claims}

- Make error in understanding and explaining complex information

- Fail to verify information they create and share either for lack of verification skills or reflex

2. Lack of access to accurate information to check false claims against

- Create and share false information due to lack of access to accurate information

- Restricted access to accurate official information

- Lack of trust in official information

3. Bad actors create false information to cause harm to particular targets

- To cause harm by spreading a computer virus

- To cause harm through malice to particular individual

- To cause harm through malice to a particular business or sector

4. Unknown actors create false information for political or social effect

- By sowing division between or distrust of particular communities; distrust in institutions; fears related to the economy or people's finances; fears related to crime; fears or panic in other fields or general

\section{Individuals, organisations, to raise their audience for financial or other reward}

- Hoaxer wanting the gratification of pulling a hoax

- Junk news sites or pages wanting to increase audience for financial reasons

- Satirist wanting either to make a point, or increase audience for financial reasons

- Social media influencer/page wanting to increase audience for financial, other reasons

- Social media user wanting to increase audience for gratification

- Traditional media wanting to increase audience for financial, other reasons 


\section{Businesses, legitimate or illegitimate, with an agenda}

- Business talking down its competitors' performance, services

- Businesses talking up its performance, services, sector

- Business, orgs seeking attention - to promote their brand

- Self-styled health practitioners wanting to increase clients

\section{General public - no known affiliation}

- To promote information that they think helpful

- To engage in a public discussion or area of speculation

- To generate support for cause or point of view that matches theirs

- To undermine support for cause or point of view that contradicts theirs

\section{Media with a political/social agenda}

- To undermine support for a cause or point of view

- To generate support for a cause or point of view

\section{Miscellaneous interests}

- Individual or group seeking to deter or promote a particular behaviour $^{137}$

\section{Non-governmental organisations, campaigners}

- To promote information that they think helpful

- To undermine support for a cause or point of view that matches theirs

- To generate support for a cause or point of view that contradicts theirs

\section{Politicians, officials and social, political or religious activists}

- To increase their own support

- To undermine support for an opponent

- To generate support for a policy or cause

- To suppress voting in an election

137 See this as an example: misinformation at a local level to deter behaviour a group objected to. https://factcheck.afp.com/no-johannesburg-has-not-banned-informal-waste-collectors 
- To 'defend their people/religion', or 'stir division'*(depends on viewpoint)

- To express or spread their fears of vaccines

- To promote belief in religious phenomena

\section{I2. Scammers and hoaxers seeking money or data}

- Scammers seeking money or personal data

\section{(xvi) Explanation of finding on factors that may have caused false claim}

In this section, the database sets out an explanation of the finding on factors that have or may have caused or contributed to the creation of the misinformation. The motivation of some, such as financial scams or political smears is clear. In other cases, individuals who made false claims have acknowledged and explained an error. In such cases, the causes can be attributed with reasonable certainty. Where cause is hard to deduce this uncertainty is acknowledged.

\section{(xvii) Factors that may have facilitated the spread of the claim}

The database also identifies the factors that may have facilitated or played a part in facilitating the spread of the misinformation, over and above two factors which are highly important, and mentioned in the report, but apply to most entries and hence not highlighted here.

1. the availability and functionality of social media and messaging apps that enable and encourage sharing - particularly of emotionally charged content

2. the availability and functionality of other channels such as links between information that is broadcast via TV and radio and offline community networks, that or encourage sharing of information

The factors the database identifies, using evidence drawn from the fact-checks, and evidence from existing research on the reasons individuals share informa$\operatorname{tion}^{138}$, are as follows:

\section{Adherence to a pre-existing view, mindset or knowledge - including}

- Acceptance of a stereotype of community or group

- Adherence to conspiracy theories

I 38 Vicol, DO. (2020) 'Who is most likely to believe and to share misinformation?' Full Fact. https://fullfact.org/media/uploads/who-believes-shares-misinformation.pdf 
- Strongly held views on identity-related issues

- Belief in supernatural or religious phenomena

- Adherence to and desire to spread or defend particular religious, political, social views

- Hostility to a foreign power

- Hostility to and/or lack of trust in those in authority/the elite

- Limited understanding of science

- Mindset that finds it acceptable to illustrate a situation with an image of another (real but different) situation

- Mindset that speculates about topic of public interest

\section{Emotional response to the information - including}

- It confirms a pre-existing view of the world

- It is seen as an example to follow

- It is seen as funny/amusing

- It is seen as good news, provokes a sense of relief

- It is seen as shocking and daring or shocking and amazing

- It is something authorities/elite 'don't want people to know'

- It makes readers feel confirmed in their view and in the know

- It provokes anger, outrage

- It provokes empathy, pity, desire to help

- It provokes fears in general

- It provokes fears of danger to children

- It provokes interest in the lives of the famous

- It provokes the desire, need to secure a job offer or giveaway

- It provokes the desire to share information you consider helpful

\section{Error and/or the lack of a verification reflex - including}

- Individuals/orgs make error in understanding and explaining complex information

- Individuals/orgs fail to verify information they create and share either for lack of verification skills or reflex

- Individuals/orgs have restricted access to accurate official information

- Individuals/orgs lack trust in official information 


\section{(xviii) Explanation of finding on factors that may have facilitated spread}

In this section, the database sets out an explanation of the findings on factors that have or may have facilitated the spread of the misinformation, beyond the functionalities of social and traditional media. This is done through references to existing research into factors that facilitate the spread of information and evidence from the specific fact-check.

\section{(xix) Potential durability of the false claim}

Evidence from both cognitive science and longitudinal studies of belief in false information, suggests that much misinformation is, to cite Stephen Lewandowski's word 'sticky' - belief in the false claim persisting even when reliable evidence is presented that the information is false ${ }^{139}$. Not all false information has the same effect, however. Not only do other studies show that repeated correction of false information can reduce belief in false information over time, but certain forms of false information are naturally less durable than others. The database categorises claims as

1. Easily disproven ${ }^{140}$

2. Naturally disproven by course of events

3. Potentially durable

4. Uncertain durability

\section{(xx) Explanation of finding on durability of false claim}

In this section, the database sets out an explanation of the findings on the durability of the false information - based on evidence from the fact-check.

\section{(xxi) Type of claim's possible effects on belief or understanding}

False information may have different effects on individuals' beliefs or understanding from no effect, where the information is not believed, to the creation of an entirely new false belief. Starting from a scale set out by Joseph Klapper in 1960, the database categorises false information as having, potentially one or more of the following effects - if believed.

1. Prevention of change in belief or understanding

2. Reinforcement of existing belief or understanding

3. Minor change in form, intensity of belief or understanding

| 39 https://journals.sagepub.com/doi/|0.1 |77/|529|006/245 I018.

I 40 For example - so called 'fake death notices' claiming falsely that a prominent person has been killed. 
4. Conversion from one belief to another or understanding

5. Creation of false new belief or understanding

\section{(xxii) Explanation of finding on type of effects on belief or understanding}

In this section, the database sets out an explanation of the findings on the type of effects on belief or understanding based on evidence drawn from the fact-check such as (i) whether the situation described is new, (ii) whether responses suggest the audience has pre-existing views on the topic, (iii) whether responses suggest views have been changed.

\section{(xxiii) Whether the claim is actionable near term - if believed}

The potential for false information to cause harm by changing individuals' beliefs or understanding, depends - in part - on whether or not the changed belief or understanding is one on which the individual has (i) the capacity and (ii) motivation to take some form of action that may be prejudicial to themselves or others.

For example, when misinformation circulates on messaging apps advising people to take a 'health cure', members of the public may have both capacity and feel motivated to follow the advice or suggest others in their circle do so. If the misinformation relates to a policy issue, individual members of the public may have limited capacity to act but policy-makers may be able to do so.

The database assesses each entry for evidence of the combination of audience capacity and motivation to act, based on evidence in the fact-check. Setting aside the question of whether the audience could either spread or peacefully protest the situation falsely defined, it asks whether either individual members of the public or policy-makers could take potentially harmful action, in the near-term, if they believed the false information, or whether there is no such action they would have the capacity and motivation to take. 'Policy-makers' are defined in these terms as anyone in a position to set or define the rules guiding the actions of others such as parliamentarians, members of the judiciary, health administrators and employers.

The database cross-checks these findings against evidence of actual harm to establish whether there is any correlation between whether and by whom misinformation is actionable and harm.

\section{(xxiv) Explanation of finding on actionability}

In this section, the database sets out an explanation of the findings on actionability, based on evidence in the fact-checks and cross-checking with evidence of actual harms caused. 


\section{(xxv) Type of 'consequential effect' - if claim believed}

Not all changes of belief or understanding cause an action or feeling that has any consequence. Others do or may bring a change of some value to the individual or society, whether to their benefit or harm. This section of the database identifies whether, according to the best evidence available, the changes in belief or understanding if they occur may have led or might contribute to potential effects for individuals or society. Based on evidence from the fact-checks, further investigations and studies, entries are rated as:

1. No actual or potential consequential effect identified

2. Actual or potential beneficial effect identified

3. Actual or potential harmful effect identified

\section{(xxvi) Explanation of finding on type of consequential effect}

In this section, the database sets out an explanation of the findings on the type of consequential effect identified. If the effect is identified as of no consequence, or actually or potentially beneficial, the reason for and details of that finding are explained here.

\section{(xxvii) Degree of confidence claim caused actual harm}

The degree of confidence that a claim in the database directly caused harmful effects varies from cases to case. The database categorises that confidence as follows (See below the subsequent field where we explain the evidence).

1. No evidence was identified that the claim caused actual harm

2. Evidence suggests claim may have caused actual harm

3. Strong evidence shows that the claim caused actual harm

\section{(xxviii) Field and form of actual harm caused}

The database then sets out the field in which the actual harm was caused, and the form, or sub-field, of the harm identified. The fields identified are as follows:

1. Physical harms - from vigilante and gender-based violence to harms to individuals' and public health

2. Harms to mental health - from personal distress to public alarm

3. Harms to fairness, social cohesion - from entrenching negative stereotypes to enflaming social divisions

4. Harms to the justice system - from distorting particular cases to judicial policy

5. Harms to the political system - from suppressing voting, to distorting the focus of debate 
6. Harm to business, economy - from company reputations to economic policy

7. Harms to the environment - from endangering wildlife to distorting policy focus

8. Harm to international relations - from distorting public understanding to government policy

9. Harm to individuals' finances, practical harms - from financial loss to identity theft, and the spreading of computer viruses

10. Harm through distorted understanding of the natural world miscellaneous

\section{(xxix) Evidence of actual harm caused}

In this section, the database sets out an explanation of and evidence for the findings on actual harm caused, with links to sources where appropriate.

\section{(xxx) Whether claim had potential to cause harm}

The database then identifies whether evidence suggests that the false claim has the potential to cause harm and how. The fields identified are as follows:

1. Yes, subject to conditions

2. Yes, through cumulative effect

3. No apparent potential to cause substantial harm*

( ${ }^{*}$ other than reduction in faith in information sources in general - an effect discussed in the report)

\section{(xxxi) Field and form of harm claim had potential to cause}

The database then sets out the field in which the actual harm was caused, and the form, or sub-field, of the harm identified. The fields identified are as follows:

1. Physical harms - from vigilante and gender-based violence to harms to individuals' and public health

2. Harms to mental health - from personal distress to public alarm

3. Harms to fairness, social cohesion - from entrenching negative stereotypes to enflaming social divisions

4. Harms to the justice system - from distorting particular cases to judicial policy

5. Harms to the political system - from suppressing voting, to distorting the focus of debate 
6. Harm to business, economy - from company reputations to economic policy

7. Harms to the environment - from endangering wildlife to distorting policy focus

8. Harm to international relations - from distorting public understanding to government policy

9. Harm to individuals' finances, practical harms - from financial loss to identity theft, and the spreading of computer viruses

10. Harm through distorted understanding of the natural world miscellaneous

\section{(xxxii) Explanation for finding on potential to cause harm}

In this section, the database sets out an explanation of and evidence for the findings on the potential of the claim to cause harm, with links to sources where appropriate.

\section{(xxxiii) Potential scale of harm - from one-to-one to one-to-many}

The scale of the harm that can follow from misinformation depends in part on its audience: whether the harm is one they suffer, themselves, or one they cause to others and, in the latter case, their position to affect others through their role in their community or wider society. The database thus categorises potential harm as carried out:

1. One-to-one self

2. One-to-one other

3. One to many

4. Many to 1

5. Many to many

\section{(xxxiv) Evidence for finding on potential scale of harm}

In this section, the database sets out an explanation of and evidence for the findings on the potential scale of the harm that may be caused, with links to sources where appropriate.

\section{(xxxv) Potential durability of harm}

The degree of harm that can follow from misinformation depends in part, also, on the permanence, or durability of that harm. In the simplest terms, harm that leads 
to individuals dying is permanent. A temporary increase in mental stress may be ameliorated over time.

The database categorises harms as

1. Permanent

2. Durable

3. Transitory

4. Uncertain

\section{(xxxvi) Evidence for finding on potential durability of harm}

In this section, the database sets out an explanation of and evidence for the findings on the potential scale of the harm that may be caused, with links to sources where appropriate.

\section{(xxxvii) Whether response to claim may have mitigated harm}

Finally, the database identifies instances in which

(i) the misinformation that was shared was questioned or factchecked by the public and/or subject of the misinformation

(ii) the originators responded either to this questioning of their claims or the questioning of their claims by the fact-checking organisations

Recent research from the United States ${ }^{141}$ has suggested that the questioning of misinformation shared online, by members of the public who are sceptical about it, has a significant effect in reducing the spread and the perceived credibility of the information. The report both (i) cross-checks this evidence to determine whether there is any observable correlation between the questioning of the misinformation and evidence of harm and (ii) set outs the theoretical evidence mentioned above.

\section{(xxxviii) Evidence for finding on mitigation of harm}

In this section, the database sets out an explanation of and evidence for the findings on mitigation of harm.

I4I Bode, L, Vraga, E. 'Americans are fighting coronavirus misinformation on social media'. Washington Post. May 7, 2020. https://www.washingtonpost.com/politics/2020/05/07/americans -are-fighting-coronavirus-misinformation-social-media/ 


\section{AUTHOR INFORMATION}

Peter Cunliffe-Jones has been a visiting researcher and Co-Director of a course on media freedom at the University of Westminster since 2019, focusing on misinformation. In 2012, after a career in journalism, he founded the first fact-checking organisation in Africa. After stepping down in 2019, he was named senior advisor to the International Fact-Checking Network (Twitter @PCunliffeJones, ORCID: https://orcid.org/0000-0003-3023-7386).

Assane Diagne is a journalism and media freedom expert based in Dakar, Senegal. A lecturer at the Ecole Supérieure de Journalisme, des Métiers de l'Internet et de la Communication (EJICOM) in Dakar, and former Chief Editor of the Agence de Presse Senegalese, he was in 2019 named West Africa Director of Reporters Without Borders (Twitter @assaned).

Alan Finlay is an Internet and media rights researcher, and lecturer with the University of the Witwatersrand, in Johannesburg, South Africa. He has written extensively on issues of access to information, freedom of expression and Internet rights.

Sahite Gaye is a researcher and lecturer at the Centre d'Etudes des Sciences et des Techniques de l'Information (CESTI) at l'Université Cheikh Anta Diop de Dakar (UCAD) Dakar, Senegal. His focus is on the structures, uses and norms of digital communications among organisations and society, in francophone West Africa in particular (Twitter@SahiteGaye).

Wallace Gichunge is Founder and Executive Director of the Centre for Media and Information Literacy in Kenya, and Africa Region Representative to the UNESCO Global Alliance for Partnerships on Media and Information Literacy. His academic focus is on media literacy, governance and political communication (Twitter @GichungeW).

Chido Onumah is the Coordinator of the African Centre for Media and Information Literacy, in Abuja, Nigeria. His academic focus is on media and information literacy in West Africa, as a means of enhancing democracy and accountability (Twitter: @conumah, ORCID: https://orcid.org/0000-0001-9734-3568).

Cornia Pretorius is a researcher and lecturer in journalism and media studies in the School of Communication of North-West University's Potchefstroom site in South Africa. The focus of her PhD study is news literacy, disinformation and journalism in South Africa (Twitter @corniap). 
Anya Schiffrin is Director of the Technology, Media and Communications specialisation at the School of International and Public Affairs, at Columbia University, United States. She writes on journalism and development around the world (Twitter@anyaSIPA). 


\section{MISINFORMATION POLICY IN SUB-SAHARAN AFRICA}

\section{From Laws and Regulations to Media Literacy}

Misinformation Policy in Sub-Saharan Africa is a single volume containing two research reports by eight authors examining policy towards misinformation in Sub-Saharan Africa.

The volume first examines the teaching of media literacy in state-run schools in seven Sub-Saharan African countries as of mid-2020, as relates to misinformation.

It explains the limited elements of broad media and information literacy (MIL) included in the curricula in the seven countries studied and the elements of media literacy related specifically to misinformation taught in one province of South

Africa since January 2020. The authors propose a theory of 'misinformation literacy' - six fields of specific knowledge and skills required to reduce students'

susceptibility to false and misleading claims. Identifying obstacles to the introduction and effective teaching of misinformation literacy, the authors make five recommendations for the promotion of misinformation literacy in schools, to reduce the harm misinformation causes.

The second report in the volume examines changes made to laws and regulations related to 'false information' in eleven countries across Sub-Saharan Africa 20162020 from Ethiopia to South Africa. By examining the terms of such laws against what is known of misinformation types, drivers and effects, it assesses the effects of punitive policies and those of more positive approaches that provide accountability

in political debate by promoting access to accurate information and corrective speech. In contrast to the effects described for most recent regulations relating to misinformation, the report identifies ways in which legal and regulatory frameworks

can be used to promote a healthier information environment.

\section{The Authors}

Peter Cunliffe-Jones, Assane Diagne, Alan Finlay, Sahite Gaye, Wallace Gichunge, Chido Onumah, Cornia Pretorius and Anya Schiffrin 